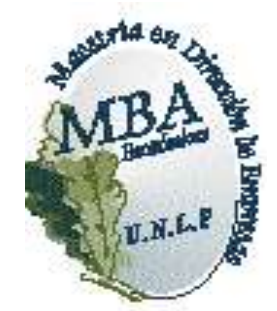

Universidad Nacional de La Plata

Facultad de Ciencias Económicas

MBA - Maestría en Dirección de Empresas

\title{
Mercado de Capitales Argentino: Efectos de los fondos estatizados del sistema previsional sobre el mercado bursátil y las acciones cotizantes
}

Trabajo final para optar al título de Magister

Autor: Cr. Juan Manuel Salvatierra

Director: Dr. Daniel Alberto Lauría

\section{La Plata}

31 de octubre de 2011 


\section{Índice}

1. Planteo del Problema..................................................................................... 1

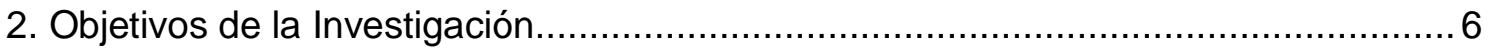

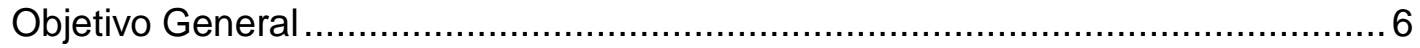

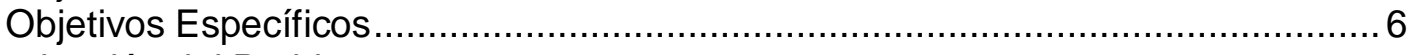

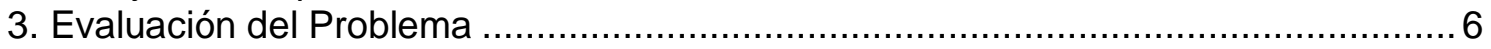

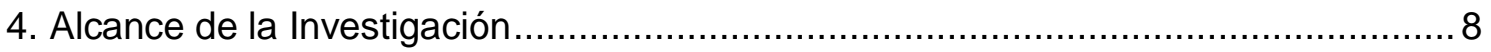

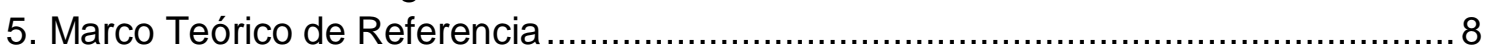

5.1. Antecedentes de la Investigación .......................................................... 8

Breve reseña histórica del financiamiento con capital propio y de los

mercados de valores........................................................................... 8

Liquidez en los mercados de acciones. ................................................. 10

La gestión de las AFJP en la cartera de acciones (Años 1994-2008)............ 12

Anomalías en la eficiencia del mercado de acciones, información asimétrica,

capital flotante y derechos políticos........................................................... 14

El paso a ser considerado mercado de frontera. ....................................... 17

El marco institucional y su calidad......................................................... 18

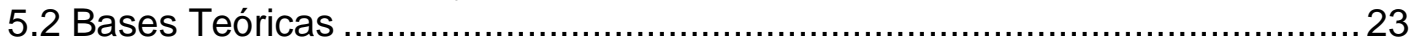

Sistema de capitalización de los fondos previsionales ...............................23

Marco histórico y estructura del Sub Sistema de jubilaciones y

pensiones privados en Argentina ................................................. 23

Las inversiones de los fondos previsionales públicos........................26

Los primeros indicios hacia la nacionalización y su concreción.............27

El Fondo de Garantía de Sustentabilidad (FGS) de la ANSES............. 30

Las Fuentes de recursos y composición del FGS................................ 32

Los criterios de inversión del fondo de garantía y su composición. ....... 35

Administración operativa del fondo.................................................... 37

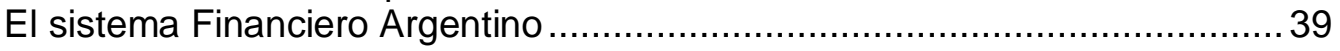

Definición y generalidades del sistema financiero ............................... 39

El Mercado de Capitales Argentino ................................................... 41

La arquitectura del Mercado de Capitales Argentino........................ 41

Participantes y Reguladores del mercado de capitales argentino. ... 42

Los Inversores institucionales ......................................................... 43

Participación del FGS en empresas a través de acciones. .................. 45

La moderna teoría de carteras de inversión. ...................................................49

El objetivo de la administración de carteras de inversión. ......................50

Estructuras y aspectos importantes en el armado de una cartera de

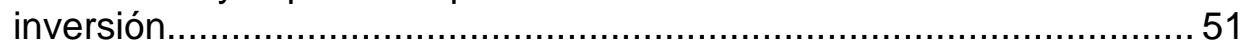

El riesgo y la incertidumbre en la teoría de carteras............................55

Frontera eficiente y la elección de portafolios óptimos de acuerdo con el

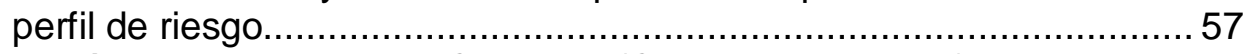

La Línea del Mercado de Capitales (Capital Market Line) y el Teorema

de la Separación (Tobin).................................................................. 59

Línea del Mercado de Capitales (LMC) .......................................... 61

Estrategias de administración de portafolios: Gestión Activa y Pasiva. 62

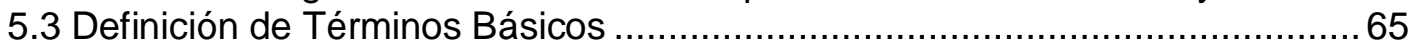

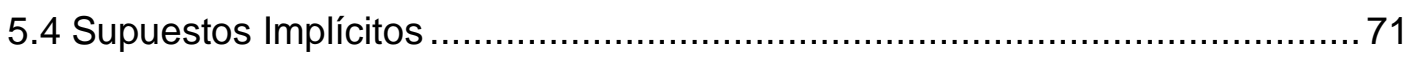

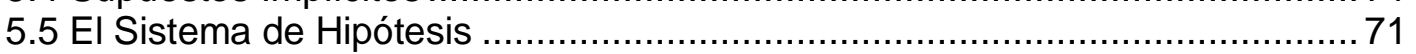

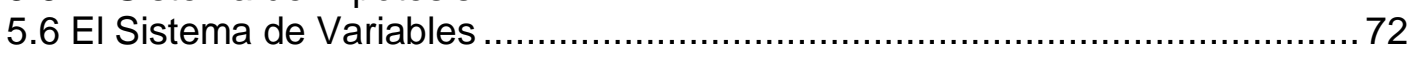

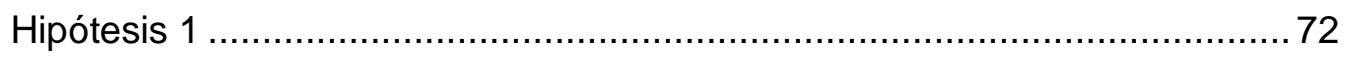




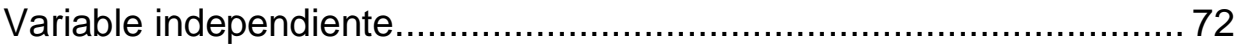

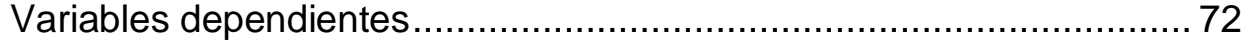

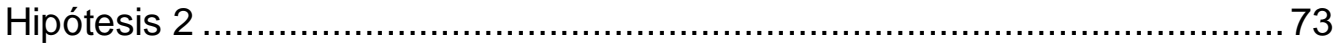

Variables independientes .......................................................... 73

Variable dependiente ........................................................... 74

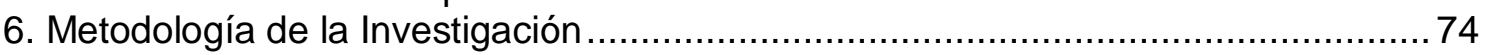

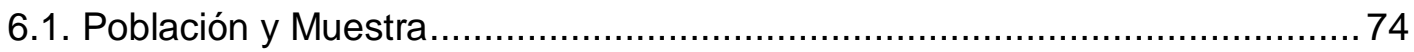

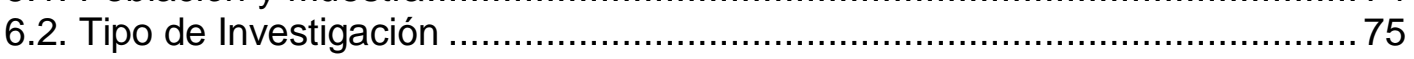

6.3. Técnicas de Recolección de Datos .................................................. 75

6.4. Técnicas de Análisis ...................................................................... 77

Volumen y Liquidez. ....................................................................... 78

Evolución del volumen operado de acciones que cotizan en la BCBA . 78

Estudio del evento........................................................................ 79

Exclusión del Efecto Precio de las acciones.................................... 80

Indicador relacionado al nivel de actividad. ..................................... 81

Capital Flotante (Free Float).................................................................. 83

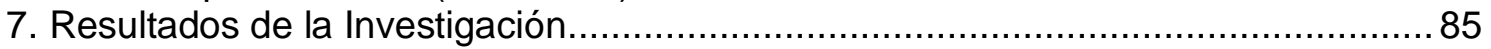

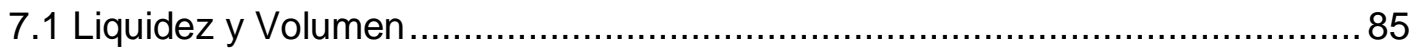

Evolución del volumen operado de acciones que cotizan en la BCBA ...........85 85

Monto operado anual en el MERVAL en términos nominales...............85

Monto nominal operado mensualmente en el MERVAL. ....................87

Promedios diarios negociados en el MERVAL .................................. 92

Monto nominal anual y promedio diario negociado en el MERVAL en

dólares...........................................................................................93

Monto operado anual en pesos en el MERVAL en términos reales......94

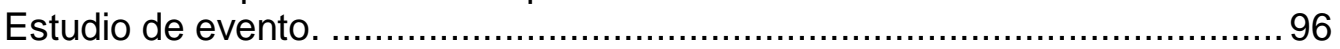

Exclusión del Efecto Precio de las acciones............................................99

Indicador relacionado al nivel de actividad. ...............................................98

Indicador del volumen negociado en relación al producto. ................... 99

7.2 Capital Flotante (Free Float)................................................................ 102

Análisis normativo acerca de la tenencia y límites en acciones .................. 102

Variaciones en la cartera de acciones ..................................................... 106

Sectores de la economía Argentina y empresas con participación estatal... 108

Capital flotante (free float) y flotación extendida en las empresas argentinas

Derecho a voto del FGS y del grupo controlante sobre el total de votos de las

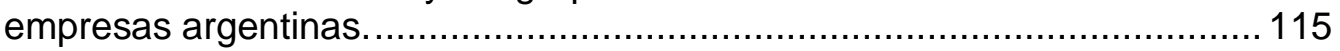

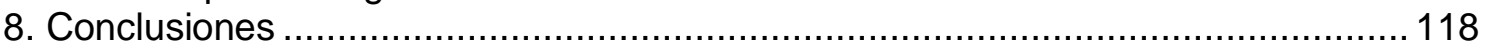

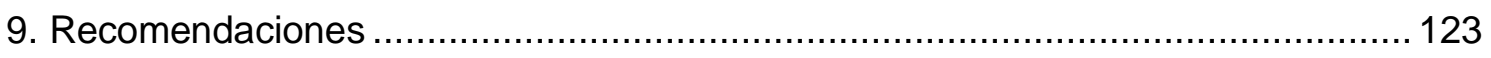

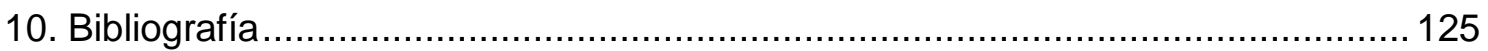

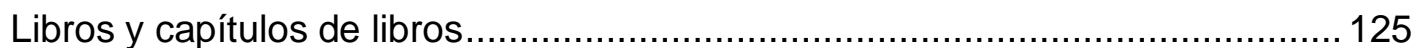

Trabajos y publicaciones consultadas......................................................... 126

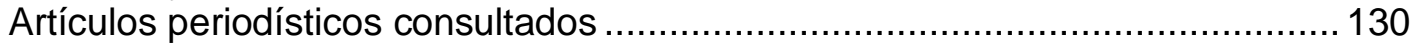

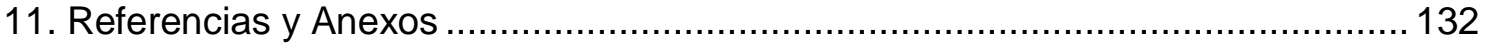

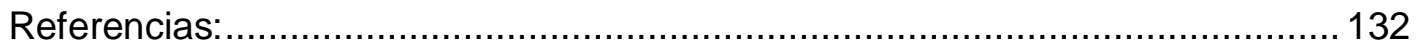

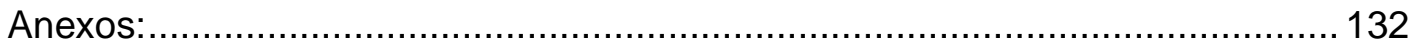




\section{Planteo del Problema}

Las Administradoras de Fondos de Jubilaciones y Pensiones (AFJP), constituían los inversores institucionales más importantes que tenía Argentina, sin embargo en octubre de 2008 fueron subrogadas por el Estado Nacional. La tenencia de acciones que administraban las AFJP, son administradas actualmente por el Fondo de Garantía de Sustentabilidad (FGS) de la Administración Nacional de la Seguridad Social (ANSES), la cual mantiene en cartera las participaciones en empresas argentinas que cotizan en el mercado de valores.

Las AFJP mantenían un sistema de rentabilidad mínima, por el cual los rendimientos debían superar ese límite, lo cual demostró no ser tan efectivo para proteger los ahorros de los aportantes y limitó las posibilidades de diversificación de las carteras. Inducía a un comportamiento de tipo manada, por parte de todos los fondos de pensión intentando replicar la cartera promedio del mercado. Con las AFJP se incorporó en su momento en el mercado local, un demandante natural como inversor institucional que le proporcionaba liquidez al mercado y facilitaba la utilización de dichos instrumentos en el financiamiento de largo plazo.

Dapena (2007), describe que hasta el año 1994 el mayor volumen de comercialización total del mercado estaba originado en la compraventa de acciones de empresas (consistente con la oferta pública de acciones de empresas privatizadas y el capitalismo popular para que participe la mayor cantidad de ciudadanos en la propiedad de empresas con origen público). Con la incorporación del sistema privado de pensiones se crearon estos inversores institucionales que se convirtieron en un actor principal del mercado de capitales, y con un impacto significativo en la liquidez del mercado de bonos públicos.

Esta liquidez del mercado de títulos públicos se debió al déficit financiero provocado por la creación del subsistema privado de pensiones, al quedarse el Estado sin esos fondos públicos, las AFJP compraban dichos instrumentos de acuerdo con los límites establecidos por ley. Si un Estado gasta en exceso, su afán de financiar este gasto termina por absorber el ahorro privado (sea de manera compulsiva o por métodos de mercado) impulsando hacia arriba las tasas de interés, lo que se conoce en 
economía como crowding out. Es decir, que el objetivo de un mercado de capitales desarrollado, que es permitir canalizar efectiva y eficientemente el ahorro de una economía hacia las oportunidades de inversión más rentables, contribuyendo al crecimiento de la economía, y al bienestar de la sociedad, quedaba sometido a las necesidades de financiamiento estatal.

Por otro lado, la falta de liquidez en el mercado accionario por el tipo de operaciones que captaban las AFJP y la competencia que hacía el Gobierno con sus bonos podía ser considerado como un factor relevante para el subdesarrollo del instrumento de inversión en participaciones de capital como son las acciones (en inglés, equity) (Dapena, 2003).

Según Barraza (2009), el impacto económico que provocó el anuncio de nacionalización de los fondos previsionales privados tuvo un efecto negativo en los precios de las acciones negociadas públicamente en la Bolsa de Comercio de Buenos Aires (BCBA). Como conclusión de su trabajo, menciona que la caída drástica en la liquidez del mercado y los cambios en las condiciones de negocios están entre las opciones más altamente consideradas por afectar los derechos de propiedad, una de las instituciones más importantes en la vida económica de un país, alterando de este modo las percepciones y expectativas de los agentes económicos, y que son variables potencialmente útiles para su análisis que debieran ser puestas a prueba.

En la Figura 1 se muestra la evolución del principal índice de la BCBA en Argentina, que es el MERVAL, como así se expone la evolución del índice MERVAL Argentina (M.AR) que refleja el comportamiento de las empresas argentinas, ambos en el período desde la salida de la cesación de pago de la deuda en el año 2005 hasta fines del año 2010. En las tendencias expuestas se puede observar el efecto de la crisis internacional, y lo ocurrido en el mercado de acciones argentino, principalmente durante los años 2008 y 2009. 


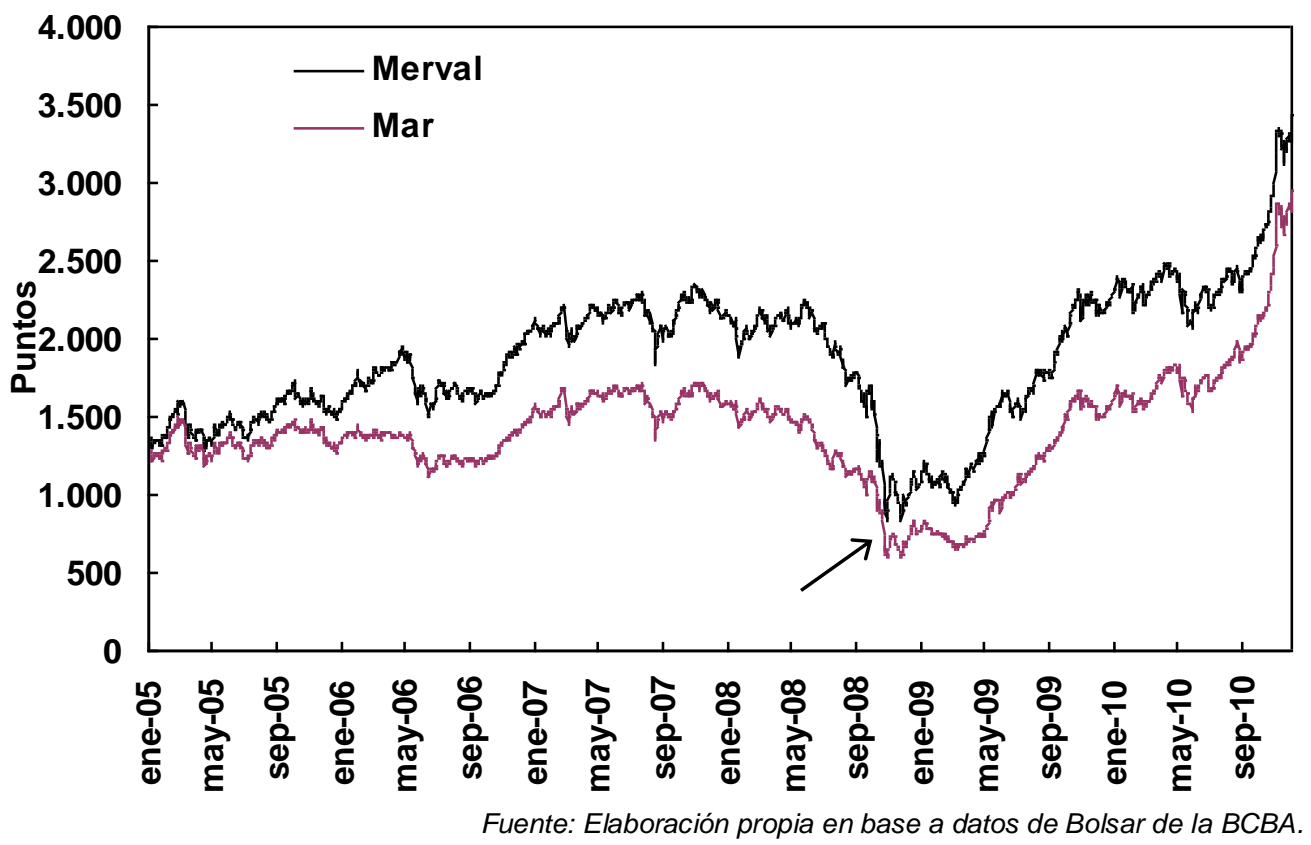

Figura 1: Evolución diaria del índice MERVAL y M.AR para la serie temporal años 2005 2010. La flecha indica el comienzo de la crisis financiera internacional y lo ocurrido en el país.

Los precios agregados de estos índices representados (que miden la evolución del precio del mercado de acciones) dependen principalmente de las ganancias de las empresas y de sus posibilidades de crecimiento. Los mismos pueden ser afectados por la liquidez internacional, las expectativas sobre la marcha de la economía local y los eventos políticos- económicos y financieros que tanto a nivel internacional como local afectan las perspectivas de desarrollo de la economía (Ver Dapena, 2003).

El mercado de capitales de acciones de Argentina negocia volúmenes menores que sus comparables en América Latina, y la capitalización del mercado en relación al Producto Bruto Interno (PBI), no se encuentra como un indicador muy desarrollado según información del World Federation of Exchanges (WFE) y el Fondo Monetario Internacional (FMI). Esto se puede ver reflejado en la Figura 2, y en el detalle adjunto en el Anexo Tabla 1, donde la importancia del mercado de valores en Argentina sobre la economía es muy baja. Es fundamental, tener un mercado secundario de acciones líquido para facilitar la emisión primaria de instrumentos. Y así poder facilitar las transacciones de los activos financieros en efectivo, al precio vigente, facilitando la competencia y la eficiencia en el mercado. 


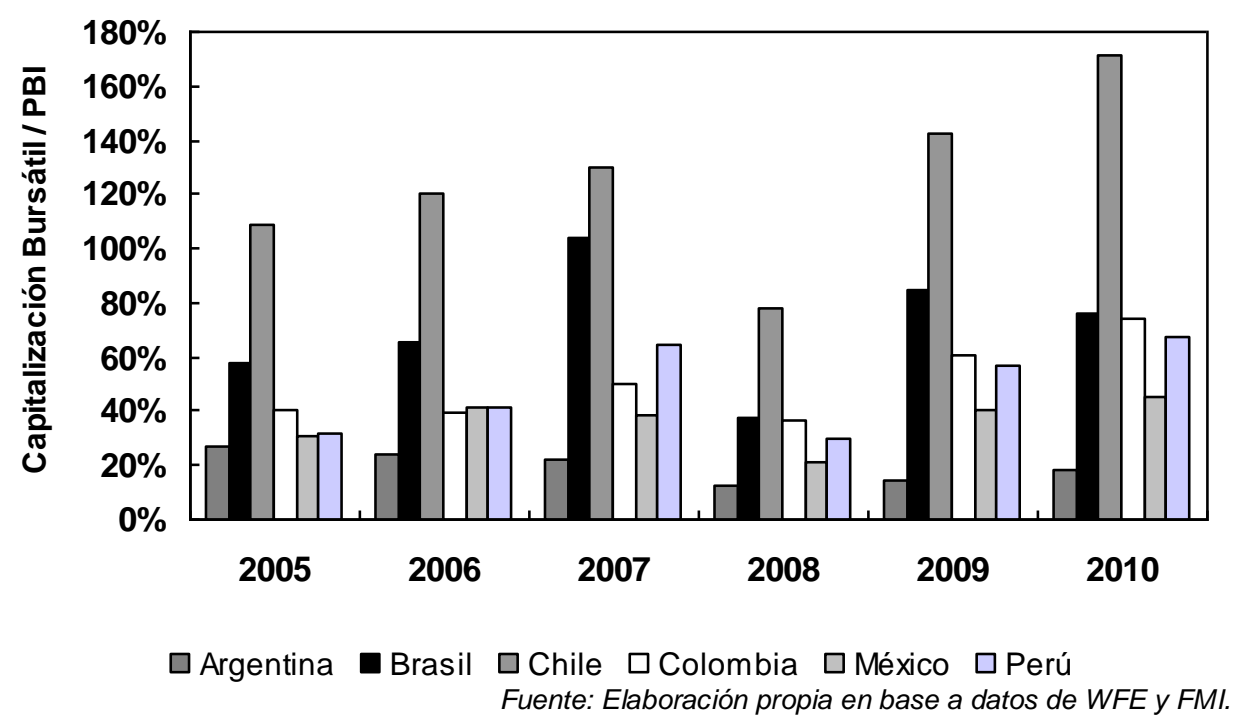

Figura 2: Indicador de la importancia de los mercados de valores en las economías nacionales de Argentina y de otros países latinoamericanos. El indicador muestra la capitalización bursátil sobre el PBI a precios corrientes (años 2005 -2010). Los valores para construir el indicador fueron expresados todos en dólares.

Históricamente en Argentina la tenencia de acciones en el free float ${ }^{1}$ de los inversores institucionales de las empresas cotizantes nunca implicó una suficiente influencia sobre el gobierno corporativo de las mismas. Pero si, se ha limitado la habilidad de hacer trading sin impactar en los precios del mercado. Rotman (2009) sugiere entre varias recomendaciones aumentar el floating accionario mínimo de las empresas cotizantes, abriendo un poco más el capital de algunas empresas que cotizan en bolsa, pero que prácticamente son cerradas.

Por su parte, Irigoyen (2006) expresa que "La inestabilidad y la volatilidad general de la economía en los últimos cincuenta años, generada en gran parte por una política fiscal irresponsable, desencadenaron un estado de inseguridad jurídica que fue convalidado mediante la violación reiterada a los derechos de propiedad por parte del soberano (...) La falta de reglas de juego claras y estables atenta tanto contra la oferta (ahorro) como contra la demanda (inversión) de fondos en el mercado local"2. El mercado de capitales necesita de reglas de juego claras y estables, y es un rol indelegable del Estado proveerlas y garantizar su cumplimiento, impidiendo modificaciones ante la conveniencia de turno de la administración central. Las

\footnotetext{
1 En todo este trabajo se utilizará los términos "free float", "flotación", "floating" y "capital flotante" indistintamente, para referenciar al porcentaje del capital social de una empresa que no está en poder del grupo o accionistas controlantes.

${ }^{2}$ Ver IRIGOYEN, C. (2006) "Mercado de capitales: desarrollo para atraer nuevos inversores y emisores en forma sistemática”. Página 13.
} 
distintas modificaciones a la normativa actual, en especial el hecho de que el Estado quiera hacer valer sus derechos societarios que le corresponden según su participación en las distintas empresas presenta una dificultad adicional ante las distintas interpretaciones jurídicas, como los conflictos de interés latentes.

Por el lado de la institucionalidad, North (1991) indica que las "Instituciones son restricciones construidas por el hombre que estructuran la interacción política, económica y social. Estas consisten tanto en restricciones informales (sanciones, tabús, costumbres, tradiciones y códigos de conducta) como en reglas formales (Constituciones, Leyes, Derechos de Propiedad)"3. Las instituciones hacen a la vida económica de los países y la afectación de una institución como el derecho de propiedad modifica las preferencias de los agentes económicos sobre las decisiones que deben tomar. Dichas instituciones en el mercado de capitales debieran conducir a la merma o disminución de los costos de transacción y de las asimetrías de información, al incremento de la inversión y, por ende, a facilitar el crecimiento de la economía.

Jensen y Meckling (1976), plantean que pueden existir problemas de agencia entre accionistas mayoritarios y minoritarios, o entre accionistas y la administración (management) de las firmas. Bajo este enfoque, un accionista minoritario puede pensar que uno mayoritario busca quedarse con parte de sus ganancias, o hacer negocios con la firma en beneficio propio y en perjuicio de los accionistas minoritarios. Rotman (2009) propone en su trabajo establecer que una acción es igual a un voto como requisito, para establecer transparencia, seguridad jurídica, respeto incondicional para el accionista minoritario y reglas de juego claras.

Como consecuencia de un escaso desarrollo de los mercados, aparecen los problemas de asimetrías de información, al existir factores de tipo estructural o institucional que hacen difícil que la información sea distribuida entre todos los participantes, que los contratos sean debidamente respetados y que los precios reflejen la información existente.

\footnotetext{
3 Traducción de NORTH D. C. (1991) “Institutions”. Página 97.
} 
Volviendo a las AFJP, al no tener comisiones relacionadas con el desempeño de la cartera de inversiones se desligaba los incentivos de estos gestores fiduciarios de los intereses de los afiliados y creaba un problema típico de principal y agente.

Todo lo mencionado precedentemente y los antecedentes citados, trae consigo un obstáculo para el mercado de capitales argentino en general, y al mercado accionario en particular, trayendo problemas en la credibilidad institucional del país, en el desarrollo y accionar del mercado de capitales argentino.

\section{Objetivos de la Investigación}

\section{Objetivo General}

Evaluar las consecuencias y los efectos en la gestión de la cartera de acciones de los fondos previsionales provenientes de su estatización, y los cambios que dicha medida hubiere ocasionado en el mercado bursátil argentino.

\section{Objetivos Específicos}

1. Describir las variaciones en el MERVAL en el volumen y liquidez entre el año 2005 y el 2010.

2. Analizar cómo la actual conformación de acciones del FGS proveniente de las AFJP, afectó el floating del mercado accionario argentino.

\section{Evaluación del Problema}

El mercado de capitales de Argentina, y especialmente el de acciones, es muy pequeño en relación a su economía real y en comparación a otros países de la región. Uno de los temas pendientes en materia económica, es el mayor desarrollo del mercado de capitales, especialmente el de acciones, para que acompañe el crecimiento económico del sector privado y público.

La falta de desarrollo del mercado de capitales tiene sus orígenes tanto en factores macroeconómicos como microeconómicos, como así regulatorios. Muchos analistas mencionan que para incentivar su desarrollo se debería desarrollar una moneda local de largo plazo y que sea reserva de valor. $Y$ que para mantener un nivel de precios 
estable a través del tiempo se necesita una coordinación adecuada entre la política monetaria y fiscal. Hasta llegar a este anhelo económico de Argentina de tener una moneda fuerte, y poder ir sobrepasando contextos inflacionarios los instrumentos indexados son una buena opción.

Debido a su escaso volumen, cualquier cambio de las reglas de juego tiene impactos importantes sobre este mercado. El conocimiento de los principales cambios ocasionados por la salida de los inversores institucionales es de fundamental importancia, especialmente en un mercado de capitales poco desarrollado, como lo es el argentino.

En Argentina, puede ser por una cuestión cultural, no es habitual que empresas con capital abierto dispongan de muchas acciones que sean susceptibles de cambiar de manos habitualmente. Sino que la posesión de la mayoría de las acciones está en dominio de accionistas estables que buscan el control. Ciertamente en la práctica de este mercado, gran parte de los accionistas mayoritarios de empresas cotizantes mantienen su participación sin ofrecerla a otros inversores en el mercado.

Sin lugar a dudas, la administración de la cartera de acciones que posee el FGS resalta la importancia en las decisiones de inversión del organismo previsional por la alta participación relativa que posee en las empresas argentinas que cotizan. La gestión de las mencionadas acciones podría haber afectado y estar afectando la liquidez del mercado de valores, reduciendo el volumen operado y generando la presencia de imperfecciones (anomalías).

El FGS de la ANSES, reemplazando a las AFJP, convirtiéndose en el inversor institucional más importante del país y uno de los organismos con mayores activos de Latinoamérica refuerza la importancia de los efectos que derivan de su gestión. Por ello la significatividad que conlleva su actuar, y el interés que genera en el mercado local a los distintos participantes. En consecuencia, es importante conocer como se ha movido el mercado accionario en términos de volumen negociado entre otras características luego de la reforma, para determinar los efectos producidos por la gestión de los fondos. 


\section{Alcance de la Investigación}

La presente investigación tiene un carácter exploratorio, de la gestión del FGS enfocado principalmente en su cartera de acciones y la incidencia del problema mencionado precedentemente en los volúmenes operados en el Mercado de Valores (MERVAL) de la BCBA. A tal fin, se toma como inicio de referencia el año 2005 por ser un año cercano a la fecha del traspaso de la administración de las inversiones y ser el año del canje de deuda soberana, hasta fines del año 2010.

Por otro lado, se analizó el efecto provocado en el floating de las empresas cotizantes en dicho mercado, en las que el FGS tiene acciones, en el período iniciado con el traspaso de los fondos administrados por las AFJP hasta diciembre del año 2010.

Una limitación que presentará este trabajo es que solamente se analizó la tenencia de acciones de empresas consideradas argentinas por la legislación pertinente. Es decir, de la cartera heredada se excluyeron las empresas extranjeras por no ser activos elegibles como inversión por parte del FGS, ya sean acciones ordinarias, programas de ADR (American Depositary Receipts) o CEDEAR (Certificados de Depósitos Argentinos).

\section{Marco Teórico de Referencia}

\subsection{Antecedentes de la Investigación}

\section{Breve reseña histórica del financiamiento con capital propio y de los mercados de valores.}

Según los trabajos de Dapena (2007) y Fornero (2008) sobre la reseña histórica de los mercados de valores, los instrumentos de participación en el capital (acciones/equities) y de deuda (bonos/bonds), establecen que los mismos fueron desarrollados en el siglo XVI. En el presente caso se centra en las acciones, que son una fuente de financiamiento que no tiene un compromiso de pago especifico como el interés, participando de las ganancias y pérdidas por tener que afrontar el riesgo 
del negocio, por ello se lo denomina (renta variable). Por otra parte, los inversores de acciones por la responsabilidad limitada no pueden acceder a valores negativos, por ello una acción nunca puede valor menos que cero.

La primera empresa en emitir acciones de firmas de capital conjunto (joint stock company) de manera pública, fue la Russia Company, fundada en 1533. En esos tiempos, las acciones preferidas fueron populares debido a la regulación que limitaba los préstamos a las firmas a un tercio o menos de su capital suscripto. Asimismo, los primeros mercados de valores, se establecieron en la ciudad de Amberes (Bélgica) en el año 1460, en la ciudad de Lyon y Toulouse (Francia) en los años 1506 y 1549 respectivamente y en Hamburgo (Alemania) en el año 1558. Vale la aclaración, que en ellos no se realizaban transacciones de acciones. Asimismo se puede afirmar, que los mercados de valores están relacionados a su organización política de alguna manera, pero se van desarrollando con el crecimiento económico de los países.

En el año 1611 se abrió la Bolsa de Amsterdam (Países Bajos), que fue la plaza bursátil más importante hasta que tomaron su lugar la de Londres (Inglaterra) y, posteriormente, la de Nueva York (EE.UU) que es el centro financiero mundial hasta hoy día. En el siglo XX, con la explosión de países políticamente independientes, se han formado numerosos mercados de valores, con una tendencia de los últimos años a la fusión de los distintos mercados mundiales, entre diversas potencias continentales. El último caso importante de fusión fue en el año 2011, que toca de cerca a la Argentina por ser mercados de la región, cuando los mercados de Santiago (Chile), Lima (Perú) y Bogotá (Colombia) se unificaron en el Mercado Integrado Latinoamericano (MILA) con el objetivo de unir las plataformas de negociación de valores y así concentrar un mayor número de emisores, inversores e intermediarios buscando una sinergia positiva.

Dapena (2007) expone que los autores Allen y Gale (1988) afirman que el desarrollo del mercado de títulos estadounidense fue impulsado por la activa comercialización de bonos utilizados para financiar la Guerra Civil, y por las vastas necesidades de fondos que demandaban las empresas ferroviarias para financiar sus emprendimientos. 
Por último, se establece que el financiamiento con capital propio, es decir con la emisión de acciones, permite tener mayor flexibilidad a una economía en general, ya que se puede acomodar en forma más eficiente en la volatilidad de los precios. Ello permite evitar costos de incumplimientos o renegociaciones contractuales, problemas de insolvencia financiera por las deudas tomadas, entre diversas contingencias que pueden aparecer. En contraposición a ello, el financiamiento de empresas a través del ahorro es preferible a la utilización de instrumentos de participación en el capital cuando se quiere evitar costos de asimetrías de información y por posibles incumplimientos en contextos volátiles.

\section{Liquidez en los mercados de acciones.}

En el mercado de capitales de Argentina los activos financieros que poseen mayor liquidez son los títulos públicos, y por ende absorben la mayor cantidad del volumen total negociado. Por la falta de desarrollo del mercado de capitales en general, pueden surgir problemas de costo de transacción y asimetrías de información entre otros efectos. Ello puede provocar situaciones que motiven el racionamiento del crédito y similares consecuencias. Asimismo, al estar subdesarrollado el mercado provoca restricciones de liquidez para algunos grupos económicos, que deberán buscar una creciente generación propia de ahorros, destinando una mayor proporción de su ingreso a dicho objetivo.

Todos los costos de transacción que aparecen en una economía pueden afectar la liquidez o el volumen comercializado. Para el presente estudio, se definió a los costos de transacción como todos aquellos costos reales o institucionales, monetarios o no, que dificultan el intercambio de bienes y servicios con relación a los mercados financieros. En el presente caso fue, el cambio en la administración fiduciaria de los fondos previsionales privados por parte de privados hacia el estado.

Centrándose en la liquidez, que es el objeto de estudio de este apartado, es un factor muy importante en un mercado de capitales, dado que un mercado secundario líquido facilita la emisión primaria de instrumentos y por ende una mayor fuente de financiación para la economía en general. Dando una mayor dinámica a la entrada y 
salida de los inversores individuales e institucionales facilitando la competencia, la realización de transacciones, la transparencia y la eficiencia en el mercado.

Los antecedentes empíricos según describe Dapena (2003), de las consecuencias de la falta de liquidez en el mercado accionario sobre una economía, se pueden fundamentar en el trabajo de Levine y Zerbos (1998) donde encuentran que la liquidez en los mercados, medida tanto por el valor del volumen de transacciones con relación al tamaño del mercado como por la liquidez del mercado con relación al tamaño de la economía, está positiva y fuertemente relacionada con el crecimiento (tanto corriente como futuro) de las economías.

La determinación de la relación entre la valuación de activos financieros con cotización pública y las variables macroeconómicas, es de fundamental importancia para determinar el efecto en la liquidez del mercado. El trabajo realizado por Kawamura (2010) en su apartado sobre valuación de activos expone el modelo de Lucas (1978) para encontrar precios de equilibrio de los activos. Dicho modelo relaciona el problema de la valuación de activos financieros con factores macroeconómicos, especialmente el consumo, a través de la aplicación del método de modelación de equilibrio general intertemporal sin certeza.

De las distintas comprobaciones empíricas y extensiones del modelo de Lucas, se trae de referencia el trabajo de Lagos (2008). Quien introduce la presencia de acciones y bonos que no solamente se constituyen como canal o medio de ahorro sino que asimismo poseen un rol de medio de cambio, trayendo implícitamente los motivos del dinero de Keynes (transacción, precaución y especulación). Ello implica que estos dos activos adquieren una propiedad de liquidez, en el sentido de poder convertirse en consumo (de bienes que se transan en mercados descentralizados). Por lo que ello genera un rendimiento adicional para cada activo, el llamado premio o prima por tener liquidez.

Entre las distintas conclusiones de Kawamura (2010), establece que "[...] dada la muy baja liquidez del mercado accionario de Buenos Aires, cualquier afirmación que pueda intentarse realizar sobre la validez o no de alguna versión del modelo de Lucas podría parecer aventurado. Claramente, la falta de volumen para una alta 
proporción de las acciones que cotizan en la Bolsa de Comercio quita consistencia y credibilidad a todo test econométrico (o de otra índole) desarrollado originalmente para mercados de mucho mayor volumen". ${ }^{4}$ Dichas recomendaciones sirven para trabajos futuros sobre modelos de valuación de activos en mercados con características como el argentino, lo cual es ajeno al objeto de este trabajo pero sirve como indicio al fin propuesto de la presente investigación para evaluar la liquidez y volumen del mercado local.

El mercado de acciones de Argentina presenta la característica de tener una fuerte concentración de la liquidez en pocas especies que concentran el volumen negociado. Acompañado de un gradual proceso de deslistamiento tanto de acciones como de agentes de bolsas en las últimas décadas, reducen las posibilidades de diversificación para las carteras de inversión (Irigoyen, 2006).

La negociación de acciones con baja liquidez posee ventajas y desventajas que es correr con el principal riesgo de no poder salir de la posición, porque el spread (distancia entre la punta compradora y la vendedora) es mayor, por eso se complica si se desea hacer day-trade (compra y venta en el día). Por ello, uno de los principales problemas de las acciones puede ser la baja liquidez que tenga, dado que cuando el inversor quiera vender su posición deba pagar un spread extra. En acciones líquidas, el spread es pequeño, mientras que en las ilíquidas la distancia es grande y además se puede tardar varias ruedas de negociación en venderlas. En síntesis, más allá de lo atractivo que puede parecer una acción, siempre es aconsejable conocer la capitalización bursátil de la empresa y el grado de libertad de mercado con que cuenta, para evitarse algún disgusto a la hora de intentar liquidar el mencionado título.

\section{La gestión de las AFJP en la cartera de acciones (Años 1994-2008).}

En una apreciación general, las AFJP invertían en acciones que cotizaban en la BCBA en el panel general, y especialmente en el MERVAL de acuerdo con la normativa que las enmarcaba. En su mayoría seguía como benchmark a las

\footnotetext{
4 Ver KAWAMURA, E. (2010) "Valuación de activos financieros: ¿Qué nos enseñan más de cincuenta años de investigación?" En: Progresos en Finanzas. BEBCZUK, R. (Editor) Página 58.
} 
empresas integrantes del MERVAL o BURCAP, y realizaban sus correcciones de acuerdo con las modificaciones que hacía la composición de la cartera de estos índices en forma trimestral en el caso del MERVAL.

Es decir, los administradores de portafolios (portfolio managers) no realizaban trading diario de sus posiciones por lo general, y debían cumplir toda la regulación de inversiones establecida por la Superintendencia de AFJP (SAFJP). Asimismo, si se excedían en sus límites de tenencia por cantidad de nominales o por la apreciación del precio o por cambios en su calificación, debían desprenderse de las mismas en un tiempo estipulado y prudente. Como se expuso en el planteo del problema del presente trabajo, las administradoras se comportaban en forma de manada en la conformación de las carteras siguiendo a las empresas líderes y más grandes del sector de jubilaciones privadas como fueron en la mayoría del tiempo que existieron las AFJP Orígenes y Consolidar. El incentivo que tenían las AFJP era no desviarse del promedio de rentabilidad de la industria para no ser multados por el organismo de contralor, y generalmente las firmas pequeñas tomaban como benchmarck al sistema. Estas no podían seguir a las grandes compañías líderes porque les implicaba una estructura e inteligencia que no podían financiar.

Las extinguidas AFJP participaron en forma activa de todas las nuevas aperturas de capital que realizaban empresas locales en las denominadas Ofertas Públicas Iniciales (OPI) o en idioma inglés IPO (Initial Public Offering) en la bolsa local. Dando en la mayoría de los casos bajos resultados por ganancia de capital a través del tiempo, dado que los precios caían una vez aceitada su cotización en el mercado secundario. Ciertamente, en su momento hubo una pérdida para los afiliados a las AFJP por suscribir en el mercado primario la acción correspondiente, que luego se tomó su tiempo recuperar lo invertido o se obtuvieron bajas tasas de retorno. A ello adicionándoles la poca distribución de dividendos que realizaban las empresas por sus utilidades. Algunos ejemplos en su momento fueron las OPI de Socotherm Argentina (noviembre del año 2006), del Banco Patagonia (julio de 2007), del Grupo Clarín (octubre del año 2007) y Consultatio (mayo de 2008). 


\section{Anomalías en la eficiencia del mercado de acciones, información asimétrica, capital flotante y derechos políticos.}

Aunque no sea un antecedente específico al presente objeto de estudio, vale la referencia al trabajo realizado por Cantó (2001). El mismo mide la eficiencia del mercado de capitales argentino (julio de 1995 y junio de 2001), buscando identificar retornos extraordinarios (presión al alza de los papeles) provocados por el flujo de fondos volcados al mercado por las AFJP en la tercera semana del mes por su recaudación. Trabajó sobre más de veinte papeles locales y dos índices de acciones, y se encontraron indicios de una ineficiencia, la cual se vuelve más significativa al corregirse la serie por el efecto de cambio de mes. Aunque aun así, no puede afirmarse categóricamente que la mencionada ineficiencia realmente se deba a la causa propuesta o que su existencia pueda eventualmente ser utilizada para conseguir retornos extraordinarios.

En términos generales las anomalías son casos inconsistentes con la hipótesis de eficiencia de mercado que, no son arbitrados por el mercado. Entre estas últimas se encuentra el efecto enero (mayores retornos en ese mes), el efecto lunes o fin de semana (menores retornos en ese día), el efecto cambio de mes (mayores retornos en ese momento), efecto tamaño, entre otras. El mencionado efecto tamaño que provoca ineficiencias en el mercado, puede haberse generado en el mercado argentino si se demuestra un cambio importante en el valor operado ante el evento de la estatización de la administración de los fondos previsionales.

Volviendo al tema de información asimétrica y problemas de agencia Roubini (2010) expresa que "(...) existen enormes problemas de representación en el sistema financiero porque los actores principales (como los accionistas) no pueden controlar el accionar de los agentes (máximos responsables ejecutivos, gerentes, operadores, banqueros) que persiguen sus propios intereses. El problema no es sólo que los accionistas de largo plazo son estafados por agentes de corto plazo codiciosos; hasta los accionistas tienen problemas de representación. Si las instituciones financieras no tienen suficiente capital, y los accionistas no tienen gran parte de su pellejo en juego, llevarán a los CEO y a los banqueros a asumir un apalancamiento y riesgos excesivos, porque su propio capital contable no está en juego." Y continúa 
expresando que "Existe un doble problema de representación, ya que los principales accionistas -los individuales- no controlan a las juntas y a los CEO. Estos accionistas están representados por inversores institucionales cuyos intereses, agendas y relaciones amistosas muchas veces los alinean más estrechamente con los CEO y gerentes de las firmas." 5

En el mismo sentido, Benedicto XVI (2009) habla de la responsabilidad social de la empresa y la difusión con fuerte convicción que la gestión de la empresa no puede tener en cuenta únicamente el interés de sus propietarios, sino también el de todos los otros sujetos que contribuyen a la vida de la empresa: trabajadores, clientes, proveedores de los diversos elementos de producción, la comunidad de referencia (los llamados stakeholders). Por su parte expresa lo siguiente: "En los últimos años se ha notado el crecimiento de una clase cosmopolita de manager, que a menudo responde sólo a las pretensiones de los nuevos accionistas de referencia compuestos generalmente por fondos anónimos que establecen su retribución. Pero también hay muchos managers hoy que, con un análisis más previsor, se percatan cada vez más de los profundos lazos de su empresa con el territorio o territorios en que desarrolla su actividad." Por otra parte su santidad hace la salvedad que muchas veces tiene sus beneficios invertir en el extranjero, siempre contemplando la justicia y los prejuicios que se generen en el lugar donde se generó el capital al no utilizarse allí. En el mismo capítulo de la Encíclica se transmite que, a pesar de la fuerte liberalización de los mercados de capitales, el importante desarrollo tecnológico para inducir a un pensamiento lineal que invertir, es sólo un hecho técnico y no humano ni ético. Para finalizar Benedicto XVI expresa que "(...) Se ha de evitar que el empleo de recursos financieros esté motivado por la especulación y ceda a la tentación de buscar únicamente un beneficio inmediato, en vez de la sostenibilidad de la empresa a largo plazo, su propio servicio a la economía real y la promoción, en modo adecuado y oportuno, de iniciativas económicas también en los países necesitados de desarrollo"

Estos dichos se pueden ver reflejados en la gestión del FGS de la ANSES que invierte los recursos de los aportantes en la economía doméstica, y trata de fomentar

\footnotetext{
${ }^{5}$ Ver ROUBINI, N. (2010) "Gordon Gekko volvió a nacer y no morirá con reformas tibias"

6 Ver BENEDICTO XVI (2009) "Carta Encíclica Caritas in Veritate” .Capítulo tercero: Fraternidad, desarrollo económico y sociedad civil. Punto 40. Páginas 74 a 77.
} 
el crecimiento de largo plazo. Como así la defensa de sus intereses en la participación en empresas privadas queriendo hacer respetar sus derechos políticos, e indirectamente representando a los inversores minoristas. Ya que se necesita incurrir en costos de monitoreo por parte de accionistas (generalmente minoristas) que no siguen de cerca la gestión de la empresa en el momento de la distribución de utilidades, para que aquellos que tengan el control o tengan información diferencial no saquen su provecho en beneficio propio.

Por ello, la incursión de la ANSES en las asambleas de las sociedades en forma activa y haciendo valer sus derechos como accionistas al buscar su beneficio propio, en forma colateral beneficia a los accionistas minoritarios que muchas veces no se lo ha respetado. Todo ello, adicionado a los costos de monitoreo y seguimiento que los inversores individuales e institucionales deben realizar, protegidos con un adecuado marco legal y judicial servirá para el desarrollo del mercado de acciones, y el buen gobierno corporativo que pregona el Decreto 677/01.

La parte del capital que se negocia libremente entre el resto de los inversionistas en términos anglosajones se definiría como free-float (capital flotante) o acciones que no están en manos del núcleo duro accionista o controlante de la compañía. Puntualmente, se puede definir como el porcentaje o parte del capital social de una empresa que no está controlado por los accionistas mayoritarios y que cotiza libremente en el mercado. Que una firma posea un free float reducido no necesariamente es una mala señal, ya que los inversores individuales e institucionales tienen como objetivo incrementar su rendimiento y buscan para ello acciones de empresas que estén bien administradas por quienes tienen el conocimiento del sector de la economía, así como la industria específica en la que se desenvuelve. Las empresas al abrir su capital y cotizar en la bolsa de valores, no necesariamente licuan su control sino que están incorporando socios que comparten el riesgo total del negocio (riesgo económico y financiero). 


\section{El paso a ser considerado mercado de frontera.}

Mención aparte, merece lo sucedido en el año 2008. Aparte de la gran crisis mundial y el efecto de lo estudiado en el presente trabajo, las acciones de empresas argentinas sufrieron otro golpe adicional. El banco Morgan Stanley, a través de su subsidiaria, elabora los índices de referencia (o benchmarks) de la mayor parte de los países que poseen mercados accionarios. Forma parte de un cálculo que guía a la mayor parte de los administradores de fondos en la confección de sus carteras, porque para poder decir que le ganó al promedio hay que tomar un índice de referencia. Los administradores siguen pasivamente la estrategia de rebalancear sus portafolios tal como lo hace su benchmark realizando los cambios más importantes. La Argentina paso de ser considerado un país de mercado emergente para el mercado accionario, a ser califica como mercado de frontera para el índice MSCI Barra que elabora el mencionado banco. Los cambios de criterios que se utilizan son cualitativos, como cuantitativos para determinar si un país es desarrollado, emergente o de frontera. Entre los atributos que se miden son el desarrollo económico que posee el país; el tamaño y liquidez del mercado de capitales; y el nivel de acceso para el inversor extranjero.

Pero puntualmente para Argentina, entre otros factores, el cambio de clasificación fue debido a que Tenaris, la principal empresa del índice de acciones en ese año, pasó de ser una empresa en el índice de la Argentina a una empresa del índice de Italia. Por lo que ya no es considerada una empresa Argentina por más que aquí haya sido fundada, que su casa matriz esté ubicada en el país y que la mayor parte de su management sea argentino. Como consecuencia de lo anterior, la Argentina pasó de representar el $2.3 \%$ del $\mathrm{MSCl}$ Latinoamérica a tan sólo el $0.6 \%$, sin poder calificar como emergente y pasando a otro grupo de países, por lo que ya no se es destino de fondos de inversiones recurrentemente. Es decir, pasó de estar en el Índice MSCI EM (Emerging Markets) Latin America (al 30 de mayo de 2011 integrado por los índices de Brasil, Chile, Colombia, México y Perú), a pertenecer al Índice MSCI Frontier Markets.

La empresa del Grupo Techint, al tener residencia legal en Luxemburgo, es considerada una empresa extranjera por lo que el FGS de la ANSES no la puede 
mantener en cartera por la normativa vigente, teniendo un plazo acorde para desprenderse de las acciones. En la BCBA de Argentina las 6 empresas extranjeras que cotizan son Andes Energía (AEN) de Inglaterra; Petróleo Brasileiro (APBR) de Brasil; Banco Santander Hispano (STD); Repsol YPF (REP) y Telefónica (TEF) de España; y Tenaris (TS) de Italia.

\section{El marco institucional y su calidad.}

A las instituciones se las define como las normas que permiten coordinar las acciones de los individuos en la sociedad y dar previsibilidad respecto de las acciones de los demás individuos. La buena calidad institucional es determinante para el desarrollo de los países según se desprende de distintos trabajos que se mencionan a continuación.

Con el proceso de globalización que se vive en el mundo y la gran interrelación entre los países, se debe brindar reglas claras y predecibles para contar con una ventaja competitiva. A la hora de establecer un clima favorable para el funcionamiento de las distintas políticas de Estado y así mejorar la calidad de vida de sus ciudadanos se debe pregonar por instituciones sólidas. Ello permitirá atraer inversiones y flujos de capitales hacia el país, que permanezcan por períodos largos y estables, como así retener los ahorros de los ciudadanos locales evitando la fuga de capitales. Países que cuenten con los marcos institucionales más fuertes, estables, están en mejores condiciones de aprovechar las oportunidades que brinda la globalización. Las funciones económicas básicas atribuidas al marco institucional son la de reducir parcialmente los costos de transacción, otorgando certidumbre y predictibilidad a la interacción social; y por otro lado, facilitar la coordinación de los agentes económicos.

El trabajo de Alonso y Garcimartin (2009) tiene en cuenta estas funciones económicas, por lo que la calidad de las instituciones las define por cuatro criterios básicos:

- Eficiencia estática: medida por la capacidad que una institución tiene para promover equilibrios que agoten las posibilidades que brinda la frontera tecnológica. 
- Credibilidad (o legitimidad): medida por la capacidad de la institución para trazar contratos inter-temporales creíbles; es decir, para generar marcos normativos que sean asumidos y condicionen, efectivamente, la conducta de los agentes.

- Seguridad (o predictibilidad): medida por la capacidad para reducir la incertidumbre asociada a la interacción humana; es decir, para otorgar seguridad y estabilidad a las relaciones sociales, disminuyendo así los costos de transacción.

- Adaptabilidad (o eficiencia dinámica): la capacidad de las instituciones para anticiparse a los cambios de la realidad social; o, cuando menos, para generar los incentivos que facilitan la adaptación de los agentes sociales a esos cambios.

Por otro lado, distintos estudios a nivel mundial evalúan a través de índices el grado de desarrollo y calidad institucional - económica de los distintos países del mundo. Son elaborados por organismos multilaterales, agencias calificadoras de riesgos, instituciones académicas y organizaciones no gubernamentales, entre otras organizaciones. Estos indicadores son muy diversos y en muchos casos subjetivos basados de extracciones realizadas en encuestas a distintos agentes económicos. En el presente, no se busca explicaciones en las distintas críticas que se les hace por el rigor estadístico que utilizan ni por su construcción, en la mayoría de los casos comparando jerarquías entre países, más que de mediciones absolutas, sino buscar antecedentes en la temática.

La utilización de algunos indicadores de medida de la calidad institucional está cargada de valoraciones implícitas que muchas veces no se dan a conocer, como sería la asociación de calidad institucional con la flexibilidad y la libertad con la que operan los mercados. Ergo, muchas veces los mencionados trabajos esconden intereses de quienes las elaboran y quien los financia en búsqueda de otros fines no explícitos. Por ello su utilización y conclusiones se deben tomar con las precauciones de caso, así como los limitantes que los mismos acarrean.

Las limitaciones que se aprecian en algunos indicadores institucionales, es que no siempre distinguen lo que es una institución de lo que es el resultado de esa institución. En muchos otros casos de construcción de indicadores compuestos, no siempre se fundamenta adecuadamente el método que se utiliza para agregar los 
distintos componentes, ni el modo de ponderación a los distintos factores dependiendo del país analizado. En muchos países, los datos disponibles no son de suficiente calidad como para confiar en las mediciones, obteniendo información heterogénea entre países, lo que dificulta las comparaciones internacionales y pierde la esencia de comparación de una década a otra (Alonso y Garcimartin, 2009)

Entre los índices más reconocidos a nivel mundial se encuentra el de Libertad Económica elaborado por Heritage Foundation y Wall Street Journal. Donde la Argentina se ubicó en el año 2010 en el puesto 138 sobre un total de 179 economías evaluadas, el puesto más bajo desde que se confecciona el índice en el año 1995, lo que revela el deterioro progresivo en materia de libertad económica según esta fundación de carácter liberal. Respecto a las variables contempladas por este indicador, los puntos más bajos se obtienen en derechos de propiedad y corrupción. Por otro lado, remarca que la intervención del estado en la economía ha crecido de modo significativo siendo en el mercado laboral donde más ha empeorado debido a más regulaciones y controles.

Otro indicador relevante que se elabora en la Argentina por Martín Krause de la Fundación Libertad y Progreso, de ideología netamente liberal es el Índice de Calidad Institucional $(\mathrm{ICl})$. Es elaborado en base a datos estadísticos como a opiniones de expertos, tanto por organismos internacionales como por institutos de investigación o think tanks, permitiendo diversidad de opiniones en muchos casos con un fuerte sesgo ideológico.

$\mathrm{El} \mathrm{ICl}$ contiene dos componentes, uno sobre calidad de las instituciones políticas y otro de las económicas. De acuerdo con el trabajo publicado en el año 2011, la Argentina empeoró su desempeño en materia de institucionalidad de manera ininterrumpida desde 2006 llegando al puesto 125 de 194 totales en el año 2011. Según el informe la Argentina muestra en términos generales malos desempeños en materia de libertad económica, competitividad y respeto a la ley. Los mayores cambios negativos desde que comenzara a publicarse este indicador en el año 2007 corresponden a Argentina y Nicaragua. 
El mencionado índice es una mezcla de otros indicadores reconocidos a nivel internacional. En su componente de instituciones políticas, incluye el Indicador sobre el Respeto del Derecho (Rule of Law) que elabora el Banco Internacional de Reconstrucción y Fomento (BIRF) (conocido comúnmente como Banco Mundial); el componente Voz y Rendición de Cuentas del mismo organismo internacional; el informe Libertad de Prensa elaborado por Freedom House y el indicador de Percepción de la Corrupción elaborado por Transparency International.

Por el lado de indicadores relacionados a instituciones de mercado (económicos), se halla el de Competitividad Global elaborado por el World Economic Forum (WEF), el de Libertad Económica de Heritage Foundation y Wall Street Journal (mencionado precedentemente), el de Libertad Económica en el Mundo del Fraser Institute de Canadá, y Haciendo Negocios (Doing Business) también elaborado por el Banco Mundial.

A modo de ejemplo se menciona que el índice de Libertad Económica tiene en cuenta en su elaboración entre otros conceptos al tamaño del gobierno (gastos, impuestos, empresas Estatales); la estructura legal y seguridad del derecho de Propiedad; el acceso a una moneda confiable; libertad para comerciar internacionalmente; regulaciones sobre el crédito, el trabajo y los negocios; entre otros. El Índice de Competitividad Global está compuesto por tres subíndices: el de requerimientos Básicos (Instituciones, Infraestructura, Macroeconomía, Salud y Educación Primaria); Promotores de la Eficiencia (Educación Superior y Capacitación, Eficiencia de los Mercados y Disponibilidad Tecnológica) y los Factores de Sofisticación e Innovación (Sofisticación Empresarial e Innovación).

El índice que indaga sobre Respeto del Derecho, tiene en cuenta las variables de independencia de la justicia; la protección del derecho de propiedad; existencia de crimen organizado y violento; pérdidas como resultado de crímenes; cumplimiento de los contratos gubernamentales y privados; efectividad de la ley (respeto); confianza en la Corte Suprema, los jueces y en la policía; honestidad de los funcionarios judiciales; rapidez de sus decisiones; etcétera. 
Mención aparte merece uno de los objetivos de las instituciones que es tener acceso a una moneda confiable. La moneda es una institución fundamental que permite multiplicar los intercambios y la cooperación en el mercado; y también el desarrollo de un sistema financiero sustentable y particularmente un mercado de capitales de largo plazo. Por lo que Krause (2007) menciona que "Si el Estado impone en primer lugar la obligación de usar la moneda estatal (curso forzoso) y luego deteriora el valor de la moneda impidiendo además que los ciudadanos se protejan utilizando otra, está minando un elemento institucional de sustancial importancia" ${ }^{\prime 7}$. Ese deterioro se ve como un impuesto distorsivo que no es votado por ningún representante del pueblo, distribuye ingresos de acreedores a deudores, confisca la propiedad y viola la libertad económica de los ciudadanos.

Los cambios institucionales se producen en forma lenta y pausada, y resulta apresurado sacar conclusiones por cambios de un año a otro, pero un lustro permite observar tendencias, aunque siempre resulta necesario destacar que se están evaluando posiciones relativas (Krause, 2011). Entre otras cosas, poseer calidad institucional significa poseer más y mejores oportunidades, mayor nivel de vida, de inversiones y de innovación en un país.

Los resultados del $\mathrm{ICl}$ evidencian un deficiente desempeño de Argentina en materia institucional tales como en cada uno de los índices que lo componen. Estos indicadores son confeccionados por distintas organizaciones y con diferentes metodologías, mostrando claramente la necesidad imperiosa de emprender reformas estructurales que conduzcan a un progreso socioeconómico sustentable. Dichos indicadores deberían ser comparados con otros elaborados por distintas corrientes de pensamiento, que pongan foco en lo social y en el desarrollo humano para no caer en el error de tergiversar las conclusiones por las distintas anteojeras ideológicas.

Krause (2011) en una entrevista periodística ${ }^{8}$ acerca de la puntuación de la Argentina en el índice, menciona que noticias como la estatización de las AFJP, la prohibición

\footnotetext{
7 Ver KRAUSE, M. (2007) “Calidad de las Instituciones y Competencia Institucional”. Página 13.

8 Ver artículo periodístico en EL CRONISTA (2011) "El país está entre las naciones del mundo que más cayeron en calidad institucional". Jueves 16 de junio de 2011.
} 
de las importaciones y las exportaciones o la manipulación de estadísticas son datos que inciden en esta categoría.

Las recomendaciones y conclusiones derivadas de estos trabajos se encuentran en la necesidad de fortalecer el Estado de Derecho a través de tratados internacionales que permitan a los ciudadanos recurrir a instancias supra-nacionales en defensa de sus derechos, la remoción de las barreras al comercio, a las inversiones, y al movimiento de personas, la descentralización gubernamental, y la eliminación y simplificación de regulaciones (Krause, 2007)

\subsection{Bases Teóricas}

\section{Sistema de capitalización de los fondos previsionales}

Marco histórico y estructura del Sub Sistema de jubilaciones y pensiones privados en Argentina

La reforma previsional impulsada en los noventa ante los cambios de paradigma avizorados en Chile (año 1981) sobre la financiación y administración de los recursos previsionales, se plasmó con la sanción en fecha 23 de septiembre del año 1993 con la Ley 24.241 creando el Sistema Integrado de Jubilaciones y Pensiones (SIJP). El SIJP, participante del Sistema Único de Seguridad Social (SUSS) tenía un alcance nacional, salvo excepciones, y cubría las contingencias de vejez, invalidez y muerte de las personas que se desempeñaban como trabajadores dependientes y autónomos, amparando a los mismos y sus derechohabientes.

Los principios de este sistema en líneas generales, eran los de Universalidad, Solidaridad, Equidad, Libertad, Eficacia, Transparencia y Credibilidad. EI SIJP era un sistema previsional mixto porque estaba integrado por dos regímenes que coexistían:

$\Rightarrow \quad$ Régimen de reparto o Régimen Previsional Público, administrado por el Estado, a través de ANSES. 
$\Rightarrow \quad$ Régimen de capitalización, que otorgaba prestaciones que se financiaban con la capitalización individual, que eran administrados por gestores privados, las AFJP, que eran fiscalizados por un organismo de control: Superintendencia de AFJP (SAFJP).

Estos regímenes tenían una estructura de tres pilares: el primero funciona (actualmente) bajo el esquema de reparto con solidaridad intergeneracional (los trabajadores activos financian a los pasivos del momento); el restante capitalizaba los aportes obligatorios y voluntarios de sus afiliados (bajo un esquema de seguridad y rentabilidad en las inversiones).

Era obligatoria la incorporación de trabajadores mayores de 18 años, dependientes del Estado Nacional, de los gobiernos provinciales y municipales que transfirieron sus sistemas previsionales a la Nación, trabajadores dependientes del sector privado, y trabajadores autónomos. Asimismo, era de incorporación voluntaria para los directores de sociedades anónimas que tributaban obligatoriamente como trabajadores autónomos y que desearan incorporarse voluntariamente como dependientes por actividades remuneradas que realizaban para la sociedad, otros socios de sociedades que no debían tributar como autónomos. Quedaban exceptuado el personal militar de las fuerzas armadas, de seguridad y policiales, entre otros.

Para la Opción de cambio de Régimen, los trabajadores podían optar libremente por el régimen al que querían derivar sus aportes. Esa decisión debía ser ejercida dentro de los treinta días de su ingreso al SIJP. De no ejercitar dicha opción, el trabajador era considerado indeciso y se derivaban sus aportes a una administradora en función de un procedimiento de asignación mensual que efectuaba ANSES, donde se distribuían los afiliados indecisos entre todas las administradoras con menores comisiones. Una limitación importante, era que se podía cambiar del régimen de reparto al de capitalización, pero no a la inversa.

El afiliado o beneficiario del régimen de capitalización tenía derecho a cambiar de administradora (traspaso) con las siguientes limitaciones: a) podía traspasarse hasta dos veces por año calendario.; b) Si era afiliado, debía registrar al menos cuatro 
meses de aportes en la administradora que abandonaba; c) Si era beneficiario, y estaba percibiendo retiro programado o retiro fraccionario, debía registrar al menos cuatro cobros en la administradora que abandonaba. La constitución de la oferta privada de estos servicios, cuyo objeto formal era la provisión de un seguro previsional bajo la formación de un portafolio de activos, se encontraba restringida por la normativa mencionada que originó el sistema.

Existían cuatro grandes categorías de propiedad del capital de las AFJP en la Argentina: bancos públicos, empresas de capital extranjero (bancos y empresas), compañías de seguros y aquellas originadas vía acción sindical. Es decir que la mayoría de estas sociedades, formaban parte de conglomerados financieros (brindaban al menos dos servicios financieros entre: bancos, valores y seguros). Al comienzo del sub régimen de capitalización existían 24 administradoras privadas, y a Octubre del año 2008 quedaban solo 10, lo que demuestra cómo se fue concentrando el mercado a lo largo de los años. Este significativo proceso de concentración durante esos años, ocurrió especialmente durante los primeros cuatro años, observándose un leve descenso posterior, e intensificándose nuevamente al concluir el año de la crisis del año 2001.

La reducción en el número de administradoras no determinó necesariamente mayor concentración en la estructura del mercado, sino la presencia de cambios en la participación de cada una de las firmas en la industria y la interacción entre las mismas. Esto se fundamenta de acuerdo con estudios realizados por la SAFJP y la Facultad de Ciencias Económicas de la Universidad de Buenos Aires (UBA), donde se monitoreaba la industria con dos índices: el de concentración a la cuarta firma y el índice de Herfindahl, que tomaban en cuenta la cantidad de afiliados y aportantes en sus fórmulas (Apella - Maceira y Katz, 2004).

En materia de inversiones, el marco normativo que encuadraba a las AFJP podía haber sido modificado en sus límites en general, principalmente la exposición al sector público dado el carácter de fondos privados. Se podría haber incentivado a los gestores de estos fondos privados con una remuneración variable en función de los resultados de la cartera y requerir capital en función del riesgo asumido para proteger el capital de los aportantes. Otro punto puede ser haber avanzado para que se 
invierta en empresas argentinas, y limitar la tenencia de activos extranjeros para asegurar el capital ante cambios bruscos e inesperados financieros en el resto del mundo.

Dicha política de las administradoras de invertir en instrumentos financieros de empresas extranjeras no significaba otra cosa que la transferencia al exterior de ahorro argentino. No teniendo en cuenta, el problema histórico de las empresas locales del acceso a financiamiento que les permita concretar inversiones para su desarrollo. Otra incoherencia se da cuando se manifiesta que uno de los objetivos con el que se creó el sistema de jubilación privada fue el de fomentar el mercado de capitales argentino. Si las AFJP invertían el ahorro de los trabajadores en empresas extranjeras, se reducían las posibilidades de que las locales puedan salir a la oferta pública.

\section{Las inversiones de los fondos previsionales públicos}

Con los fondos obtenidos, las AFJP invertían en activos financieros que menciona la Ley 24.241 SIJP, en el Capítulo V: Inversiones. Allí en el Artículo 74 se detallan taxativamente las clases de instrumentos que podían adquirir y el límite porcentual que debían tener de cada activo en referencia al total de la cartera. Por realizar estas inversiones, las administradoras cobraban comisiones, para asegurar rentabilidad y seguridad en los fondos.

Una de las inversiones que podían realizar era en acciones, que es el centro de esta investigación. Se las menciona en el inciso h) del mencionado artículo: "Acciones de sociedades anónimas nacionales, mixtas o privadas cuya oferta pública esté autorizada por la Comisión Nacional de Valores, hasta el cincuenta por ciento (50\%). La operatoria en acciones incluye a los futuros y opciones sobre estos títulos valores, con las limitaciones que al respecto establezcan las normas reglamentarias.”; i) "Acciones de empresas públicas privatizadas, autorizadas a la oferta pública por la Comisión Nacional de Valores, hasta el veinte por ciento (20\%)." y I) "Títulos valores emitidos por sociedades extranjeras admitidas a la cotización en mercados que la Comisión Nacional de Valores determine, hasta el diez por ciento (10\%)". 
Cabe mencionar que todos los títulos valores, públicos o privados que podían ser objeto de inversión por parte de los fondos de jubilaciones y pensiones, debían estar autorizados para la oferta pública y ser transados en mercados secundarios transparentes que brinden diariamente información veraz y precisa sobre el curso de las cotizaciones en forma pública y accesible al público en general.

La Comisión Nacional de Valores (CNV) determinaba y determina los mercados que reúnen los requisitos enunciados en la normativa. Como así, la marco regulatorio vigente enuncia las limitaciones, prohibiciones y la calificación de riesgo que deben tener las inversiones realizadas. Para cumplir el criterio de seguridad, la mayoría de los fideicomisos y obligaciones negociables en la cartera del FGS está actualmente valuada como Grado de Inversión (Investment Grade) por las principales agencias de calificación locales e internacionales. En tanto, los títulos públicos podrían mejorar su calificación en los próximos meses a raíz de diversas acciones que está llevando adelante el Gobierno Nacional (como la negociación de la deuda con el Club de París).

Según la Internacional Social Security Association (ISSA) a nivel global los fondos previsionales públicos tienen una tenencia promedio de instrumentos de renta fija en el orden del $85,5 \%$. Si se excluye los países de EE.UU. y Japón se llega al $57,7 \%$ del total de los activos que manejan los fondos previsionales públicos alrededor del mundo invertidos en instrumentos de renta fija, seguidos por las inversiones en acciones, con poco más del $11 \% \mathrm{y}$, en un porcentaje significativamente menor, otros activos como depósitos, disponibilidades en efectivo, préstamos, y bienes raíces, entre otros (ISSA, 2007).

\section{Los primeros indicios hacia la nacionalización y su concreción.}

El Gobierno en el año 2007, anunció una medida que obligó a las AFJP a repatriar 8.000 millones de pesos del fondo de sus afiliados que estaban invertidos en Brasil para invertir en financiar la llamada economía real del país (proyectos productivos o de infraestructura). 
Luego, con la sanción de la Ley 26.222, se permitió la libre movilidad de los aportantes entre los dos regímenes que coexistían hasta ese momento. Asimismo, los aportes de los trabajadores en ambos regímenes se igualaron al $11 \%$ a partir del 1 de enero de 2008, para que no haya incentivo a favor del régimen de capitalización.

Por otro lado, dicha ley unificó la fórmula de cálculo de la Prestación Compensatoria (PC) y la Prestación Adicional por Permanencia (PAP) en $1.5 \%$ de la base jubilatoria promedio de los últimos 10 años para los trabajadores dependientes, o de toda la historia laboral con aportes para los trabajadores autónomos o monotributistas, por cada año aportado.

Con esta primer reforma de la Ley 24.241, los trabajadores que al llegar a los 50 años (mujeres) o 55 años (hombres) tenían ahorrado en la AFJP menos de $\$ 20.000$ en su cuenta de capitalización individual fueron considerados afiliados al Régimen Previsional Público para garantizarles prestaciones mínimas. Los fondos que estaban acumulados en la AFJP fueron transferidos dentro del plazo de 90 días al Estado, salvo que el afiliado manifestara expresamente su voluntad de permanecer en el Régimen de Capitalización.

Previo a la estatización, en ese mismo año se estaba trabajando en un proyecto para otra nueva modificación de la Ley № 24.241 donde los organismos estatales como la SAFJP y la cámara que agrupaba a los privados la Unión de Administradoras de Fondos de Jubilaciones y Pensiones (UAFJP) participaban del proyecto. El mismo trataba la creación de multifondos, basado en la existencia de dos fondos, uno que se llamaría Fondo de Jubilaciones y Pensiones Tipo 1 y otro Tipo 2. Las AFJP deberían transferir el saldo de la CCI del Fondo Tipo 1 a la de Tipo 2 a partir que los afiliados hombres alcancen los 55 años de edad y las mujeres los 50 años. Se tenía como propuesta el plazo de 10 años para que el procedimiento de transformación de saldo con el objetivo de suavizar las fluctuaciones del mercado. Los saldos podrían permanecer en el fondo Tipo 1 cuando los afiliados se expresen en tal sentido su voluntad. Lo que se intentaba era seguir los pasos de Chile donde existen varios fondos con distintas carteras de inversiones de acuerdo con el nivel de riesgo del aportante. Se buscaba con el proyecto, que aquellas personas que estén cercanas a 
su retiro no sufran las variaciones de los mercados financieros, y se les asignaba una cartera aún más conservadora.

El 20 de octubre de 2008, el gobierno argentino anunció la intención de la unificación del SIJP en un único régimen previsional público, financiado por medio de un sistema solidario de reparto. Por lo que se crea el Sistema Integrado Previsional Argentino (SIPA), en las condiciones promulgadas por la Ley 26.425 , donde se elimina el Régimen de Capitalización, que es absorbido y sustituido por el Régimen de Reparto.

Se decidió transferir en especie a la ANSES los recursos que integraban las Cuentas de Capitalización Individual $(\mathrm{CCl})$ de los afiliados del Régimen de Capitalización, con excepción de los fondos destinados a financiar las rentas vitalicias. Dichos activos (cartera de inversiones que administraban las AFJP) pasaron a integrar el FGS del Régimen Previsional Público de Reparto creado por el Decreto 897/07 del Poder Ejecutivo Nacional. La mencionada ley establece que la totalidad de los recursos del fondo de garantía únicamente podrán ser utilizados para pagos de los beneficios del SIPA, sin perjuicio que el activo del fondo se invierta aplicando criterio de seguridad y rentabilidad adecuados, contribuyendo al desarrollo sustentable de la economía real a efectos de garantizar tanto el crecimiento económico de la República Argentina como el incremento de los recursos de la seguridad social. Se realizó una excepción por los ingresos de importes en las $\mathrm{CCl}$ de afiliados bajo la figura de "imposiciones voluntarias" y/o "depósitos convenidos“, que podrán transferirlos a la ANSES o a una administradora de fondos de jubilaciones y pensiones. Lo cual ya habiendo pasado unos años, no se ha definido el destino de estos aportes, aunque existe un fallo reciente acerca de esta temática.

Asimismo, se estableció que las inversiones permitidas serán las previstas en el Artículo 74 de la Ley 24.241, rigiendo las prohibiciones del Artículo 75 de la citada ley y las limitaciones de su Artículo 76. Es decir, es el mismo menú de instrumentos de inversiones que utilizaban las AFJP, quedando prohibida la inversión de los fondos en el exterior. Otra de la diferenciación importante es que la ANSES no percibe comisión alguna por la administración de los fondos de los aportantes al sistema. 
El Estado con esta modificación, garantiza un haber mínimo a los afiliados, incluyendo a los que estaban comprendidos en el Régimen de Capitalización y hoy están a cargo de ANSES, salvo los que perciben una renta vitalicia y que no poseen Prestación Básica Universal (PBU) y Prestación Compensatoria (PC), los cuales no están alcanzados por la garantía mencionada. Asimismo, en materia de seguridad social se sucedieron numerosas políticas tendientes a mejorarla en la Argentina (Movilidad jubilatoria, Asignación Universal por Hijo y Embarazo, entrega de netbooks a estudiantes con el Programa Conectar-Igualdad, entre otras políticas) cuyo análisis dista y escapa de los objetivos principales de este trabajo.

\section{El Fondo de Garantía de Sustentabilidad (FGS) de la ANSES.}

La finalidad que tiene la creación del FGS es la de procurar contribuir, con la aplicación y asignación de sus recursos, al desarrollo sustentable de la economía argentina, a los efectos de garantizar el círculo virtuoso entre el crecimiento económico sostenible, el incremento de los recursos destinados al sistema previsional argentino y la preservación de los activos del FGS.

Otro de los fines es, la posibilidad de poder atenuar el impacto financiero que sobre el régimen previsional público pudiera ejercer la evolución negativa de variables económicas y sociales tanto nacionales como extranjeras. Como así, constituirse como fondo de reserva, a fin de instrumentar una adecuada inversión de los excedentes financieros del régimen previsional público. Asimismo se busca contribuir a la preservación del valor y/o rentabilidad de los recursos que administra el fondo de garantía. Por otro lado se busca que el fondo, sirva para atender eventuales insuficiencias en el financiamiento del régimen previsional público, a efectos de preservar la cuantía de las prestaciones previsionales.

La finalidad del FGS condice con las nuevas perspectivas y tendencias a nivel mundial de los fondos previsionales públicos. Dado que orientan a pensar la seguridad social como un concepto dinámico, a la vez que cobra importancia el análisis de la rentabilidad social de la inversión, más allá de la rentabilidad financiera. Por lo que el objetivo de estos fondos públicos es salvaguardar la capacidad de los regímenes de seguridad social para pagar prestaciones y brindar servicios, y generar 
ingresos procedentes de la inversión de estos fondos que ayuden a financiar las prestaciones y servicios.

Uno de los antecedentes institucionalizados semejantes del FGS que se pueden traer como ejemplo con sus diferencias, es el plan de seguros del Gobierno de los Estados Unidos de América para las pensiones, llamado Corporación de Garantía sobre Jubilaciones (en inglés, Pension Benefit Guarantee Corporation) creado al amparo de la Ley de Seguridad de Ingresos por Jubilación (Employee Retirement Income Security Act, ERISA) del año 1974 (Stiglitz, 2003) ${ }^{9}$.

En la Figura 3 se observa la evolución histórica de la cartera del FGS de la ANSES desde fines de diciembre de 2008 hasta diciembre de 2010, donde el fondo se incrementó un $78 \%$ con un crecimiento interanual del $41 \%$ y $26,4 \%$, respectivamente.

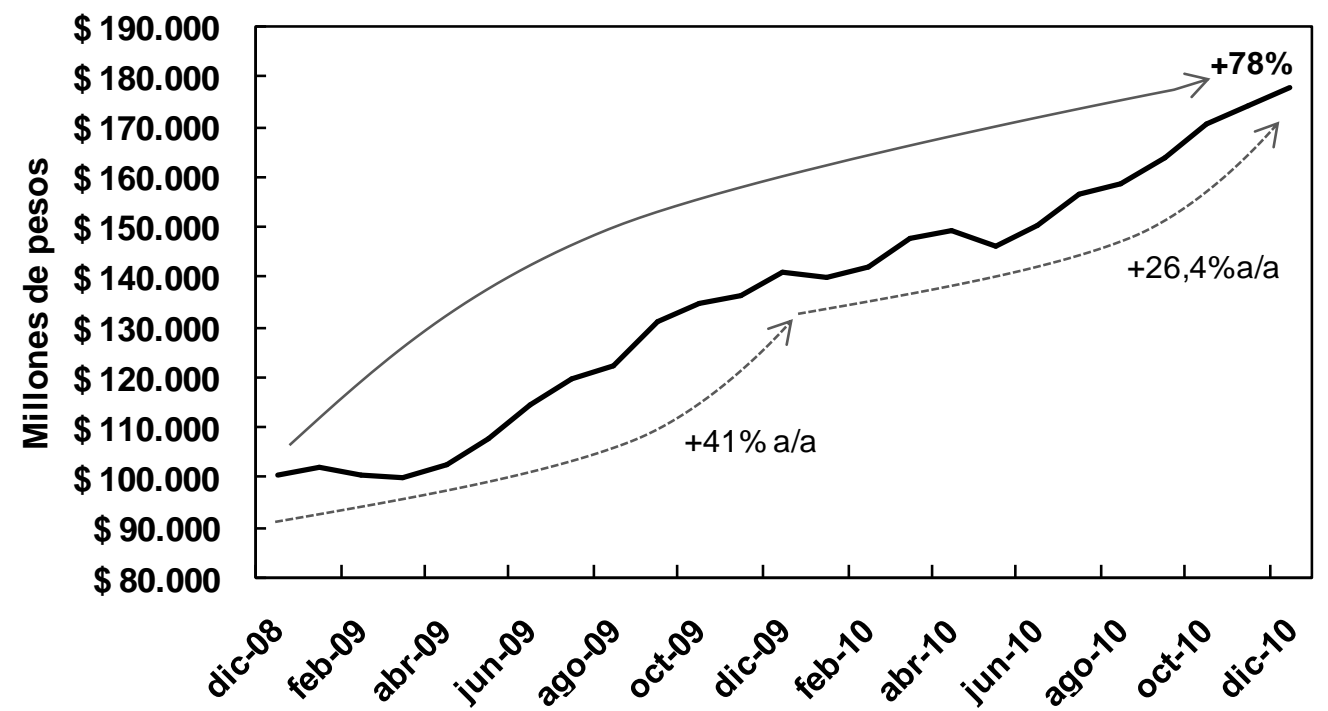

Fuente: Elaboración propia en base a ANSES

Figura 3: Evolución de la cartera del FGS de la ANSES (en millones de pesos nominales) (Diciembre 2008- Diciembre 2010). Las flechas discontinuas inferiores muestran la variación interanual del rendimiento total del fondo, y la línea continua superior el rendimiento en todo el período analizado.

La ISSA expresa que "en muchos países los fondos de la seguridad social representan gran parte del mercado de capitales. Por tanto, la inversión de estos fondos debe tener en consideración los objetivos nacionales a largo plazo, que pueden no ser enteramente reflejados si se aplica una estrategia basada

\footnotetext{
${ }^{9}$ Ver STIGLITZ (2003) "Los felices 90. La semilla de la destrucción. La década más próspera de la historia como causa de la crisis económica actual". Capítulo: 8 El riesgo como modo de vida. Donde desarrolla la gestión del riesgo en fondos de pensión y los problemas en EEUU ante la propuesta de privatización en los noventa del sistema de seguridad social. Página 227 a 247.
} 
exclusivamente en la maximización de beneficios". Y agrega que "la sostenibilidad de cualquier régimen de seguridad social depende del crecimiento económico nacional"10.

\section{Las Fuentes de recursos y composición del FGS.}

El primer aporte de la cartera total del fondo proviene, como se dijo de los activos en especie que recibió el Régimen Previsional Público, como consecuencia de la transferencia de los saldos de las cuentas de capitalización ocurrida en el año 2007. Seguidamente, por la mayor transferencia de activos que recibió el Régimen Previsional Público, como consecuencia de la transferencia de los saldos de las cuentas de capitalización en cumplimiento de la Ley № 26.425. Este stock de activos financieros eran los que gestionaban las AFJP. Se puede afirmar, que al momento de la estatización de los aportes del sistema de capitalización, el FGS se integró en un $20 \%$ del total con lo que ya poseía este fondo (Decreto $897 / 07$ ) y un $80 \%$ restante proveniente de las carteras de inversión de las administradoras privadas.

Por otra parte, el FGS puede recibir fondos del superávit presupuestario anual del ANSES, como sucedió a fines del año 2009, durante el año 2010 y lo que va del año 2011 donde se transfirieron alrededor de \$5.300 millones. Otro importante aporte al fondo, son las rentas provenientes de las inversiones que realiza el FGS en todos los instrumentos que se poseen. Por otro lado, queda abierta la posibilidad que se establezca por parte del Estado cualquier otro aporte mediante su previsión en la Ley de leyes, es decir el Presupuesto Nacional.

A continuación, se expone en la Tabla 1, la composición de cartera de inversiones al 05/12/2008, que es cuando se recibe el stock desde las AFJP, y se lo compara al $30 / 04 / 2010$. Se puede observar que la cartera se incrementó un 51,99\% en su totalidad. Asimismo, se observa como las inversiones van siendo reorientadas por la ANSES hacia proyectos productivos o de infraestructura (+441,18\%) y la desinversión en activos del exterior (-43,72\%). Vale mencionar, que la variación positiva de varios de estos rubros se debió a la recuperación de los títulos valores,

\footnotetext{
10 Ver ANSES (2010) "El manejo de los fondos de pensión alrededor del mundo: Una comparación internacional con la Argentina”. Página 4.
} 
luego de la profunda crisis del año 2008, y posterior recuperación de la economía internacional y local.

Tabla 1: Composición de la cartera resumida de inversiones del FGS al 05/12/2008 y al 30/04/2010 (en millones de pesos).

\begin{tabular}{|c|c|c|c|c|c|}
\hline \multirow{2}{*}{ RUBRO } & \multicolumn{2}{|c|}{$\begin{array}{l}\text { CARTERA FGS AL } \\
05 / 12 / 2008\end{array}$} & \multicolumn{2}{|c|}{$\begin{array}{c}\text { CARTERA FGS AL } \\
30 / 04 / 2010\end{array}$} & \multirow{2}{*}{ VARIACION } \\
\hline & MONTO & PARTICIPACION & MONTO & PARTICIPACION & \\
\hline Depósitos en bancos & 3.519 & $3,58 \%$ & 7.303 & $4,89 \%$ & $107,53 \%$ \\
\hline $\begin{array}{l}\text { Operaciones de crédito público de la } \\
\text { Nación }\end{array}$ & 58.427 & $59,48 \%$ & 91.076 & $61,01 \%$ & $55,88 \%$ \\
\hline Plazo Fijo & 10.215 & $10,40 \%$ & 11.439 & $7,66 \%$ & $11,98 \%$ \\
\hline Acciones & 7.844 & $7,99 \%$ & 15.895 & $10,65 \%$ & $102,64 \%$ \\
\hline Títulos Valores Extranjeros & 5.137 & $5,23 \%$ & 2.891 & $1,94 \%$ & $-43,72 \%$ \\
\hline Proyectos Productivos o de Infraestructura & 2.183 & $2,22 \%$ & 11.814 & $7,91 \%$ & $441,18 \%$ \\
\hline Otros & 10.899 & $11,10 \%$ & 8.869 & $5,94 \%$ & $-18,63 \%$ \\
\hline TOTAL & 98.224 & $100,00 \%$ & 149.287 & $100,00 \%$ & $51,99 \%$ \\
\hline
\end{tabular}

Fuente: Elaboración propia en base a información provista a la Comisión Bicameral - Congreso de la Nación (01/06/10) por la ANSES. http://www.anses.gob.ar/FGS2/archivos/Presentacion Bicameral Junio2010.pdf

En términos generales, desde sus inicios la gestión del FGS ha aplicado la liquidez y lo producido de las ventas de activos externos a inversiones productivas tendientes a atenuar el ciclo económico. Como se mostró en la Tabla 1 se han destinado muchos recursos a la inversión en proyectos productivos o de infraestructura (inciso Q) cumpliendo los fines del fondo, como los fideicomisos financieros SISVIAL para obras de infraestructura vial en todo el país, programas de construcción de viviendas provinciales, la central nuclear Atucha II, las Centrales de Enarsa (centrales termoeléctricas Brigadier López, Ensenada de Barragán y Barcazas), préstamo a la General Motors para desarrollo del Proyecto Viva, incentivo a la industria automotriz, la inversión en cédulas hipotecarias del Banco Hipotecario, fideicomiso de infraestructura hídrica, entre otras inversiones. En la mayoría de los instrumentos adquiridos poseen oferta pública su estructuración financiera, o tienen informes de viabilidad económica, financiera y social de universidades nacionales donde tendrá impacto el desarrollo de las inversiones. La inversión realizada en infraestructura representa una de las alternativas más beneficiosas para el desarrollo social dentro del espectro de proyectos vinculados a la economía real, por su estrecho vínculo con el crecimiento de la economía, por su rol activo de generador de empleo y la incidencia en el multiplicador económico. 
Por otro lado el FGS ha participado en operaciones de crédito público con el objeto de ayudar al Tesoro Nacional a despejar el horizonte de vencimientos y con ello reducir la percepción de riesgo soberano de los inversores.

Tabla 2: Estructura de la cartera de inversiones del FGS al 31/12/2010 (millones de pesos).

\begin{tabular}{|l|r|r|}
\hline \multicolumn{1}{|c|}{ Instrumento } & \multicolumn{1}{c|}{ Pesos } & \multicolumn{1}{c|}{ Participación } \\
\hline Saldos disponibles & $8,048,171,067$ & $4.52 \%$ \\
\hline Saldos a aplicar en próximos desembolsos de operaciones & $5,623,373,000$ & $3.16 \%$ \\
\hline Otros créditos & $17,736,497$ & $0.01 \%$ \\
\hline Inversiones & $164,326,448,386$ & $92.31 \%$ \\
\hline Operaciones de crédito público de la Nación & $96,729,278,453$ & $54.34 \%$ \\
\hline Títulos emitidos por entes estatales & $751,631,741$ & $0.42 \%$ \\
\hline Obligaciones negociables de largo plazo & $1,735,619,102$ & $0.97 \%$ \\
\hline Obligaciones negociables de corto plazo & $10,180,000$ & $0.01 \%$ \\
\hline Plazo fijo & $14,726,333,344$ & $8.27 \%$ \\
\hline Acciones de sociedades anónimas & $22,864,030,450$ & $12.84 \%$ \\
\hline Acciones de empresas privatizadas & $471,255,458$ & $0.26 \%$ \\
\hline Fondos comunes de inversión & $3,001,158,151$ & $1.69 \%$ \\
\hline Títulos valores extranjeros & $276,746,448$ & $0.16 \%$ \\
\hline Contratos negociables de futuros y opciones & $189,679,402$ & $0.11 \%$ \\
\hline Cédulas y letras hipotecarias & $26,960,776$ & $0.02 \%$ \\
\hline Fondos de inversión directa & $62,105,537$ & $0.03 \%$ \\
\hline Fideicomisos financieros estructurados & $3,777,022,766$ & $2.12 \%$ \\
\hline Otros fideicomisos financieros & $220,713,339$ & $0.12 \%$ \\
\hline Proyectos productivos o de infraestructura & $19,483,446,883$ & $10.94 \%$ \\
\hline Inversiones en trámite irregular & 286,535 & $0.00 \%$ \\
\hline \multicolumn{1}{|c|}{ TOTAL } & $\mathbf{1 7 8 , 0 1 5 , 7 2 8 , 9 4 9}$ & $\mathbf{1 0 0 . 0 0 \%}$ \\
\hline
\end{tabular}

Fuente: Informe periódico Macroeconómicos y Financieros del mes de enero de 2011 (datos a diciembre de 2010) del

Como se puede observar en la Tabla 2, los proyectos productivos a fines del año 2010, son el tercer instrumento con mayor participación de la cartera con casi un $11 \%$ respondiendo al objetivo de incrementar el financiamiento de inversiones con alto impacto en la economía real.

En materia de asignación de los fondos destinados a depósitos a plazo fijo, reorientó las colocaciones preferentemente hacia bancos públicos que sean lo más federal posible y que realicen préstamos al sector productivo. Los bancos que son agentes financieros de las provincias recibieron una mayor cantidad de capital, y se redujo el capital colocado en entidades financieras no bancarias. Es decir, hubo un cambio en la gestión del FGS con respecto a lo que hacían las AFJP, en lo referido a la 
administración de la liquidez. En resumen para esta clase de activo, se mantuvo la diversificación entre bancos del sistema financiero, preferentemente aquellos que prestan al sector privado tanto para el consumo como para las PyMES y para inversiones productivas, en detrimento de aquellas que utilizan el fondeo para la intermediación de títulos valores, de acuerdo con lo estipulado por el Acta №1/2009 del Comité del FGS. Otra forma de gestión de la liquidez fue la realización de subastas de fondos para depósitos a plazo fijo dirigidos, a fin de incrementar la capacidad de financiamiento para las PyMES, el consumo, autopartes y prefinanciación de exportaciones, entre otros fines. Las mismas eran realizadas a través del Mercado Abierto Electrónico (MAE) en una rueda de negociación especial, dando la máxima transparencia a la distribución de los fondos entre las entidades financieras que participaron.

El tema de las acciones se desarrollará en otros puntos del presente trabajo, pero sirve enunciar la suba que tuvo este rubro debido a la revalorización de estos activos. Desde el 05/12/08, fecha del traspaso de los fondos hasta fines de 2010 el índice general de la Bolsa de Comercio de Buenos Aires subió más del 200\%.

En referencia a los fondos comunes de inversión $(\mathrm{FCl})$, se pone foco en los rescates realizados por el FGS de los fondos invertidos en el exterior por temas normativos, y en los fondos denominados de money market o de dinero por la baja rentabilidad de los mismos y la comisión que les cobraban por su administración. El FGS al tener un alto flujo de fondos líquidos puede gestionar eficientemente su liquidez, pudiendo conseguir rendimientos más competitivos sin pagar comisiones en otros activos. Otro punto a considerar es la inversión realizada en $\mathrm{FCl}$ denominados PyMES bajo reglamentación de la CNV y otros fondos dedicados a invertir en infraestructura y desarrollo de la economía argentina.

\section{Los criterios de inversión del fondo de garantía y su composición.}

Los criterios generales de inversión se basan en el artículo 15 de la Ley 26.222, donde se establece que el activo del FGS se invertirá de acuerdo con criterios de transparencia, seguridad y rentabilidad adecuados, contribuyendo al desarrollo sustentable de la economía real, a efectos de garantizar el círculo virtuoso entre 
crecimiento económico y el incremento de los recursos de la seguridad social. La seguridad y la transparencia en las inversiones que realiza el FGS constituyen un pilar central de su estrategia financiera, económica y social, dada la finalidad del Fondo. Por eso, todas las operaciones están sujetas a estrictas normas financieras y el accionar del FGS es monitoreado y auditado por una amplia gama de órganos de control. La rentabilidad es otro importante criterio de inversión por el cual el FGS guía su accionar, a fin de preservar e incrementar el valor de sus activos. Rentabilidad entendida no sólo desde un punto de vista financiero, sino también social, la cuál es muy difícil de cuantificar en términos objetivos.

Habida cuenta del círculo virtuoso presente entre las inversiones del FGS y el nivel de actividad y de empleo de la economía en su conjunto, es interesante entender, que las inversiones no solamente se analizarán en forma tradicional fundamentada en la viabilidad económica y financiera, sino que se evaluará la parte social. La evaluación social puede entenderse como la evaluación privada tradicional (rendimiento/riesgo) más los efectos que el proyecto podría generar sobre el conjunto de la economía y la sociedad, considerando los riesgos, impactos sociales y externalidades que lo atañen. Una importante diferencia con la administración privada de los recursos previsionales, es que queda prohibida la inversión de los fondos en el exterior.

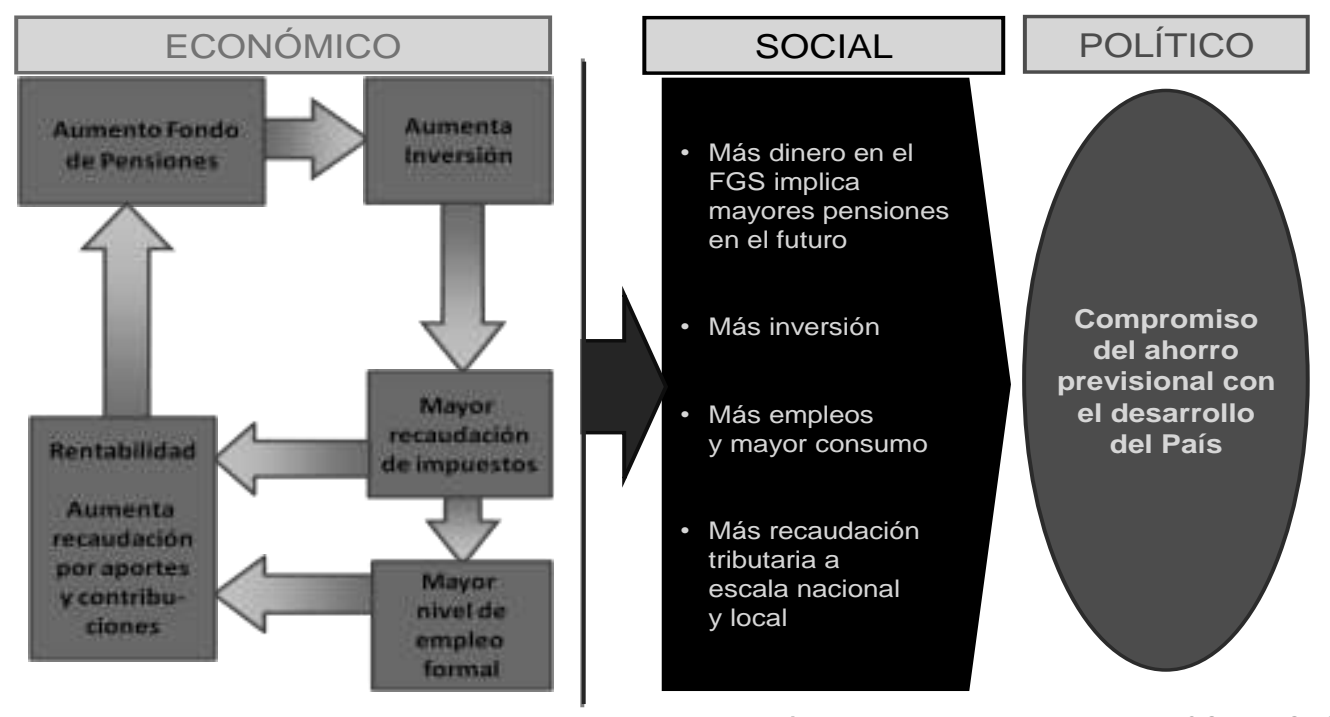

Figura 4: Ejemplificación del círculo virtuoso de las inversiones del FGS de la ANSES con efecto en lo Económico, Social y Político. 
El uso de los fondos que se administran, se pueden utilizar en el caso que durante la ejecución de un presupuesto se presentaren situaciones de contingencia o coyunturales que requieran su utilización para el pago de las prestaciones previsionales del Régimen Público de Reparto. Una condición muy importante, es que la totalidad de los recursos únicamente podrán ser utilizados para pagos de los beneficios del SIPA.

\section{Administración operativa del fondo.}

La administración operativa del FGS está a cargo de la ANSES, quien goza de autonomía financiera y económica. Dicho organismo nacional, posee una Subdirección de Operación del FGS que se encarga de implementar las directrices establecidas por el Comité Ejecutivo del FGS. La subdirección mencionada es contemplada por la ANSES, en su presupuesto operativo los gastos que demande la administración del FGS, siendo este último la fuente de financiamiento. Una cosa distintiva con respecto a la administración de los fondos por parte de privados, es que la ANSES como ya se mencionó, no percibe comisión alguna por la administración del FGS. La administración del FGS está alcanzada por la Ley 24.156 y sus modificatorias.

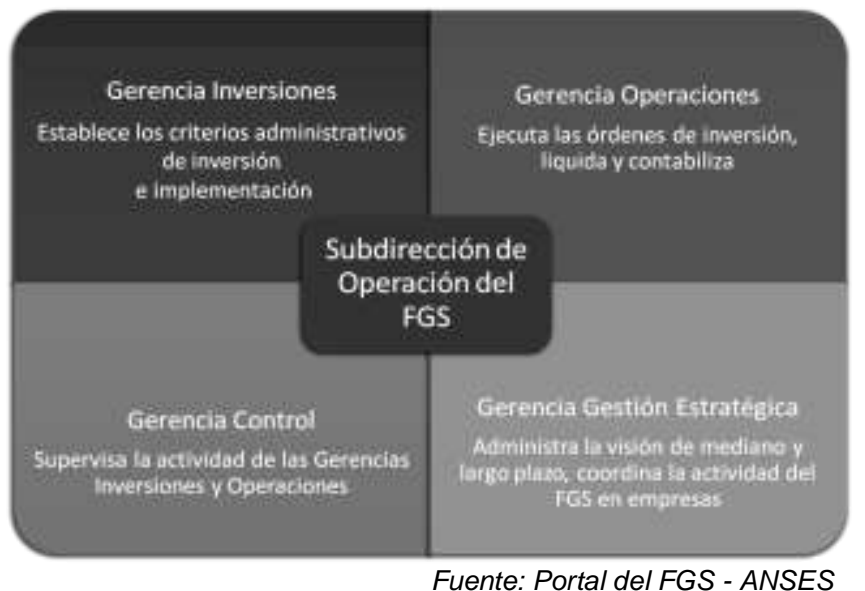

Figura 5: Organigrama principal y gerencias operativas del FGS de la ANSES a Diciembre de 2010.

Las decisiones y plan de inversiones en términos estratégico son elaborados por el Comité Ejecutivo del FGS. Dicho comité está integrado por el Director Ejecutivo de la ANSES el cual se constituye como Director de dicho Comité, el Secretario de 
Hacienda, el Secretario de Finanzas y el Secretario de Política Económica pertenecientes al Ministerio de Economía y Finanzas Públicas de la Nación.

Se reúne mensualmente de acuerdo con su reglamento, y traza las líneas directrices dentro de las cuales se tienen que enmarcar las inversiones del FGS. Asimismo fija los principios de seguridad y rentabilidad, contemplando los impactos de las decisiones de inversión en la macroeconomía, especialmente en la creación de empleo así como en la generación de recursos tributarios adicionales que percibiría la ANSES. Siempre sus políticas de inversiones se realizan monitoreando la diversificación de riesgos y adecuación temporal de las inversiones que aseguren el cumplimiento de los objetivos del FGS. Por todas las funciones encargadas al Comité Ejecutivo, la ANSES no podrá apartarse de los lineamientos y directivas fijadas. Dicho comité se encarga de la aprobación o rechazo de las solicitudes de operaciones activas que haya recibido el Subdirector del FGS o el Director Ejecutivo de la ANSES y que éstos hayan remitido al Comité Ejecutivo para su análisis.

Por otro lado existe un Comité de Inversiones, presidido por el Subdirector de Operación del FGS, Gerente de Inversiones, Gerente de Operaciones y Gerente de Gestión Estratégica (actualmente dicha Gerencia fue fusionada con la de Inversiones). Allí se evalúan la adminisibilidad y procedencia de propuestas de financiamiento de proyectos productivos y de infraestructura, como así las posibles suscripciones de oferta primaria de títulos valores emitidos por el Estado en sus diversos estamentos y el mercado en general. Además se establecen y discuten políticas de valuación de los distintos activos financieros, detección de oportunidades de inversión por parte del fondo y la negociación de títulos valores que se posean en el mercado secundario.

EI FGS de la ANSES posee diversos controles cruzados de parte de distintos órganos internos y por parte del Estado con auditorias y supervisión, como serían los controles que realiza la Gerencia de Control del FGS de la ANSES y la Auditoria del FGS de la ANSES. El Consejo del FGS monitorea los recursos del sistema previsional que está integrado por un miembro de ANSES; un miembro de la Jefatura de Gabinete de Ministros; dos representantes de órganos consultivos de jubilados y pensionados del ANSES; tres representantes de los trabajadores de las 
organizaciones más representativas; dos representantes de las organizaciones empresariales más representativas; dos representantes de las entidades bancarias más representativas; un diputado y un senador, todos con cargos ad honorem y designados por el PEN a propuesta de las entidades respectivas. Por otro lado está la Comisión Bicameral del Poder Legislativo de la Nación (integrada por seis senadores y seis diputados); la Auditoria General de la Nación (AGN); la Sindicatura General de la Nación (SIGEN) y la Defensoría del Pueblo de la Nación. Ante ellos la ANSES debe responder a cada una de los interrogantes que aparecen y explicar el desarrollo de la gestión con los destinos y proyecciones de los recursos, dándole transparencia a la administración.

\section{El sistema Financiero Argentino}

\section{Definición y generalidades del sistema financiero}

El sistema financiero, se puede definir como un conjunto de elementos estructurales cuyo fin primordial es canalizar los excedentes financieros de algunos agentes económicos (inversores) para cubrir las necesidades financieras de otros agentes (emisoras) a través de los intermediarios del sistema. Los elementos estructurales que lo integran pueden ser el modelo económico, el marco jurídico y el conjunto histórico-cultural de un país.

Entre las distintas funciones que deben cumplir los mercados financieros se encuentran las de generar un proceso adecuado de determinación de precios de los activos (libre concurrencia de oferentes y demandantes de productos); proporcionar liquidez a los distintos activos; y reducir el costo y los plazos de transacción de los diversos instrumentos.

La primera diferenciación que se puede realizar en cualquier sistema financiero, y centrándonos en el de Argentina, es entre el mercado bancario o de dinero y el mercado de capitales. 


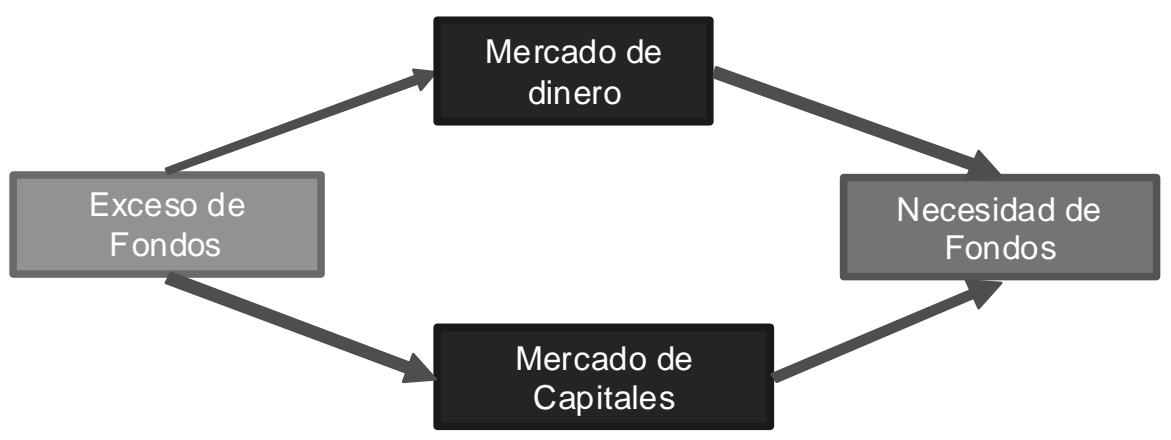

Figura 6: Esquema simplificado del sistema financiero argentino.

En el mercado bancario o de dinero, se ofrece y se demanda activos financieros que por su propia naturaleza no sólo están destinados a la financiación de proyectos, sino también a cubrir necesidades de tipo coyuntural o temporario. Las instituciones clásicas de este mercado son las entidades financieras y los bancos, en Argentina se rigen bajo la Ley $\mathrm{N}^{\circ}$ 21.526. Su principal y tradicional negocio es el de tomar depósitos por la cual paga una tasa pasiva; y presta dinero a otros agentes económicos cobrando una tasa activa. Es decir, el denominado spread bancario, compuesto por la tasa activa menos la tasa pasiva.

En cambio, el mercado de capitales, ofrece y demanda activos financieros de mediano y largo plazo, por ejemplo los más tradicionales como los títulos de deuda públicos (bonos) y privados (obligaciones negociables) y los títulos de capital (acciones), entre otros instrumentos existentes. Las instituciones clásicas de este mercado son las Bolsas y los mercados de valores, de cada país, región o ciudad importante.

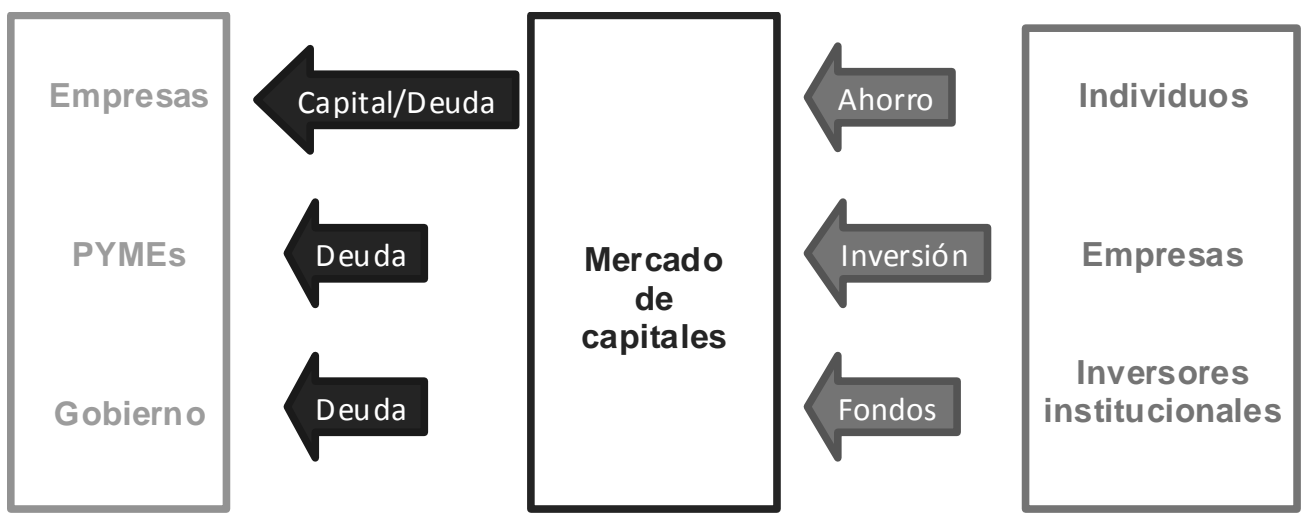

Figura 7: Esquema simplificado del funcionamiento del mercado de capitales. 
Como se precisó, el presente trabajo se centró en el mercado de capitales argentino, y dentro del mismo en el mercado de acciones. Y dentro de este segmento se estudió puntualmente la participación que heredó el FGS de la ANSES de la tenencia que poseían bajo su administración las AFJP.

\section{El Mercado de Capitales Argentino}

El mercado de capitales en el mundo, se lo puede definir como lo hizo Gabbi (2005) como "(...) un excelente movilizador de recursos, porque concilia los intereses de los inversores, de obtener mayor rentabilidad con diversificación del riesgo, con la de los empresarios, de obtener el financiamiento necesario para el desarrollo de sus negocios, a los mejores costos que el mercado les puede ofrecer". ${ }^{11}$

Dentro de las funciones de un mercado de capitales, se encuentran las de ser fuente de financiamiento de las empresas y del estado en sus distintos grados y ser un orientador del ahorro hacia las actividades productivas. Un mercado de capitales sólido es fundamental para el desarrollo económico del país.

\section{La arquitectura del Mercado de Capitales Argentino}

El mercado de capitales de Argentina, está normado por la Ley 17.811 de Oferta Pública como se aprecia debajo en la Tabla 3 y el Decreto 677/01 y regulado por la CNV.

Está compuesto por intermediarios que poseen distintas bolsas y mercados, los cuales utilizan distintos sistemas de negociación. Asimismo, cada uno de ellos posee sistemas de compensación y liquidación, como así agentes de depósito, custodia de los títulos valores y quienes llevan el registro de las operaciones. No se quiere avanzar en desarrollar la función de los agentes, ni de las bolsas y mercados, por no ser objeto principal de este trabajo. Por lo que se adjunta la siguiente síntesis del mercado realizada por Muñoz (2006).

\footnotetext{
11 Ver GABBI (2005). "Un mercado bursátil funcional al desarrollo de las empresas medianas nacionales". 11 a Conferencia Industrial Argentina. Página 105.
} 
Tabla 3: Arquitectura simplificada del mercado de capitales argentino.

\begin{tabular}{|c|c|c|c|}
\hline Regulación & \multicolumn{3}{|c|}{ CNV - Oferta Pública, Ley 17.811 (1968), Dec. 677/01 } \\
\hline Intermediación & $\begin{array}{c}\text { BCBA (MERVAL) / } \\
\text { Bolsas y Mercados } \\
\text { del Interior }\end{array}$ & $\begin{array}{l}\text { Mercado Abierto } \\
\text { Electrónico } \\
\text { (MAE) }\end{array}$ & $\begin{array}{l}\text { De futuros y } \\
\text { opciones } \\
\text { MATBA / } \\
\text { ROFEX }\end{array}$ \\
\hline $\begin{array}{l}\text { Sistemas de } \\
\text { Negociación }\end{array}$ & $\begin{array}{c}\mathrm{PISO} / \mathrm{SINAC} / \text { rueda } \\
\text { continua }\end{array}$ & $\begin{array}{l}\text { Punto a Punto } \\
\text { SIOPEL }\end{array}$ & $\begin{array}{l}\text { MATBA: Piso } \\
\text { ROFEX: } \\
\text { electrónico }\end{array}$ \\
\hline $\begin{array}{l}\text { Compensación } \\
\text { y Liquidación }\end{array}$ & $\begin{array}{c}\text { Merval / Caja de } \\
\text { Valores }\end{array}$ & $\begin{array}{c}\text { Argenclear / } \\
\text { Euroclear / } \\
\text { Clearstream / } \\
\text { CRYL / DTC / } \\
\text { SCL / Caja de } \\
\text { Valores }\end{array}$ & $\begin{array}{c}\text { MATBA: Propia } \\
\text { ROFEX: } \\
\text { Argentina } \\
\text { Clearing House }\end{array}$ \\
\hline $\begin{array}{c}\text { Depósito, } \\
\text { Custodia y } \\
\text { Registro de las } \\
\text { Operaciones }\end{array}$ & Caja de Valores & $\begin{array}{c}\text { Euroclear / } \\
\text { Clearstream / } \\
\text { DTC / SCL / } \\
\text { Caja de Valores }\end{array}$ & \\
\hline
\end{tabular}

Una clasificación tradicional del mercado de capitales, establece un mercado primario y un mercado secundario. En el mercado primario, se negocian las nuevas emisiones de capital canalizando directamente los ahorros a la inversión productiva. Y en el mercado secundario, se negocian activos financieros ya colocados, con la importante función de dar liquidez al mercado.

Participantes y Reguladores del mercado de capitales argentino.

Dentro del mercado de capitales, se encuentra como participantes a las emisoras de los distintos títulos de valores que pueden ser el Estado, las empresas, que crean fondos de inversión abiertos o cerrados, fideicomisos, valores de corto plazo (VCP), acciones, bonos, obligaciones negociables, según el caso, entre diversos instrumentos existentes. Otros participantes son los inversores, ya sean los Institucionales y minoristas, que son los que ofertan los recursos o demandan los activos. $Y$ los intermediarios financieros, que son aquellos que facilitan el acceso al mercado y son como agentes de colocación de los ahorros, dando propiedad indirecta a los ahorristas sobre sus activos de inversiones.

Los reguladores del Mercado de Capitales Argentino son la CNV, el Banco Central de la República Argentina (BCRA) y la Superintendencia de Seguros de la Nación 
(SSN). Antes de la estatización de los fondos privados de pensiones también existía como ya se vio la SAFJP.

La misión de la CNV, es la de promover el desarrollo de un mercado de capitales amplio, transparente y competitivo, mediante un marco regulatorio que facilite la canalización del ahorro privado, minorista e institucional, para cubrir las necesidades de financiamiento de la economía real. Dentro de sus funciones se encuentra la de regular, fiscalizar y controlar el mercado de capitales. Por otro lado, dictar la normativa e instrumentos ajustados a la dinámica macro y macroeconómica; promover la educación financiera del público inversor y protección del inversor minorista. Se rige bajo la Ley de Oferta Pública, Ley № 17.811 dictada en el año 1968, y el Decreto №677/2001.

Asimismo, el BCRA como máxima autoridad monetaria del país, tiene como misión primaria y fundamental de preservar el valor de la moneda, como lo indica su cartel en la entrada de su sede. Entre sus funciones se encuentra la de regular la cantidad de dinero y el crédito en la economía y el dictado de normas en materia monetaria, financiera y cambiaria. Debe vigilar el buen funcionamiento del mercado financiero y aplicar la Ley de Entidades Financieras y demás normativas. Como así, actuar como agente financiero del Gobierno Nacional, concentrar y administrar sus reservas de oro, divisas y otros activos externos, y propender al desarrollo y fortalecimiento del mercado de capitales y ejecutar la política cambiaria.

Por último, la SSN es un organismo público descentralizado dependiente del Ministerio de Economía y Finanzas Públicas. Tiene como misión principal la de controlar las actividades de evaluación e inspección de los operadores del mercado de seguros para garantizar el cumplimiento de las legislaciones y regulaciones vigentes (Ley de Entidades de Seguros № 20.091).

\section{$\underline{\text { Los Inversores institucionales }}$}

A nivel mundial, y poniendo el foco particularmente en América Latina, existen inversores institucionales del sector público. Estos organismos son pertenecientes a los sistemas de seguridad social, cajas de previsión, entre otros. Son un mecanismo 
muy importante de captación de ahorro y de inversión, captando los recursos de cuotas patronales, y aportes de los distintos gobiernos. Destinan sus recursos a la prestación de servicios médicos, pensiones, jubilaciones, seguros, y demás servicios sociales. Asimismo, son un medio importante para canalizar al mercado recursos a largo plazo, con la compra de valores públicos y privados, y otorgamiento de créditos a largo plazo. Se rigen por las legislaciones de previsión social de cada uno de los países. (V. g.: Instituto Mexicano de Seguridad Social; Caja de Jubilaciones y Pensiones de Paraguay; ANSES; Instituto de Previsión Social de la Provincia de Bs. As. (IPS); y actualmente el FGS de la ANSES; etc.).

Dentro del sector privado, se encuentran las compañías aseguradoras privadas, las administradoras privadas de fondos de pensión (Ejemplos en Argentina las ex AFJP; en Chile las Administradoras de Fondos de Pensión -AFP-; en México las Administradoras de Fondos para el Retiro -AFORE-, etc.), las distintas cajas previsionales profesionales y los denominados Endowment funds o fondos de fundaciones con propósitos específicos (de caridad, educativos, ecológicos, etc.). Canalizan una parte importante de sus recursos hacia el mercado de capitales, con la compra de valores de renta fija, público y privado, y créditos a largo plazo.

En particular, las Empresas de Seguros, quienes no sólo realizan sus labores propias, sino que hacen otras actividades que repercuten en el funcionamiento y evolución del mercado de capitales, como inversiones inmobiliarias, inversiones de renta fija o variable, concesión de préstamos, etc. Poseen una supervisión estatal en los distintos países como se señaló para la Argentina; realizan un análisis de la información financiera y contable, y la observación de normas legales y administrativas. A las compañías de seguros, se las puede dividir por categorías según producto: Seguros de vida, Seguros de salud y Seguros de propiedad (property and liability); o por categorías según su propósito de inversión: compañías de seguros de vida (cobran primas que son invertidas para hacer frente a los pagos de las pólizas de seguro) y compañías de seguros generales (cobran primas que son invertidas para hacer frente a los pagos de los siniestros).

Por el lado de los fondos de pensión privados, su aparición está estrechamente vinculada al acelerado desarrollo de los sistemas y redes de seguridad social que se 
verificó a partir de la década de 1970, junto al también vertiginoso desarrollo de los mercados de capitales y avances tecnológicos, que ampliaron significativamente las opciones de inversión. Se los puede dividir en forma conceptual en dos tipos, aquellos con un beneficio definido y los de contribución definida.

Los planes de pensión de beneficio definido, prometen abonar a los empleados una suma específica de dinero en forma mensual, a partir del momento del retiro. E riesgo de inversión es asumido por la compañía aportante, ya que el beneficio otorgado se calcula por una fórmula actuarial que es independiente de cómo se encuentran invertidos los activos del plan (los objetivos son de cumplir con la tasa de retorno actuarial del plan, fijada en base a supuestos de salarios corrientes y expectativas de salario, patrones de retiro, esperanza de vida, porcentaje del salario promedio de últimos años, etc.). Por la otra parte, están los planes de pensión de contribución definida, que no prometen abonar a los empleados una suma específica de dinero en forma mensual, a partir del momento del retiro. El riesgo de inversión es asumido por el empleado ya que la compañía sólo tiene la obligación de realizar las contribuciones mensuales durante el proceso de aporte y no está obligada a hacerlo al momento del retiro, y va a tener injerencia en las decisiones de inversión.

Las principales diferencias de los inversores institucionales con los individuales, es que poseen mayores restricciones de tipo regulatorio y mayores exenciones impositivas. Por otro lado poseen un horizonte mayor de inversión y el riesgo como una definición más cualitativa.

\section{$\underline{\text { Participación del FGS en empresas a través de acciones. }}$}

Las acciones heredadas por parte del FGS de la ANSES - Ley $\mathrm{N}^{\circ}$ 26.425, significaron en muchas de estas empresas incorporar un socio estratégico o no esperado, dependiendo del sector de la economía donde se desarrolla o de la participación relativa del ente estatal sobre el capital social. La ANSES ha podido designar Directores titulares y asesores del Directorio en una veintena de empresas de distintos rubros de la economía pudiendo hacer respetar su pleno derecho como accionista. Las empresas que han aceptado la designación de Directores son aquellas que vienen de procesos de privatizaciones, o la ANSES posee una alta 
participación relativa y/o tienen un vínculo estratégico con el Estado en la actividad que desarrollan (subsidios, servicios públicos, proyectos comunes, regulación tarifaria, etc.). Esto se vio modificado por el Decreto del Poder Ejecutivo Nacional $\mathrm{N}^{\circ}$ 441/2011, donde el Estado Nacional busca ejercer todos sus derechos políticos que le correspondan.

Como se vio, el Estado Nacional, o mejor dicho los fondos de aportantes al sistema público de reparto de presentes y futuros jubilados, poseen participación en empresas que cotizan en la BCBA. Dicha participación dada por la tenencia de acciones de las empresas, que el FGS heredó de las AFJP y las que poseía la ANSES, es en relación al capital social de la misma. Por lo que los fondos previsionales poseen inversiones en sectores de la economía Argentina como el de electricidad, petróleo, gas y petroquímica, agronegocios, siderurgia, real estate, telecomunicaciones y medios, servicios financieros, transporte e infraestructura y consumo masivo. En muchas de ellas, la participación relativa con respecto al capital es muy alta, superando el $20 \%$. La posición relativa que ha tomado el organismo previsional, se describe seguidamente en la Tabla 4.

Tabla 4: Empresas privadas locales con participación del FGS-ANSES a Diciembre de 2010.

\begin{tabular}{|l|c|}
\hline \multicolumn{1}{|c|}{ Empresa } & $\begin{array}{c}\% \text { del Capital } \\
\text { Social }\end{array}$ \\
\hline Banco Macro & $30,90 \%$ \\
\hline S.A. San Miguel & $26,96 \%$ \\
\hline Gas Natural BAN & $26,63 \%$ \\
\hline Consultatio S.A & $26,62 \%$ \\
\hline Edenor S.A. & $26,41 \%$ \\
\hline Distribuidora de Gas Cuyana & $26,12 \%$ \\
\hline Siderar S.A. & $25,97 \%$ \\
\hline Telecom Argentina S.A. & $24,98 \%$ \\
\hline Transportadora de Gas del Sur S.A. & $23,10 \%$ \\
\hline Pampa Energía S.A. & $22,48 \%$ \\
\hline Grupo Concesionario del Oeste & $21,56 \%$ \\
\hline Mirgor S.A. & $21,54 \%$ \\
\hline Emdersa S.A. & $20,96 \%$ \\
\hline Grupo Financiero Galicia S.A. & $20,44 \%$ \\
\hline Imp. y Exp. de La Patagonia S.A. & $20,24 \%$ \\
\hline Molinos Río de La Plata S.A. & $19,99 \%$ \\
\hline Transener S.A. & $18,78 \%$ \\
\hline Socotherm Americas S.A. & $18,59 \%$ \\
\hline Solvay Indupa S.A. & $16,71 \%$ \\
\hline Banco Patagonia S.A. & $15,25 \%$ \\
\hline Endesa Costanera S.A. & $13,40 \%$ \\
\hline
\end{tabular}

\begin{tabular}{|l|c|}
\hline \multicolumn{1}{|c|}{ Empresa } & $\begin{array}{c}\% \text { del Capital } \\
\text { Social }\end{array}$ \\
\hline Camuzzi Gas Pampeana S.A. & $12,65 \%$ \\
\hline Petrobrás Energía S.A. & $11,84 \%$ \\
\hline Juan Minetti S.A. & $11,31 \%$ \\
\hline Capex S.A. & $10,73 \%$ \\
\hline Aluar Aluminio Argentino S.A.I.C. & $9,30 \%$ \\
\hline Grupo Clarin S.A. & $9,00 \%$ \\
\hline Quickfood S.A. & $8,97 \%$ \\
\hline Metrovías S.A. & $8,55 \%$ \\
\hline Metrogás S.A. & $8,13 \%$ \\
\hline BBVA Banco Francés S.A. & $7,50 \%$ \\
\hline Euromayor S.A. & $6,25 \%$ \\
\hline Banco Hipotecario Nac. S.A. & $4,87 \%$ \\
\hline IRSA Inversiones y Representaciones & $4,47 \%$ \\
\hline Central Puerto S.A. & $3,95 \%$ \\
\hline Cresud S.A. & $3,50 \%$ \\
\hline Alto Palermo S.A. & $1,38 \%$ \\
\hline Transportadora de Gas del Norte S.A. & $0,73 \%$ \\
\hline Ledesma S.A. & $0,38 \%$ \\
\hline Tenaris S.A. & $0,22 \%$ \\
\hline Y.P.F. S.A. & $0,01 \%$ \\
\hline Alpargatas S.A.I.C. & $0,01 \%$ \\
\hline
\end{tabular}

Fuente: Elaboración propia en base a ANSES. 
El rendimiento esperado de un portafolio de activos financieros como en este caso, y analizando el caso particular de las acciones, se lo puede representar como el promedio ponderado de los rendimientos de los activos que lo integran. Es decir los pesos relativos o ponderaciones que se encuentran representados por las proporciones invertidas en cada una de estas empresas.

El retorno efectivo para este tipo de instrumentos, se calcula sumando los ingresos por dividendos que pagan los activos (si es que tienen una política de dividendos activa) y la ganancia (pérdida) de capital dada por la variación positiva (negativa) de los precios. Las inversiones en acciones que posee el FGS no hay ninguna duda la ganancia de capital que se obtuvo dada la generalizada variación positiva de los precios. Por otro lado, se obtuvo un rendimiento por los dividendos cobrados (dividend yield), en aquellas empresas que repartieron las utilidades líquidas y realizadas en forma de dividendos en efectivo aprobadas por asamblea $y / 0$ su organismo regulador. A continuación en la Tabla 5 , se exponen los dividendos en efectivo cobrados por el FGS por la participación en las empresas privadas.

Tabla 5: Dividendos en efectivo distribuidos por Empresas privadas al FGS-ANSES.

\begin{tabular}{|c|c|c|}
\hline En-Gara & 2009 & 2010 \\
\hline Telecom Angenina SA & - & 5263.088 .645 \\
\hline Sidear SA & - & 599.248 .425 \\
\hline Mofoos Rio de la Plita SA. & 547.979 .930 & 581.780 .543 \\
\hline Banco Maca SA & $\$ 45.913 .152$ & 564.278 .431 \\
\hline Tenain's SA & 562.014 .787 & 539.785 .464 \\
\hline BEVA Banco Francés SA & 5 31.8B0 206 & 536.013 .820 \\
\hline Banco Patagonia SA & 519.548 .984 & 532.893 .1687 \\
\hline Petrobras Arg. SA & 531.894 .466 & 532.568 .743 \\
\hline Telefónica SA & 583.079 .475 & 57.786 .887 \\
\hline Otrus & 595.972 .073 & 565.890 .595 \\
\hline Iotal & $\$ 419223.073$ & $\$ 723.334 .641$ \\
\hline
\end{tabular}

Fuente: ANSES. http://www.anses.gob.ar/FGS/archivos/Presentacion_Bicameral_Abril2011.pdf

En distintos momentos de estos años, el FGS de la ANSES ha asegurado que no venderá las acciones que tienen en cartera, salvo las de empresas extranjeras. A pesar de los embates de la oposición política al Gobierno Nacional, a través del Congreso de la Nación para que esos recursos se utilicen para la tan mentada propuesta pero de poca factibilidad sustentable del aumento al $82 \%$ móvil para jubilados y pensionados. 
Distintas versiones periodísticas ${ }^{12}$ indicaron que operadores financieros se acercan a la ANSES a proponerle distintas estrategias para que el sistema previsional público se desprenda de la participación que tiene en ciertas empresas o que vienen de procesos de privatización. Muchas de estas empresas, al no tener suerte con la compra del paquete accionario, tienen intenciones de sacar del Directorio al representante del Estado, lo cual han optado empezar a plantearse incrementar su capital social, previendo que la ANSES no hará opción de incorporar capital en la emisión primaria y así licuar la participación relativa del fondo de pensión público. En otros casos, empresas han querido comprarle su participación accionaria en bloque a la ANSES, para no afectar el precio de las mismas, tampoco teniendo éxito en su estrategia.

De todas formas, si el FGS quisiera liquidar toda su posición de acciones de las empresas, a un promedio histórico operado de acciones diarias o un monto promedio negociado determinado, se tardaría muchísimas ruedas del mercado, dependiendo de la liquidez y volumen de la acción de que se trate. Esto se debe, a que el mercado secundario local de acciones es muy pequeño, y al intentar vender una parte de estas posiciones implicaría asumir pérdidas muy fuertes, ya que se influiría en el precio y forzaría a la baja en su cotización.

Por otro lado, con anterioridad al decreto 411/11, en otras empresas la ANSES ha querido hacer valer sus derechos societarios, y en las respectivas asambleas de accionistas solicitaba el derecho político a voto por la tenencia accionaria que posee y en oportunidades ha tenido reticencia en su solicitud. Es decir, otros accionistas, generalmente el grupo controlante de las empresas mencionan la limitación al derecho de voto que surge del artículo 76 inciso f) de la Ley $N^{\circ} 24.241$, cuya vigencia ha ratificado el artículo $8^{\circ}$ párrafo tercero de la Ley 26.425, por lo que el derecho a voto de la ANSES se ve limitado al $5 \%$ del capital social, en aquellos casos que el organismo estatal posea una participación mayor. La limitación de la acumulación de votos se hacía con las AFJP, es decir no podían juntar su tenencia accionaria para hacer valer sus derechos en forma conjunta como bloque. Este principio de limitación provenía desde su origen, copiando al sistema chileno para evitar problemas de

\footnotetext{
12 Ver artículo periodístico de GUARINO, J. (2010) "Pese a las presiones, la ANSeS descarta vender las acciones locales que tiene en cartera" Diario El Cronista - Finanzas \& Mercados.
} 
control societario de los distintos conglomerados financieros y tratando de evitar conflictos de intereses cruzados.

La ANSES ha cuestionado la limitación al derecho de voto de su tenencia accionaria en varios casos, mencionando la existencia de dictámenes recaídos en las actuaciones caratuladas "Petrobras Energía Participaciones s/Consulta ANSES s/Asamblea 30/01/09" (Expte. $\mathrm{N}^{\circ}$ 422/2009) en trámite ante la CNV. En dichos dictámenes se habría concluido que no corresponde limitar en forma alguna el derecho de voto de dicho accionista. Por lo que la ANSES, en dichas Asambleas hace expresa reserva de derechos y acciones que pudieren corresponderle en virtud de los artículos 251 y 252 de la Ley de Sociedades de Comerciales (LSC) № 19.550.

Lo novedoso a toda esta cuestión, es que el día 13 de abril de 2011 fue publicado en el Boletín Oficial el Decreto Nro. 441/2011 del Poder Ejecutivo Nacional (PEN), en virtud del cual se decretó la derogación del inciso f) del artículo 76 de la Ley del SIJP $N^{\circ} 24.241$, el cual establecía que en ningún caso las inversiones realizadas en una sociedad nacional o extranjera habilitarán para ejercer más del cinco por ciento $(5 \%)$ del derecho de voto, en toda clase de asambleas, cualquier sea la tenencia respectiva. Por lo expuesto precedentemente, y con el fin de que la ANSES cuente con herramientas e instrumentos jurídicos adecuados, mediante el Decreto se resolvió la derogación de la Norma, permitiéndole en consecuencia a la ANSES el ejercicio de los derechos societarios que le correspondan según su participación cualquiera fuere ésta última, entre ellos los de voto, para cumplir los objetivos de la Ley № 26425.

\section{La moderna teoría de carteras de inversión.}

La denominada Teoría de Carteras o Teoría de Portafolios es uno de los pilares de las finanzas modernas. El origen histórico, data del año 1952 desarrollada por Harry M. Markowitz. En ese año publica dos artículos de investigación "The utility of wealth" (Journal of Political Economy) y "Portfolio Selection" (Journal of Finance), que son vistos y considerados como el origen y punto de partida de la moderna teoría de portafolios. Sin embargo, la referencia por antonomasia habitual de este tema es su libro publicado en el año 1959, llamado "Portfolio Selection: Efficient Diversification of 
Investments", en el que amplía, profundiza y aclara operativamente la formulación inicial (Markowitz, 1959).

Otro académico que hizo un aporte jugoso y sustantivo a esta teoría fue James Tobin en el año 1958, quien estudió algunos aspectos de la demanda del dinero. Asimismo, no se pueden obviar ni pasar por alto los trabajos de Von Neumann y Morgenstern desarrollados a mediados del siglo pasado, así como los del siglo XVIII de Bernoulli, los cuales resultan ser los antecedentes y precedentes importantes al desarrollo de la misma. Por otra parte, vale traer a referencia, que en el año 1990, Markowitz recibió el Premio Nobel de Economía junto a Merton Miller y William Sharpe, todos ellos por sus trabajos pioneros en la teoría de economía financiera.

\section{El objetivo de la administración de carteras de inversión.}

Los trabajos pioneros realizados por Markowitz (1952 y 1959), se iniciaron como toda teoría con supuestos preestablecidos, que se enuncian y detallan a continuación. En primer lugar, el análisis se realiza sobre un solo tipo de activo: las acciones. Dejando de lado otro tipo de activos financieros muy importantes como son los títulos de deuda (bonos públicos y privados). Otros de los supuestos, es que las tasas de rentabilidad histórica de las acciones, cuando se miden en intervalos lo suficientemente pequeños de tiempo, se ajustan razonablemente bien a una distribución estadística normal. Seguidamente se preestablece, que si un inversor se encuentra ante dos activos que tienen igual riesgo (o varianza) elegirá aquel que posea mayor rentabilidad esperada. Al mismo tiempo, si un inversor tiene que optar entre dos activos que tienen igual rendimiento esperado elegirá aquel que posea menor riesgo.

En definitiva, Markowitz formula la teoría de la selección óptima de cartera como un balance (trade off) entre las dimensiones básicas de las finanzas: Riesgo y Rendimiento; dando una expresión formal a la idea de que la diversificación de cartera es un método efectivo para reducir el riesgo. Asimismo se afirma que, si hay dos criterios, riesgo y rendimiento, era natural suponer que los inversores realizarán su elección en el conjunto de combinaciones riesgo-rendimiento que cumplen el óptimo de Pareto. Es decir, se asume que los inversores tienen una conducta 
racional, y diversifican su inversión porque están preocupados por el riesgo tanto como por el rendimiento de los activos.

Se podría sintetizar las ideas expuestas, en que la teoría comienza con un inversor ya sea individual o institucional, el cual tiene una determinada suma de dinero dispuesto a invertir hoy. Por consiguiente, realiza la inversión por un período determinado (holding period), pudiendo ser la longitud de uno o más períodos. Al terminar este período el inversor vende su tenencia y vuelve su dinero o activos a su poder, quien luego consume o reinvierte; o hace ambas cosas.

En efecto, el principal objetivo de la administración de carteras, es el diseño, armado y construcción de un portafolio de inversiones con un determinado nivel de rendimiento-riesgo. $Y$ a esta altura del desarrollo de la temática, se puede afirmar y explicar que este objetivo podría desmenuzarse de dos formas: por un lado, se desea obtener el máximo rendimiento para un nivel de riesgo dado; o bien, reducir al mínimo el riesgo, dado un cierto nivel de rendimiento que se desee obtener.

Otra idea central, es que el inversor o los inversores que verdaderamente ganan a largo plazo no son los que obtienen el mayor rendimiento en un determinado período. Si no, son el/los que permanece/n en el tiempo con un adecuado binomio retorno / riesgo. Las distintas estrategias a aplicarse, considerarán el caso particular y el perfil de riesgo de los inversores. El éxito en el diseño y el armado de una cartera devendrá de tener en cuenta muchos aspectos.

\section{Estructuras y aspectos importantes en el armado de una cartera de inversión.}

En términos netamente teóricos, el armado de la estructura de la cartera del FGS se asemejaría a una de las políticas tradicionales como es el retorno absoluto (total return). Es decir, que todas las clases de activos se incluyen en esta política de retorno, no importando la fuente de ingreso (si es por intereses o por apreciación del capital), teniendo una política más flexible, donde se deben especificar las clases de activos, los rangos a invertir y la flexibilidad que se le otorga al administrador, no atándose a la evolución de ningún índice. Los otros enfoques tradicionales de políticas en la construcción de portafolios serían de Income o ingreso (el ingreso por 
ejemplo por intereses, se puede gastar y las ganancias de capital se reinvierten), de growth $\mathrm{o}$ crecimiento (generalmente orientadas a acciones y propiedades inmobiliarias, enfocadas a incrementar el valor del capital, carteras de largo horizonte y baja necesidad de liquidez), y de Income y growth (balanceado) ( es una mezcla de inversiones de renta fija que generan intereses e inversiones de renta variable/real estate que generan crecimiento del capital).

Seguidamente, se describen y detallan algunos aspectos relevantes a tener en cuenta en la construcción de un portafolio:

I) Definición de clases de activos a ser incluidos en el portafolio (Renta variable: acciones; renta fija: bonos soberanos y corporativos; productos financieros derivados; proyectos reales, índices, ETF - Exchange Traded Fund-, commodities, monedas, real estate, etc.). Es decir, la clase de activos a incluir en el portafolio, si son reales o financieros, y si se tiene acceso a los distintos mercados. Algunos casos que se pueden traer a colación, son el de los $\mathrm{FCl}$, donde en su reglamento de gestión se exponen las limitaciones que tendrán para trabajar las portfolios managers en los activos a incluir dentro de las carteras; o las proporciones y limitaciones legales impuestas a compañías de seguros; O las limitaciones de la Ley № 24.241 y modificatorias para las inversiones que puede realizar el FGS de la ANSES.

II) Perfil de riesgo del inversor: propenso al riesgo, conservador o neutro, averso al riesgo. Seguidamente se necesita conocer el perfil de riesgo del inversor, y aquí se determinará aquella combinación de riesgo/retorno con la cual el inversor se sienta ameno y cómodo, la cual es una característica sumamente ligada a su criterio personal. El nivel de tolerancia al riesgo del inversor, se lo puede definir como aquella combinación de riesgo / retorno con la cual el inversor se sienta satisfecho, la cual es una característica sumamente subjetiva.

Asimismo, Olivo (2008) define a la aversión al riesgo como el "disgusto" con el mismo. Cada uno de los inversores tiene un grado distinto de aversión al riesgo, dependiendo de las distintas historias personales en éxitos, fracasos, experiencias, estudios, prejuicios, psicología de masas e individual, entre otros motivos. Todo 
dependerá de la voluntad del inversor al asumir un mayor riesgo, para lo cual querrá ser compensado con un mayor nivel de rentabilidad esperada.

Una de las herramientas tradicionalmente utilizadas para determinar el nivel de tolerancia del riesgo de los inversores es un test a través de un cuestionario. Las distintas respuestas a cada pregunta poseen un puntaje y la sumatoria de los mismos determinará una calificación del perfil del inversor: si es conservador, moderado o agresivo. Otro método, mucho más complejo es utilizar cálculos matemáticos para determinar el perfil de riesgo, complementada con curvas de indiferencia.

III) Principios de diversificación: cartera con inversiones en distintas regiones, países, sectores, instrumentos financieros; activos de renta fija y variable, activos financieros que se caracterizan por su alta diversificación, etc. La utilización de los principios de diversificación deberá aplicarse para eliminar la concentración en pocos activos que le agregarán mucha volatilidad a la cartera, haciendo uso de las covarianzas, incorporando al portafolio aquellos activos de mejores perspectivas de apreciación pero sobre todo de menor coeficiente de correlación entre ellos.

IV) Longitud del plazo de inversión: corto-mediano-largo plazo. La longitud del plazo de inversión es muy importante, dado que no es lo mismo invertir en un activo de renta fija de corto plazo o un activo de renta variable como una acción o un bono de larga duration de un país emergente. Porque se tiene más tiempo para realizar la inversión, que estará sujeta a un mayor riesgo en el período de espera pero por lo que se espera un retorno superior, acorde con el riesgo asociado. La longitud u horizonte de la inversión, se lo puede denominar como el período por el cual se estará dispuesto a mantener una inversión determinada. Se pone como ejemplo, los portafolios que administran los fondos de pensiones, como sería el FGS, al ser el dinero de personas jubiladas o que se jubilarán en un futuro quizás dentro de diez, veinte o treinta años, las inversiones serán expuestas a la incertidumbre y aleatoriedades del largo plazo. El horizonte de la inversión estará muy vinculado al ciclo de vida del inversor. Las personas jóvenes en sus primeros años de su actividad económica seguramente tendrán un horizonte de largo plazo, por lo que podrá tener inversiones más riesgosas y rentables. 
V) Definición del índice de referencia o benchmark del portafolio. Hay que recordar que un mercado a largo plazo es eficiente de acuerdo con los postulados de Fama (1970) dado que un inversor no le puede ganar sistemáticamente al mismo, por lo que necesita una referencia contra el cual compararse. Sirve como patrón de medida para evaluar el rendimiento de la cartera. Independientemente del nivel de beneficioriesgo obtenido por el administrador de carteras, siempre se busca determinar el rendimiento relativo. Cuando se dice rendimiento relativo del portafolio, se hace referencia a la comparación que se le hace con el rendimiento de otro activo. Un ejemplo de ello es, comparar el rendimiento de la cartera administrada con el de un índice, o con otros fondos de inversión. Algunos ejemplos de benchmark que se utilizan en la administración de carteras de inversión sería, si un fondo de inversión se compone de acciones que cotizan en Argentina, el índice de referencia sería el índice MERVAL (Mercado de Valores), o el MERVAL Argentina, o el MERVAL 25, o el Panel General, o el BURCAP, todos elaborados por la Bolsa de Comercio de Buenos Aires. Si se deseara invertir en renta variable (acciones) de empresas brasileñas se utilizaría como benchmark el Índice BOVESPA de la Bolsa de San Pablo de Brasil; o en Japón el índice NIKKEI 225 de Tokio. Si el objetivo sería superar el promedio de las principales acciones del mercado global, su referencia podría ser el índice MSCl All World Index. Por el lado de títulos de renta fija global se puede tener como benchmark el JP Morgan Global Bond Index para emisiones soberanas a nivel mundial. Otro ejemplo de índice que mide la evolución de los países denominados BRIC (Brasil, Rusia, India y China) es el llamado MSCI BRIC, creado por el broker Morgan Stanley Capital Internacional.

VI) Asignación estratégica de cada clase de activo en el largo plazo. Se realizará para cada clase de activo que contendrá la cartera, teniendo en cuenta el mediano y largo plazo, dependiendo de las diversas circunstancias de la economía en general, de la región, del sector y del activo en particular.

VII) Asignación táctica de clase de activo en el corto plazo. O también llamada de corto plazo, dependerá de la visión que tenga el administrador de portafolio de cada uno de los activos, ver las posiciones de los rangos, dependiendo de la coyuntura de ese momento. Lo mencionado es lo que generalmente se le denomina stock picking (elección de acciones) o market timing (momento de mercado). Es decir, se deberá 
determinar según el análisis macro y coyuntural de la economía y las expectativas del mercado, la sobrestimación (overweight), subestimación (underweight) o mantener la misma participación (neutral) de cada tipo de inversión en la cartera; esto se realizará para cada una de las etapas de selección de la cartera, con el plan táctico acorde con el momento que se atraviese.

VIII) Estrategia de selección a usar dentro de cada clase de activo. El último punto que queda es encarar la estrategia a usar dentro de cada clase de activo. Se debe realizar la selección de activos y también la ponderación de los mismos en la cartera. A tal fin, ya se expuso como se definía la asignación estratégica y táctica de cada activo.

Todo este proceso parece complejo, por lo que se necesita de los conocimientos y herramientas adecuadas para su gestión. Sobre todo se requiere del rebalanceo permanente de las posiciones en función de la nueva información que llega al mercado. Cada inversor individual o institucional tendrá estos y otros factores que deberá considerar para construir su cartera, como serían los aspectos tributarios, legales y regulatorios que impactarán en cada decisión de inversión que se realice dependiendo si son inversores institucionales o individuales.

\section{El riesgo y la incertidumbre en la teoría de carteras.}

La teoría de carteras fue el origen de una formalización muy importante de la teoría financiera. Seguidamente se transcriben expresiones acerca del riesgo que realizaran Harry Markowitz y William Sharpe, extraídas del trabajo de Fornero (2006).

Markowitz enuncia al inicio de su artículo del año 1952: "Pensemos en la regla de que el inversor considera (o debería considerar) el rendimiento esperado como algo deseable y la varianza del rendimiento como algo indeseable". Y finalizando el texto propone que "En los escritos financieros a menudo aparecen los términos "rendimiento" y "riesgo". Usualmente, si se reemplazara el término "rendimiento" por "rendimiento esperado" y "riesgo" por "varianza del rendimiento" existirían pocos cambios en el significado aparente de los mismos" ${ }^{\prime 13}$. Por lo que Harry Markowitz en

\footnotetext{
${ }^{13}$ Ver FORNERO, R. A. (2006) “Usos de “Riesgos” en Finanzas de Empresas”. Página 58.
} 
su análisis no define el concepto de riesgo, sino los efectos de la regla de inversión basada en el rendimiento esperado y la varianza del rendimiento. Asimismo, no identifica el riesgo con la varianza del rendimiento; sólo sugiere que ésta puede ser utilizada como aproximación al riesgo.

Por su parte Sharpe (1970), en su trabajo de teoría de carteras, expresa y deja de lado explícitamente la distinción entre Riesgo e Incertidumbre que hacen otros: "A los términos riesgo e incertidumbre se les da en algunas ocasiones significados diferentes. Se dice que una situación de riesgo existe si un individuo desea basar sus decisiones en distribuciones de probabilidad". (Hay quien restringe el término aún más, refiriéndose sólo a situaciones en las que las distribuciones de probabilidad se han obtenido objetivamente).

De todas formas, siempre hay o certeza o incertidumbre.

"La teoría de carteras se relaciona con la toma de decisiones en condiciones de riesgo. No obstante, la palabra incertidumbre es demasiado útil como para abandonarla. Aquí se la usa en su sentido popular para hacer referencia a una situación en que el futuro no puede predecirse con certeza. Más aún, se la usa como sinónimo de riesgo".

"La teoría de carteras no puede ser de ayuda directa para aquellos que consideran que las distribuciones de probabilidad son difusas (fuzzy). El alcance de esta 'inconcreción' se ha denominado grado de ignorancia. Un decididor tiene dos alternativas. Puede actuar como si una distribución específica fuera significativa; entonces, la teoría de carteras puede utilizarse directamente. O puede rechazar el actuar así; en tal caso, la teoría no tiene ninguna utilidad”.

"Resumiendo, la teoría de cartera supone que los inversores están inseguros, pero que no son ignorantes." 14

Markowitz (1952) planteó que la varianza del rendimiento es aquello que el inversor considera, o debería considerar, indeseable. Por lo que es una medida relativamente simple de riesgo, a partir de la cual formalizó la noción de diversificación de la cartera como una reducción de riesgo gratuita, en el sentido de que no se requiere una disminución compensadora en el rendimiento. Dio una expresión formal a la noción de que el riesgo de la inversión está bien descrito como la variabilidad del

\footnotetext{
14 Ver FORNERO, R. A. (2006) “Usos de “Riesgos” en Finanzas de Empresas”. Página 58.
} 
rendimiento esperado, y relacionó esta idea general con la medida estadística de la varianza (o el desvío estándar).

De todos modos, la noción formal de diversificación de cartera es válida con otras medidas estadísticas de riesgo. El mismo Markowitz (1959) consideró que la semivarianza negativa podía utilizarse como medida adecuada de riesgo. Lo que planteó en 1959, fueron dos medidas de desvío negativo (downside risk): la semivarianza con respecto al rendimiento medio y la semivarianza con respecto a un rendimiento al que se apunta (objetivo, target).

Es claro que al pensar en la variabilidad como indicador de riesgo se refería a la variabilidad del rendimiento estimado. Pero como ésta no es observable se ha difundido ampliamente también la cuantificación de ese indicador de riesgo mediante la varianza del rendimiento en el pasado. El problema que se puede presentar es que si la evaluación de carteras se realiza para un horizonte largo se suele utilizar la variabilidad del rendimiento observado en períodos más cortos, y esto implica supuestos adicionales acerca del comportamiento de la variabilidad de los títulos.

\section{Frontera eficiente y la elección de portafolios óptimos de acuerdo con el perfil de riesgo.}

Las mejores combinaciones posibles de distintos activos, se conoce como cartera o portafolio eficiente. Así, los distintos inversores racionales seleccionarán su portafolio eficiente dependiendo de sus preferencias y tolerancias al riesgo.

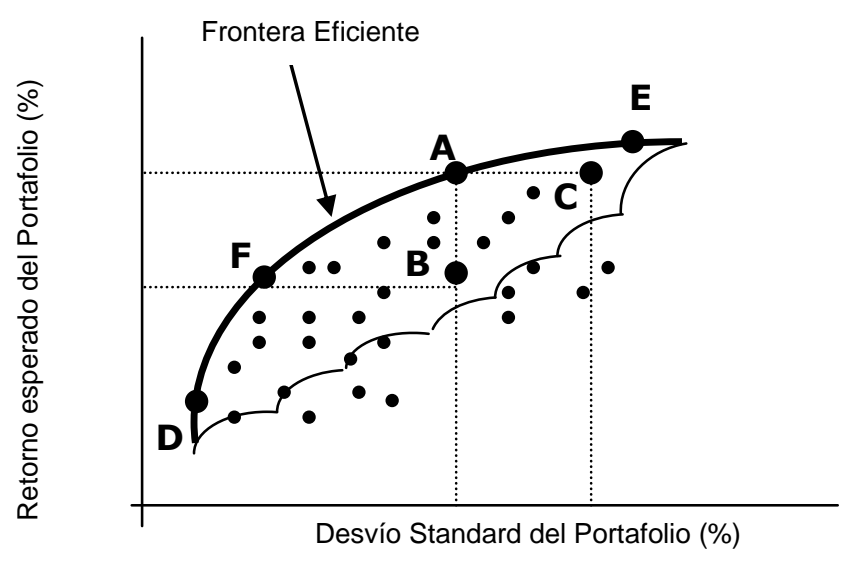

Fuente: Elaboración propia en base a Elbaum (2006).

Figura 8: Construcción de una frontera eficiente con los distintos portafolios eficientes. 
Ya sean los inversores individuales o institucionales, todos desean aumentar sus niveles de rentabilidad esperada y reducir el riesgo, por lo tanto sólo se estaría interesado en aquellas carteras que se encuentra sobre la línea curva. En la Figura 8 la frontera eficiente está compuesta por las carteras D, F, A y E. Cada punto representado en la figura mencionada, representa una cartera, se podría haber representado infinita cantidad de portafolios. Siempre se mantendrá esa forma de sombrilla o paraguas, independientemente de la cantidad de carteras representadas. Sí podrá su forma cambiar de acuerdo con la cantidad de activos que se considere para el armado de la cartera. Se puede demostrar que la cantidad de "arcos" del paraguas será igual al doble de los activos de la cartera menos uno $(2 \mathrm{~N}-1)$.

Como se estableció, la frontera de eficiencia muestra las carteras posibles más eficientes que el mercado ofrece a un inversor. Pero para decidir en qué cartera invertir es necesario determinar las actitudes del inversor frente al riesgo. Para seleccionar la cartera óptima, cada inversionista tendrá sus propias curvas de indiferencia, que representarán sus preferencias al riesgo y al rendimiento para un monto de utilidad determinado. Si los inversores tienen aversión al riesgo, como es uno de los supuestos de la teoría de carteras, sus curvas de indiferencia serán de pendiente positiva, es decir la tasa marginal de intercambio rendimiento - riesgo será creciente.

En definitiva, el inversionista es indiferente entre cualquier combinación de rendimiento esperado y desviación estándar en una curva específica de indiferencia. Los inversores más reacios al riesgo (conservadores) tienen sus curvas de indiferencia con mayor pendiente, mientras los menos reacios (agresivos) tienen sus curvas más planas. Por lo que si se conocen las curvas de indiferencia y la frontera eficiente del portafolio, surge un único portafolio óptimo para cada inversor, que será el punto tangencial de la curva de indiferencia con la frontera eficiente. En la Figura 9 se observa que el punto $\mathrm{J}$ puede ser una cartera óptima para un averso al riesgo, en cambio la cartera A sería para un inversor más amante al riesgo. 


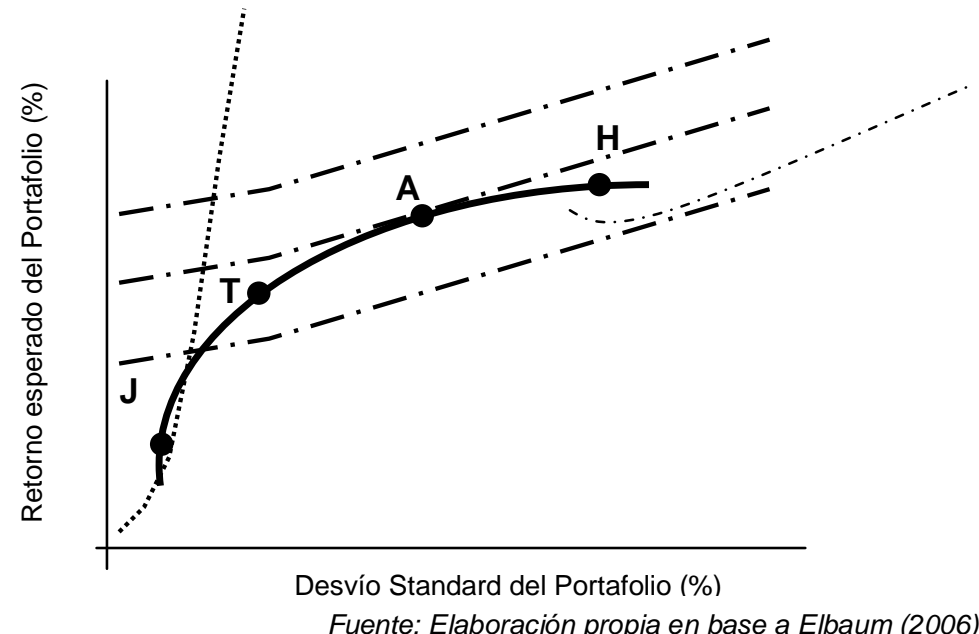

Figura 9: Elección de carteras óptimas de acuerdo con el perfil de riesgo del inversor.

Todos los inversores tienen distintas curvas de indiferencia dado un valor de utilidad determinado. El inversor racional siempre buscará su portafolio óptimo, perteneciente a la frontera de eficiencia y ubicado en la curva de indiferencia más alta posible. La cartera óptima surge de la confluencia de las preferencias subjetivas de cada inversor sobre riesgo rendimiento y las oportunidades de portafolios de inversión que el mercado brinda, y las condiciones legales y estatutarias de los inversores institucionales.

\section{La Línea del Mercado de Capitales (Capital Market Line) y el Teorema de la Separación (Tobin).}

En el presente apartado se desarrolla en uno de sus puntos la conformación de la Línea del Mercado de Capitales, cuando se permite operar en corto, abordándose a continuación el Teorema de la Separación desarrollado por Tobin (1958), relativo a la asignación óptima de una cartera financiera.

Tobin tomó como partida el trabajo de Markowitz y las nociones económicas tradicionales aportadas por Keynes, Hicks y Kaldor sobre asignación óptima de inversiones. Markowitz estableció que existía una frontera eficiente riesgorendimiento para una colección de activos riesgosos y que los inversores seleccionarán su posición en función de sus preferencias al riesgo. Tobin, por su parte, extiende las posibilidades de inversión insertando el dinero (un título con rendimiento cierto), por lo que se llega al teorema de la separación (two - fund separation theorem). Tobin plantea que los individuos pueden diversificar sus inversiones entre un título sin riesgo (dinero) y una cartera única de títulos con riesgo 
(que es la elegida por todos). Diferentes actitudes frente al riesgo, como las que se vinieron desarrollando, resultan en diferentes combinaciones de la cartera de títulos con riesgo y del título sin riesgo. Esto es válido si los resultados posibles de las inversiones siguen una distribución normal, ya que en este caso las curvas de indiferencia de media y varianza de un inversor adverso al riesgo son convexas.

La introducción de la tasa libre de riesgo sumó una nueva dimensión en el análisis, dando a los inversores una opción adicional. Es decir, les permite seleccionar sus carteras y luego combinarlo en varias proporciones con una inversión libre de riesgo.

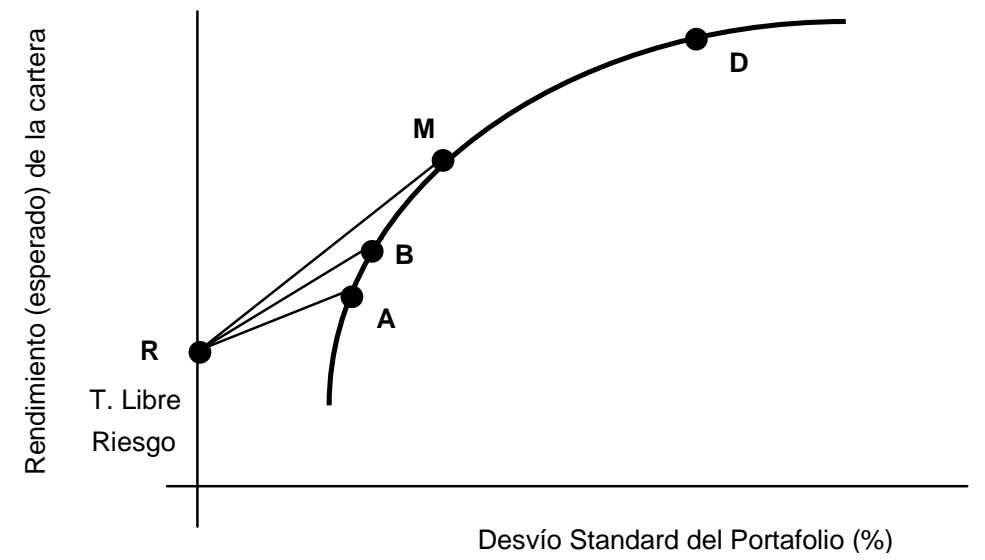

Figura 10: Elección de carteras óptimas introduciendo la tasa libre de riesgo.

El retorno y riesgo de los distintos portafolios son los promedios ponderados de los retornos y riesgos de los activos individuales. En la Figura 10 se pueden ver las distintas combinaciones de carteras, es decir, entre la que contiene activos libre de riesgo (cartera $\mathrm{R}$ ), con las distintas carteras de acciones que forman parte de la frontera eficiente ( $A, B$ y $M$ ). Al tener en la cartera activos riesgosos y activos libre de riesgo, cuando se determina la covarianza de los rendimientos de los mencionados activos, será por definición cercana a cero.

Por otro lado, las líneas que los conectan, representan las combinaciones posibles de los portafolios riesgosos y el activo libre de riesgo. Se puede trazar como líneas rectas ya que la varianza y retorno de esta combinación es simplemente un promedio ponderado. Estas combinaciones de carteras son dominantes a los que se encuentra por debajo del portafolio A. Esto se fundamenta, dado que por cada cartera hay una cartera en la línea R-A que tiene el mismo riesgo y más retorno o el mismo retorno y menor riesgo. Asimismo, la línea que conecta $R$ y $B$ domina a $R-A$, y así se puede seguir trazando líneas que dominan a otras hasta llegar a la que es tangente a la 
frontera eficiente, en este caso el punto $M$, que es la línea que domina a todas las carteras.

Concluyendo, se puede afirmar que todo inversor racional, mezclando diferentes proporciones del activo libre de riesgo y portafolios riesgosos, llegará a la conclusión que la línea R-M, tangente a la Frontera de Eficiencia, le plantea la combinación riesgo- rendimiento que domina a todas las demás. Corresponde afirmar, que invertir en un activo libre de riesgo se lo puede asimilar a prestar (Lending), y como hasta ahora no se puede estar corto en el activo riesgoso (go short o en castellano "irse en corto"), la nueva frontera eficiente estaría dada por la línea recta R-M y luego por la curva M-D.

\section{Línea del Mercado de Capitales (LMC).}

La frontera eficiente, cuando se incorpora la posibilidad de operar a la tasa libre de riesgo, se extiende por ser posible alcanzar mejores combinaciones endeudándose o prestando a la tasa libre de riesgo. En equilibrio todos los inversionistas con aversión al riesgo elegirán aquella alternativa que les brinde una combinación óptima entre inversiones libres de riesgos (Rf: risk free) y una cartera formada con activos riesgosos $(M)$, representada en el gráfico que se expone seguidamente.

Recordar que la cartera óptima o cartera de mercado (M): es el punto de tangencia con el conjunto de carteras eficientes, es decir que, ofrece la mayor prima por riesgo esperada por unidad de desviación típica. De la unión de estos dos puntos, o sea la tasa libre de riesgos Rf y la cartera $\mathrm{M}$, y a esto se le introduce la posibilidad de "irse corto" en el activo riesgoso; se obtiene la nueva frontera eficiente que se denomina la Línea de Mercado de Capitales (LMC) o en terminología inglesa Capital Market Line (CML). El proceso por el cual uno vende un activo que no tiene se llama "irse corto" o "short selling". Esto se realiza alquilando el activo por un tiempo determinado y vendiéndolo en el mercado, para hacerse el efectivo con la intención de recomprarlo más barato en el futuro. Por el alquiler se paga una tasa interés y en definitiva es tomar prestado dinero (borrow). 
La Línea del Mercado de Capitales muestra la relación retorno-riesgo para carteras eficientes cuando prestar y tomar prestado (short selling) es posible a la misma tasa (libre de riesgo). En el mundo real los inversores no enfrentan la misma tasa a la que prestan y toman prestado. Es por eso que la Capital Market Line o la frontera eficiente pudiendo prestar y tomar prestado es diferente.

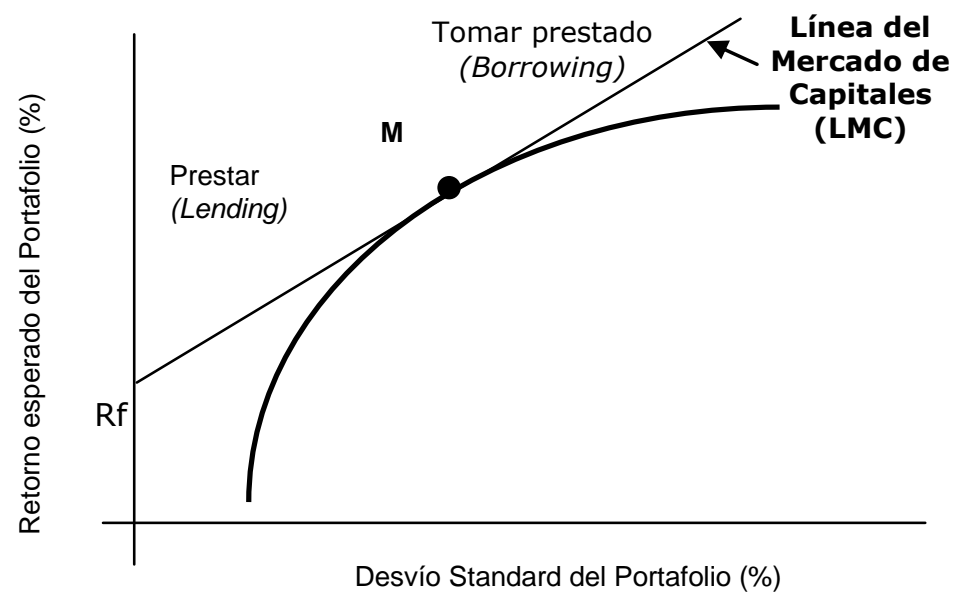

Figura 11: Construcción de la Línea del Mercado de Capitales (LMC).

El Teorema de Separación (o de Tobin), se deduce de la Línea del Mercado de Capitales, que indica que la composición del mejor portafolio no depende solamente de la actitud del inversor hacia el riesgo. Describe que la decisión de inversión está separada de la decisión de financiamiento. Por ello se plantea dos etapas bien diferenciadas a la hora de armar la cartera más eficiente:

- Etapa Objetiva: Encontrar el portafolio óptimo (M) formado exclusivamente por activos con riesgo.

- Etapa Subjetiva: Determinar la mezcla óptima entre la cartera M y los activos libres de riesgo, prestando dinero o endeudándose. Esto permite extender las combinaciones de riesgo y rendimiento, más allá de la frontera eficiente de acuerdo con las preferencias individuales y sus niveles de tolerancia al riesgo.

\section{Estrategias de administración de portafolios: Gestión Activa y Pasiva.}

Para comenzar, se considera que la administración de carteras de inversión se puede realizar tanto desde un enfoque de Gestión Activa como de Gestión Pasiva. Las operaciones que se realizan bajo una gestión activa tienen como objetivo principal incrementar el retorno esperado de la cartera, por ende se busca ganarle al 
benchmark. Pero también pueden existir otros objetivos como la reducción del riesgo de la cartera (diversificando en activos, proyectos, regiones, países, sectores, monedas, etc.), generación de efectivo, expansión, efecto en la economía real como sería el caso del FGS, entre otro fines.

En cambio la gestión pasiva, solo se limita a tener operaciones apuntando a otros objetivos que puedan tener los inversores; en particular replicar la performance de un benchmark o índice predeterminado. Ambas tienen sus ventajas y desventajas, teniendo que evaluar el inversionista el costo - beneficio que provoca la utilización de una $u$ otra de las gestiones.

La administración de portafolios a través de la gestión pasiva, tiene ventajas en su favor, que son las que se enumeran seguidamente:

- Menores costos operativos.

- Menores costos de transacción.

- Menores honorarios de gestión.

- Más fácil la elección de un gestor pasivo.

- A priori, se tiene menor tracking error (error de réplica).

Las desventajas de este tipo de gestión son:

- Riesgo del Benchmark elegido.

- Menor retorno activo.

Como se mencionara anteriormente, la gestión pasiva intenta replicar la performance de un benchmark o índice predeterminado. Al mismo tiempo, se procurará que el retorno activo esperado y ex - ante tracking error, sean iguales a cero. Al realizar el indexing se deben considerar estos tres aspectos que se desarrollan a continuación:

$\Rightarrow$ La elección del método, es decir la tecnología a emplear para replicar los índices seleccionados. En la práctica se pueden utilizar los métodos que seguidamente se exponen: Exhaustive sampling (full replication - muestreo exhaustivo, replicación total -), Optimised sampling (muestreo optimizado), Synthetic replication (copia sintética) y el Stratified sampling (muestreo estratificado). 
En el Exhaustive sampling se realiza la copia total del índice, teniendo las mismas acciones con iguales ponderaciones en la cartera. Para utilizar este método se necesita poca información y se logran valores mínimos de tracking error. Los aspectos negativos que trae aparejado son la iliquidez que se puede tener de ciertos activos. Asimismo, se debe analizar el tamaño de la cartera y la cantidad de acciones del índice para ver si es realmente conveniente, por los mayores costos de trading, de monitoreo y administrativos. Se recomienda su utilización cuando se tiene un monto administrado elevado con respecto al índice o cuando el índice se compone de pocas acciones.

Con el Stratified sampling se construye la cartera en tres etapas, considerando los factores, el peso mínimo, y la liquidez de los activos a incluir. Al construir una cartera, por ejemplo se pueden dejar de lado aquellos activos financieros que se encuentren por debajo de un peso mínimo (v. gr. 5\% de peso mínimo). Esta clase de tecnología evita segmentos ilíquidos, por lo que provoca menores costos en la gestión, y también requiere menos información. Las cosas para observar es que tiene un mayor tracking error, y se obtiene un control de riesgo limitado. Se recomienda su utilización cuando se encuentra el portafolio indexado por un índice amplio con partes ilíquidas o cuando el tamaño de la cartera no es lo suficientemente grande para cubrir las desventajas de exhaustive sampling.

En el Optimised sampling, se realiza la construcción de la cartera mediante el uso de un optimizador. Las ventajas que representa son la disposición de una medida exante de tracking error; y trae consigo un mayor control del mismo (sensibilidades a los factores de riesgo). La contra que trae aparejada este método es la mayor necesidad de información y los mayores costos (parcialmente resuelto por modelos de riesgo disponibles).

El último método que se desarrolla que sirve para replicar un índice, es el Synthetic replication. El mismo utiliza efectivo (cash) y futuros (derivados) para replicar una determinada posición de mercado. Trae como beneficio que es fácil su implementación, y se realiza en pocas operaciones. Su implementación es más económica, conlleva menores costos de transacción, de servicios de custodia e impuestos. Los puntos en contra de este método, son la inexistencia de contratos de 
futuro de ciertos índices (mayor tracking error); un mayor tracking error por dividendos, la necesidad de renovación de futuros a vencimiento; y un tracking error por diferencia de tasa a la que está colocado en dinero en efectivo (cash).

$\Rightarrow$ Elección del Benchmark: Para realizar la indexación se deben considerar ciertos factores; como la liquidez de los activos; el tipo de exposición deseada; los futuros sobre el índice; el tamaño de la cartera comparada con la cantidad de acciones del índice; y el tracking error. Esta elección del índice está ligada a la elección del método de indexación: Narrowly - based index (índices con pocas empresas): se recomienda full replication (exhaustive sampling) o synthetic replication. Broad based index (índices con varias empresas): no se recomienda full replication (exhaustive sampling) ni synthetic replication.

$\Rightarrow$ Elección del tracking error: La elección del benchmark está ligada a la elección del método de indexación y ligada a la elección del tracking error. El tracking error al ser una medida de control, se deben poner parámetros, el cual será conveniente si es pequeño, dependiendo de los instrumentos financieros que contenga la cartera.

\subsection{Definición de Términos Básicos}

- ADR (American Depositary Receipts): Los ADR son instrumentos negociables emitidos por un banco de los EEUU que dan título a las acciones de las empresas que quieren cotizar en la Bolsa de Nueva York ya que son mantenidos en custodia por el banco emisor correspondiente.

- Acciones: cada una de las partes en que se divide el capital de las empresas constituidas jurídicamente bajo la forma de sociedad anónima en Argentina.

- Activos de Renta Fija: son aquellos para los cuales se encuentra establecido en forma anticipada el flujo de fondos futuros (que incluye los intereses) que se van a pagar por un período determinado.

- Activos de Renta Variable: son aquellos en los cuales los pagos futuros dependen, por ejemplo, del resultado de una actividad determinada y corren con el riesgo del negocio.

- AFJP: Las administradoras de fondos de jubilaciones y pensiones eran empresas de servicios destinadas a la prestación de servicios de previsión social. Eran organizaciones con patrimonio propio, que cumplían con el fin fijado por la Ley № 
24.241, administrar el fondo de jubilaciones y pensiones y otorgar las prestaciones establecidas por la ley. Cada administradora podía administrar un solo fondo y debía llevar su propia contabilidad separada de la del fondo. Esta separación era esencial al régimen de capitalización porque la administradora era propiedad de sus accionistas y el fondo era propiedad de los afiliados.

- Análisis Fundamental: estudia todas las variables económicas y financieras que se perciben como explicativas del comportamiento de los precios de los instrumentos financieros que se están evaluando.

- Análisis Técnico: se dedica a estudiar el comportamiento pasado de precios y volúmenes negociados para proyectar el futuro a través de gráficos, y poder anticiparse a los movimientos del mercado.

- Anomalías: son casos inconsistentes con la hipótesis de eficiencia de mercado que, pese a ser ampliamente conocidos, no son arbitrados por el mercado.

- Arbitraje: Beneficio que resulta de las diferencias de precio cuando el mismo título valor, moneda o commodity se comercializa en dos o más mercados.

- Benchmark: índice de referencia; que es la cartera testigo con la que se comparan los rendimientos de una cartera. Es establecido por el administrador de activos o por el titular de una cartera de inversión.

- Capitalización Bursátil (Market Capitalization): Con referencia a una compañía determinada, representa el valor de mercado de las acciones que integran su capital. Con referencia a una bolsa, es el valor de mercado de la totalidad de las acciones ordinarias y preferidas, coticen o no coticen. El importe, en el primer caso, surge de efectuar el producto del capital por el precio de la compañía, en tanto que en el segundo se efectúa la sumatoria de los valores que corresponden individualmente a todas las sociedades cotizantes.

- Cartera de inversión (portafolio o portfolio): conjunto o combinación de activos financieros o reales; ya sean acciones de distintas empresas, títulos públicos, bonos corporativos, commodities, propiedades, índices, monedas, efectivo, y demás activos posibles. En todo este trabajo se utilizan los términos "portafolio", "portfolio" y "carteras" indistintamente, para referenciar a un conjunto de activos.

- CEDEAR (Certificados de Depósitos Argentinos): Los Cedear son certificados representativos de depósito de acciones de sociedades extranjeras u otros valores, sin autorización de oferta pública en Argentina. 
- Coeficiente de correlación lineal: medida estadística que muestra la tendencia del movimiento simultáneo de dos variables. El coeficiente toma valores comprendidos entre $1 \mathrm{y}-1$.

- Conglomerado Financiero: Grupo corporativo que ofrece un amplio rango de servicios financieros, típicamente incorporando al menos dos de los siguientes: bancos, valores y seguros. Definición del Foro Conjunto sobre Conglomerados Financieros (Banco de Pagos Internacionales, BIS).

- Covarianza: medida estadística del grado de movimiento conjunto entre dos variables aleatorias.

- Curva de indiferencia: curva trazada en un gráfico, donde cada punto de una curva (que indica diferentes combinaciones de las dos variables: rendimiento-riesgo) genera exactamente el mismo nivel de satisfacción a un inversor dado.

- Diversificación: es la tenencia de muchos y diversos activos riesgosos (v. gr. acciones, bonos, commodities, etc.), con el fin de reducir el riesgo conjunto de la cartera. Implica distribuir los recursos entre activos riesgosos de distinto tipo y riesgo, versus concentrarlos en un solo tipo de activo y estar expuestos a un solo tipo de riesgo.

- Duration (duración): Es el promedio ponderado (efectivo) de tiempo de una serie de flujos de fondos de caja fijo de un activo. Normalmente se expresa en años. Las ponderaciones se determinan por medio de factores de valor presente. Se interpreta como el plazo de vida de un bono cupón cero equivalente.

- Elasticidad: Término utilizado frecuentemente para indicar la sensibilidad de una variable a las variaciones de otra. Así, la elasticidad de $X$ con respecto a $Y$ significa la variación porcentual de $X$ por cada variación porcentual de un $1 \%$ de $Y$.

- Free float: se define como el porcentaje del capital social que no está en poder del grupo o accionistas controlantes. Las empresas listadas en la BCBA están obligadas (por el Reglamento de Cotización de la BCBA) a brindar esta información (lo hacen a través de la Síntesis de Estados Contables presentada trimestralmente). A partir de esos datos, el free float de cada empresa se calcula como $100 \%$ menos el porcentaje en poder del grupo controlante.

- Hedge Fund (Fondos de Cobertura): Fondos de inversión que buscan rentabilidades positivas sin tener en cuenta la tendencia del mercado utilizando posiciones cortas, swaps, futuros, estrategias de arbitraje y apalancamiento. 
- Índice Bolsa - Nivel General (Composite Index - Bolsa): Las acciones de sociedades constituidas en el país, son ponderadas por capitalización bursátil. Las compañías extranjeras gravitan en función de su participación en el valor efectivo operado. Las acciones componentes del índice deberán cumplir con la condición de haber negociado al menos durante el $20 \%$ de las ruedas durante el período de referencia. Al comienzo de cada trimestre calendario se efectuará una reconfiguración de la estructura del indicador, tomándose como lapso de referencia los seis meses anteriores.

- Índice Burcap (Burcap Index): Este índice representa el valor de mercado (en pesos) de una cartera de acciones, integrada por todas las especies incluidas en el Índice Merval. El día en que se inició el cálculo del indicador (fecha base) se determinó la participación de cada acción en forma proporcional a su valor de mercado. Idéntico procedimiento se aplica cada vez que se reestructura el Índice Merval. La fecha base es el 30 de diciembre de 1992.

- Índices Bursátiles: Con ellos se resume la evolución del mercado bursátil. Es la media de los índices de las acciones consideradas, calculados como la relación entre la cotización actual y la existente en el momento que se toma como base. Existen índices que engloban todas las acciones cotizadas, de sectores, de conjuntos de bolsas, etc.

- Índice de Herfindahl o Índice de Herfindahl e Hirschman (IHH): es una medida (uso general en economía, economía política, y otras disciplinas) de la concentración económica en un mercado. $\mathrm{O}$, inversamente, la medida de falta de competencia en un sistema económico. A más alto el índice, más concentrado, menos competitivo, el mercado.

- Índice M.AR.: Este índice busca reflejar el comportamiento de las empresas argentinas dentro del sistema bursátil. La metodología de este indicador ha procurado mantener la estructura básica del Índice Merval, tomando la evolución de este último como base común hasta el 30 de diciembre de 1999, período previo a la inclusión de empresas extranjeras en el mercado accionario local, y al incremento de la participación de los CEDEARs en el volumen total negociado. EI MAR se genera a partir de una muestra de las operaciones para un período de seis meses anteriores a cada recomposición, que excluye las sociedades extranjeras y los CEDEARs. El criterio utilizado para la selección es el orden decreciente de participación en la 
operatoria de contado en el mercado de concurrencia, excluyendo toda empresa que no haya cotizado un número de ruedas considerado representativo.

- Índice Merval (Merval Index): Este índice representa el valor de mercado (en pesos) de una cartera de acciones, seleccionadas de acuerdo con la participación en la cantidad de transacciones y el monto operado en la Bolsa de Comercio de Buenos Aires. La fecha y valor base son: 30 de junio de 1986 igual a \$ 0,01. El Índice Merval se computa continuamente durante la jornada de transacciones. La nómina de sociedades y sus ponderaciones se actualizan trimestralmente, de acuerdo con la participación de cada especie en el mercado, durante los últimos seis meses. La participación de las acciones incluidas en el valor del índice se computa en varias etapas. Todas las acciones cotizantes son consideradas en forma decreciente, de acuerdo con su participación, hasta un acumulado del $80 \%$.

- Índice Merval 25: índice bursátil con una cantidad fija de empresas, diseñado para reflejar el comportamiento de los 25 papeles de mayor participación bursátil, conservando la estructura básica del tradicional Índice Merval. El Merval 25 está formado por las primeras 25 acciones del ranking de participación bursátil que considera el volumen negociado y la cantidad de operaciones de los seis meses anteriores a la recomposición trimestral de la cartera, siendo un requisito excluyente haber cotizado como mínimo en un 80 por ciento de las ruedas del período.

- Información privilegiada o confidencial (inside information): Información sobre aspectos financieros y económicos de una compañía, que no está al alcance de la mayoría de los accionistas y del público en general. Por lo general, las autoridades nacionales de los mercados de valores son muy severas con respecto al uso de dicha información para evitar que los directores y personal jerárquico se beneficien en detrimento de otras personas y que distorsionen el mercado efectuando operaciones en bloque.

- Insider Trading: Práctica prohibida por Ley por algunas bolsas consistente en comprar o vender según informaciones secretas sobre ciertos valores, que se obtienen por la presencia de cargos de responsabilidad, o por confidencias recibidas desde el interior de las empresas.

- Instrumentos Financieros: indican el derecho que tiene quien lo posee a recibir, en el futuro, dinero por parte del emisor (Ej.: bonos, acciones, obligaciones negociables $(\mathrm{ON})$, valores de corto plazo (VCP), valores representativos de deuda (VRD), etc.). 
- Liquidez: Característica de un título valor o commodity con suficientes unidades en circulación como para que puedan realizarse operaciones importantes sin que se produzca una caída considerable del precio.

- Mercado de capitales: ofrece y demanda activos financieros de mediano y largo plazo, como las obligaciones negociables y las acciones; con la función principal de canalizar el ahorro hacia la inversión productiva.

- Mercados eficientes: competencia entre los distintos participantes que intervienen en el mismo, guiados por el principio del máximo beneficio, conduce a una situación de equilibrio en la que el precio de mercado de cualquier título constituye una buena estimación de su precio teórico o intrínseco (valor actual de todos los flujos de caja esperados).

- Mercado de Valores: son entidades autorreguladas constituidas legalmente bajo la forma de sociedades anónimas. Sus principales funciones están relacionadas con la concertación, liquidación, vigilancia y garantía de las transacciones realizadas en el mercado.

- Riesgo: variabilidad de los futuros rendimientos de una inversión en torno a su valor esperado. De esta forma cuantos más dispersos estén los rendimientos respecto de la media, más riesgosa será considerada la inversión, y por otro lado, cuanto más concentrada en torno a su valor esperado está la distribución de los rendimientos, será menos riesgosa.

- Riesgo no sistemático: también llamado riesgo diversificable, riesgo único, riesgo residual o riesgo específico de una empresa; es la parte de la variabilidad de un activo que puede ser eliminado a través de la diversificación eficiente por deberse a hechos aleatorios cuyo impacto no es generalizado.

- Riesgo sistemático: también llamado riesgo no diversificable o riesgo de mercado, está relacionado al mercado en general, a las condiciones generales de la economía, a los factores macroeconómicos, factores políticos, entre otras diversas causas, por lo que no se pueden eliminar vía la diversificación ya que repercutirán en todos los activos de la economía.

- Tasa libre de riesgo: En teoría y generalmente, se consideran como activos libre de riesgo a los bonos del tesoro norteamericano (Treasury Bonds). Sin embargo, para Argentina a este rendimiento se le debe adicionar un spread por riesgo país. Asimismo, debe tenerse presente que los activos libre de riesgo poseen cero varianza esperada en su retorno. 
- Tracking error (error de réplica): indica el peor período posible de inversión en el período analizado, es decir la máxima pérdida de rentabilidad entre el máximo y el mínimo valor de un fondo en dicho período. Describe la volatilidad de la diferencia de rentabilidad entre un fondo y su benchmark.

- Volatilidad: La volatilidad (Desviación Estándar) es un método estadístico para evaluar en qué medida se desvían (oscilan hacia arriba y hacia abajo) una serie de valores con respecto a su promedio. Un Fondo con "alta volatilidad" significa que este Fondo puede mostrar variaciones importantes (a la alza o a la baja) dependiendo de las condiciones imperantes en los mercado.

- Volumen operado promedio diario: Surge de dividir el volumen total operado en cada mes, clasificado según tipo de instrumento y mercado de negociación, por el número de ruedas bursátiles del mes.

\subsection{Supuestos Implícitos}

- Se respetan las condiciones suficientes de Mercados Eficientes planteadas por Eugene F. Fama (1970):

- que no haya costos de transacción.

- toda la información disponible puede ser libremente utilizada por los participantes en el mercado.

- existe acuerdo sobre las implicaciones que la información tiene sobre el precio actual y distribución de los precios futuros de cada valor.

- Supuestos de la Teoría de Carteras de Inversión (Portfolio Theory). Harry M. Markowitz (1952).

\subsection{El Sistema de Hipótesis}

1. La nacionalización del sistema privado de jubilaciones y pensiones conllevó a una reducción drástica de la liquidez y volumen operado en el mercado de acciones.

2. La concentración en pocas manos (grupo controlante y FGS), produjo serias limitantes en el floating de las empresas cotizantes. 


\subsection{El Sistema de Variables}

\section{Hipótesis 1}

\section{Variable independiente}

* Tiempo, la serie histórica que se analizó fue desde el año 2005 al año 2010.

\section{$\underline{\text { Variables dependientes }}$}

Volúmenes promedios diarios, mensuales y anuales negociados de las acciones cotizantes del Mercado de Valores de la Bolsa de Comercio de Buenos Aires.

* Índice de Precios Implícitos (IPI) del PIB a precios de mercado (Base $1993=100$ ) que elabora trimestralmente el Instituto Nacional de Estadística y Censos (INDEC).

* Cantidad total de acciones negociadas de las empresas que integran el índice MERVAL.

* Producto Bruto Interno (PBI) a precio de mercado y precios corrientes de la República Argentina.

- Relación entre las variables de volumen anual y trimestral operado de acciones y el Producto Bruto Interno (PBI) a precio de mercado y precios corrientes. 


\begin{tabular}{|c|c|c|c|}
\hline Variable & Definición conceptual & $\begin{array}{l}\text { Definición } \\
\text { operacional }\end{array}$ & Indicadores \\
\hline Tiempo & $\begin{array}{l}\text { Magnitud física que permite } \\
\text { ordenar la secuencia de los } \\
\text { sucesos, estableciendo un } \\
\text { pasado, un presente y un futuro. }\end{array}$ & $\begin{array}{l}\text { Período de la } \\
\text { serie histórica que } \\
\text { se analizará. }\end{array}$ & $\begin{array}{l}\text { * Año } 2005 \text { hasta el } \\
\text { año } 2010 . \\
\text { *Meses entre los } \\
\text { años } 2005 \text { y } 2010 . \\
\text { * Días entre los } \\
\text { años } 2005 \text { y } 2010 .\end{array}$ \\
\hline $\begin{array}{l}\text { Volúmenes promedios } \\
\text { diarios, mensual y } \\
\text { anual negociado }\end{array}$ & $\begin{array}{l}\text { Volumen promedio diario, } \\
\text { mensual y anual histórico que se } \\
\text { negoció un título en un mercado, } \\
\text { o el volumen promedio diario, } \\
\text { mensual, anual negociado que } \\
\text { posee un activo o índice en el } \\
\text { mercado. }\end{array}$ & $\begin{array}{l}\text { Volumen } \\
\text { promedio diario, } \\
\text { mensual, anual } \\
\text { de cotización de } \\
\text { las acciones e } \\
\text { índices al cierre } \\
\text { del mercado. }\end{array}$ & 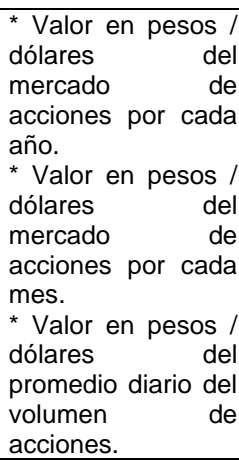 \\
\hline $\begin{array}{c}\text { Índice de Precios } \\
\text { Implícitos (IPI) anual } \\
\text { del PIB a precios de } \\
\text { mercado (Base } 1993= \\
\text { 100) }\end{array}$ & $\begin{array}{l}\text { El deflactor anual del PBI, que } \\
\text { muestra los precios implícitos del } \\
\text { producto bruto de todos los } \\
\text { bienes y servicios que se } \\
\text { producen en el país, sin } \\
\text { considerar los importados, de } \\
\text { todos los sectores de la } \\
\text { economía. }\end{array}$ & $\begin{array}{lr}\text { Indicador que } \\
\text { muestra la } \\
\text { inflación anual de } \\
\text { todos los bienes y } \\
\text { servicios de una } \\
\text { economía. }\end{array}$ & $\begin{array}{l}\text { *Muestra la } \\
\text { variación } \\
\text { porcentual de la } \\
\text { inflación en forma } \\
\text { anual. }\end{array}$ \\
\hline $\begin{array}{c}\text { Cantidad de acciones } \\
\text { negociadas }\end{array}$ & $\begin{array}{l}\text { Cantidad total de acciones } \\
\text { negociadas de las empresas que } \\
\text { integran el índice MERVAL. }\end{array}$ & $\begin{array}{l}\text { Número de } \\
\text { acciones } \\
\text { transadas en el } \\
\text { MERVAL en los } \\
\text { años y promedio } \\
\text { diario. }\end{array}$ & $\begin{array}{lr}* \quad \text { Número } & \text { de } \\
\text { acciones } & \\
\text { negociadas } & \text { por } \\
\text { cada año. } & \\
\text { *Valor } & \text { en } \\
\text { cantidades } & \text { del } \\
\text { mercado } & \text { de } \\
\text { acciones como } & \text { comedio diario. } \\
\end{array}$ \\
\hline $\begin{array}{c}\text { Producto Bruto Interno } \\
\text { corriente a precio de } \\
\text { mercado }\end{array}$ & $\begin{array}{l}\text { Conjunto de bienes y servicios } \\
\text { que se producen dentro de las } \\
\text { fronteras de un país en un } \\
\text { período determinado, teniendo en } \\
\text { cuenta los impuestos indirectos, a } \\
\text { precios corrientes. }\end{array}$ & $\begin{array}{l}\text { Valor de todos los } \\
\text { bienes y servicios } \\
\text { que se producen } \\
\text { el país en un } \\
\text { período en } \\
\text { moneda corriente. }\end{array}$ & $\begin{array}{l}{ }^{*} \text { Valor en } \$ \text { del PBI } \\
\text { corriente p.m. } \\
{ }^{*} \text { Valor en USD del } \\
\text { PBI corriente p.m. }\end{array}$ \\
\hline $\begin{array}{c}\text { Relación Volumen } \\
\text { trimestral/anual } \\
\text { Operado de acciones y } \\
\text { PBI trimestral/anual } \\
\text { corriente a p.m. }\end{array}$ & $\begin{array}{l}\text { Coeficiente que nos muestra la } \\
\text { evolución en el tiempo del } \\
\text { indicador construido. }\end{array}$ & $\begin{array}{l}\text { Indicador } \\
\text { realizado entre el } \\
\text { volumen } \\
\text { trimestral/anual y } \\
\text { el producto anual } \\
\text { y trimestral de la } \\
\text { economía. }\end{array}$ & $\begin{array}{l}{ }^{*} \text { Vol. Trimestral- } \\
\text { anual operado/PBI } \\
\text { trimestral-anual } \\
\text { corriente p.m. }\end{array}$ \\
\hline
\end{tabular}

\section{Hipótesis 2}

\section{$\underline{\text { Variables independientes }}$}

Tenencia de acciones argentinas heredadas del traspaso en especie de las AFJP

y del FGS 1, que posee en cartera el Fondo de Garantía de Sustentabilidad de la ANSES.

Floating de las empresas donde el FGS tiene participación en su capital social. 
* Participación relativa en el capital social que posee el Grupo Controlante en las empresas que el FGS posee acciones.

* Participación relativa en el capital social que posee el FGS de la ANSES en las empresas.

\section{$\underline{\text { Variable dependiente }}$}

* Participación relativa en el capital social flotante, luego de restar la tenencia del grupo controlante y el FGS de la ANSES.

\begin{tabular}{|c|c|c|c|}
\hline Variable & Definición conceptual & $\begin{array}{l}\text { Definición } \\
\text { operacional }\end{array}$ & Indicadores \\
\hline $\begin{array}{c}\text { Tenencia de } \\
\text { acciones del FGS }\end{array}$ & $\begin{array}{l}\text { Tenencia de acciones Argentinas } \\
\text { cotizantes en la BCBA, heredades de } \\
\text { las AFJP por el traspaso de los fondos } \\
\text { privados hacia el estado y del FGS 1, } \\
\text { que posee el FGS en los distintos } \\
\text { años. }\end{array}$ & $\begin{array}{lr}\text { Cantidad } & \text { de } \\
\text { acciones } & \text { en } \\
\text { empresas } & \\
\text { Argentina entre el } \\
\text { año 2008 al } \\
2010 .\end{array}$ & $\begin{array}{l}\text { * } \quad \text { Cantidad de } \\
\text { acciones } \\
\text { ordinarias. } \\
\text { * Cantidad de } \\
\text { ADR. }\end{array}$ \\
\hline $\begin{array}{l}\text { Floating } \\
\text { (Flotación) }\end{array}$ & $\begin{array}{l}\text { Porcentaje del capital social que no } \\
\text { está en poder del grupo o accionistas } \\
\text { controlantes. }\end{array}$ & $\begin{array}{l}\text { Se calcula el } \\
100 \% \text { del capital } \\
\text { social menos el } \\
\text { porcentaje en } \\
\text { poder del grupo } \\
\text { controlante. }\end{array}$ & \begin{tabular}{l}
\multicolumn{3}{c}{ Participación } \\
relativa de las \\
acciones flotando \\
en el mercado \\
secundario. \\
* Cantidad de \\
acciones flotando \\
en el mercado \\
secundario.
\end{tabular} \\
\hline $\begin{array}{c}\text { Grupo } \\
\text { Controlante }\end{array}$ & $\begin{array}{l}\text { Porcentaje del capital social que está } \\
\text { en poder del grupo o accionistas } \\
\text { controlantes. }\end{array}$ & $\begin{array}{lr}\text { Se calcula la } \\
\text { cantidad } & \text { de } \\
\text { acciones del } \\
\text { capital social que } \\
\text { posee en su } \\
\text { poder del grupo } \\
\text { controlante. } \\
\end{array}$ & $\begin{array}{l}\text { * Participación } \\
\text { relativa del Grupo } \\
\text { Controlante. } \\
\text { * Cantidad de } \\
\text { acciones } \\
\text { Grupo Controlante. }\end{array}$ \\
\hline $\begin{array}{l}\text { Acciones del } \\
\text { FGS de la } \\
\text { ANSES }\end{array}$ & $\begin{array}{l}\text { Porcentaje del capital social que está } \\
\text { en poder del FGS de la ANSES de las } \\
\text { distintas empresas. }\end{array}$ & $\begin{array}{|lr|}\text { Se calcula la } \\
\text { cantidad } & \text { de } \\
\text { acciones } & \text { del } \\
\text { capital social que } \\
\text { posee el FGS. }\end{array}$ & $\begin{array}{l}\text { * } \text { Participación } \\
\text { relativa del FGS. } \\
\text { * Cantidad de } \\
\text { acciones del FGS. }\end{array}$ \\
\hline $\begin{array}{c}\text { Acciones } \\
\text { flotantes sin } \\
\text { Grupo de Control } \\
\text { ni FGS } \\
\text { (Flotación } \\
\text { extendida) }\end{array}$ & $\begin{array}{l}\text { Porcentaje del capital social que no } \\
\text { está en poder del Grupo Controlante, } \\
\text { ni del FGS de la ANSES. }\end{array}$ & $\begin{array}{lr}\text { Se calcula la } \\
\text { cantidad } & \text { de } \\
\text { acciones } & \text { del } \\
\text { capital social que } \\
\text { no posee el } \\
\text { Grupo } \\
\text { Controlante, ni el } \\
\text { FGS. }\end{array}$ & $\begin{array}{l}\text { * Participación } \\
\text { relativa de las } \\
\text { acciones flotantes. } \\
\text { * Cantidad de } \\
\text { acciones flotando. }\end{array}$ \\
\hline
\end{tabular}

\section{Metodología de la Investigación}

\subsection{Población y Muestra}

En este trabajo se estudió el mercado de acciones de empresas que cotizan en el Mercado de Valores de la BCBA de la Argentina, especialmente en las que el FGS tiene participación accionaria. 


\subsection{Tipo de Investigación}

Se realizó un diseño de investigación descriptivo y explicativo, para analizar los cambios ocasionados en el mercado de acciones argentino, debido a la salida de las AFJPs y analizar la gestión del FGS en la cartera de acciones que se posee.

\subsection{Técnicas de Recolección de Datos}

El procedimiento empírico que se realizó fue la observación, mediante la búsqueda individual de datos, para luego ser evaluados y analizados. Los instrumentos que se utilizaron, son cuadernos de notas para la recopilación de apuntes o datos interesantes; libros de biblioteca personal y de instituciones referentes a la temática en cuestión; empresas de servicios financieros (Bloomberg, Reuters, Bolsar) para bajar la información necesaria en planillas de cálculo, de sitios de internet institucionales de la BCBA, de Instituto Argentino de Mercado de Capitales (IAMC), del World Federation of Exchange (WFE) y laptop personal para utilizar los sistemas operativos de cálculo y escritura.

Para comprobar la hipótesis sobre liquidez y volumen se utilizó información secundaria de la serie histórica de los volúmenes diarios, mensuales y anuales negociados de Bolsar de la BCBA, específicamente de la sección Research/Series históricas/Montos negociados. Bolsar es un emprendimiento de la BCBA y es propietaria de la información contenida, a la que tienen exclusivo acceso los usuarios del Servicio Bolsar. Dicha sección muestra la serie directa de los datos provistos por la Gerencia de Operaciones de la BCBA, por lo cual son datos finales oficiales y están corroborados. Se eligió la serie de datos de Bolsar por el prestigio institucional, la exactitud y confiabilidad de su contenido y la seriedad del compromiso que asume ante los usuarios de información del mercado bursátil argentino.

Dicha serie histórica se comparó con informes mensuales, especiales y anuarios del IAMC. Este órgano técnico es el área de investigación de Mercado de Valores de Buenos Aires (Merval), y tiene como función principal brindar un servicio de asesoramiento integral a los Agentes y las Sociedades de Bolsa y difundir la dinámica del mercado de capitales como una alternativa de inversión y financiamiento. La serie histórica publicada en Bolsar de la BCBA, tiene algunas 
diferencias con los volúmenes operados mensuales y anuales con las del IAMC. Dichas diferencias se pueden deber a que el IAMC publica las cifras del mes en su informe mensual, sin las correcciones de los datos de los últimos tres días del respectivo mes. Es decir, muchas veces puede pasar que cuando se realizan informes hay datos que están pendientes o pueden haber cambios en los mismos, incluso hay datos que están disponibles 72 horas después del cierre del mercado. Otro motivo que puede ocurrir, es que no se consideraron operaciones que se dieron de baja o se corrigieron en los últimos tres días del mes de referencia. Otra razón de las diferencias se puede dar como consecuencia de operaciones de cable (paridad exterior) dado que el IAMC utiliza un tipo de cambio de dólar de bancos mayorista y la BCBA utiliza el tipo de cambio del Banco de la Nación Argentina (BNA). De todas formas, los resultados y la tendencia estadística son indiferentes de la serie histórica que se tome dado que se llega a conclusiones e inferencias similares.

Para excluir el efecto precio en el volumen negociado, se utilizó la serie histórica del sistema de información financiera Bloomberg, de la función PX_VOLUME del índice MERVAL. La función descrita muestra el número total de acciones negociadas de las empresas que componen el índice en cada uno de los días de la serie al cierre de la rueda que le provee la BCBA.

Para la segunda hipótesis acerca del capital flotante, se utilizó en principio la legislación de las ex AFJP y la que rige actualmente para el FGS. Para observar la gestión del FGS se utilizaron las Actas emitidas por el Comité Ejecutivo del FGS hasta fines de 2010, publicadas en el portal oficial del FGS de la ANSES. La limitación presentada es que no se tuvo el acceso en algunos de los anexos de las mencionadas actas, de acuerdo con la información pública suministrada por la ANSES, donde se encuentran entre otra información la cartera de inversiones a cada momento.

Y para comparar las variaciones de la cartera heredada con su respectiva evolución en el período bajo estudio, se partió del último Comunicado Estadístico № 22-08 de fecha 28/11/2008 de la SAFJP. A ello se le adicionó las acciones provenientes del FGS 1 de la ANSES creado por el Decreto 897/07. En este último caso no se tuvo el detalle de las acciones que poseía el FGS 1, dado que nunca fue publicada su 
tenencia con la discriminación de cada uno de los activos. Pero se sabe según información pública de la ANSES que al 31/10/2008 se poseía en acciones de empresas 1.331,42 millones de pesos. ${ }^{15}$

Sin embargo, del sitio oficial de la ANSES se sacó el porcentaje de la participación en empresas privadas que poseía el mencionado organismo estatal hasta Diciembre de 2010. Por otro lado para determinar la tenencia accionaria del/os grupo/s controlante/s de las empresas argentinas donde el FGS posee participación se utilizó información secundaria recolectada de los Estados Contables trimestrales y anuales que las empresas listadas deben presentar ante la BCBA obligatoriamente, especialmente del Artículo 62 y 63 in fine del Reglamento de cotización. En el mencionado Artículo 62 se focalizó en el inciso o) "Cantidad de acciones discriminadas por clases y con indicación de sus porcentajes respecto del capital social - que, a la fecha de cierre de los estados contables, pertenecen al accionista o grupo controlante de la sociedad"; p) "Cantidad de acciones a que dan derecho los valores representativos de deuda convertibles en acciones y/u opciones de compra de acciones de la sociedad, correspondiente a la titularidad del accionista o grupo controlante y porcentaje que representan sobre el capital social luego de la pertinente emisión. (...)" y q) "Identificación del accionista controlante de la sociedad, indicando denominación y domicilio (...)." Como así también, se tomó información del IAMC, Bloomberg, Reuters y de los sitios de Internet de las distintas empresas en su parte institucional de relación con el inversor, como todo hecho relevante e información útil para el análisis del objeto en cuestión.

\subsection{Técnicas de Análisis}

Con el fin de evaluar las consecuencias y efectos del pasaje de la administración y de los fondos previsionales por parte de gestores privados hacia el estado, y la provocación de cambios importantes dentro del mercado bursátil argentino, se analizó a partir de la recopilación de información secundaria y la generación de información de los principales cambios en el mercado de acciones argentino.

15 De acuerdo con Informes especiales a Noviembre de 2008 de la ANSES. http://www.anses.gob.ar/FGS/politicas-transparencia/archivos/Mintrab.pdf 
En la Figura 12, se presenta un esquema simplificado de la metodología que se utilizó. Esta sección se dividió en dos secciones, para poder simplificar el estudio de las hipótesis planteadas y la metodología que se utilizó.

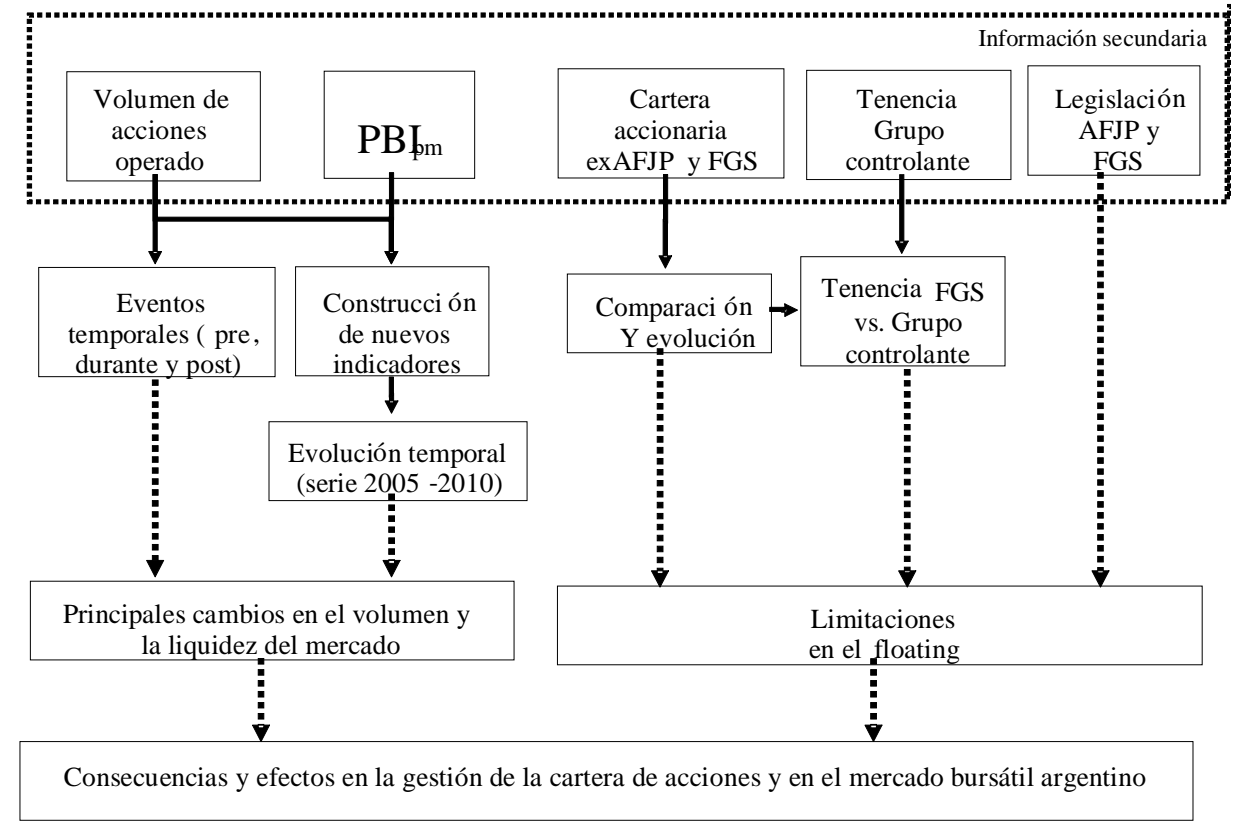

Figura 12: Esquema simplificado de la metodología planteada.

\section{Volumen y Liquidez.}

Para probar la hipótesis sobre la reducción del volumen negociado y por ende en la liquidez del mercado de acciones de Argentina, se utilizaron distintas técnicas empíricas. Y así poder comprobar y poder inferir acerca del rol que pudo haber tenido la gestión del FGS en la misma.

\section{Evolución del volumen operado de acciones que cotizan en la BCBA}

Se analizó en primera instancia para el período comprendido entre los años 2005 y 2010 la evolución del volumen operado (anual, mensual y promedio diario) de acciones que cotizan en la BCBA. Todos estos análisis se realizaron en términos nominales y en pesos argentinos. Posteriormente se analizó los montos anuales y promedio diario nominal negociado en dólares estadounidenses. El tipo de cambio utilizado es el de cierre del respectivo año en cuestión, y de acuerdo con el valor implícito de la serie histórica de operaciones de la BCBA en dólares. 
Otro análisis que se hizo fue determinar la evolución del monto negociado anual en el MERVAL en términos reales, es decir sacando el efecto inflacionario. Para determinar la inflación entre los años 2005 y 2010 se utilizó como proxy el Índice de Precios Implícitos (IPI) del PIB a precios de mercado (Base $1993=100$ ) que elabora trimestralmente el Instituto Nacional de Estadística y Censos (INDEC). Y no se utilizó el cuestionado Índice de Precios al Consumidor (IPC) que elabora dicho organismo estatal, ni los que elaboran las consultoras privadas y entes de estadística provinciales, dado que miden la inflación de una canasta de bienes de consumo y no el de la totalidad de la economía como se necesita para el presente trabajo. Dicho índice oficial de precios al consumidor comenzó a ser polémico a partir de la intervención en el INDEC en enero de 2007, poniéndose foco de discusión en el relevamiento de los precios y no así en su metodología. El IPI, o también llamado deflactor del $\mathrm{PBI}$, muestra los precios implícitos del producto bruto de todos los bienes y servicios que se producen en el país, sin considerar los importados, de todos los sectores de la economía como precios de la construcción, inversión, servicios, etc. Se utilizó este indicador dado que es muy utilizado por economistas del sector público como los del BCRA, economistas privados y sindicatos, a partir que el IPC se transformó en una herramienta controvertida.

\section{Estudio del evento.}

Seguidamente, se realizó un simple estudio de evento, comparando tres períodos en relación al hecho disparador. El evento bajo estudio es el anuncio de la estatización y en la administración de los fondos de jubilaciones privados producida el 20 de octubre de 2008. Se buscó determinar si el evento en cuestión tuvo un efecto en la liquidez del mercado de acciones cotizantes, y si hizo disminuir el volumen mensual y diario operado de acuerdo con la gestión que realiza el FGS. Para analizar el mencionado evento en el período analizado se realizó una división comparando tres períodos:

a) pre-evento: período comprendido entre enero de 2005 y septiembre de 2008 .

b) evento per se: período comprendido entre octubre de 2008 y diciembre de 2008 ( $4^{\circ}$ trimestre de 2008).

c) post-evento: período comprendido entre enero de 2009 y diciembre de 2010. 
El período que comprende el evento per se, se tomó desde el mes de octubre de 2008 como inicio del evento, dado que el rumor y la noticia cobró fuerza cuando salió publicada el lunes 20 de octubre de 2008 en el diario Clarín y en Página 12 (Montenegro, 2011). Al día siguiente fue anunciado por el Poder Ejecutivo Nacional la estatización y la creación del sistema único de reparto.

Se eligieron las series de tiempo dado que esta técnica empírica utiliza series individuales y ha encontrado una adecuada aceptación en su aplicación en los estudios de eventos, diseñados para estudiar el comportamiento del precio de las acciones frente a eventos corporativos. Provee los medios para aislar el impacto de un evento sobre una variable relevante y determinar la significancia de tal impacto. Asimismo, ha provisto de valiosa información sobre el modo en que los operadores procesan la llegada de nueva información en las políticas de empresas, y si el evento en cuestión no haya sido anticipado por el mercado y que no haya provocado cambios importantes en la empresa o en la economía. Los métodos de serie de tiempo se utilizaron en trabajos empíricos de la eficiencia de mercado en sentido débil, revisando los rendimientos históricos. Bebczuk (2010) cita y recomienda los trabajos que utilizaron esta técnica, como el de Kothari y Warner (2008) y Campbell, Lo y Mac- Kinlay (1997). Otro ejemplo es el trabajo de Barraza (2009) que buscaba determinar si el evento de la estatización de los fondos previsionales privados afectó estadísticamente sobre los precios de las acciones, quien utilizó distintas ventanas de evento, entre otros objetivos buscados por dicha investigación.

\section{Exclusión del Efecto Precio de las acciones.}

Para sacar el efecto de la variación y volatilidad de los precios de las acciones, se utilizó como proxy la cantidad total de acciones negociadas de las empresas que integran el índice MERVAL. Lo que se pretendió mostrar es si la caída en los precios de los activos financieros a nivel mundial y local pudo haber afectado el volumen negociado en acciones. Asimismo, sí la recuperación de los precios de todos los activos financieros, luego de que la crisis empezara a convertirse en recuperación haya afectado al volumen negociado. Dicha variable, el volumen, puede haber sido afectada dado que contiene el producto del precio de las acciones por la cantidad negociada. Vale aclarar que el incremento de los precios pudo haber reducido la 
cantidad negociada, dado que con determinado monto a invertir se comprarían menos acciones.

Las acciones negociadas, como se mencionó, son del índice MERVAL que representa el valor de mercado en pesos de una cartera de acciones, seleccionadas de acuerdo con la participación en la cantidad de transacciones y el monto operado en la BCBA. En este caso se utilizaron las cantidades negociadas de las empresas que componían el referido índice en cada trimestre de la serie histórica del año 2005 al 2010.

La limitación que posee este análisis, es que la nómina de sociedades integrantes del mencionado índice y sus ponderaciones se actualizan trimestralmente, de acuerdo con la participación de cada especie en el mercado, durante los últimos seis meses. Asimismo, todas las acciones cotizantes son consideradas en forma decreciente, de acuerdo con su participación, hasta un acumulado del $80 \%$. Es decir, la corrección correspondiente a los cambios en la composición del índice MERVAL no se consideró, dado que no afectaría al disparador del planteo realizado.

\section{Indicador relacionado al nivel de actividad.}

Por último y con el fin de analizar el efecto que el crecimiento de la economía nacional pudo haber tenido sobre el mercado de acciones, se construyó un nuevo indicador que relacionó el volumen con el índice macroeconómico argentino que describe de mejor manera el producto nacional, es decir el PBI. Esto permitió estudiar el evento de las estatización de las AFJP y sus consecuencias en la liquidez, con mayor precisión. Para medir el nivel de actividad de la Argentina se utilizó el PBI a precios de mercado, a precios corrientes del INDEC, trimestral y anual para los años 2005-2010. Como así, los volúmenes negociados trimestralmente y anualmente a precios corrientes, para homogeneizar el análisis de las variable.

Para la utilización del PBI a precios corrientes expresados en millones de pesos sacados de la fuente INDEC, dado que presenta los resultados trimestrales anualizados, se realizó un ajuste para obtener el nivel de actividad trimestral. Esto significa que el organismo técnico cuando publica sus resultados, toma los valores de 
cada trimestre y los multiplican por cuatro. Por lo que para obtener los valores no anualizados, fueron divididos por cuatro y así obtener los respectivos valores trimestrales.

La utilización de un indicador del producto de la economía se fundamenta estadísticamente, en los resultados encontrados en investigaciones que relacionan el rendimiento del mercado de acciones y fundamentalmente el PBI. Artículos citados por Kawamura (2010) como el de Fama (1990) o Schwert (1990) muestran que una porción importante de los retornos de las acciones en la Bolsa de Nueva York pueden explicarse por variaciones futuras del producto de la economía. Ello demuestra que la performance de la Bolsa podría tomarse, al menos en el sentido de correlación estadística, como un indicador líder de la actividad económica. La gran depresión del año 1929, proveniente del crash bursátil, y la otra gran crisis iniciada en 2007, demuestran en términos informales la correlación de la variable elegida de la economía real y la de la actividad financiera.

Más precisamente, el indicador construido, para indicar la participación relativa del mercado de acciones sobre la economía Argentina, se utilizó la relación volumen nominal efectivo trimestral y anual negociado en acciones, con el concepto económico elegido que describe en nivel de actividad de Argentina. Este indicador es muy utilizado a nivel mundial para determinar la participación del mercado de capitales sobre la economía de los distintos países para establecer el grado de desarrollo del mencionado mercado.

Luego, para representar gráficamente la relación obtenida e interpretarla con las variables que la componen se realizó una estandarización o normalización de las mismas. Es decir que las variables Volumen trimestral negociado y $\mathrm{PBI}$ trimestral fueron divididas por su promedio para que tengan el mismo rango de valores y puedan ser comparables en su evolución y desarrollo. Las variables divididas por su promedio (Volumen negociado y PBI trimestral) se las denominó "Variable estandarizada". Las mismas se obtuvieron tomando el monto en pesos de la variable en cuestión del trimestre considerado, y se lo dividió por el monto promedio simple de la variable en cada caso. Matemáticamente se expresa de la siguiente manera la Variable estandarizada del volumen trimestral negociado (VEv), siendo: 


$$
V E V=\frac{\text { Volumentrimestralnegociado(t) }}{\text { promedioVolumentrimestralnegociado(I trim.2005-IV trim.2010) }}
$$

Y la expresión algebraica para la Variable estandarizada del Producto Bruto Interno a precios de mercado y corrientes (VEpbi), es la siguiente:

$$
V E p b i=\frac{\mathrm{PBI} \text { trimestral a p.m. } \mathrm{y} \text { precioscorrientes }(\mathrm{t})}{\text { promedioPBI trimestrala p.m.y precioscorrientes(I trim.2005-IV trim.2010) }}
$$

Por una cuestión de magnitudes comparables, también fue necesario que al indicador construido se realizara la división de cada valor de variable por su promedio a los efectos de compararlas.

\section{Capital Flotante (Free Float).}

Con el fin de analizar las limitaciones en el free float (capital flotante) que pudo provocar la gestión de la cartera del FGS en el mercado secundario de acciones, se realizaron distintas actividades.

En primer lugar, se analizó y comparó la legislación que regía para las AFJP, y los principales cambios introducidos para el accionar del FGS en este tipo de inversión elegible. Esto se hizo a partir de los boletines oficiales y de las actas del Consejo de Inversiones del FGS de la ANSES. Para este punto específico, se hizo un análisis lógico de los cambios normativos. Ciertamente, para determinar la gestión y las decisiones de compra-venta de acciones en el mercado secundario que pudo realizar en su portafolio el FGS, se analizaron todas las Actas emitidas por el Comité Ejecutivo del FGS. Es decir, se revisaron las cuarenta actas producidas desde el 05/02/2009, fecha que se emitió el Acta № 1 hasta fines del año 2010, más precisamente el 20/12/2010 cuando se elaboró el Acta № 40 (Ver detalle Anexo Tabla 7). También se estudiaron estos actos administrativos dado que contemplan todas las directrices generales de inversión que realizó el fondo durante el período de gestión.

Seguidamente, se comparó la composición del portafolio en acciones heredado por la ANSES, a partir del traspaso de los fondos previsionales privados administrados 
hasta ese momento por las AFJP (diciembre de 2008 hasta diciembre de 2010). Se utilizó como partida el Comunicado Estadístico $\mathrm{N}^{\circ} 22$ de la SAFJP de fecha 28/11/2008 (Ver Anexo Tabla 8 cartera de acciones argentinas ex AFJP) y se le sumó las acciones provenientes del FGS 1 de la ANSES creado por el Decreto 897/07 con la limitación presentada. Para toda esta parte, el método estadístico que se utilizó fue un análisis univariado de cada variable cuantitativa objeto de observación.

Luego, con la información recolectada del portal del FGS de la ANSES, se obtuvo el dato acerca de la participación en empresas privadas que poseía el mencionado organismo estatal. Con ello se consiguió en forma estimada el número de acciones que poseía a fines del año 2010, en las 41 empresas nacionales, al multiplicar ese valor relativo por el capital social de la empresa.

En algunos casos, ello fue comprobado con la información trimestral y anual que deben presentar las empresas luego de aprobar sus estados contables, recolectada de la CNV para dar cumplimiento a los Artículos 62 y 63 in fine del Reglamento de Cotización de la BCBA, acerca de la información contable complementaria a presentar por las firmas autorizadas a cotizar. Es decir, se realizó un seguimiento de la evolución de la tenencia de la ANSES en dichas empresas en el tiempo bajo estudio. Con ello se hizo un estudio de las distintas empresas en las que se posee mayor participación accionaria, y a qué sectores de la economía nacional pertenecen. Posteriormente se determinó para el mismo período, la tenencia accionaria del/os grupo/s controlante/s de las empresas argentinas donde el FGS posee participación. Y se calculó el porcentaje del total del capital social que está en manos del grupo/s controlante/s.

Con toda esta información recabada, sirvió para determinar y responder al meollo de la cuestión de este apartado. Por otro lado, se estimó el capital flotante de las 41 empresas, restando del capital social lo que está en poder del grupo/s controlante/s. Una vez, obtenido estos porcentajes de free float, se restó la participación relativa de la ANSES, para llegar a lo llamado free float extendido o flotación extendida.

Por último, para avanzar en esta temática se estimó los votos que poseían el ANSES en las empresas privadas y el grupo/s controlante/s en las Asambleas del órgano 
político de las mismas a fines del año 2010.

\section{Resultados de la Investigación}

\subsection{Liquidez y Volumen}

\section{Evolución del volumen operado de acciones que cotizan en la BCBA}

Para analizar la liquidez en el mercado de acciones del Mercado de Valores de Buenos Aires se estudió el volumen comercializado en este mercado secundario. El mismo se realizó en diversas etapas como se precisó precedentemente, que se exponen a continuación.

\section{Monto operado anual en el MERVAL en términos nominales.}

En la Figura 13 se observan series de datos referentes al monto nominal operado en forma anual entre el período del año 2005 y 2010 del mercado de acciones en el MERVAL de Argentina. La misma mide el volumen anual de comercialización de acciones operados en el Mercado de Valores de Buenos Aires.

Monto negociado anual

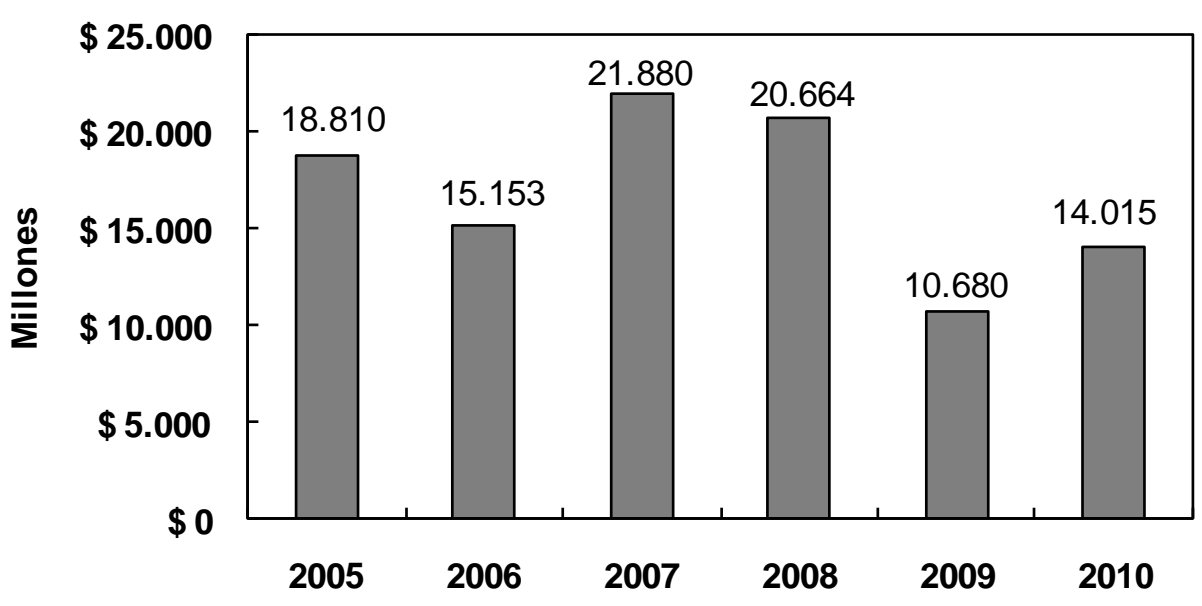

Fuente: Elaboración propia en base a datos de Bolsar de la BCBA.

Figura 13: Monto anual negociado en términos nominales (en pesos) (2005-2010) en el MERVAL (Ver detalle en el Anexo Tabla 2).

En el año 2005, que es punto de partida del estudio, se negociaron casi $\$ 19.000$ millones en acciones. Se parte de este año por ser el año del exitoso canje de la deuda en default de Argentina. Cayendo en el año 2006 en un $-19,44 \%$ el volumen anual transado, en comparación al año precedente. Al año siguiente se tuvo una 
fuerte recuperación superando los $\$ 21.800$ millones negociados en estos activos financieros durante todo el año 2007.

Debe considerarse en este análisis la crisis ocurrida en los Estados Unidos de América en el año 2008 como consecuencia de las hipotecas subprime o de baja calificación que terminó de afectar a todo el mundo en mayor o menor medida. Por lo que se puede observar en el año 2008 una caída en el volumen operado en - 5,56\% respecto al año 2007, donde se negociaron $\$ 20.663 .995 .891$ en acciones. A la crisis externa, exógena al mercado argentino se le adicionó el acontecimiento doméstico ocurrido el 20 de octubre cuando el gobierno nacional argentino anunció su intención de transferir los activos administrados hasta ese entonces por las AFJP a la ANSES. Según informes del IAMC esto generó en un comienzo un nuevo aumento de la incertidumbre, llevando la volatilidad de los índices bursátiles domésticos a niveles de más del triple de los observados durante el año 2008, y similares a los registrados en el año $2002^{16}$.

Seguidamente se puede observar cómo cayó drásticamente en el año 2009, a casi la mitad del volumen operado el año previo, con una reducción en el monto negociado cercano a los \$ 10.000 millones. Ello pudo ser afectado presumiblemente por la recesión mundial y local, y la salida de los mayores inversores institucionales del país. Durante el año 2010 el volumen negociado en acciones se recuperó llegando a valores cercanos a los $\$ 14.000$ millones, lo que implicó un aumento de $31,23 \%$ respecto de 2009. Esta recuperación se pudo haber producido parcialmente, por la recuperación de los precios de todos los activos financieros a nivel global y local.

Como hecho relevante, el Índice Merval registró durante ese año nuevos récordes históricos para su medición en pesos. El camino en alza del Índice Merval también fue alimentado por el anuncio del Gobierno en torno a las negociaciones con el Club de Paris para reestructurar la deuda pendiente con ese organismo. El Merval en sus picos de alza, y medido en dólares, se acercó muchísimo al máximo histórico del 1 de junio de 1992.

\footnotetext{
16 Ver Anuario Bursátil 2008 del IAMC, en la Página 24 a 29. http://www.iamc.sba.com.ar/Imgs/Dyn/ArchivosLenguajes/5106-2010-4-7T15-33-0.pdf
} 


\section{Monto nominal operado mensualmente en el MERVAL.}

Para avanzar y realizar un análisis más profundo se analizó el monto operado mensual en pesos en el mercado de acciones argentino. A continuación se expone la Figura 14 con los montos operados mensualmente entre los años 2005 y 2010.

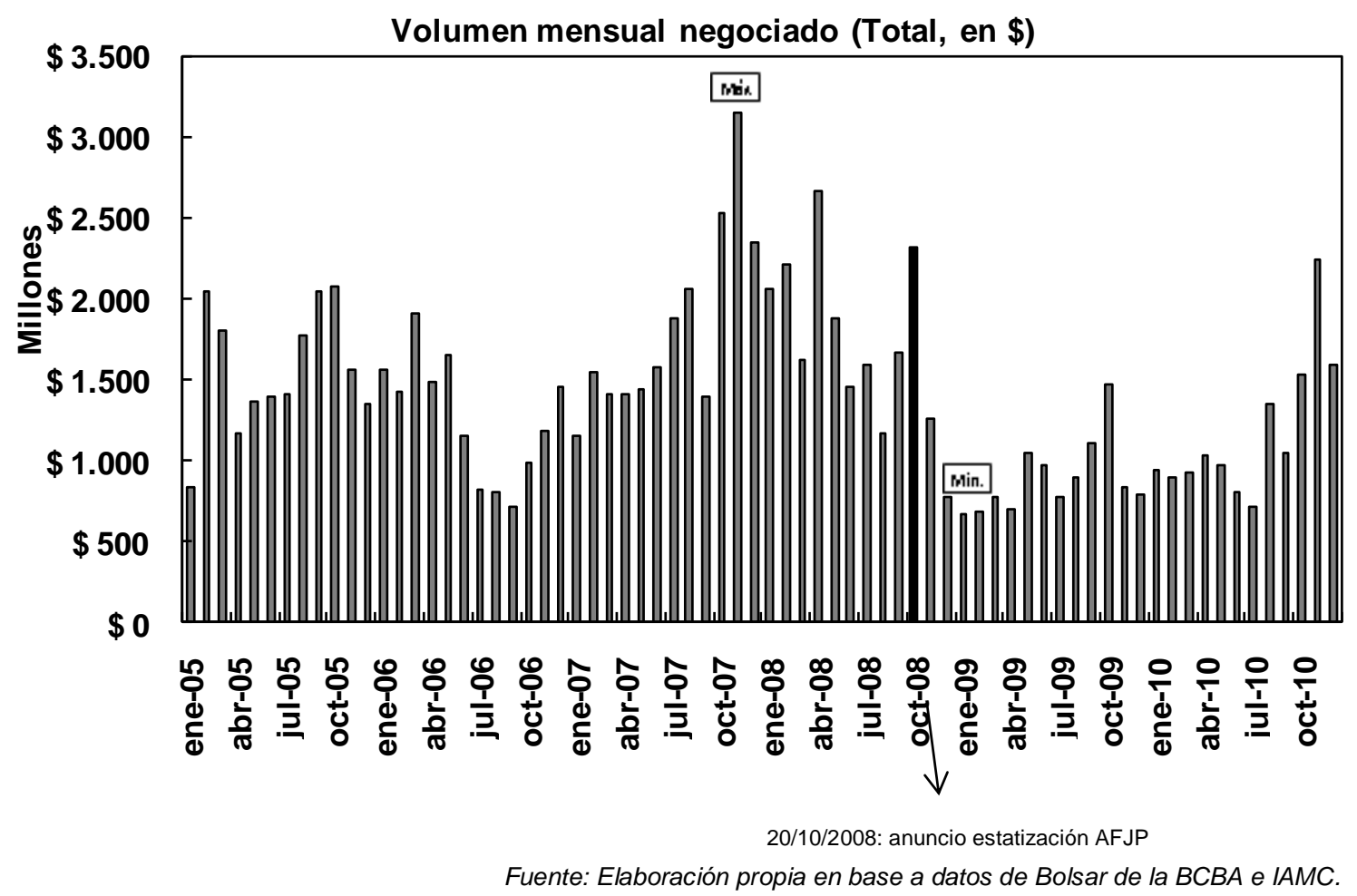

Figura 14: Monto mensual negociado (en pesos) (período 2005-2010) en el MERVAL. La flecha indica el día del anuncio de la estatización de los fondos previsionales privados.

En el año 2005, luego del canje de deuda, que tuvo una quita sin precedentes del $70 \%$ del capital y una adhesión de más del $76 \%$ entre las características más importantes, el mercado de acciones comenzó a tener una senda en el crecimiento de su volumen negociado. A fines de ese año fue el anuncio del Gobierno Nacional de la cancelación de la deuda pública con el Fondo Monetario Internacional (FMI) con reservas del BCRA. Seguidamente, a comienzos del año 2006 se mantuvo el sendero alcista, con un contexto internacional acompañando, dada las bajas tasas de los bonos del Tesoro de EE.UU. a 10 años, y un mercado local ayudado por la cancelación de la deuda con el FMl y los buenos balances presentados por las empresas locales. Ya a partir de mayo de 2006 comienza a caer el volumen negociado en forma mensual, llegando a un piso en el mes de septiembre de dicho 
año. Ello pudo ser debido a la caída de los principales precios de los commodities, y los temores por estanflación que surgía en EE.UU.

A partir de allí comienza el rally alcista en la tendencia de los volúmenes mensuales operados, llegando a su pico en el mes de noviembre de 2007, acompañando la burbuja financiera que se venía gestando a nivel mundial, y el buen momento económico del país. Todo ello a pesar de los efectos negativos que aparecieron ese año para el país, como las dudas que empezaron a surgir en el IPC del INDEC y el empeoramiento de la situación del mercado inmobiliario de EE.UU. Por otro lado la autoridad monetaria, el BCRA, a comienzos del último trimestre aplicó un conjunto de medidas para evitar cualquier falta de liquidez en el sistema financiero.

Con la crisis subprime desembarcada en el año 2007, sus consecuencias se hicieron más pronunciadas a partir del 14 de septiembre de 2008 con la caída del cuarto mayor banco de inversión de Wall Street de ese entonces, llamado Lehman Brothers. La premisa de que era demasiado grande para caer, quedó atrás y no hubo un rescate por parte del sistema financiero de EEUU como se había hecho con distintos bancos y financieras, para evitar un efecto sistémico en el mercado. Con ello, el Departamento del Tesoro de EE.UU. quiso limitar la dispersión de la crisis y lo dejó quebrar negando el respaldo financiero que necesitaban los bancos. Como se mencionó fue muy distinto a lo actuado con el banco Bear Stearns, cuando JP Morgan salió a su rescate. Por otra parte, en el caso de las agencias hipotecarias Fannie Mae y Freddie Mac, los reguladores no tenían otra salida que ponerlas bajo su custodia por ser su capital en parte del sector público y el contagio que podían tener sobre el conjunto del sistema financiero.

Asimismo, se puede observar en la Figura 14 como a partir del mes de octubre del año 2008 cae el volumen operado por mes abruptamente. Luego de octubre del año en cuestión, donde se operaron más de $\$ 2.300$ millones por el efecto de la estatización de los fondos previsionales, donde hubo una ola vendedora de acciones; el volumen cayó en noviembre de ese año un $46 \%$ respecto del mes anterior. Y en diciembre del citado año, cae un $38 \%$ el volumen comparado con el mes de noviembre. En estos últimos meses del año 2008 y los primeros meses del año 2009 se comienza a notar la ausencia de los mayores inversores institucionales donde se 
les había subrogado todos sus derechos y administrar fondos de terceros. Por otra parte, el año 2008 en sus primeros meses comenzó en lo económico y político en Argentina con un conflicto que duró varios meses entre el Gobierno Nacional y todo el sector agropecuario del país repercutiendo en la actividad económica-financiera y generando mayor incertidumbre.

Enero y Febrero del año 2009 comienza con buenos anuncios en temas de la deuda soberana de Argentina, dado que el canje de préstamos garantizados a nivel local tuvo una aceptación cercana al $100 \%$, dado que la mayoría de su tenencia estaba en la cartera que administraban las ex AFJP, y que a partir de la estatización estaban bajo la órbita de la ANSES. Por su lado, el resultado del canje de préstamos garantizados a nivel internacional tuvo una aceptación cercana al $80 \%$. En estos meses se vio reflejado un bajísimo nivel de volumen negociado en acciones, como ya se apreció en la Figura 14 ut supra.

A pesar de la recuperación observada hacia fines de octubre del año 2009, el mercado volvió a caer en noviembre. En Diciembre de ese año, se puede destacar el anuncio de la creación del fondo de reservas excedentes del Banco Central para garantizar el pago de las obligaciones con tenedores de títulos privados y organismos internacionales para dar previsibilidad, y allanar el acercamiento del país al financiamiento en los mercados externos. Esta decisión traería un efecto en lo institucional para el país, por los problemas políticos suscitados entrados el año 2010 entre el presidente de la entidad monetaria argentina y el ejecutivo nacional.

Luego de que pasara más de un año de la recuperación en los montos negociados en el año 2009, en agosto de 2010 comienza a incrementarse el volumen transado en forma mensual, superando en todos los meses más de mil millones de pesos en operaciones. Llegando al nivel más alto de negociación en el mes de noviembre de 2010, desde octubre de 2008.

Como puntos importantes, durante el período analizado se registró un máximo operado en el mes de noviembre de 2007, donde se negociaron $\$ 3.150 .778 .287,35$. En contrapartida, el mínimo volumen se registró en el mes de enero de 2009, donde se operaron en acciones $\$ 666.949 .706$,8 ya cuando las AFJP no podían realizar más 
inversiones en el mercado. Cabe mencionar que, con excepción del mes de octubre, todos los meses del segundo semestre del año 2008 presentaron un volumen promedio diario inferior al promedio anual. La excepción de octubre como se mencionó, pudo estar relacionada con una fuerte corriente vendedora por el efecto como se dijo, entre otros posibles, de la modificación del sistema previsional dado por la estatización de los fondos administrados por las AFJP. Siempre asumiendo que el evento bajo estudio, haya sido el más relevante en dicho mes, y considerándolo como un efecto negativo en lo institucional que pudo provocar la noticia en el país, y otros acontecimientos que pudieran haber ocurrido en dicho lapso.

En los Estados Unidos de América, luego de la Gran Recesión 2008-09 que tuvo su epicentro por esas tierras, para contribuir a la recuperación económica de ese país como global y dar soporte a los activos financieros, se implementó el plan de compra de activos tóxicos al sector financiero denominado Quantitive Easing (QE1) o relajamiento monetario por parte de la Reserva Federal (FED) de EE.UU.

En el mercado de acciones de Argentina, el año 2010 muestra una recuperación a partir del tercer trimestre como ya se mencionó, luego de que se despejaran en parte las dudas a nivel mundial de la ruptura de la Unión Europea. A nivel local luego de la exitosa reapertura del canje de la deuda que continuaba en default luego del canje 2005, permitió la suba de la calificación soberana por parte de algunas calificadoras de riesgo. Como así, la presentación de balances con resultados favorables de las empresas, que trajeron significativas subas en las acciones argentinas, principalmente del sector bancario.

Por otro lado, la reafirmación en noviembre de 2010 por la FED de su política de expansión monetaria a través de la recompra de títulos de deuda. La FED implementó esta medida de flexibilización monetaria denominada Quantitive Easing 2 (QE2) y fue una continuación del plan QE1. Con el mismo se buscó a través de la inyección monetaria combinada con bajas tasa de interés, un incremento en el consumo y la inversión, y por efecto derrame en un resurgimiento de la actividad económica norteamericana en general, siempre monitoreando la inflación en su economía. 
Los bonos del Tesoro de EEUU considerados libre de riesgo, durante este período analizado nunca dejaron de ser los activos seguros por excelencia, a pesor de ser el lugar donde se originó la crisis. Frente a este escenario de subas de retornos y menores riesgos, los países emergentes se vieron perjudicados en parte ya que los inversores se volcaron hacia activos libres de riesgo, dado que se produce el llamado fly to quality (vuelo a la calidad). Es importante lo que pasa en los mercados líderes a nivel mundial y en América, por el alto nivel de correlación existente entre los rendimientos de sus índices bursátiles. Como sería la correlación positiva entre el MERVAL, con los índices de EE.UU. como el Standard \& Poor's 500, el Dow Jones Industrial Average y el NASDAQ (National Association of Securities Dealer Automated Quotation).

Como se anticipó, la suba de la calificación de riesgo de Argentina otorgada por las agencias internacionales, y la aprobación en Estados Unidos de la reforma del sistema financiero para evitar nuevas crisis como la ocurrida en 2008, actuaron en forma positiva sobre las acciones, luego de desembarcar precedentemente en los títulos públicos. Así, el 20 de septiembre de 2010, el Índice Merval registró un nuevo récord histórico para la medición en pesos llegando a los 2.533.2 puntos. El fallecimiento del presidente Kirchner generó expectativas sobre posibles cambios en lo político y en lo económico transfiriendo esa expectativa al mercado de acciones, principalmente en aquellas empresas relacionadas con los servicios públicos que poseen congelamiento de tarifas. El anuncio del Gobierno Nacional en torno a las negociaciones con el Club de Paris para reestructurar la deuda pendiente con ese organismo, fue otro de los factores que pudo haber ayudado al alza del volumen negociado.

Asimismo, en la Figura 14 se muestra la recuperación mencionada en el año 2010, este incremento en el volumen comercializado se movió en parte gracias a la recuperación en los precios de los activos, y la alta liquidez internacional luego de la crisis internacional asociado al flujo de capitales. Vale mencionar, que pese a las mejoras avizoradas en el año 2010, falta consolidarse a través de los meses para volver a los niveles precedentes a la crisis del 2008. 
Como cierre, se puede establecer parcialmente que en la serie observada, la caída en el volumen negociado en acciones es contemporánea a la eliminación del sistema que participaban las AFJP.

\section{Promedios diarios negociados en el MERVAL}

A continuación se realizó un nuevo análisis de la liquidez de este mercado accionario, por lo que se estudió el volumen promedio diario negociado en el mismo período. En la Figura 15 se observa el promedio diario operado entre el año 2005 y 2010 en acciones en el MERVAL de Buenos Aires.

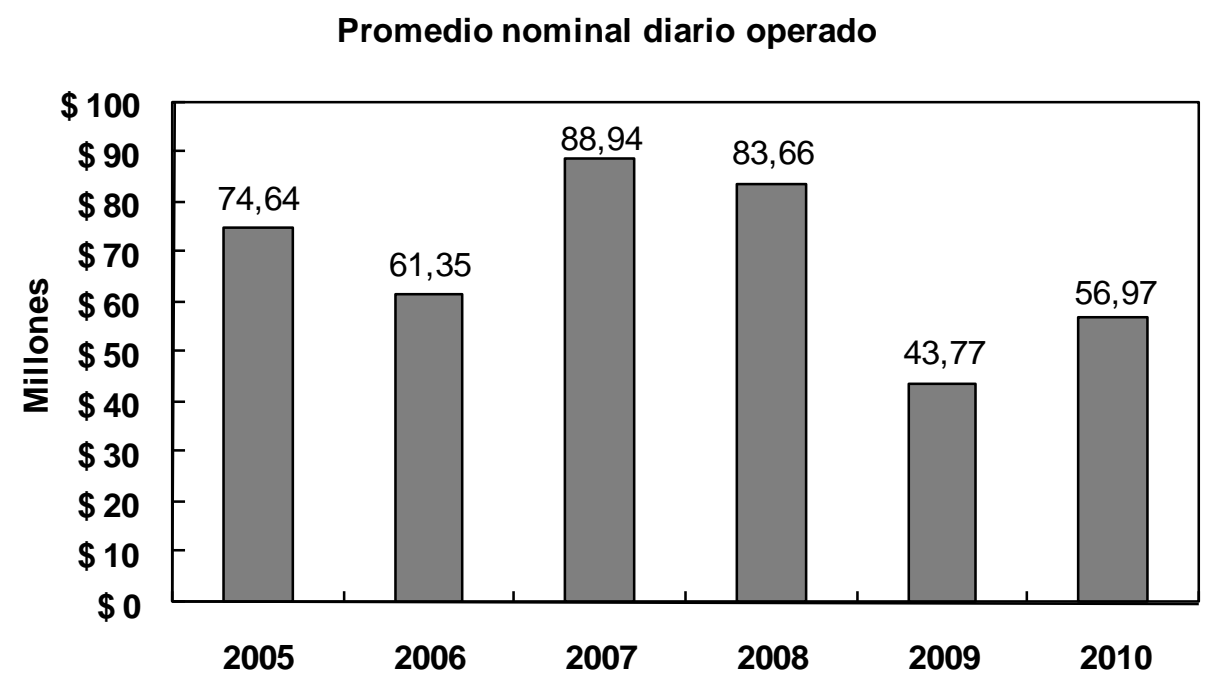

Fuente: Elaboración propia en base a datos de Bolsar de la BCBA.

Figura 15: Monto nominal promedio diario negociado (en pesos) (Período 2005-2010) en el MERVAL. (Ver detalle en el Anexo Tabla 3).

En términos generales, se observa cómo la liquidez en el mercado de acciones cae en el año 2009 fuertemente. Asimismo, se refleja que el año con mayor liquidez del período analizado fue el año 2007, luego del afianzamiento del mercado local luego del canje de deuda soberana. La tendencia de la evolución de los montos negociados como promedio diario, es muy similar a lo visto en la tendencia de lo negociado anualmente.

En términos particulares, durante el año 2005 se negoció en promedio $\$ 74,64$ millones en 252 ruedas. El año 2006 trajo un volumen de operación inferior en un $17,81 \%$ al año anterior, negociándose más de \$ 61,35 millones. A partir del año 2007 se incrementó un $44,98 \%$, el promedio diario operado en acciones con respecto al 
año precedente. El volumen promedio diario negociado durante el año 2008, alcanzó los $\$ 83,65$ millones, considerando un total de 247 ruedas bursátiles. Este dato fue un $5,94 \%$ inferior a los $\$ 88,94$ millones de 2007 . En el promedio diario como se demuestra en la figura, a partir del año 2008 comienza a caer el volumen negociado. Acentuado con la caída estrepitosa de un valor cercano a $48 \%$ en el año 2009, no llegando a los \$ 44 millones diarios en los 244 días operados. Esto demuestra la importante caída en la negociación de acciones producidas en el MERVAL.

En cuanto al volumen promedio diario de acciones negociado durante el año 2010, alcanzó casi los $\$ 57$ millones, considerando un total de 246 ruedas bursátiles. Este valor implicó un aumento del 30,16\% respecto de los casi $\$ 44$ millones de 2009, viéndose un recupero interesante y alentador en este mercado.

\section{Monto nominal anual y promedio diario negociado en el MERVAL en dólares.}

A continuación se expone en la Figura 16 lo analizado precedentemente, pero valorizados los montos nominales negociados en dólares de los Estados Unidos de América. Como se precisó, los tipos de cambio utilizados son de cierre del respectivo año en cuestión, y de acuerdo con el valor implícito de la serie histórica de operaciones de la BCBA. Se puede apreciar una mayor caída en el monto anual operado medido en dólares en un 56,43\% desde el año 2008 al 2009, mayor al medido en pesos argentinos. Esto se puede explicar en parte por la devaluación que tuvo la moneda argentina con respecto al dólar, pasando de \$3,158 por cada USD a fines de 2008 a $\$ 3,746$ a fines de 2009 , es decir un aumento del $18,63 \%$. Por otro lado, se observa la mayor variación en dólares en el promedio diario cuando se estima la caída cercana al 56\% entre el año 2008 y 2009.

Por lo visto e inferido, en términos generales las tendencias observadas son las mismas que las observadas en pesos, salvo las mayores acentuaciones producidas por la mayor volatilidad presentada. 

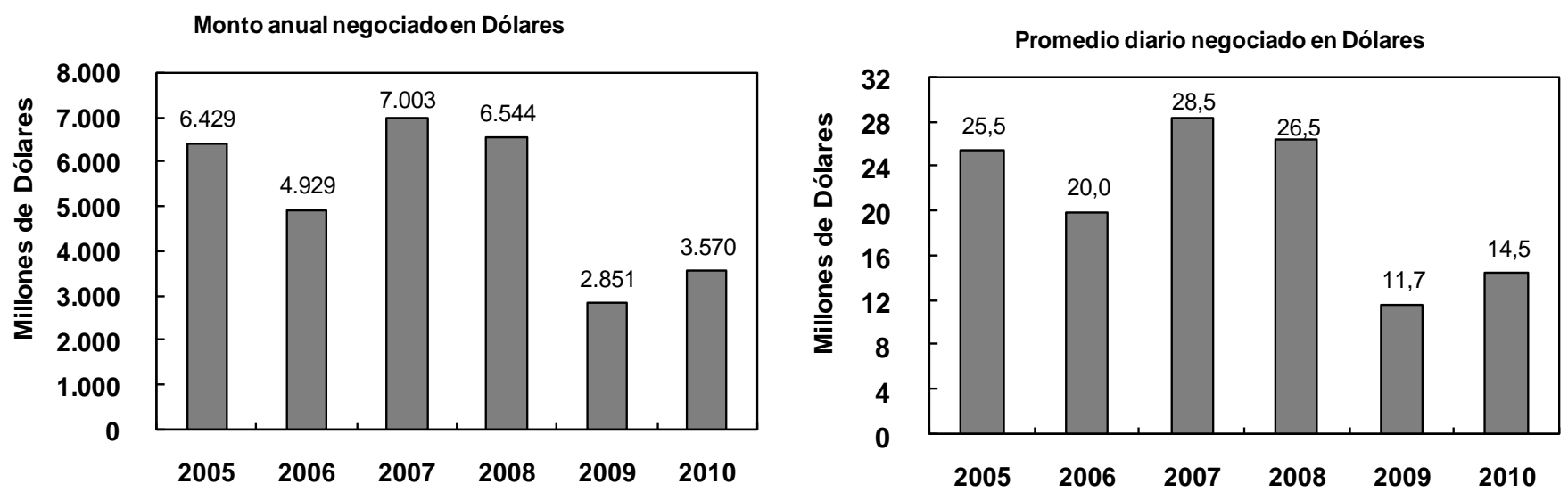

Fuente: Elaboración propia en base a datos de Bolsar de la BCBA.

Figura 16: Monto anual negociado (en dólares) y promedio diario negociado (en dólares) (Período 2005-2010) en el MERVAL. (Ver detalle en el Anexo Tabla 4).

\section{Monto operado anual en pesos en el MERVAL en términos reales.}

Para sacar el efecto que genera la inflación en el monto negociado, se realizó una estimación del monto transado en términos reales. En la Figura 17 que se adjunta a continuación, se puede observar el IPI de los años bajo estudio y los montos negociados en valores homogéneos.

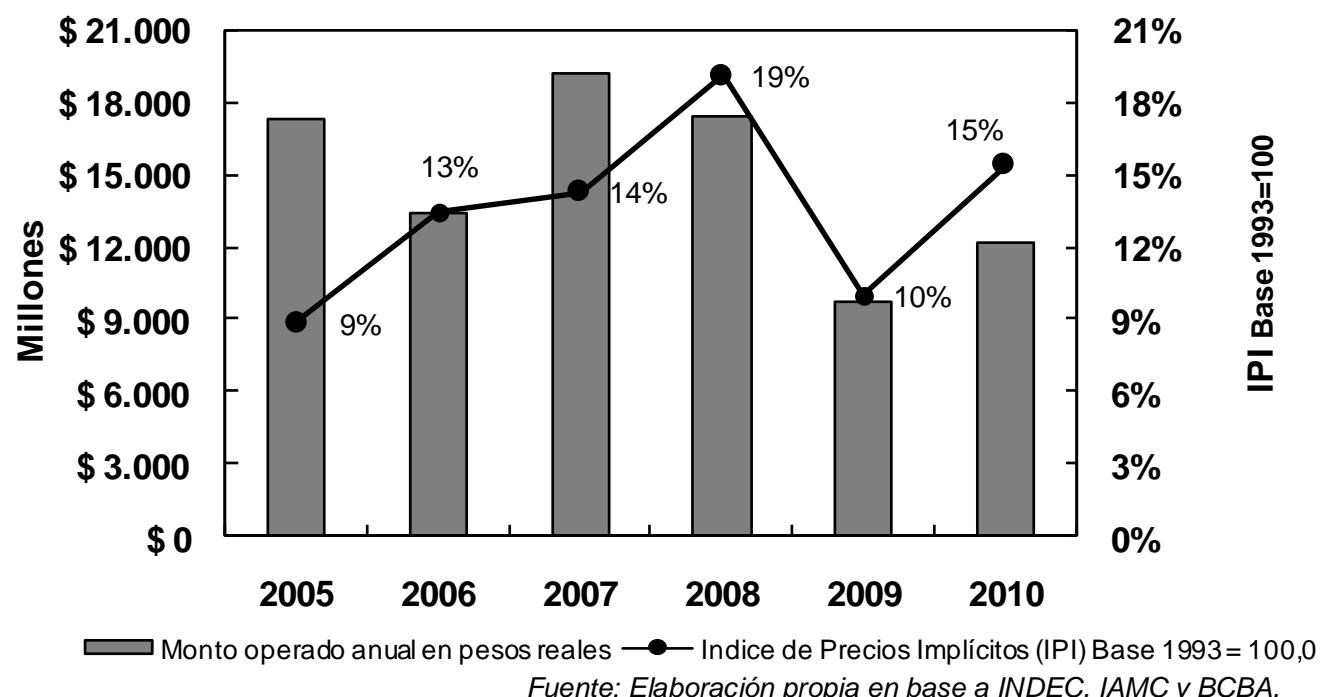

Figura 17: Monto anual negociado en términos reales (en pesos) (Periodo 2005-2010) en el MERVAL e Índices de Precios Implícitos del PBI (Base $1993=100)$ c.f. y a precios corrientes. (Ver detalle en el Anexo Tabla 5).

En el año 2005, en términos reales se negociaron $\$ 17.282$ millones, con un deflactor del PBI para ese año del 8,84\%. Cayó el volumen real anual un $22,70 \%$ en el año 2006 con respecto al año precedente. La recuperación del 2007 en el monto real transado fue de más del $43 \%$, con un índice de precios implícito del $14,26 \%$. En 
cambio en el año 2008 se evidencia una disminución del 9,37\% en lo negociado, notándose un efecto inflacionario en toda la economía del 19,07\% anual.

Ya en el año 2009, con la recesión mundial y local instalada, que comenzó en el mercado financiero y se trasladó a la economía real, se evidencia la abrupta caída en la negociación en términos reales superando los $\$ 9.700$ millones, mostrando una disminución en términos relativos del 44,04\%. La desaceleración de la economía para ese año demuestra, la amortiguación en la evolución de la inflación no llegando al $10 \%$ anual, mostrando una disminución a la presión alcista sobre los precios. Como ya se ha demostrado en los distintos análisis, acá también en el año 2010 el monto real operado se incrementa, en este caso un $25,08 \%$ comparado al año previo, no llegando a superar la cifra de $\$ 12.200$ millones negociado en el año, a pesar de tener una inflación de dos dígitos.

De acuerdo con lo observado, el análisis realizado en términos reales arriba a las mismas conclusiones que en términos nominales, mostrando una variación negativa más moderada en el año 2009, pero más pronunciada en año 2008, que son los años donde se pone mayor énfasis en el enfoque. 


\section{Estudio de evento.}

En la Figura 18 se puede observar los tres períodos analizados, y ver la evolución en el producido en las acciones transadas en la BCBA.

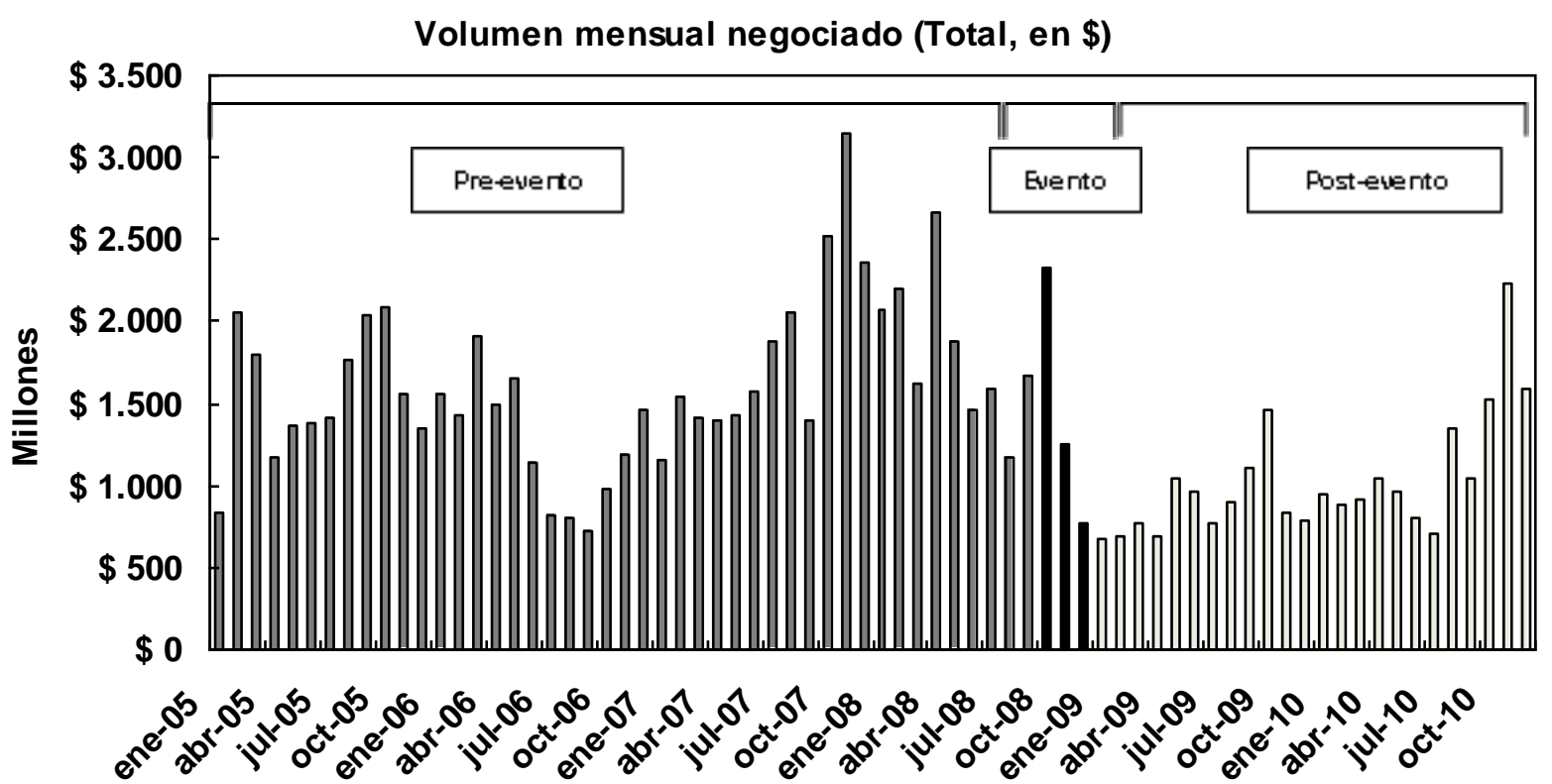

Fuente: Elaboración propia en base a datos de Bolsar de la BCBA

Figura 18: Monto mensual negociado (en pesos) (Período 2005-2010) en el MERVAL dividido y agrupado en tres períodos: Pre-evento, Evento y Post-evento.

En el Pre-evento, que es el período comprendido entre enero de 2005 y septiembre de 2008, hubo 45 meses en los cuales se transaron acciones en el mercado. El volumen promedio mensual operado fue poco más de $\$ 1.600$ millones. En el cuarto trimestre del año 2008, que es el período del evento, se negociaron en promedio \$ 1.450 millones, mostrando una caída de casi $10 \%$ en el volumen operado con respecto al promedio mensual del Pre-evento. Por último, en el denominado Postevento se negociaron valores cercanos a los $\$ 1.029$ millones en promedio mensual, cayendo un $29,04 \%$ con respecto al evento propiamente dicho. Esto muestra la disminución en lo negociado en cada uno de los meses luego de lo ocurrido en el cuarto trimestre de 2008.

Si se toma la variación total, entre el Post-evento y el Pre-evento, el volumen promedio mensual cayó en un $35,83 \%$. Esto demuestra y ratifica la caída en la liquidez que sufrió el mercado de acciones luego del evento bajo estudio. La variación en términos absolutos llegó a cifras cercanas a los $\$ 600$ millones, en lo que se dejó de transar en el mercado secundario en acciones, en forma mensual. 
Asimismo, se realizó el mismo análisis que se confeccionó en forma mensual pero como promedio diario. Durante el Pre-evento se negoció en forma diaria más de $\$ 77,42$ millones. Durante el Evento el promedio cayó a $\$ 72,50$ millones, en términos relativos un $-6,35 \%$. Y en el Post-evento, el promedio diario transado fue por arriba de $\$ 50,39$ millones, con una caída del $30,49 \%$, mostrando la caída en el volumen negociado luego de la intervención estatal. Lo significativo es que luego del evento estudiado, el volumen negociado en forma diaria cayó en más de \$27 millones comparado a lo que negociaba en forma diaria previo a octubre de 2008 como se refleja en la Tabla 6.

Tabla 6: Meses y días negociados en los períodos, monto total negociado en las etapas (en pesos) en el MERVAL, promedio mensual y diario negociado (en pesos) en las etapas y sus variaciones (\%).

\begin{tabular}{|c|r|r|r|}
\hline Concepto & \multicolumn{1}{|c|}{ Pre-evento } & \multicolumn{1}{c|}{ Evento } & \multicolumn{1}{c|}{ Post-evento } \\
\hline Meses operados & 45 & 3 & 24 \\
\hline Días operados & 932 & 60 & 490 \\
\hline Monto Operado en la etapa & $\$ 72.156 .481 .511$ & $\$ 4.350 .239 .902$ & $\$ 24.694 .956 .803$ \\
\hline Promedio mensual Operado & $\$ 1.603 .477 .367$ & $\$ 1.450 .079 .967$ & $\$ 1.028 .956 .533$ \\
\hline Var. \% período anterior & $\mathrm{N} / \mathrm{A}$ & $-9,57 \%$ & $-29,04 \%$ \\
\hline Var. \% período total & $\mathrm{N} / \mathrm{A}$ & $\mathrm{N} / \mathrm{A}$ & $-35,83 \%$ \\
\hline Promedio diario Operado & $\$ 77.421 .118$ & $\$ 72.503 .998$ & $\$ 50.397 .871$ \\
\hline Var. \% período anterior & $\mathrm{N} / \mathrm{A}$ & $-6,35 \%$ & $-30,49 \%$ \\
\hline Var. \% período total & $\mathrm{N} / \mathrm{A}$ & $\mathrm{N} / \mathrm{A}$ & $-34,90 \%$ \\
\hline
\end{tabular}

Fuente: Elaboración propia en base a datos de Bolsar de la BCBA

Evaluando todo el período, el volumen diario operado bajó casi un $35 \%$, afirmando la mayor falta de liquidez en el mercado de acciones de Argentina luego de esta decisión por parte del estado.

\section{Exclusión del Efecto Precio de las acciones.}

Como se puede observar en la Figura 19 que se acompaña, se detecta cómo cae la cantidad de acciones transadas ya sea en cantidades anuales como en el promedio diario en el MERVAL, desde el año 2005 hacia el año 2006. En términos porcentuales la caída en ambos rubros supera el $36 \%$ desde un año hacia al otro.

Luego de dicha disminución, el mercado accionario mejora los dos años siguientes, aumentando el año 2007 más del 35\% en las cantidades negociadas y el $43,70 \%$ el año 2008, siempre comparado con sus años previos respectivamente. En el año 2009, se observa la fuerte caída en las cantidades negociadas en forma anual y en el 
promedio diario, mostrando en términos relativos un descenso de más del $50 \%$. Es decir, en forma diaria y anual se operó la mitad en cantidades de lo que se venía negociando.
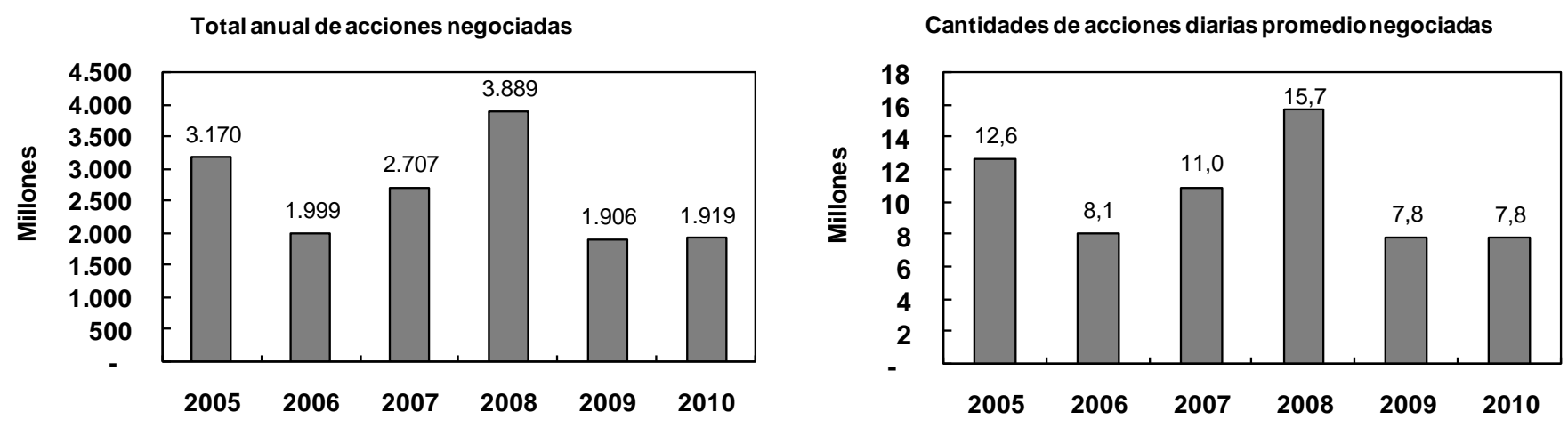

Fuente: Elaboración propia en base a datos de Bloomberg en base a $B C B A$

Figura 19: Cantidad anual negociadas de acciones y promedio diario negociado (Período 2005-2010) en el MERVAL. (Ver detalle en el Anexo Tabla 6).

En el año 2010, se puede observar cómo se estabiliza el número de acciones transadas en el mercado secundario ya sea a nivel anual, como en el promedio diario. En términos anuales se negociaron una cifra similar al año anterior llegando a más de 1.900 millones, y el promedio diario también se estabilizó en las 7.800.000 acciones transadas.

Ello puede explicar y reflejar parcialmente, al sacar el efecto de las variaciones en los precios de las acciones, cómo la salida de los mayores inversores institucionales afectó en la cantidad de acciones negociadas. Los resultados obtenidos muestran las mismas conclusiones a las arribadas en el análisis de los volúmenes en sus distintas variantes, es decir, las consecuencias que provocó en la liquidez del mercado de acciones el pasaje de la gestión de la cartera de acciones hacia el FGS. La diferenciación en este caso fue que a partir del año 2009 se negocia la mitad en cantidad de acciones en el MERVAL de lo que se negociaba en el año 2008, y no llegando a los niveles del año 2006 que son los mínimos del período bajo análisis.

\section{Indicador relacionado al nivel de actividad.}

Para terminar, se exponen los resultados obtenidos en la construcción del indicador, que relaciona los volúmenes negociados con el nivel de actividad local. 
Indicador del volumen negociado en relación al producto.

En la Tabla 7 se expone la construcción del indicador que contiene el volumen comercializado en moneda corriente en relación al PBI a precios de mercado y corriente, en términos anuales y trimestrales. Se puede observar como el ratio anual cae a través del tiempo, comenzando en $3,54 \%$ del PBI en 2005 y terminando en valores inferiores al 1\% del PBI en el año 2010. Si se sigue el desarrollo trimestral de lo negociado en relación al producto trimestral, se puede identificar cómo va cayendo año a año, en sus respectivos períodos la mencionada relación.

En el año 2006 el indicador toma un valor de 2,32\%, mostrando una caída respecto al año anterior del $34,52 \%$. Al año siguiente se observa una recuperación en la relación del 16,31\% llegando lo negociado al 2,69\% sobre el PBI. Ya entrada la crisis a partir del tercer trimestre en el año 2008 , cae un casi $26 \%$ el ratio anual, llegando al $2 \%$. A partir del primer trimestre del año 2009, el indicador trimestral comienza a establecerse en valores mínimos superando en pocos trimestres el $1 \%$ del volumen comercializado sobre el PBI trimestral, debido posiblemente a la salida de la operatoria de las AFJP en el mercado.

La peor variación anual en términos relativos del índice construido se dio en el año 2009 , donde tuvo una performance negativa de más del 53\%, llegando a valores de 0,93\% sobre el PBI anual. Al año siguiente, en 2010 hubo una recuperación del $4,19 \%$ en el indicador, pero mostrando valores muy lejanos a los encontrados al inicio del análisis, no superando el valor del $1 \%$. 
Tabla 7: Indicador volumen trimestral y anual de acciones negociado en el MERVAL (en pesos) sobre PBI trimestral y anual a precios de mercado (en pesos) (2005-2010), y sus variaciones interanuales (\%).

\begin{tabular}{|c|c|c|c|c|c|}
\hline Año & Trimestre & $\begin{array}{c}\text { Volumen } \\
\text { Efectivo } \\
\text { negociado } \\
\text { (en millones \$) }\end{array}$ & $\begin{array}{c}\text { PBI a precios de } \\
\text { mercado (Millones de } \\
\$ \text {, a precios corrientes) }\end{array}$ & $\begin{array}{c}\text { Volumen } \\
\text { Comercializado } \\
\text { en relación al } \\
\text { PBI (en \%) }\end{array}$ & $\begin{array}{l}\text { Var. \% anual } \\
\text { Volumen/PBI }\end{array}$ \\
\hline \multirow{5}{*}{2005} & & $18.810,23$ & $531.938,72$ & $3,54 \%$ & \multirow[t]{5}{*}{ N/A } \\
\hline & I & $4.686,44$ & $114.190,93$ & $4,10 \%$ & \\
\hline & II & $3.915,63$ & $138.102,96$ & $2,84 \%$ & \\
\hline & III & $5.225,26$ & $136.057,04$ & $3,84 \%$ & \\
\hline & IV & $4.982,90$ & $143.587,79$ & $3,47 \%$ & \\
\hline \multirow{5}{*}{2006} & & $15.152,71$ & $654.438,99$ & $2,32 \%$ & \multirow[t]{5}{*}{$-34,52 \%$} \\
\hline & I & $4.893,58$ & $141.998,58$ & $3,45 \%$ & \\
\hline & II & $4.286,97$ & $169.569,62$ & $2,53 \%$ & \\
\hline & III & $2.352,07$ & $167.049,31$ & $1,41 \%$ & \\
\hline & IV & $3.620,09$ & $175.821,48$ & $2,06 \%$ & \\
\hline \multirow{5}{*}{2007} & & $21.879,78$ & $812.455,83$ & $2,69 \%$ & \multirow[t]{5}{*}{$16,31 \%$} \\
\hline & I & $4.102,24$ & $170.279,96$ & $2,41 \%$ & \\
\hline & II & $4.411,90$ & $208.781,32$ & $2,11 \%$ & \\
\hline & III & $5.336,38$ & $206.865,82$ & $2,58 \%$ & \\
\hline & IV & $8.029,26$ & $226.528,73$ & $3,54 \%$ & \\
\hline \multirow{5}{*}{2008} & & $20.664,00$ & $1.032 .758,26$ & $2,00 \%$ & \multirow[t]{5}{*}{$-25,70 \%$} \\
\hline & I & $5.883,39$ & $221.910,75$ & $2,65 \%$ & \\
\hline & II & $6.000,88$ & $276.985,71$ & $2,17 \%$ & \\
\hline & III & $4.429,48$ & $264.387,70$ & $1,68 \%$ & \\
\hline & IV & $4.350,24$ & $269.474,10$ & $1,61 \%$ & \\
\hline \multirow{5}{*}{2009} & & $10.680,05$ & $1.145 .458,34$ & $0,93 \%$ & \multirow[t]{5}{*}{$-53,40 \%$} \\
\hline & I & $2.124,23$ & $248.240,56$ & $0,86 \%$ & \\
\hline & II & $2.712,70$ & $298.843,11$ & $0,91 \%$ & \\
\hline & III & $2.765,02$ & $292.198,73$ & $0,95 \%$ & \\
\hline & IV & $3.078,10$ & $306.175,94$ & $1,01 \%$ & \\
\hline \multirow{5}{*}{2010} & & $14.014,91$ & $1.442 .655,38$ & $0,97 \%$ & \multirow[t]{5}{*}{$4,19 \%$} \\
\hline & I & $2.752,71$ & $304.345,20$ & $0,90 \%$ & \\
\hline & II & $2.809,71$ & $377.071,42$ & $0,75 \%$ & \\
\hline & III & $3.098,39$ & $366.464,17$ & $0,85 \%$ & \\
\hline & IV & $5.354,10$ & $394.774,60$ & $1,36 \%$ & \\
\hline
\end{tabular}

Como ya se estableció, Argentina carece de desarrollo en el mercado de capitales, y más aún el mercado de acciones por carecer de profundidad y liquidez, esto queda demostrado en los resultados expuestos. A pesar de la recuperación en la variación en el índice en el año 2010 con respecto al 2009, se observa que, considerando el volumen operado trimestralmente y anual en relación al PBI, el mercado de capitales en acciones de Argentina tiene un largo recorrido para seguir creciendo. 
La Figura 20 muestra el volumen trimestral comercializado de acciones en el MERVAL en relación al PBI trimestral (no anualizado). Se observa como la tendencia de la relación construida fue cayendo con el paso del tiempo. El mencionado indicador, copia en forma intertemporal la evolución y tendencia que mostró el volumen negociado en acciones visto en los precedentes análisis. Mientras que el nivel de actividad de la economía Argentina tuvo un crecimiento y evolución favorable durante todo el período, el volumen negociado no acompañó en la misma sintonía dicho crecimiento.

Por otra parte, el volumen negociado trimestralmente se ha mantenido a través del tiempo con altibajos y con volatilidad, mostrando inestabilidad en su conformación con una tendencia levemente bajista. Se puede apreciar, que partir del cuarto trimestre de 2008 se ve reflejado con mayor énfasis este desacople entre el crecimiento económico con el incremento en los montos negociados en acciones. Por otro lado, a pesar de la recuperación trimestral en los volúmenes operados a partir del último cuarto del año 2009, el mayor crecimiento de la economía opacó la reversión descrita en el mercado de acciones.

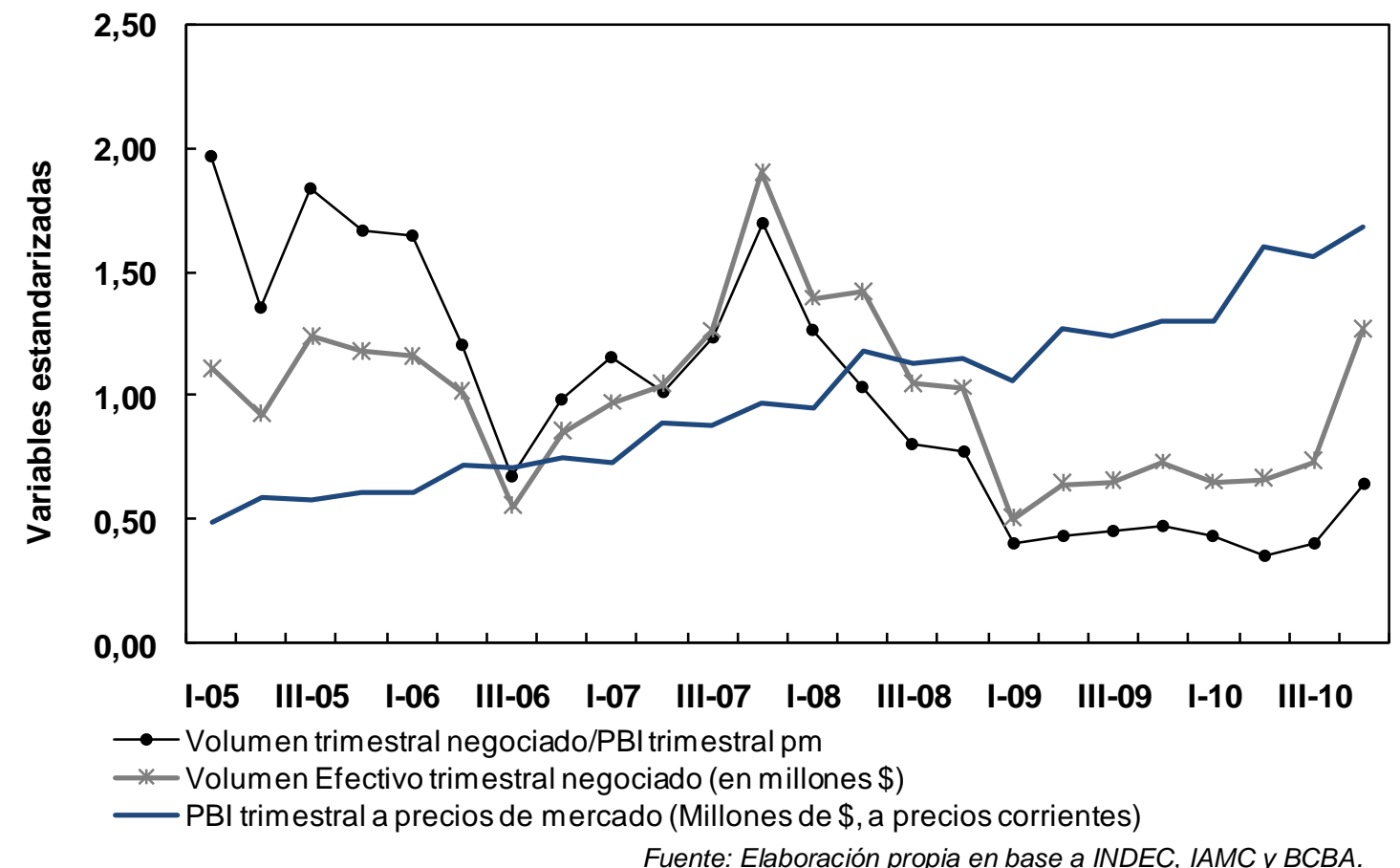

Figura 20: Variables estandarizadas del Indicador del volumen trimestral sobre PBI trimestral (\%), el Volumen trimestral negociado y del PBI a precios de mercado y precios corrientes (en pesos) (Período 2005-2010). 


\subsection{Capital Flotante (Free Float).}

\section{Análisis normativo acerca de la tenencia y límites en acciones}

Del análisis de las Actas del Comité Ejecutivo de la ANSES, se pudo establecer que prácticamente no se negociaron en el mercado secundario tenencia de acciones de empresas argentinas, heredadas de los fondos administrados por las AFJP, ni del FGS 1. Si se pudo dilucidar que se negociaron los respectivos CEDEARS y se comenzó con el proceso de desarme de la posición en empresas extranjeras por ser activos no elegibles por el FGS (Ver Anexo Tabla 7 Resumen con la descripción de los puntos tratados en las Actas del Comité Ejecutivo del FGS de la ANSES). En casi todos los actos administrativos revisados, se observa la realización de un informe sobre la concurrencia a las asambleas de Sociedades Anónimas por parte de representantes de la ANSES en las que se posee participación. Por su parte, de acuerdo con el Plan de Inversiones definido en las actas mencionadas, no se observan distinciones particulares en cuanto a la inversión en acciones en forma específica.

Como se mencionó en la parte teórica, el monto total invertido en acciones por parte del FGS, a partir del año 2009 subió notablemente como consecuencia de la revalorización de estos activos. En cambio, no se produjeron grandes modificaciones en las tenencias nominales en acciones de ANSES, con excepción de algunos dividendos en acciones recibidos, y algunas operaciones puntuales realizadas para aprovechar el timing del mercado.

El Artículo 74 de la Ley № 24.241, donde se encuentran los instrumentos que podían invertir las AFJP y ahora el FGS, los incisos k) y l) entre otros, fueron modificados por el Artículo 15 del Anexo III del Acta № 1/2009 del Comité Ejecutivo del FGS. En dichas modificaciones se define que el Fondo podrá tener hasta un máximo del $0 \%$ (cero por ciento) de títulos valores emitidos por Estados extranjeros u organismos internacionales y de títulos valores emitidos por sociedades extranjeras admitidas a la cotización en mercados que la CNV determine. A su vez dicho artículo del acta, establece un límite máximo como porcentaje del fondo a invertir en acciones locales del $50 \%$ y de acciones de empresas privatizadas del $20 \%$. 
En este caso, importa la modificación del inciso "l" que fue modificado por el artículo $4^{\circ}$ del Decreto № 2103/08 vigente a partir del 09/12/08 que elimina dicho porcentaje de tenencia de acciones extranjeras. Sin embargo, se estableció un plazo máximo de 2 años para vender las tenencias heredadas, establecido en el artículo № 39 de los Principios de Seguridad y Rentabilidad de las inversiones con activos del FGS del Acta $\mathrm{N}^{\circ} 1 / 2009$.

En el Artículo 17 del Anexo III de la citada acta, menciona que ningún instrumento emitido o respaldado por un mismo emisor, puede mantener más del $2 \%$ del fondo invertido, exceptuando al Estado Nacional. Este punto fue modificado por el punto 2 del Acta $\mathrm{N}^{\circ} 16$ de fecha 19/01/10 acerca de la ampliación de los límites por emisor hasta un 3\% del Artículo 17. Y en el Artículo 18 del Anexo III de Acta № 1, cuando establece los límites de los incisos h) acciones e i) acciones de empresas privatizadas del Artículo 74 de la Ley 24.241 , fijó un $2 \%$ del fondo el monto de inversión en acciones de un mismo emisor. A continuación aclara, que las tenencias de acciones extranjeras, CEDEAR, y ADR recibidas de las AFJP se pueden mantener sin que ello constituya un exceso a los límites fijados. Otros límites puestos por este anexo, fue el establecido en el Artículo 19 punto c) el cual considera que las inversiones en títulos de sociedades de inversión no representen una proporción mayor al $10 \%$ del valor de la cartera de acciones de empresas nacionales.

El Artículo 8 de la Ley № 26.425, establece específicamente la prohibición respecto de invertir los fondos del FGS en el exterior. A su vez, las Actas № 15, 18 y 20 del Comité Ejecutivo del FGS establecieron la necesidad de comenzar con la venta de activos del exterior, entre ellos las cuotas partes de los $\mathrm{FCl}$ del exterior, a los fines de generar la liquidez necesaria para la financiación de proyectos productivos y de infraestructura proyectada para el año 2010.

El Acta № 15 del Consejo del FGS, en su punto 4 realiza una consideración de la situación de los inversores en situación irregular. Cuando se transfirieron los activos que estaban en las $\mathrm{CCl}$ de los afiliados que pertenecían al régimen de capitalización del SIJP por la unificación en el SIPA en un único régimen público, algunas acciones que ingresaron a la cartera se encontraban en situación irregular. Un emisor se encuentra en dicha situación, cuando los instrumentos emitidos no cuentan con la 
calificación de riesgo en los casos que sea requerida o se haya retirado o se haya suspendido la autorización para emitir ofertas públicas y/o para cotizar en los mercados autorizados por la CNV en los que sea requerida. Todos los instrumentos en los que se invierte deben contar con la calificación requerida por la Ley 24.241 y normas complementarias, para el caso de las acciones deben tener como mínimo una calificación de 2 por parte de las calificadoras de riesgo autorizadas. En estos casos se aplica el plazo mencionado en el Artículo $\mathrm{N}^{\circ} 39$ del Acta $\mathrm{N}^{\circ} 1$, que al final del punto del Acta $N^{\circ} 15$ se estiró el plazo de 2 años para regularizar dicha situación, para que cuente desde el 01/01/2010. Las acciones que al 30/11/2009, estaban en una situación irregular eran Distribuidora Gas Cuyana, Socothern Americas, Metrovias, Metrogas, Euromayor, Emdersa, Capex, Transportadora Gas del Norte y Ledesma.

Cerca del $80 \%$ de la tenencia de activos del exterior de titularidad del FGS, eran acciones de Tenaris S.A. (TS) y Telefónica (TEF), por lo que se comenzó y terminó en el año 2011 con el proceso de enajenación de las acciones mencionadas. La ANSES ha realizado en su momento un análisis normativo vigente con respecto a las inversiones del FGS, la profundidad del mercado local y las distintas alternativas de salida que ofrecieron los agentes del mercado. El FGS aprovechó la gran subida de valor que tuvieron las acciones de TS y TEF durante el 2009 y 2010, para realizar el proceso de venta en el mercado internacional, dado que en el mercado local al ser muy reducido en términos de volúmenes y liquidez pudo afectar el valor de las mismas. Es importante resaltar la gestión del FGS en el proceso de desinversión en Tenaris, no ocurriendo la misma situación con Petrobras y los CEDEARS de Telefónica que se encuentran en cartera, por la diferente coyuntura que tuvieron en su evolución dichos papeles.

Luego de la autorización de la venta de estos instrumentos en acciones ordinarias y/o en programas de ADR, se autorizó la liquidación de CEDEAR en cartera del FGS, ya sea a través de su venta o mediante su aplicación para la integración de cuota partes de $\mathrm{FCl}$ abiertos PYMEs o de renta fija que apliquen lo producido a financiamiento de infraestructura de las industria del país para que ayude a cumplir con el fin del FGS. 
Entrando en los derechos políticos, por la participación que tenía la ANSES en las distintas empresas argentinas, pudo designar directores en algunas firmas de acuerdo con los votos que poseía o de acuerdo con la negociación realizada con los socios controlantes. Lo novedoso a toda esta cuestión de la participación del FGS en empresas privadas, es que el día 13 de abril de 2011 fue publicado en el Boletín Oficial el Decreto № 441/2011 del Poder Ejecutivo Nacional (PEN), en virtud del cual se decretó la derogación del inciso f) del Artículo 76 de la Ley del SIJP № 24.241. El cual establecía que en ningún caso las inversiones realizadas en una sociedad nacional o extranjera habilitarán para ejercer más del cinco por ciento $(5 \%)$ del derecho de voto, en toda clase de asambleas, cualquier sea la tenencia respectiva. Por lo expuesto precedentemente, y con el fin de que la ANSES cuente con herramientas e instrumentos jurídicos adecuados, mediante el Decreto se resolvió la derogación de la Norma, permitiéndole en consecuencia a la ANSES el ejercicio de los derechos societarios que le correspondan según su participación cualquiera fuere ésta última, entre ellos los de voto, para cumplir los objetivos de la Ley № 26.425.

Por otro lado, con anterioridad al Decreto 411/2011 en distintas empresas la ANSES ha querido hacer valer sus derechos societarios, y en las respectivas asambleas de accionistas solicitaba el derecho político a voto por la tenencia accionaria que posee y en oportunidades ha tenido reticencia en su solicitud. Es decir, otros accionistas, generalmente el grupo controlante de las empresas mencionan la limitación al derecho de voto que surge del Artículo 76 inciso f) de la Ley № 24.241, cuya vigencia ha su entender fue ratificado por el artículo $8^{\circ}$ párrafo tercero de la Ley 26.425. Por lo que el derecho a voto de la ANSES se ve limitado al 5\% del capital social, en aquellos casos que el organismo estatal posea una participación mayor. La limitación de la acumulación de votos se hacía con las AFJP, es decir no podían juntar su tenencia accionaria para hacer valer sus derechos en forma conjunta como bloque. Este principio de limitación provenía desde su origen, copiando al sistema chileno para evitar problemas de control societario de los distintos conglomerados financieros y tratando de evitar conflictos de intereses cruzados.

La ANSES siempre ha cuestionado la limitación al derecho de voto de su tenencia accionaria en varios casos, mencionando la existencia de dictámenes recaídos en las actuaciones caratuladas "Petrobras Energía Participaciones s/Consulta ANSES 
s/Asamblea 30/01/09" (Expte. $N^{\circ}$ 422/2009) en trámite ante la CNV. En dichos dictámenes se habría concluido que no corresponde limitar en forma alguna el derecho de voto de dicho accionista. Por lo que la ANSES, en dichas Asambleas hace expresa reserva de derechos y acciones que pudieren corresponderle en virtud de los artículos 251 y 252 de la Ley de Sociedades de Comerciales (LSC) № 19.550.

En resumen, de acuerdo con el análisis legal y de sus actos administrativos, el FGS no ha tenido una gestión activa en el mercado primario ni secundario en la negociación de participaciones en empresas argentinas. Si se puede aseverar que el crecimiento en el rubro acciones se debió a un proceso de valorización generalizado (incremento por los precios de estos activos financieros) respondiendo a una actitud pasiva del FGS en el trading, y no una política activa de compra-venta que permitiese aumentar la cantidad de nominales. Si se ha demostrado su interés en hacer valer sus derechos societarios y que se respeten todos los votos que le corresponden de acuerdo con su tenencia designando directores en los casos correspondientes.

\section{Variaciones en la cartera de acciones}

De los hechos relevantes informados por las empresas ante la BCBA y la CNV, se puede resaltar las siguientes consideraciones sucedidas en las empresas que el FGS tiene participación que modificaron la tenencia en cartera. Los sucesos relevados tienen que ver con decisiones de los órganos políticos de las compañías relacionados con la política de dividendos de las mismas, cuando hacen su distribución en especie y/o los tenedores de acciones ejercen las opciones establecidas.

Partiendo de la tenencia transferida de las AFJP y del FGS 1, se llega a lo informado a Diciembre de 2010 por la ANSES. El recorrido temporal en el análisis encuentra distintos hechos que modificaron la tenencia nominal en la participación de las empresas. Los hechos más relevantes, ordenados en forma cronológica fueron los siguientes:

- La tenencia en la empresa Aluar se incrementó, dado que en fecha 19/01/2009 se pagaron dividendos en especie, dando 15 acciones por cada 100 de tenencia (Dividendos en acciones del 15\%, fue comunicado el 13 de enero de 2009). 
- La empresa Mirgor anunció en la BCBA en fecha 22/04/2009 el pago de dividendos en especie por el $100 \%$ del total de tenencias. Por lo que en fecha 29/04/2009 se recibió el pago, duplicándose la cantidad de acciones en circulación de la empresa (Ajuste integral del capital 100\%).

- La empresa San Miguel distribuyó dividendos en acciones por VN 2.055.996 pagados el 31/08/2009. El ratio de conversión del mismo fue de 1 a 1.

- El FGS recibió por parte de BBVA Banco Francés un pago de dividendos en especie en fecha 23/09/2009, el cual fue anunciado en la BCBA en fecha 17/09/2009, con un cupón de 0,137898.

- Por otro lado, Petrobras Energía S.A. absorbió por fusión a Petrobras Energía Participaciones S.A. en fecha 30/09/2009. Es decir que en el marco del proceso de fusión acordado por Petrobras Energía S.A. y Petrobras Energía Participaciones S.A. (PEPSA), se realizó el canje de la totalidad de las acciones Clase B de PEPSA en circulación por acciones Clase B de PESA admitidas a la oferta pública en la BCBA. Las acciones de Clase B de PEPSA fueron canceladas. La fusión había sido aprobada por ambas sociedades en asamblea extraordinaria el 30/01/2009, la relación de canje fue de 1 acción ordinaria Clase $B$ de PEPSA de valor nominal $\$ 1$ y con derecho a un voto por cada 0,359015136 acciones ordinarias Clase B de PESA de valor nominal $\$ 1$ y con derecho a un voto. Por lo que la empresa Petrobras Energía Participaciones S.A. fue disuelta, quedando toda la tenencia del FGS en la empresa Petrobras Energía S.A.

- La firma Cresud S.A. en fecha 23/11/2009 pagó dividendos en efectivo, asignando acciones en cartera a prorrata de las 25.000 .000 propias de VN 1. Las mismas fueron emitidas oportunamente por Cresud y adquiridas en el marco de las turbulencias que el mercado nacional e internacional evidenciaran durante el ejercicio 2008-2009 El anuncio se realizó en la Asamblea de fecha 29/10/2009, por lo que se recibieron acciones adicionales a la tenencia que se tenía en el FGS, con una cantidad de acciones a ser emitidas por warrant con un ratio de 0,05301792784. 
- Molinos Río de La Plata S.A. distribuyó dividendos según el anuncio realizado el 20/12/2010. El dividendo anticipado fue aprobado por el Directorio en su reunión del 3 de diciembre de 2010, y una de las formas de pago fue mediante la distribución en especie de 979 acciones Clase "A" en cartera de la Sociedad, todas ellas de valor nominal \$1 cada una y 5 votos por acción y 1.039 .145 acciones Clase "B" de la Sociedad que estaban en cartera, todas ellas de valor nominal $\$ 1$ cada una y 1 voto por acción. En su caso, el FGS recibió en acciones su participación correspondiente.

Asimismo, de acuerdo con la información obtenida se realizaron compras en el mercado secundario en Enero de 2010, en acciones pertenecientes al MERVAL, incrementándose la participación accionaria del FGS en el capital de las empresas no en forma significativa. Por lo que así, se llegó a la participación accionaria a Diciembre de 2010, partiendo de lo traspasado.

\section{Sectores de la economía Argentina y empresas con participación estatal.}

En primer lugar, se adjunta en el Anexo la Tabla 9 donde se expone por un lado las 41 empresas argentinas en las que el FGS posee acciones, en términos nominales y ordenadas de acuerdo con su mayor porcentaje de participación en el capital social de las empresas. Como primera conclusión, la ANSES tiene en su poder el 14,31\% del capital social de las empresas argentinas, de acuerdo con el promedio simple que se obtuvo.

Se realizó una agrupación de las empresas de acuerdo con sus actividades principales (core business) (Ver Anexo Tabla 10), y se determinó que se tiene en promedio mayor porcentaje de capital en firmas del sector de la economía argentina dedicadas a la Siderurgia con casi un 17,63\% (Siderar y Aluar). Esta clasificación se puede ver en la Figura 21, y tiene el inconveniente que depende de la cantidad de empresas en el rubro y el peso relativo de tenencia que el FGS tiene en cartera en cada una de ellas. Por otro lado, muestra la atomización sectorial en las que el ente estatal participa en las distintas empresas de la economía nacional. 
Calasificación de empresas argentinas por sectores

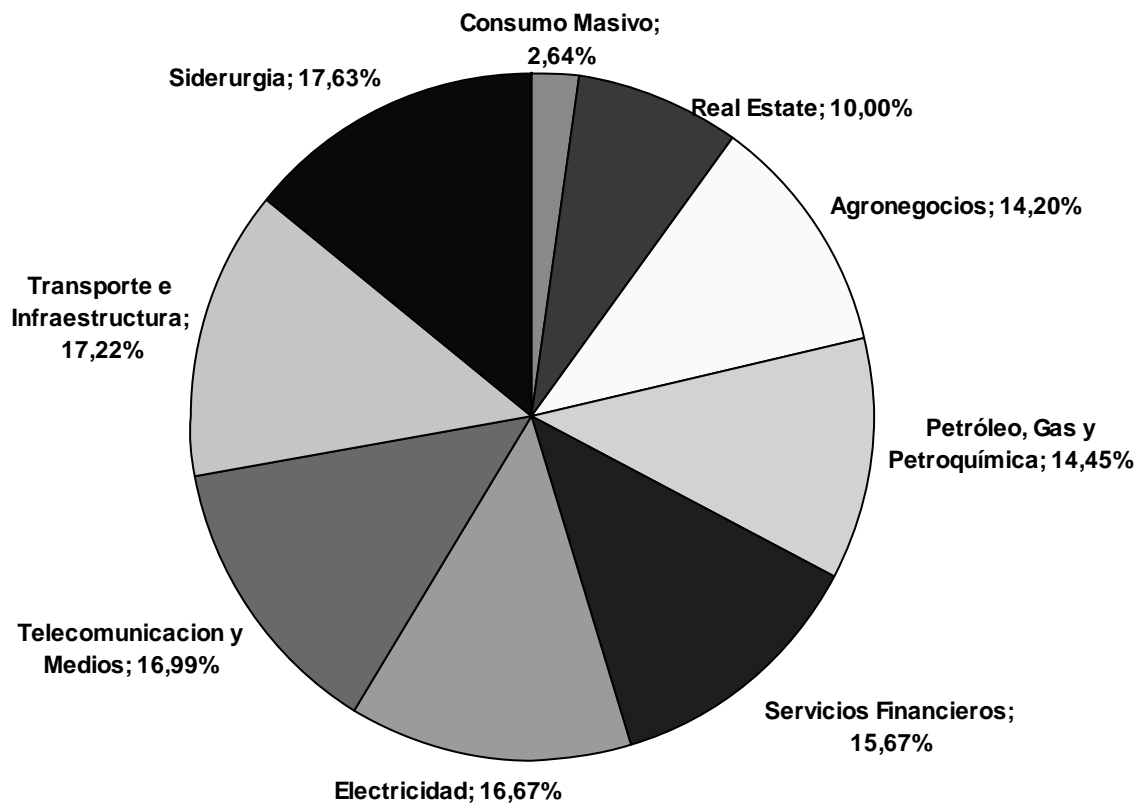

Fuente: Elaboración propia en base a dato de la ANSES.

Figura 21: Clasificación por sectores de la economía de Argentina de empresas nacionales en las que el FGS posee participación (Diciembre de 2010).

En segundo lugar y muy de cerca, sigue el sector de Transporte e Infraestructura con casi un 17,22\% del capital social (Metrovías S.A., Grupo Consesionario del Oeste y Mirgor S.A $)^{17}$. Y en tercera posición, el sector de Telecomunicaciones y Medios con valores cercanos en promedio al 17\% (con solo dos empresas como Telecom y Grupo Clarín, dado que se excluyó Telefónica por ser considerada extranjera). A continuación sigue el sector de Electricidad con un 16,67\%, con compañías dedicadas a la generación y distribución de energía (las firmas que fueron incluidas son Edenor, Emdersa, Pampa Holding, Transener, Endesa Costanera, Central Puerto y Capex).

El sector de los bancos, es decir el de servicios financieros con casi el 15,70\% como promedio del capital social es el que sigue (principales empresas Banco Macro, Grupo Financiero Galicia y Banco Patagonia). Luego seguiría el sector con mayor cantidad de empresas que el fondo invierte, es decir el de Petróleo, Gas y

\footnotetext{
17 Esta agrupación o clasificación (Ver Anexo Tabla 9) dista de ser la ideal por la diversidad de actividades agrupadas, como en este caso que se agrupa una empresa dedicada a la prestación del servicio subterráneo, otra a la concesión de peajes de autopistas y la última a la provisión de aires acondicionados para la industria automotriz como actividades principales. Todo ello es debido a la escasa profundidad del mercado de capitales argentino y de empresas con capital abierto, y la poca representatividad de la matriz productiva argentina en el sistema bursátil. La clasificación fue tomada de la información provista a la Comisión Bicameral - Congreso de la Nación (20/05/09) por parte de la ANSES.

http://www.anses.gob.ar/FGS2/archivos/Presentacion-Mayo.pdf
} 
Petroquímica con más del 14,45\% (empresas como Gas Natural BAN, Distribuidora de Gas Cuyana y Transportadora de Gas del Sur, entre otras). En el orden viene el sector de Agronegocios con 14,20\% (con empresas como San Miguel, Molinos e Importadora y Exportadora de La Patagonia como sus máximos referentes) y la actividad económica de Real Estate con un valor del 10\% (Consultatio, Euromayor e IRSA entre otras). Por último, el sector de Consumo Masivo con menos del $3 \%$ de las acciones en promedio con sólo dos empresas como Quickfood; y Alpargatas en la cual se posee escasa participación en esta última.

Otra información interesante que se procesó y se observa en el Anexo en la Tabla 9 es que en 7 empresas del total analizado, la ANSES posee más de un cuarto del capital social. Siendo el Banco Macro (sector financiero) con casi 31\%, la firma San Miguel (del sector agronegocios) cercano al 27\%, Gas Natural BAN (sector Petróleo, Gas y Petroquímica) con más del $26,63 \%$ y Consultatio (sector Inmobiliario - real estate-) también con más del $26,6 \%$, las empresas que los fondos previsionales públicos poseen mayor participación relativa.

La mayor concentración de tenencia del FGS con relación a su porcentaje sobre el capital social, se da entre el $15,01 \%$ y $25 \%$ dada esta característica en 13 compañías. Luego siguen 12 empresas en las que se tiene entre el 5,01\% y $15 \%$ del denominado equity. Y por último en las restantes 9 empresas se tiene menos del $5 \%$ del capital social.

\section{Capital flotante (free float) y flotación extendida en las empresas argentinas}

Según los informes del IAMC mensuales del período bajo estudio, el free float promedio de empresas domésticas por sector económico de todas las que cotizan en la BCBA (de acuerdo con la clasificación sectorial que realiza el organismo técnico ${ }^{18}$ ) fue a fines del cuarto trimestre de 2010 del $32,50 \%$ el promedio por sectores ${ }^{19}$ y un $31,20 \%$ el promedio por empresas. En diciembre del año 2008, el promedio del free

\footnotetext{
18 La clasificación sectorial de IAMC, así como las empresas comprendidas dentro de cada sector están disponibles en www.iamc.sba.com.ar/tutoriales/anexos. Separando y tomando 91 empresas domésticas y las 6 extranjeras.

19 Para el free float por sector se calcula el promedio de los free float de las empresas que lo integran, de acuerdo con la clasificación del IAMC.
} 
float total de sectores era $32,40 \%^{20}$, y en el último trimestre del año 2009 del $33,80 \%$. Por lo que demuestra valores en términos relativos no muy cambiantes de un año al otro.

Si se analiza por separado el promedio de las acciones domésticas del panel Merval 25 (en base al $2^{\circ}$ trimestre de 2011), el porcentaje de capital disponible para ser transado libremente en el mercado es en promedio del 40,70\% a diciembre de 2010 . La empresa con mayor capital disponible para su negociación es Pampa Energía, con un free float del 79,10\%. Le siguen Sociedad Comercial del Plata (el FGS no posee acciones de esta empresa) y del Grupo Financiero Galicia, con 77,70\% y $77,40 \%$, respectivamente. Como contrapartida, las empresas con menor capital flotante disponible para el público inversor son YPF con un 0,5\%, Banco Hipotecario con un 7,7\% (ver nota al pie $\mathrm{N}^{\circ} 22$ que está en el Anexo), y Ledesma con el 9,6\% ${ }^{21}$.

Los resultados obtenidos en este trabajo para fines del año 2010 no difieren mucho de los obtenidos por el IAMC, dado que la empresa Pampa Energía tiene el mayor free float con un valor cercano al $85 \%$, Grupo Financiero Galicia un $77,35 \%$ y el Grupo Clarín un $73,56 \%$. Por el lado opuesto, las tres empresas en que el FGS posee participación y tienen un bajo capital flotante son Ledesma, Metrovias y Alto Palermo, con un casi 9,63\%, 9,34\% y 5,11, respectivamente. En los casos donde la tenencia de los accionistas mayoritarios es elevada, la liquidez en el mercado se ve limitada por lo que los inversores individuales e institucionales no pueden comprar y vender sus títulos tan fácilmente.

Ergo, para ahondar y afinar aún más este concepto es necesario considerar el importante peso del FGS de la ANSES en la tenencia de acciones de las empresas. Las AFJP eran generadores de volumen tanto en el mercado primario como en el secundario, por lo cual ante su salida esto se vio claramente afectado en parte como fue demostrado en la Hipótesis 1 de este trabajo. Las cifras vistas tienen gran

\footnotetext{
20 Ver informe Mensual Diciembre 2010 del IAMC, en la Página 28. http://www.iamc.sba.com.ar/lmgs/Dyn/ArchivosLenguajes/6566-2011-1-11T17-19-0.pdf

${ }^{21}$ Ver informe Mensual Junio 2011 del IAMC, en la Página 9.

www.iamc.sba.com.ar/lmgs/Dyn/ArchivosLenguajes/7000-2011-7-8T13-48-0.pdf
} 
importancia si se computa el capital de las compañías en poder de los accionistas mayoritarios más la tenencia de acciones de cada empresa en poder de la ANSES.

A ello se le debería adicionar, la tenencia en cartera que muchas veces poseen otros inversores institucionales como compañías de seguros, $\mathrm{FCl}$, cajas previsionales profesionales, que muchas veces mantienen en cartera acciones por un período prolongado sin negociarlas en el mercado. Ello dependerá de las regulaciones que poseen, reglamentos de gestión, benchmark si es que tienen para ponderar su cartera, dependiendo el caso para cada tipo de inversor según lo desarrollado en la parte teórica acerca de inversores institucionales. Se puede ver que la limitación del capital social de las empresas para el inversor individual puede ser aún mayor. En efecto, si se considera el floating disponible para el resto de los inversores se reduce considerablemente. Esto es lo que se llama en el presente trabajo a la variable Floating extendido o Flotación extendida, para denominarla de alguna manera.

De los resultados obtenidos, se obtiene que el floating en las empresas que el FGS participa en promedio es del 37,09\%. Si a este porcentaje se le resta la tenencia relativa de la ANSES desciende al 22,78\% en promedio. En la Figura 22 se pueden observar las primeras 20 empresas del total, con mayor capital flotante y el efecto que se produce al sacarle la tenencia de la ANSES.

Free Float y restando tenencia del FGS (primeras 20 empresas)

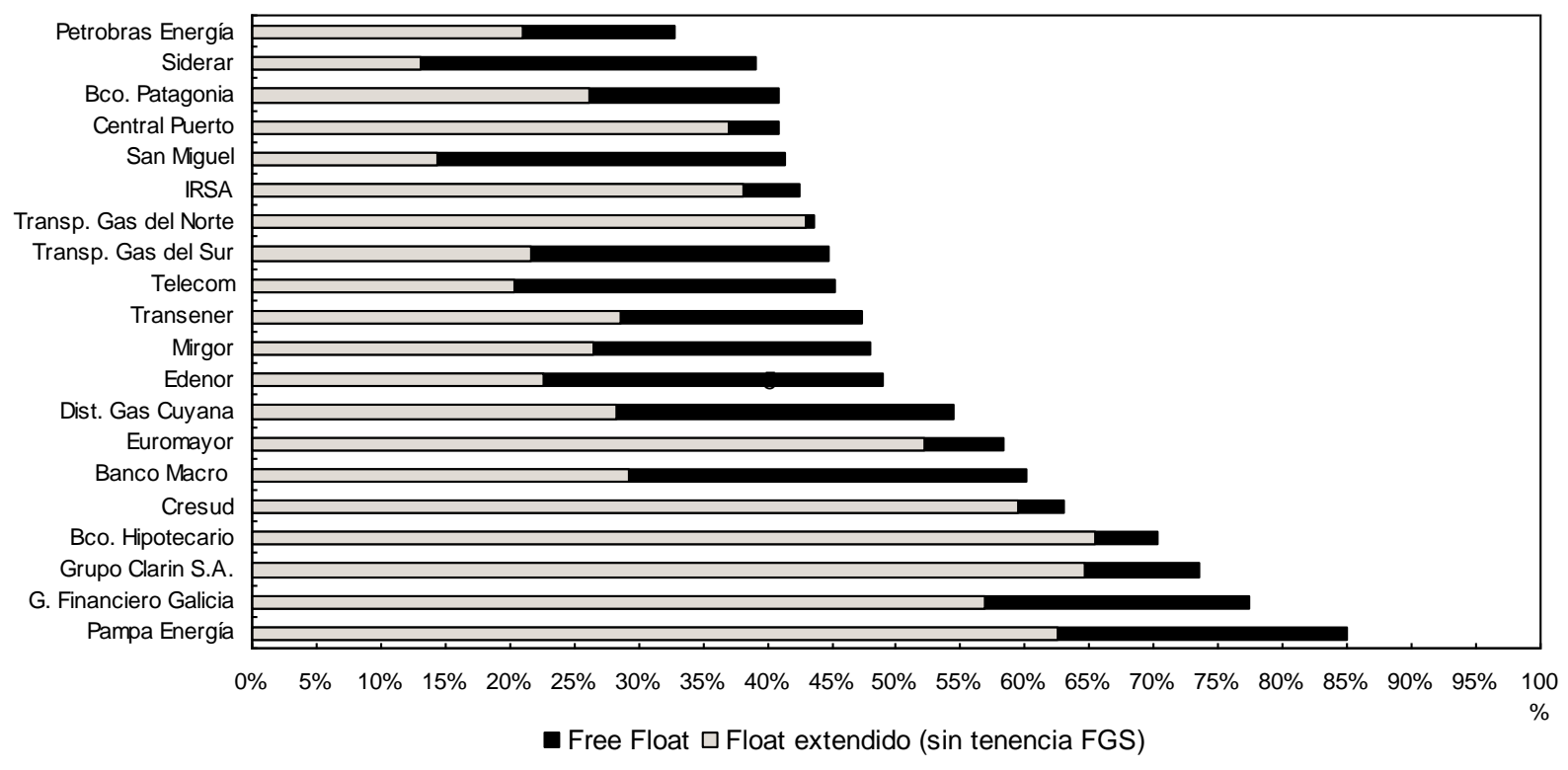

Fuente: Elaboración propia en base a datos de BCBA, ANSES y CNV.

Figura 22: Capital flotante y flotación extendida de empresas argentinas en las que el FGS posee participación (Diciembre de 2010). 
En la empresa que menos efecto produce para el público inversor la disponibilidad de acciones en el mercado, al sumar la tenencia del grupo controlante y de la ANSES, en base al cálculo realizado es en el Banco Hipotecario con un floating extendido del $65,36 \%$ (se debe tener en cuenta la salvedad realizada para esta compañía). Luego seguiría el Grupo Clarín con un valor cercano al $65 \%$ de su capital social disponible para el resto de los inversores. A continuación, las empresas Pampa Energía con un $62,46 \%$, Cresud con un porcentaje superior al 59\% y el Grupo Financiero Galicia con casi el $57 \%$ del capital social. Y por último se menciona a la empresa Euromayor con un porcentaje superior al 52\%. Estas 6 empresas mencionadas, mantienen en circulación en el mercado más de la mitad del capital social a pesar de restarles la participación del controlante y de la ANSES.

Por otro lado, y como se observa en la Figura 23, en la empresa en la que ANSES tiene un mayor impacto en el capital flotante, es decir en su floating extendido es Metrovias, dejando únicamente un $0,79 \%$ del capital social libre para el público inversor. Luego seguiría Camuzzi Gas Pampeana con un free float extendido del $1,26 \%$ y Emdersa con el 1,85\%. A continuación, Importadora y Exportadora de La Patagonia con un $2,89 \%$ y Consultatio con un $3,15 \%$ de capital social libre para el resto de los inversores. Y para determinar las empresas en que se tiene un floating extendido menor al 5\%, falta enunciar a Gas Natural Ban, Alto Palermo y Quickfood, con un 3,37\%, 3,73\% y 4,68\%, respectivamente. La mayoría de estas empresas ya presentaban un free float limitado, es decir menor al $30 \%$, pero al sacarle la tenencia de la ANSES se profundiza el escaso capital flotante libre en el mercado secundario. 
Free Float y restando tenencia del FGS (últimas 21 empresas)

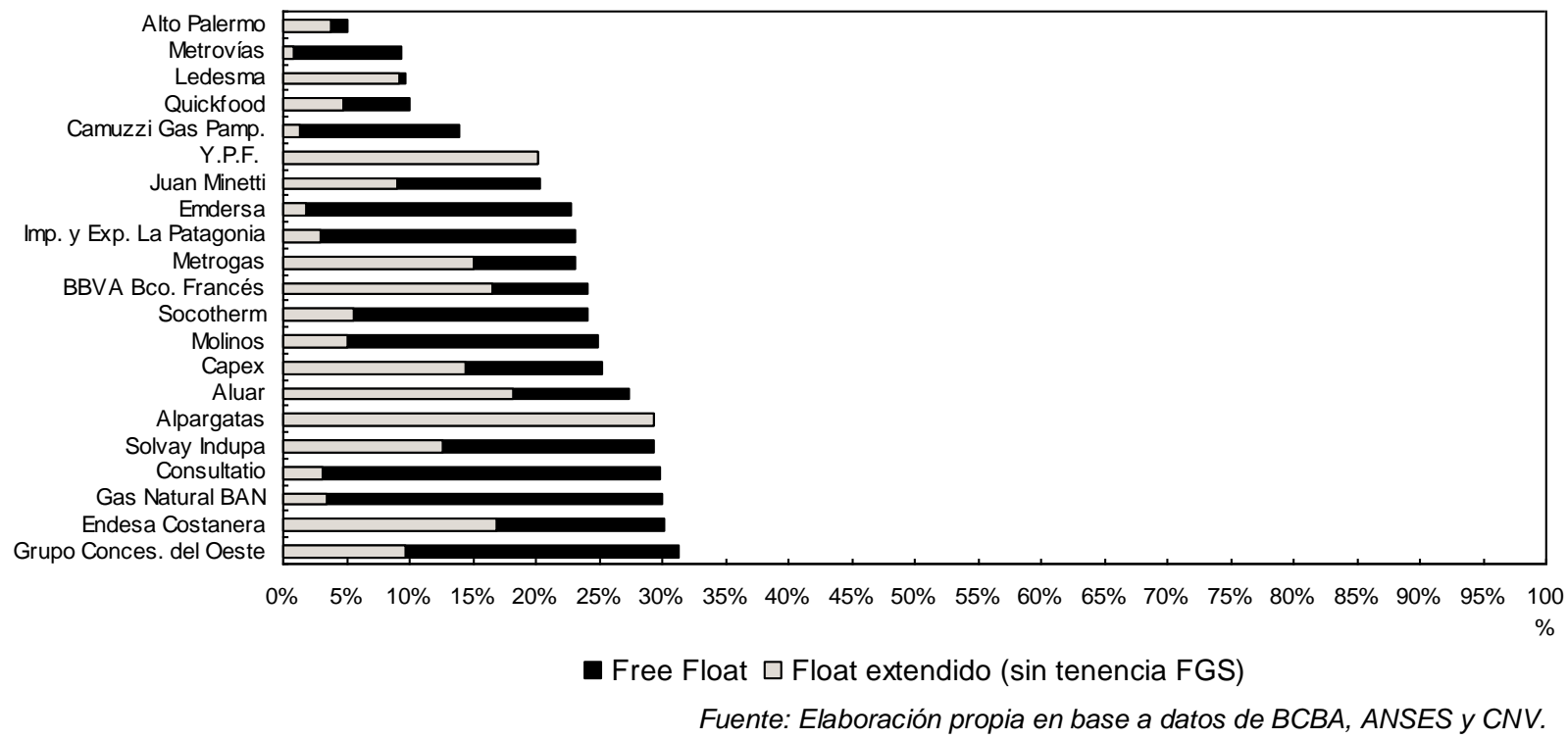

Figura 23: Capital flotante y flotación extendida de empresas argentinas en las que el FGS posee participación (Diciembre de 2010).

Por último en este apartado, en la Figura 24 se puede observar la agrupación de las 41 empresas locales en distintos niveles de capital flotante y de capital flotante extendido.

En el lado izquierdo de la figura mencionada, se puede observar la clasificación realizada acerca del floating en las empresas argentinas. Se determinó que la mayor concentración de las empresas analizadas se da en el rango entre $20 \%$ hasta $40 \%$ de capital flotante, con un casi $44 \%$ del total del capital social (18 casos de empresas). Un valor cercano al 30\% de las firmas, tenían a diciembre de 2010 un free float entre $40 \%$ hasta $60 \%$ (12 compañías).

A continuación, siguen 5 empresas con un floating entre el $60 \%$ hasta $80 \%$, y también 5 empresas con menos del $20 \%$ del capital social. Ambos casos con un porcentaje superior al $12 \%$ de los casos observados. Un solo caso mostró una flotación por encima del $80 \%$, que fue el caso visto precedentemente de Pampa Energía. 
Capital flotante de empresas argentinas

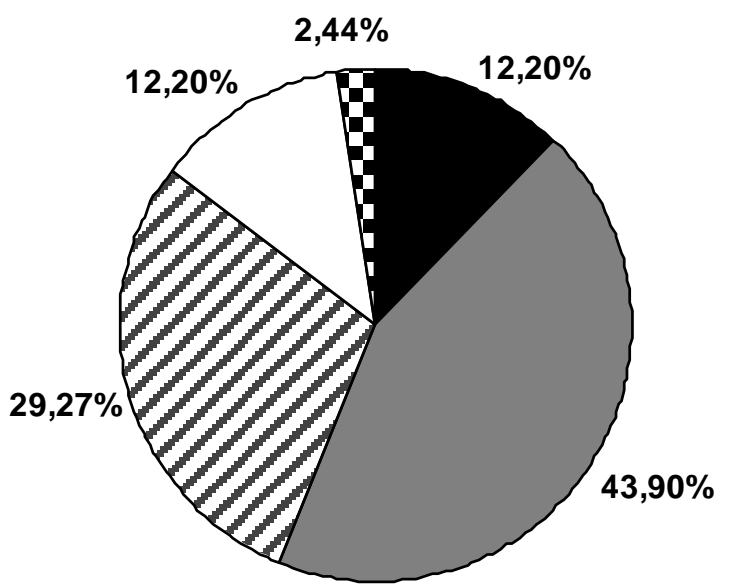

menos de $20 \%$ a entre $20 \%$ y $40 \%$ ventre $40 \%$ y $60 \%$
Flotación extendida de empresas argentinas

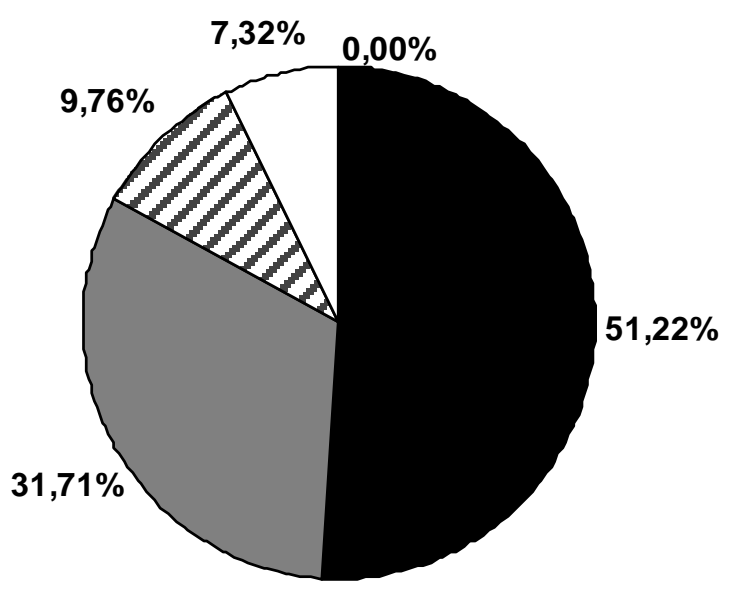

口entre $60 \%$ y $80 \%$ más de $80 \%$

Fuente: Elaboración propia en base a datos de BCBA, ANSES y CNV.

Figura 24: Capital flotante y flotación extendida de empresas argentinas en las que el FGS posee participación (Diciembre 2010).

Por otra parte, en el lado derecho de la Figura 24 se puede apreciar la clasificación que se hizo de las empresas argentinas, acerca del floating extendido. Se determinó que en más de la mitad del total de las empresas, poseían un floating extendido menor al 20\% del capital social. Es decir, que esta característica se mostró en 21 firmas del total analizadas. A continuación sigue con un valor relativo cercano al $32 \%$ del total, 13 empresas que encuadraron en la categoría entre $20 \%$ hasta $40 \%$. Es decir, que casi el 83\% de las empresas argentinas en que el FGS poseía acciones a fines del 2010, tenían un floating extendido menor al 40\%. Por último, con valores menores al $10 \%$ del total de las empresas, se encontraron las características entre $40 \%$ hasta $60 \%$ y entre $60 \%$ hasta $80 \%$ de flotación extendida, en ambas clases.

\section{Derecho a voto del FGS y del grupo controlante sobre el total de votos de las empresas argentinas.}

En el presente apartado se exponen los resultados obtenidos de la participación de la ANSES y del grupo controlante sobre los votos totales de la sociedad que le permiten ejercer el derecho político en los órganos de decisión. A grandes rasgos, se puede apreciar la mayor concentración de los votos en las sociedades controlantes, en términos relativos superiores a lo que poseían en acciones del capital social. En la Tabla 12 del Anexo se adjunta los porcentajes respectivos en cada una de las 41 
empresas, el total de votos disponibles en cada firma y lo que queda para el público inversor.

En un primer análisis, se puede decir que en las 41 empresas nacionales el organismo nacional tiene en promedio un valor cercano al $13 \%$ de los votos totales. $Y$ el grupo controlante ejerce su control en el total de los votos con un porcentaje superior al $67 \%$ en promedio.

A continuación, en la Figura 25 se puede observar la agrupación de los porcentajes sobre el total de votos, donde el FGS puede hacer valer sus derechos políticos. En ninguna de las compañías, ANSES posee más del 30\% de los votos disponibles. En la mayor cantidad de firmas, es decir en 15 de ellas representando casi un $37 \%$, se posee entre un $15 \%$ y $30 \%$ de los votos totales de la sociedad. Ello seguido por los votos que representan entre 5\% y $15 \%$ del total disponible, en un poco más del 34\%, es decir en 14 empresas. Y por último, en 12 firmas se tiene menos del $5 \%$ sobre el total de los votos, representando cerca del $30 \%$.

Participación FGS sobre total de votos

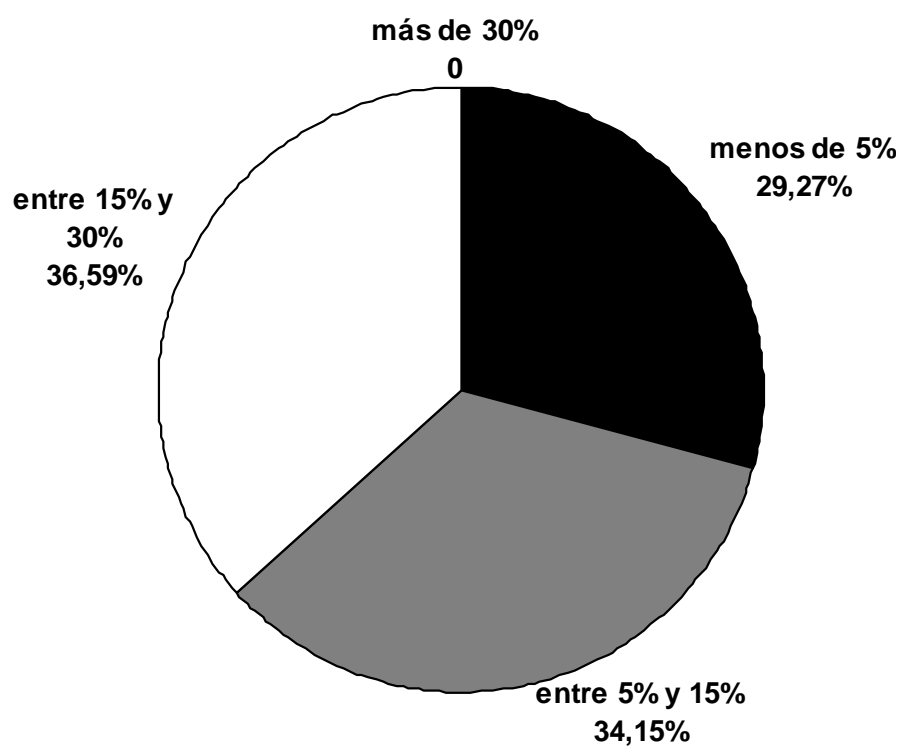

Fuente: Elaboración propia en base a datos de BCBA, ANSES y CNV.

Figura 25: Participación del FGS en los votos del capital social de empresas argentinas (Diciembre 2010).

Por el lado del grupo controlante, en la Figura 26 se puede observar la agrupación de los porcentajes sobre el total de votos. Con un valor relativo mayor al $46 \%$, los grupos controlantes poseen entre el $60 \%$ y $80 \%$ de los votos disponibles, mostrando 
su supremacía en los órganos de gobierno. Esta característica se da en 19 empresas de las 41 analizadas.

Luego, con casi el $32 \%$ del total de las empresas, es decir en 13 casos el grupo controlante posee entre el $40 \%$ y $60 \%$ de la totalidad de votos. Otro dato interesante, es que en más del $17 \%$ de las firmas (7 compañías), los controlantes tienen más del $80 \%$ de la voluntad social. En última instancia, en 2 firmas se tiene menos del $40 \%$ sobre el total de los votos, representando cerca del $5 \%$ del total.

\section{Participación controlante sobre total de votos}

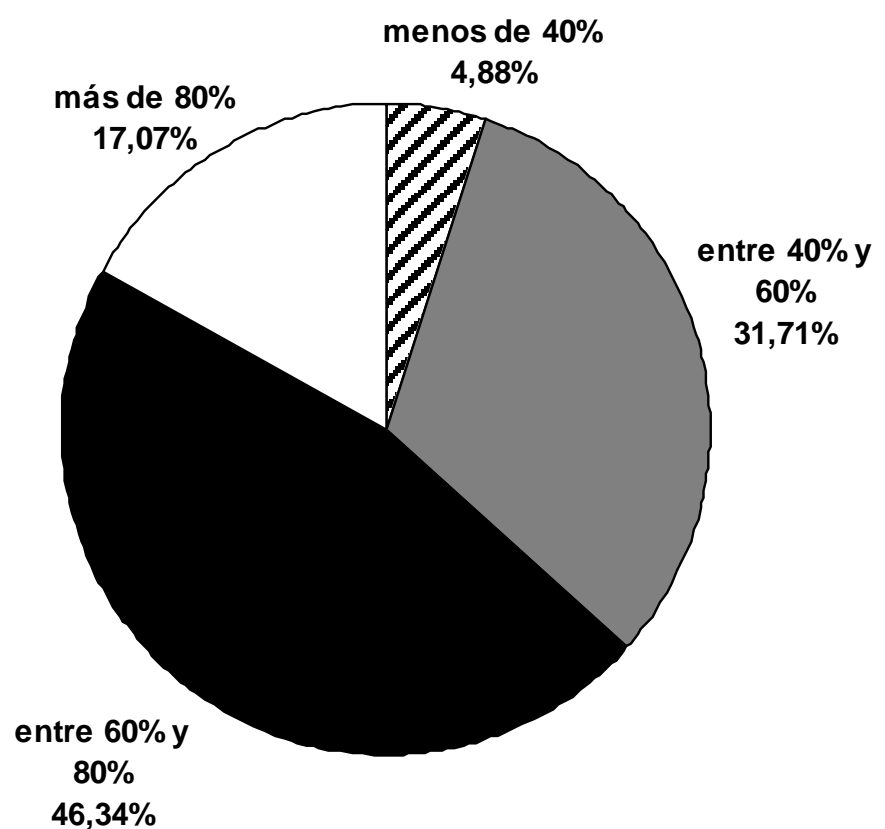

Fuente: Elaboración propia en base a datos de BCBA, ANSES y CNV.

Figura 26: Participación del Grupo Controlante sobre los votos del capital social de empresas argentinas (Diciembre 2010).

Lo analizado en este apartado, permite demostrar claramente que hay empresas que tienen una capitalización bursátil real y en otras una capitalización aparente. La capitalización real es asimilable a las firmas cuya acción sea igual a un voto en la Asamblea de Accionistas. En cambio, en la denominada aparente se ve reflejada en el caso donde difiere demasiado el porcentaje del capital social que se posee, con la participación en el total de votos. 


\section{Conclusiones}

Los estudios realizados en el presente trabajo en términos generales permiten afirmar que la gestión del FGS de la ANSES ha cumplido con su finalidad de orientar sus inversiones al financiamiento de la denominada economía real fomentando un círculo virtuoso con el crecimiento del país. El mismo ha utilizado los fondos previsionales para actividades económicas y financieras que se desarrollan en Argentina, desarmando las posiciones invertidas en el exterior 0 en empresas extranjeras.

Asimismo, ha generado una matriz de financiamiento que va creciendo de proyectos a largo plazo destinados a la infraestructura del país tanto energética, viales y de viviendas, con instrumentos estructurados pertenecientes al mercado de capitales. Otra virtud interesante, es el redireccionamiento de los depósitos a plazo fijo en entidades públicas y privadas que llegan a todo el país financiando actividades productivas para el desarrollo regional, o de los fondos comunes de inversión que invierten en productos financieros PyMES.

Sin embargo, el estado nacional al eliminar el sistema de administradoras privadas ha sacado un número interesante de inversores institucionales, que hoy se concentran en un solo inversor institucional público como es el FGS de la ANSES. EI cual concentra la tenencia de muchos títulos valores del mercado de capitales argentino, pudiendo afectar el nivel de volúmenes operado en cualquier plaza de negociación, como los precios de los mismos. Ello especialmente demostrado, en el mercado de acciones de la Bolsa de Comercio de Buenos Aires en lo que respecta al volumen negociado.

Los conflictos de intereses que acarrea el FGS no son menores, al querer hacer valer sus derechos políticos en las empresas al igual que sus derechos económicos y financieros. Aquí entran en juego las incompatibilidades de los directores que designe en los correspondientes casos, y la posibilidad de caer en un abuso de posición dominante por parte de este inversor institucional estatal tan grande. 
Los cambios que ocasionaron la medida de eliminar el subsistema de capitalización en el mercado bursátil argentino, fueron considerables en el período que se analizó. Como quedó demostrado, la cartera de acciones argentinas heredadas por el fondo público proveniente de las AFJP prácticamente no varió. O sea, que la ANSES tuvo una estrategia de mantener las acciones argentinas, teniendo una actitud totalmente pasiva buscando un rendimiento por valorización en el precio por ganancia de capital o por el cobro de dividendos de las utilidades como hizo saber en las asambleas que participó.

Respecto de la primera de las hipótesis acerca si la nacionalización del sistema privado de jubilaciones y pensiones conllevó a una reducción drástica de la liquidez y volumen operado en el mercado de acciones, los resultados obtenidos confirman la misma, dado que los análisis de este trabajo indican que los métodos que se utilizaron para evaluar la liquidez del mercado de acciones describieron de manera adecuada y significativa la relación entre la salida de las AFJP y la reducción del volumen negociado.

En todas las variantes que se utilizaron para describir las variaciones en el volumen y liquidez entre el año 2005 y el año 2010 en el MERVAL, se llegó a la misma conclusión: que a partir de la estatización de los fondos previsionales y en su gestión, los volúmenes negociados y por ende la liquidez disminuyeron considerablemente.

Particularmente, en los últimos meses del año 2008 (el 20 de octubre fue el anuncio de nacionalización) y los primeros meses del año 2009 se comenzó a sentir la ausencia de los mayores inversores institucionales donde se les había subrogado todos sus derechos y por ende no podían administrar fondos de terceros como fiduciarios. Sin embargo, esto siempre asumiendo que el evento de la eliminación del subsistema privado de jubilaciones, haya sido el más relevante en dicho mes, y considerándolo como un efecto negativo en lo institucional para el país, y otros acontecimientos que pudieran haber ocurrido en dicho lapso en el exterior como la crisis de Lehman Brothers.

Para fundamentar lo dicho, los análisis realizados acerca de la evolución del volumen operado de acciones que cotizan en la BCBA en el MERVAL, ya sea en forma anual, 
mensual, promedio diario anual en pesos nominales, como así los volúmenes negociados en dólares, demuestran que la caída en el volumen negociado en acciones es contemporánea a la eliminación del sistema que participaban las AFJP y se mantuvo hasta el final de la serie analizada. Asimismo, lo operado en forma anual en términos reales, es decir sacando la inflación, arribó a las mismas conclusiones que en términos nominales, mostrando una variación negativa más moderada en el año 2009, pero más pronunciada en el año 2008, que son los años donde se pone mayor énfasis en el enfoque. Estos resultados demuestran la importante caída en la negociación de acciones producidas en el MERVAL en dicho período.

Otra de las herramientas utilizadas para analizar el efecto en la liquidez del mercado secundario del MERVAL fue el estudio del evento, que mostró la mayor falta de liquidez en el mercado de acciones de Argentina luego de la decisión tomada por parte del estado nacional.

Por otra lado, al analizar el volumen negociado -sacando el efecto precio- se concluye que en el año 2009 se observa una fuerte caída en las cantidades negociadas en forma anual y en el promedio diario, mostrando en términos relativos un descenso de más del $50 \%$. Pero la diferenciación en este caso a las anteriores conclusiones sobre la liquidez, es que a partir del año 2009 se negoció la mitad en cantidades de acciones en el MERVAL de lo que se negociaba en el año 2008, y no llegando a los niveles del año 2006 que son los mínimos del período.

Es una verdad de perogrullo, que la Argentina necesita profundizar el desarrollo de su mercado de capitales y más aún el mercado de acciones, esto quedó demostrado en los resultados expuestos, más con los resultados obtenidos con el indicador que se construyó. En pocos trimestres luego de la estatización del sistema jubilatorio, el indicador construido fue superior al $1 \%$ del volumen comercializado sobre el PBI trimestral, debido posiblemente a la salida de la operatoria de las AFJP en el mercado. Sin embargo, mientras el nivel de actividad de la economía Argentina tuvo un crecimiento y evolución favorable durante todo el período analizado, el volumen negociado no acompañó con la misma fuerza dicho crecimiento. 
Por otra parte, los resultados encontrados referidos a la segunda hipótesis planteada concuerdan en el sentido que la concentración en pocas manos (grupo controlante y FGS), produjo serias limitantes en el floating de las empresas cotizantes.

Ello se debió a que la estructura de acciones del FGS proveniente de las AFJP, no tuvo grandes modificaciones en las tenencias nominales, con excepción de dividendos en acciones recibidos, y operaciones puntuales realizadas como excepción. Por lo que el FGS no ha tenido una gestión activa en el mercado primario ni secundario en la negociación de participaciones en empresas argentinas. Sin embargo, demostró su interés en ejercer sus derechos societarios y hacer respetar todos los votos que le corresponden de acuerdo con su tenencia designando directores en los casos correspondientes, y en forma indirecta ayudando a los inversores minoristas que se ven representados en parte ante el grupo controlante rompiendo en parte tradicionales problemas de agencia.

Conclusiones interesantes que se encontraron es que la ANSES tenía en su poder a diciembre de 2010 poco más del $14 \%$ del capital social de las 41 empresas argentinas que se tiene inversiones. El mayor porcentaje de capital que se posee es en el sector estratégico de siderurgia, mostrando también una importante atomización en participación accionaria en empresas de los diversos sectores productivos de la economía argentina. Otra conclusión importante es que en siete empresas del total analizado, los fondos previsionales de los trabajadores poseen más de un cuarto del capital social.

El caso en los cuales se presentan limitaciones en el capital flotante, es cuando la tenencia de los accionistas mayoritarios es elevada, provocando que la liquidez en el mercado se vea limitada por lo que los inversores individuales e institucionales no pueden comprar y vender sus títulos tan fácilmente. En seis empresas en que la ANSES posee participación, mantienen en circulación en el mercado más de la mitad del capital social a pesar de restarles la participación del controlante y del fondo de garantía, manteniendo la flotación en el mercado secundario con total liquidez.

La mayor concentración de las empresas analizadas se da en el rango entre $20 \%$ hasta $40 \%$ de capital flotante, con un casi $44 \%$ del total del capital social (18 casos 
de empresas de un total de 41). Asimismo, en más de la mitad del total de las empresas, poseían un floating extendido menor al 20\% del capital social. Es decir, que casi el $83 \%$ de las empresas argentinas en que el FGS poseía acciones a fines del 2010, tenían un floating extendido menor al $40 \%$.

En cuanto a los derechos políticos, se puede apreciar la mayor concentración de los votos en las sociedades controlantes, en términos relativos superiores a lo que poseían en acciones del capital social. Es decir, que hay empresas que tienen una capitalización bursátil aparente, ya que se distancia el porcentaje del capital social que se posee, en comparación con la participación en el total de votos.

El organismo de la seguridad social tiene en promedio un valor próximo al $13 \%$ de los votos totales de las 41 empresas. Sin embargo, los respectivos grupos controlantes ejercen su control en el total de los votos con un porcentaje superior al $67 \%$ en promedio. Por otro lado, en ninguna de las compañías, la ANSES posee más del $30 \%$ de los votos disponibles. $Y$ con un valor relativo mayor al $46 \%$ del total, los grupos controlantes poseen entre el $60 \%$ y $80 \%$ de los votos disponibles, mostrando su supremacía en los órganos de gobierno. Esta característica se da en 19 empresas de las 41 analizadas.

Si las empresas que tienen su capital abierto poseen una acción igual a un voto como requisito, adiciona transparencia, seguridad jurídica, respeto incondicional para el accionista minoritario y reglas de juego claras en el mercado de capitales. Asimismo, demuestra que el FGS pierde poder político en la posibilidad de tener representantes en los directorios de las empresas, al poseer menos votos en términos relativos que lo que posee en relación al capital social. A pesar de lo novedoso que fue el Decreto 441/2011, la ANSES ya había podido hacer valer sus derechos societarios y designar directores en distintas empresas. El organismo nacional se debe asegurar la debida independencia de los directores que designa, dejar en claro la lealtad que deben tener hacia el Estado que los designó, y cuál es el objetivo y estrategia que se busca.

Para finalizar, como conclusión, los resultados muestran que se necesita transmitir confianza a través del tiempo como principio fundamental, entre los distintos 
participantes del mercado de capitales y evitar cambios repentinos en el marco jurídico de los negocios.

\section{Recomendaciones}

Los resultados obtenidos podrán servir como base para el futuro diseño de normativas que incluyan la creación de inversores institucionales, como así leyes que traten de cubrir los conflictos de intereses de los directores designados por el Estado para velar por su independencia y criterio profesional.

Por otro lado seguir trabajando por la tan mentada democratización accionaria, que consistiría en la masificación de la inversión en acciones por parte de inversores individuales principalmente, ciudadanos de a pie, que puedan participar del crecimiento de las empresas más productivas y permitiendo reducir los costos de financiamiento de las firmas. Esta característica le permitiría mayor liquidez y profundidad al mercado de acciones, y dejando el camino libre para que inversores institucionales puedan volcar sus recursos genuinos al largo plazo financiando la industria y créditos hipotecarios.

Asimismo, el presente trabajo podría ser profundizado con un estudio acerca de los cambios de fines de las inversiones del Estado de los fondos previsionales. Analizando el efecto de la modificación a las reglas de juego y el marco jurídico de los negocios sobre la transparencia y el desarrollo del mercado de acciones de empresas cotizantes, realizándose encuestas y recolectando opiniones dirigidas en donde se seleccionarían personas calificadas para emitir opinión sobre los cambios producidos en la administración de las acciones que poseían las AFJP y los cambios normativos.

La institucionalidad que todo estado de derecho anhela es con la formación de instituciones sólidas, creíbles, transparentes y perdurables en el tiempo, buscando la credibilidad en las acciones y políticas. Una credibilidad que sea obtenida por cumplimiento del marco legal y judicial para la protección de accionistas minoritarios y del gobierno corporativo. Y por supuesto que tengan las instituciones la transparencia necesaria, para obtener la información fácilmente en el mercado financiero. Para todo ello se necesita una estabilidad jurídica, es decir la necesitad de 
leyes que establezcan reglas de juego claras y estables, con un rol indelegable del Estado por proveerlas y garantizar su cumplimiento, impidiendo modificaciones repentinas, sino que sean de largo plazo y para el bienestar general del pueblo.

En el mercado de acciones, se podría implementar como desarrolla Rotman (2009) entre las más interesantes ideas crear la figura del market makers (hacedores de mercados), para tener cotización obligatoria por año de por lo menos una parte mínima del capital social de cada empresa que tenga capital social abierto. Otra propuesta sería aumentar el floating accionario mínimo, obligando a abrir un poco más el capital de algunas empresas que cotizan en diferentes bolsas, pero que prácticamente son cerradas como se mostró en los resultados vistos. Y la aparición de índices representativos de todas las empresas cotizantes, para ampliar significativamente los negocios bursátiles y desconcentrar la operatoria.

Otra recomendación tomada de Zicari (2008), es la creación de una índice sustentable en la Argentina, y de fondos responsables o éticos que inviertan en proyectos con bajas externalidades negativas, y que participen inversores responsables. Las empresas que se incluyan en este índice o fondos responsables deben cumplir con la responsabilidad social empresaria (RSE), además de cumplir con los criterios tradicionales de rendimiento, riesgo y liquidez, deben considerar factores ambientales, sociales y éticos. El FGS de la ANSES podría tomar la iniciativa en exigir balances sociales y buenas prácticas en su funcionamiento a las empresas en que invierta, impulsando un estilo de gestión empresaria satisfaciendo las necesidades de los ciudadanos, con el debido cuidado de no perjudicar el normal funcionamiento de la empresa pero que brinde mayor información a los distintos inversores individuales como institucionales.

Las recientes crisis financieras en Estados Unidos y Europa deberían llevar a una muy cuidadosa reflexión de parte de los que tienen la responsabilidad de administrar la cartera de inversiones de los fondos previsionales, ya sea en la valuación de distintos instrumentos para su uso práctico en la gestión de portafolios, y el manejo de riesgo. No es un tema menor, el destino y las proyecciones de los distintos sistemas previsionales en el mundo donde los cálculos actuariales preocupan, y la Argentina no está al margen de esta problemática. 
Por ello, el Estado en este caso representado por el FGS necesita ser un fondo anti cíclico ante eventualidades que pueda presentar la seguridad social en Argentina, y ser un estandarte del Estado con su ejemplo para enseñar el definitivo camino al desarrollo del mercado de capitales. Más aún, si se quiere ayudar al progreso del mercado de acciones para poder tener participaciones en las distintas empresas y poder exigir mejores prácticas de gobierno corporativo en búsqueda del beneficio de todos, y que las mismas puedan financiar proyectos de inversión viables para su crecimiento.

\section{Bibliografía}

\section{Libros y capítulos de libros}

- APREDA, R. (1994), "El nuevo Sistema Previsional Argentino”, Ediciones Macchi.

- BEBCZUK, R.; DELFINER, M.; FANELLI, J.M.; KAWAMURA, E. y SUSMEL, R. (2010) "Progresos en Finanzas", Serie Progresos en Economía. Asociación Argentina de Economía Política. Primera Edición. Temas Grupo Editorial.

- BREALEY, R. y MYERS, S. (1998) "Fundamentos de Financiación Empresarial", Quinta Edición, Mc Graw Hill.

- BRIGHAM, E. F. y HOUSTON, J. F. (2004) "Fundamentos de Administración Financiera". Décima Edición. Ed. Thomson.

- CASTORINA, J.; LENNOX, R. y LOPEZ SANTISO, H. (2010) "Manotazos a los Fondos previsionales: Las manipulaciones del Estado y un futuro predecible", Editorial Osmar D. Buyatti.

- ELBAUM, M. A. (2006) "Administración de Carteras de Inversión". Ediciones Macchi. 2da. Edición.

- FORNERO, R. A. (2008) "Cronología de las Finanzas". Fondo Editorial Consejo Profesional de Ciencias Económicas de las Ciudad Autónoma de Buenos Aires.

- LÓPEZ DE PUGA, A. y ORIOLO, M. I. (1997) "Diccionario Bursátil - Inglés Castellano. Términos y expresiones de bolsa, economía y finanzas". Editorial Universidad.

- MesutTI, D. J.; AlvareZ, V. A. y GRAFFI, H. R. (1992) "Selección de Inversiones, Introducción a la teoría de la cartera". Editorial Macchi. 
- MONTENEGRO, M. (2011) “Es la eKonomía, estúpido". Editorial Planeta 2da. Edición.

- MUÑOZ, N. (2006) "Desarrollo del Mercado de Capitales: Un imperativo de la economía". Fondo editorial Consejo Prof. de Ciencias Económicas de la Ciudad Autónoma de Buenos Aires.

- OLIVO, S. L. (2008) "Fundamentos para la Administración de Carteras de Acciones". Fundación Bolsa de Comercio de Buenos Aires.

- PASCALE, R. (2006) "Decisiones Financieras". 4ta. Edición. Fondo Editorial Consejo Profesional de Ciencias Económicas de las Ciudad Autónoma de Buenos Aires.

- ROSS, S. A.; WESTERFIELD, R. W. y JAFFE, J. F. (2007) "Finanzas Corporativas". Séptima Edición. Mc Graw Hill.

- SHARPE, W. (1970) "Portfolio Theory and Capital Markets". McGraw-Hill. (Teoría de cartera y del mercado de capitales, Deusto, 1974).

- SHARPE, W. (2008) "Inversores y Mercados". Ediciones Deusto.

- STIGLITZ, J. (2003) "Los felices 90. La semilla de la destrucción. La década más próspera de la historia como causa de la crisis económica actual". Editorial Taurus.

- SCHVARTZ, F. (2008) "Mercado de Capitales. Transparencia y mejores prácticas.

El gobierno de las empresas cotizadas". Editorial Osmar D. Buyatti.

- VAN HORNE, J. C. (1997) "Administración Financiera". Décima Edición. Pearson Educación.

- ZICARI, A. (2008) "Fondos Éticos: Factores sociales y ambientales en carteras de inversión". Fondo Editorial Consejo Profesional de Ciencias Económicas de las Ciudad Autónoma de Buenos Aires.

\section{Trabajos y publicaciones consultadas}

- ANSES (2010) "El manejo de los fondos de pensión alrededor del mundo: Una comparación internacional con la Argentina". Serie de Informes Especiales del Fondo de Garantía de Sustentabilidad de ANSES. Enero de 2010

- ALONSO J. A. y GARCIMARTIN, C. (2009) "Criterios y factores de calidad institucional: un estudio empírico". Revista de Economía Aplicada Número 55 (vol. XIX), 2011, págs. 5 a 32. Madrid, España. 
- APELLA I., MACEIRA, D. y KATZ, J. (2004) "Economías de Escala y Barreras a la Entrada en el Mercado Argentino de AFJP". Convenio Facultad de Ciencias Económicas (UBA) - Superintendencia de AFJP (SAFJP).

- BARRAZA, J. S. E. (2009) "Información, Liquidez y Precios de los Activos en Argentina". XXIX Jornadas Nacionales de la Sociedad Argentina de Docentes en Administración Financiera. Buenos Aires entre el 7 y el 11 de Septiembre de 2009.

- BARRAZA, J. S. E. (2009) "Shocks de Información y Precios de los Activos en Argentina". Universidad Nacional del Centro de la Provincia de Buenos Aires Centro de Estudios en Administración. Tandil, 27 y 28 de Noviembre de 2009.

- BENEDICTO XVI (2009) "Carta Encíclica Caritas in Veritate. Sobre el desarrollo humano integral en la caridad y en la verdad". Editorial Paulinas. Roma, el 29 de junio del año 2009.

- CANTÓ, G. H. (2001) "Eficiencia en el Mercado Argentino de Capitales: Efectos AFJP y Cambio de Mes". Trabajo Final. Maestría en Finanzas. Universidad del CEMA.

- DAPENA, J. P. (2003) "Absorción de shocks en economías volátiles: ahorro a través de acciones en mercados de capitales. Caso Argentino 1993 - 2001". Universidad del CEMA - Fundación Bolsa de Comercio de Buenos Aires.

- DAPENA, J. P. (2007) "Rol del Mercado de Capitales en el crecimiento de la economía: literatura y evidencia para Argentina" Universidad del CEMA Fundación Bolsa de Comercio de Buenos Aires.

- ELESPE, D. (2011) "Directores del Estado en Sociedades Abiertas. Condiciones necesarias para su participación". La Ley. Viernes 6 de mayo de 2011. Página 1 a 4.

- FAMA, E. F. (1970) "Efficient markets: a review of theory and empirical work". Journal of Finance.

- FAMA, E. F. (1990) "Stock Returns, Expected Returns and Real Activity" . Journal of Finance 45, páginas 1089-1108

- FORNERO, R. A. (2006) "Usos de "Riesgos" en Finanzas de Empresas". XXVI Jornadas Nacionales de Administración Financiera, SADAF.

- GABBI, A. (2005) "Un mercado bursátil funcional al desarrollo de las empresas medianas nacionales". 11a Conferencia Industrial Argentina. ¿Por qué se 
venden las empresas argentinas? Unión Industrial Argentina (UIA). Santa Fe, Argentina, 28 y 29 de Noviembre de 2005.

- HAYZUS, J. R. (2004) "El Entorno Jurídico del Mercado de Capitales". Academia de Mercado de Capitales (AMC). Noviembre de 2004.

- INSTITUTO ARGENTINO DE EJECUTIVOS DE FINANZAS (IAEF) (2007) "Certified International Investment Analyst (CIIA®). Manual Portfolio Management". Año 2007.

- INSTITUTO ARGENTINO DE MERCADO DE CAPITALES (IAMC) (2005 a 2010) "Informe Anuario y Mensual". Año 2005 a 2010.

- INTERNATIONAL SOCIAL SECURITY ASSOCIATION (2004). "ISSA, Informe Técnico No 13". Septiembre 2004.

- INTERNATIONAL SOCIAL SECURITY ASSOCIATION (2007). "Public Scheme Reserve Funds".

- IRIGOYEN, C. (2006) "Mercado de capitales: desarrollo para atraer nuevos inversores y emisores en forma sistemática". Contribuciones de los especialistas. El país que queremos. Principios, estrategia y agenda para alcanzar una Argentina mejor. Editorial Temas.

- JENSEN, M. y MECKLING, N. (1976) "Theory of the Firm: Managerial Behaviour, Agency Costs and Ownership Structure". Journal of Financial Economics 3 (4): 305-360.

- KRAUSE, M. (2007) "Calidad de las Instituciones y Competencia Institucional". Centro de Investigaciones de Instituciones y Mercados de Argentina (CIIMA) Escuela Superior de Economía y Administración de Empresas (ESEADE). Fundación Libertad y Progreso. Buenos Aires. Publicado por International Policy Press.

- KRAUSE, M. (2011) "Índice de Calidad Institucional 2011". Centro de Investigaciones de Instituciones y Mercados de Argentina (CIIMA) - Escuela Superior de Economía y Administración de Empresas (ESEADE). Fundación Libertad y Progreso. Buenos Aires. Publicado por International Policy Press.

- LAGOS, R. (2008) "Asset Prices and Liquidity in an Exchange Economy”. Working Paper.

- LEVINE, R. y ZERBOS, S. (1998) "Stock Markets and Economic Growth". American Economic Growth 88 (3): 537-558. 
- LINTNER, J. (1965) "The valuation of risks assets and the selection of risky investments in stock portfolios and capital budgets". Review of Economics and Statistics.

- LUCAS, R. (1978) "Asset Prices in an Exchange Economy" Econometrica 46, páginas 1429-1445.

- MARKOWITZ, H. (1952) "Portfolio selection". The Journal of Finance. Vol.7 № 1. Páginas 77-91.

- MARKOWITZ, H. (1959) "Portfolio Selection: Efficient Diversification of Investments", Yale Univ. Press, 1959.

- MARKOWITZ, H. (1987) "Mean-Variance Analysis in Portfolio Choice and Capital Markets", Blackwell.

- MOODY'S INVESTOR SERVICE (2011) "Latin America's Pension Reform 30 Years On", Special comment. Lunes 17 de Octubre de 2011.

- NAVEIRO, M. (2011) "Los inversores institucionales y el mercado argentino de capitales". La Ley. Viernes 29 de julio de 2011. Páginas 1 a 7.

- NEFFA, G. (2010) "Mercados desarrollados, mercados emergentes y mercados de frontera". Revista Inversor Global. Conceptos \& Estrategias. № 73. Año 8.

- NORTH, D. C. (1991) "Institutions". Journal of Economic Perspectives. American Economic Association. Volumen $5 \mathrm{~N}^{\circ} 1$ Páginas 97 a 112.

- ROTMAN J. R. (2009) "Mercado de capitales: medidas necesarias para su modernización". Opinión. Revista del Consejo Profesional de Ciencias Económicas de la Ciudad Autónoma de Buenos Aires. Año I. Número 8. Julio de 2009.

- SALVATIERRA, J.M. (2008) "AFP: Efectos de la Crisis Internacional en el Sector Pasivo". Informe Bimensual de Coyuntura Financiera - Número 4. Facultad de Administración y Economía. Universidad de Santiago de Chile. Colaboración pág. 10. Del 12 de Diciembre de 2008 al 10 de Marzo de 2009.

- SCHWERT, G. W. (1990) "Stock Returns and Real Activity: A Century of Evidence” . Journal of Finance 45, páginas 1237-1257.

- TOBIN, J. (1958) "Liquidity preference as behavior towards risk". Review of Economic Studies, Febrero de 1958.

- VILLAR, E. (2003) "Conceptos sobre la teoría de la eficiencia de los mercados". Maestría en Administración, Facultad de Ciencias Económicas, Universidad Nacional de La Plata. 
- VILLAR, E. (2003) "Más sobre las anomalías en los mercados financieros". Maestría en Administración, Facultad de Ciencias Económicas, Universidad Nacional de La Plata.

- WALKER, E. H. (1993) "Desempeño financiero de las carteras accionarias de los fondos de pensiones en Chile ¿Ha tenido desventajas ser grandes?”. Cuadernos de Economía, Año 30; № 89, pp. 35-75. Escuela de Administración, Pontificia Universidad Católica de Chile. Abril del año 1993.

- ZABLOTSKY, E. (2001) "Eficiencia del mercado de capitales. Una ilustración", Universidad del CEMA.

- ZABLOTSKY, E. (2002) "Consideraciones sobre la eficiencia del Mercado de Capitales", Universidad del CEMA.

\section{Artículos periodísticos consultados}

- ÁMBITO FINANCIERO (2011) "Siderar presentó un recurso de amparo a la Justicia por anulación de asamblea de directorio", Diario Ámbito Financiero, Sección Economía. Lunes 18 de abril de 2011.

- BRODA, M. A. y BRODA, A. (2008) "El impacto de la política proactiva" Diario La Nación, Economía, Domingo 14 de diciembre de 2008

http://www.lanacion.com.ar/nota.asp?nota_id=1080434

- CERRUTI, J. (2011) "En qué empresas privadas el Estado podrá designar nuevos directores" Diario El Cronista. Jueves 14 de abril de 2011.

- DELLATORRE, R. (2011) “Una historia resuelta en capítulos", Diario Página/12, Sección Economía. Miércoles 13 de abril de 2011.

- EL CRONISTA (2011) "Un Decreto de Necesidad y Urgencia elimina el tope para las designaciones de ANSES", Diario El Cronista. Miércoles 13 de abril de 2011.

- EL CRONISTA (2011) "El país está entre las naciones del mundo que más cayeron en calidad institucional", Diario El Cronista. Jueves 16 de junio de 2011.

- GABIN, L. (2011) "Sin ruido financiero por la ANSeS: en la city ven un pacto para que el Estado cobre pero no avance", Diario El Cronista - Finanzas \& Mercados. Jueves 14 de abril de 2011.

- GALAK, O. (2011) "El Gobierno aumentará su injerencia en 32 empresas", Diario La Nación. Miércoles 13 de abril de 2011. 
- GUARINO, J. (2010) "Pese a las presiones, la ANSeS descarta vender las acciones locales que tiene en cartera" Diario El Cronista - Finanzas \& Mercados. Edición impresa. Miércoles 13 de Octubre de 2010.

- INFOBAE (2011) "El Gobierno nombrará más directores en empresas según su tenencia accionaria", Sección Finanzas. Martes 12 de Abril de 2011.

- LA NACIÓN (2011) "Rechazo empresario al avance del Gobierno en las compañías", Edición impresa Diario La Nación. Jueves 14 de abril de 2011.

- LA NACIÓN (2011) "Aval de la Justicia al Gobierno por Siderar", Edición impresa Diario La Nación. Miércoles 27 de abril de 2011.

- LEWKOWICZ, J. (2011) "Hará valer el peso de sus acciones", Diario Página/12, Sección Economía. Miércoles 13 de abril de 2011.

- LEWKOWICZ, J. (2011) "Fueron contra un decreto totalmente vigente", Diario Página/12, Sección Economía. Sábado 23 de abril de 2011.

- LOPEZ MURPHY, R. (2009) "Las deudas ocultas en la Anses". Edición impresa Diario La Nación. Opinión. Domingo 16 de agosto de 2009.

- LUKIN, T. (2011) "Al establishment no le gusta que lo controlen”, Diario Página/12 Sección Economía. Jueves 14 de abril de 2011.

- MATHUS RUIZ, R. (2009) “La billetera que no alcanza”. Edición impresa Diario La Nación. Escenario. Domingo 16 de agosto de 2009.

- RAMALLO, R. (2008) "Con la muerte de las AFJP se redefine el sistema financiero argentino" iProfesional.com. Finanzas. Miércoles 22 de Octubre de 2008. http://www.iprofesional.com/notas/73491-Con-la-muerte-de-las-AFJP-seredefine-el-sistema-financiero-argentino.html

- ROUBINI, N. (2010) "Gordon Gekko volvió a nacer y no morirá con reformas tibias". Project Syndicate 1995-2010. Para Diario La Nación. Economía. Domingo 22 de agosto de 2010.

- STANG, S. (2007) “Las AFJP repatriarán \$ 8000 millones". Diario La Nación. Economía. Jueves 18 de octubre de 2007.

- VAN THIENEN, P. A. (2011) "La ANSeS Traba Política de Dividendos de Empresas Cotizadas", Abogados.com.ar, 21 de marzo 2011. 


\section{Referencias y Anexos}

\section{Referencias:}

- Ley 24.241

- Ley 26.222

- Decreto 897/07

- Ley 26.245

- Decreto 2103/08

- Decreto 1602/09

- Decreto 411/11

\section{Anexos:}

Tabla 1: Indicador de la importancia de los mercados de valores en las economías nacionales de Argentina y de otros países latinoamericanos. El indicador muestra la capitalización bursátil sobre el PBI a precios corrientes (años 2005-2010). Los valores de la capitalización bursátil y el PBI están expresados en miles de millones de dólares.

\begin{tabular}{|l|r|r|r|r|r|r|}
\hline \multicolumn{1}{|c|}{ Añís } & $\mathbf{2 0 0 5}$ & \multicolumn{1}{c|}{$\mathbf{2 0 0 6}$} & $\mathbf{2 0 0 7}$ & \multicolumn{1}{c|}{$\mathbf{2 0 0 8}$} & \multicolumn{1}{c|}{$\mathbf{2 0 0 9}$} & \multicolumn{2}{c|}{$\mathbf{2 0 1 0}$} \\
\hline Argentina & $26,95 \%$ & $24,01 \%$ & $21,94 \%$ & $12,27 \%$ & $14,75 \%$ & $18,2 \%$ \\
\hline Brasil & $57,32 \%$ & $65,28 \%$ & $104,27 \%$ & $37,64 \%$ & $84,96 \%$ & $76,4 \%$ \\
\hline Chile & $108,76 \%$ & $120,04 \%$ & $129,90 \%$ & $77,78 \%$ & $142,76 \%$ & $171,6 \%$ \\
\hline Colombia & $40,54 \%$ & $39,25 \%$ & $50,32 \%$ & $36,42 \%$ & $60,46 \%$ & $73,6 \%$ \\
\hline México & $30,78 \%$ & $41,19 \%$ & $38,89 \%$ & $21,51 \%$ & $40,24 \%$ & $45,3 \%$ \\
\hline Perú & $32,03 \%$ & $41,85 \%$ & $64,61 \%$ & $29,72 \%$ & $56,53 \%$ & $67,3 \%$ \\
\hline
\end{tabular}


Tabla 2: Monto anual negociado (en pesos) (Período 2005-2010) en el MERVAL y variación interanual (\%).

\begin{tabular}{|l|c|r|}
\hline \multirow{2}{*}{ Año } & \multicolumn{2}{|c|}{ Monto negociado anual } \\
\cline { 2 - 3 } & Pesos & \multicolumn{1}{c|}{ Var. $\%$} \\
\hline 2005 & $\$ 18.810 .233 .783,02$ & $\mathrm{~N} / \mathrm{A}$ \\
\hline 2006 & $\$ 15.152 .710 .756,88$ & $-19,44 \%$ \\
\hline 2007 & $\$ 21.879 .780 .982,17$ & $44,40 \%$ \\
\hline 2008 & $\$ 20.663 .995 .890,73$ & $-5,56 \%$ \\
\hline 2009 & $\$ 10.680 .050 .429,78$ & $-48,32 \%$ \\
\hline 2010 & $\$ 14.014 .906 .373,37$ & $31,23 \%$ \\
\hline
\end{tabular}

Fuente: Elaboración propia en base a datos de Bolsar de la BCBA.

Tabla 3: Días operados anualmente, monto nominal promedio diario negociado (en pesos)

(Período 2005-2010) en el MERVAL y variación interanual (\%).

\begin{tabular}{|r|r|r|r|}
\hline \multirow{2}{*}{ Año } & \multirow{2}{*}{$\begin{array}{c}\text { Días } \\
\text { operados }\end{array}$} & \multicolumn{3}{|c|}{$\begin{array}{c}\text { Promedio nominal diario } \\
\text { operado }\end{array}$} \\
\cline { 3 - 4 } & & Pesos & \multicolumn{1}{c|}{ Var. $\%$} \\
\hline 2005 & 252 & $\$ 74.643 .785$ & $\mathrm{~N} / \mathrm{A}$ \\
\hline 2006 & 247 & $\$ 61.347 .007$ & $-17,81 \%$ \\
\hline 2007 & 246 & $\$ 88.942 .199$ & $44,98 \%$ \\
\hline 2008 & 247 & $\$ 83.659 .902$ & $-5,94 \%$ \\
\hline 2009 & 244 & $\$ 43.770 .698$ & $-47,68 \%$ \\
\hline 2010 & 246 & $\$ 56.971 .164$ & $30,16 \%$ \\
\hline
\end{tabular}

Fuente: Elaboración propia en base a datos de Bolsar de la BCBA.

Tabla 4: Tipo de cambio implícito, monto anual negociado (en dólares) (2005-2010) en el MERVAL, promedio diario negociado (en dólares) (Período 2005-2010) y variaciones interanuales (\%).

\begin{tabular}{|r|r|r|r|r|r|}
\hline \multirow{2}{*}{ Año } & Tipo de & \multicolumn{2}{|c|}{ Monto anual negociado } & \multicolumn{2}{c|}{ Promedio diario negociado } \\
\cline { 3 - 6 } & Cambio & Dólares & Var. \% & Dólares & \multicolumn{1}{c|}{ Var. \% } \\
\hline 2005 & 2,926 & USS 6.428.502.791 & N/A & USS 25.509.932 & N/A \\
\hline 2006 & 3,074 & USS 4.929.065.602 & $-23,32 \%$ & USS 19.955.731 & $-21,77 \%$ \\
\hline 2007 & 3,125 & USS 7.002.522.303 & $42,07 \%$ & USS 28.465 .538 & $42,64 \%$ \\
\hline 2008 & 3,158 & USS 6.543.715.821 & $-6,55 \%$ & USS 26.492 .777 & $-6,93 \%$ \\
\hline 2009 & 3,746 & USS 2.850.851.049 & $-56,43 \%$ & USS 11.683.816 & $-55,90 \%$ \\
\hline 2010 & 3,925 & USS 3.570.277.933 & $25,24 \%$ & USS 14.513.325 & $24,22 \%$ \\
\hline
\end{tabular}

Fuente: Elaboración propia en base a datos de Bolsar de la BCBA. 
Tabla 5: Monto anual negociado en términos reales (en pesos) (Período 2005-2010) en el MERVAL, Índices de Precios Implícitos del PBI (Base $1993=100$ ) c.f. y a precios corrientes; y variación interanual (\%).

\begin{tabular}{|c|r|r|r|}
\hline \multirow{2}{*}{ Año } & \multirow{2}{*}{$\begin{array}{c}\text { Índice de Precios } \\
\text { Implícitos (IPI) } \\
\text { Base 1993 }=\end{array}$} & \multicolumn{2}{|c|}{$\begin{array}{c}\text { Monto operado anual en } \\
\text { pesos reales }\end{array}$} \\
\cline { 3 - 4 } & $\mathbf{1 0 0 , 0}$ & Pesos reales & \multicolumn{1}{c|}{ Var. \% } \\
\hline 2005 & $8,84 \%$ & $\$ 17.282 .386 .450$ & $\mathrm{~N} / \mathrm{A}$ \\
\hline 2006 & $13,43 \%$ & $\$ 13.359 .081 .931$ & $-22,70 \%$ \\
\hline 2007 & $14,26 \%$ & $\$ 19.149 .413 .701$ & $43,34 \%$ \\
\hline 2008 & $19,07 \%$ & $\$ 17.354 .719 .773$ & $-9,37 \%$ \\
\hline 2009 & $9,98 \%$ & $\$ 9.711 .126 .805$ & $-44,04 \%$ \\
\hline 2010 & $15,38 \%$ & $\$ 12.147 .141 .032$ & $25,08 \%$ \\
\hline
\end{tabular}

Fuente: Elaboración propia en base a datos de Bolsar de la BCBA e INDEC.

Tabla 6: Cantidad de acciones negociadas en forma anual y promedio diario (Período 20052010) en el MERVAL, y sus variaciones interanuales (\%).

\begin{tabular}{|c|r|r|r|r|}
\hline \multirow{2}{*}{ Año } & \multicolumn{2}{|c|}{$\begin{array}{c}\text { Total anual de acciones } \\
\text { negociadas }\end{array}$} & \multicolumn{2}{c|}{$\begin{array}{c}\text { Promedio diario } \\
\text { Operado }\end{array}$} \\
\cline { 2 - 5 } & $\begin{array}{c}\text { Cantidades } \\
\text { anuales }\end{array}$ & \multicolumn{1}{c|}{ Var. \% } & $\begin{array}{c}\text { Cantidades } \\
\text { diarias }\end{array}$ & \multicolumn{1}{c|}{ Var. \% } \\
\hline 2005 & 3.169 .984 .332 & $\mathrm{~N} / \mathrm{A}$ & 12.629 .420 & $\mathrm{~N} / \mathrm{A}$ \\
\hline 2006 & 1.999 .386 .909 & $-36,93 \%$ & 8.062 .044 & $-36,16 \%$ \\
\hline 2007 & 2.706 .648 .272 & $35,37 \%$ & 10.958 .090 & $35,92 \%$ \\
\hline 2008 & 3.889 .420 .391 & $43,70 \%$ & 15.746 .641 & $43,70 \%$ \\
\hline 2009 & 1.906 .031 .857 & $-50,99 \%$ & 7.811 .606 & $-50,39 \%$ \\
\hline 2010 & 1.918 .872 .210 & $0,67 \%$ & 7.800 .294 & $-0,14 \%$ \\
\hline
\end{tabular}

Fuente: Elaboración propia en base a datos de Bloomberg en base a BCBA

Tabla 7: Resumen con la descripción de los puntos tratados en las Actas del Comité Ejecutivo del FGS de la ANSES (diciembre de 2008 a diciembre de 2010).

\begin{tabular}{|c|c|c|c|}
\hline $\begin{array}{c}\text { № } \\
\text { Acta }\end{array}$ & Fecha & Punto: & Descripción \\
\hline \multirow{13}{*}{1} & \multirow{13}{*}{ 05/02/2009 } & 1 & Integración del Comité Ejecutivo del FGS \\
\hline & & 2 & Adecuación del Reglamento de Funcionamiento del Comité \\
\hline & & 3 & $\begin{array}{l}\text { Fijación de los principios de seguridad y rentabilidad de las inversiones realizadas con } \\
\text { activos del FGS }\end{array}$ \\
\hline & & 4 & Activos embargados en el Citibank \\
\hline & & 5 & Líneas directrices para la inversión con los activos del FGS \\
\hline & & 6 & Convenio con la UBA \\
\hline & & 7 & Consideración del informe de la UBA respecto del "Plan incentivos a la industria automotriz" \\
\hline & & 8 & Informe de operaciones realizadas \\
\hline & & 9 & informe sobre políticas de inversiones \\
\hline & & 10 & Informe sobre montos y composición de los recursos actuales del FGS \\
\hline & & 11 & Registración contable \\
\hline & & 12 & Tratamiento de nuevos proyectos de inversión \\
\hline & & 13 & Información para la Comisión Bicameral de Control de los Fondos de la Seguridad Social \\
\hline
\end{tabular}


Mercado de Capitales Argentino: Efectos de los fondos estatizados del sistema previsional sobre el mercado bursátil y las acciones cotizantes

\begin{tabular}{|c|c|c|c|}
\hline & & 14 & Conformación del Consejo del Fondo del FGS \\
\hline \multirow{3}{*}{2} & \multirow{3}{*}{$11 / 03 / 2009$} & 1 & Informe de operaciones realizadas \\
\hline & & 2 & Informe continuación plan incentivo industria automotriz \\
\hline & & 3 & Informe sobre concurrencia a asambleas de Sociedades Anónimas \\
\hline \multirow{4}{*}{3} & \multirow{4}{*}{$13 / 04 / 2009$} & 1 & Informe de operaciones realizadas \\
\hline & & 2 & Informe continuación plan incentivo industria automotriz \\
\hline & & 3 & Creación del Grupo de Apoyo Técnico \\
\hline & & 4 & Informe sobre concurrencia a asambleas de Sociedades Anónimas \\
\hline \multirow{6}{*}{4} & \multirow{6}{*}{$18 / 05 / 2009$} & 1 & Ampliación central Atucha II \\
\hline & & 2 & Convenio con $\mathrm{BH}$ para créditos a la vivienda familiar \\
\hline & & 3 & Informe de operaciones realizadas \\
\hline & & 4 & Informe continuación plan incentivo industria automotriz \\
\hline & & 5 & Informe sobre concurrencia a asambleas de Sociedades Anónimas \\
\hline & & 6 & Informe de cartera \\
\hline 5 & $27 / 05 / 2009$ & 1 & Financiamiento General Motors \\
\hline \multirow{6}{*}{6} & \multirow{6}{*}{$29 / 06 / 2009$} & 1 & FF Enarsa Barragán Serie I \\
\hline & & 1 & FF Enarsa Brigadier Serie 1 \\
\hline & & 2 & Embargo en el Standard Charterer Bank por U\$S 7.488.735 \\
\hline & & 3 & Informe de operaciones realizadas \\
\hline & & 4 & Informe continuación plan incentivo industria automotriz \\
\hline & & 5 & Informe sobre concurrencia a asambleas de Sociedades Anónimas \\
\hline \multirow{8}{*}{7} & \multirow{8}{*}{$31 / 07 / 2009$} & 1 & Préstamos $\mathrm{BH}$ vivienda familiar \\
\hline & & 2 & Primer desembolso ENARSA \\
\hline & & 3 & Informe de operaciones realizadas \\
\hline & & 4 & Informe continuación plan incentivo industria automotriz \\
\hline & & 5 & Informe sobre concurrencia a asambleas de Sociedades Anónimas \\
\hline & & 6 & Informe de cartera \\
\hline & & 7 & Errores de las actas anteriores \\
\hline & & 8 & Se levanta la sesión \\
\hline \multirow{9}{*}{8} & \multirow{9}{*}{$26 / 08 / 2009$} & 1 & Acuerdo con BH adquisición CHA IX y X \\
\hline & & 2 & El 31/08 se integrará el segundo desembolso de ENARSA \\
\hline & & 3 & Informe de operaciones realizadas \\
\hline & & 4 & Préstamos Chaco \\
\hline & & 5 & Suscripción de AM16 \$1.400.000 \\
\hline & & 6 & Informe continuación plan incentivo industria automotriz \\
\hline & & 7 & Informe sobre concurrencia a asambleas de Sociedades Anónimas \\
\hline & & 8 & Informe de cartera \\
\hline & & 9 & 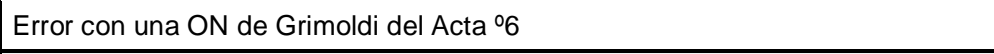 \\
\hline 9 & 02/09/2009 & 1 & Operación de canje de deuda \\
\hline \multirow{9}{*}{10} & \multirow{9}{*}{$30 / 09 / 2009$} & 1 & Suscripción de letras del tesoro en dólares u\$s 150.000 .000 \\
\hline & & 2 & Suscripción de letras del tesoro en pesos $\$ 1.350 .000 .000$ \\
\hline & & 3 & Suscripción de letras del tesoro en dólares $\$ 380.000 .000$ \\
\hline & & 4 & Suscripción de letras del tesoro en pesos $\$ 400.000 .000$ \\
\hline & & 5 & Propuesta de reconversión del Programa Federal de Construcción de Vivienda \\
\hline & & 6 & Informe de operaciones realizadas \\
\hline & & 7 & Informe continuación plan incentivo industria automotriz \\
\hline & & 8 & Informe sobre concurrencia a asambleas de Sociedades Anónimas \\
\hline & & 9 & Informe de cartera \\
\hline
\end{tabular}


Mercado de Capitales Argentino: Efectos de los fondos estatizados del sistema previsional sobre el mercado bursátil y las acciones cotizantes

\begin{tabular}{|c|c|c|c|}
\hline & & 10 & Préstamos Chaco \\
\hline 11 & $10 / 11 / 2009$ & 1 & Préstamos construcción de viviendas Prov. De Buenos Aires \\
\hline \multirow{7}{*}{12} & \multirow{7}{*}{$16 / 11 / 2009$} & 1 & VRD Serie 3 "Piedra Buena" \\
\hline & & 2 & Suscripción primaria de Valores Finduciarios $\$ 30.000 .000$ Nuevo Bancho del Chaco \\
\hline & & 3 & Suscripción BONAR X \\
\hline & & 4 & Venta DICP ; DICA ; PARP ; PARA \\
\hline & & 5 & Informe de operaciones realizadas \\
\hline & & 6 & Informe sobre concurrencia a asambleas de Sociedades Anónimas \\
\hline & & 7 & Informe de cartera \\
\hline \multirow{10}{*}{13} & \multirow{10}{*}{$10 / 12 / 2009$} & 1 & VRD serie II clase $1 \$ 36.600 .000$ SISVIAL \\
\hline & & & VRD serie II clase $2 \$ 150.000 .000$ SISVIAL \\
\hline & & 2 & ON Invap U\$S 12.000 .000 \\
\hline & & 3 & BONCOR 2017 U\$S 30.000 .000 \\
\hline & & 4 & Suscripción BONAR X \\
\hline & & 5 & Préstamos BH vivienda familiar SEGUNDA ADDENDA \\
\hline & & 6 & Segunda enmienda EPEC \\
\hline & & 7 & Informe de operaciones realizadas \\
\hline & & 8 & Informe sobre concurrencia a asambleas de Sociedades Anónimas \\
\hline & & 9 & Informe de cartera \\
\hline 14 & $11 / 12 / 2009$ & 1 & Acuerdo con BH adquisición CHA XI \$204.250.000 \\
\hline \multirow{9}{*}{15} & \multirow{9}{*}{$18 / 01 / 2010$} & 1 & Suscripción BONAR X por hasta i) $\$ 940$ millones y ii) $\$ 1.000$ millones \\
\hline & & 2 & Suscripción VRD Clase A emitidos por Albanesi Gas Clase 01, por \$110 millones \\
\hline & & 3 & $\begin{array}{l}\text { Consideración de la operación de canje de la totalidad de las ON clase } 1 \text { emitidas por Avex } \\
\text { por ON clase } 2\end{array}$ \\
\hline & & 4 & Consideración de la situación de los inversores en situación irregular \\
\hline & & 5 & Consideración de la posibilidad de la venta de títulos valores extranjeros (art. 74 inc. L) \\
\hline & & 6 & $\begin{array}{l}\text { Consideración de la ampliación de las "Líneas Directrices para la inversión en activos del } \\
\text { FGS" }\end{array}$ \\
\hline & & 7 & Consideración de las operaciones realizadas en el mes de diciembre \\
\hline & & 8 & Informe sobre concurrencia a asambleas de Sociedades Anónimas \\
\hline & & 9 & Informe de cartera \\
\hline \multirow{5}{*}{16} & \multirow{5}{*}{$19 / 01 / 2010$} & 1 & VRD Clase B Ampliación Central Nuclear Atucha II \$ 3.800.000.000 \\
\hline & & 2 & Ampliación límites por emisor de art. 17 y 18 inc. m) del Anexo III de Acta №1 \\
\hline & & \multirow{2}{*}{3} & SISVIAL: suscripción VRD Serie III clase $1 \$ 100.000 .000$ \\
\hline & & & SISVIAL: suscripción VRD Serie III clase $2 \$ 200.000 .000$ \\
\hline & & 4 & Reclasificación de los VRD de SISVIAL para que entren en el inc. q) \\
\hline 17 & $05 / 02 / 2010$ & 1 & VRD Serie $1 \$ 600.000 .000$ Hídrico primera emisión \\
\hline \multirow{8}{*}{18} & \multirow{8}{*}{$15 / 02 / 2010$} & 1 & Suscripción BONAR $X$ por hasta i) $\$ 1.760$ millones y ii) $\$ 1.000$ millones \\
\hline & & 2 & $\begin{array}{l}\text { Consideración del modelo de acuerdo con ser celebrado por las Sociedades de Bolsa que } \\
\text { participen de la venta de títulos valores extranjeros }\end{array}$ \\
\hline & & 3 & Consideración segundo desembolso Brigadier Lopez por $\$ 115$ millones \\
\hline & & 4 & Reclasificación de las CHA para que sean inciso q) \\
\hline & & 5 & Consideración de las operaciones realizadas en el mes de enero \\
\hline & & 6 & Consideración de las mandas e informes de las Asambleas \\
\hline & & 7 & Consideración de la cartera al 31/12/2009 \\
\hline & & 8 & Situación de los activos financieros constituidas por Socotherm Argentina S.A. y Capex S.A. \\
\hline 19 & 08/02/2010 & 1 & VRD Barragán \$335.000.000 \\
\hline
\end{tabular}




\begin{tabular}{|c|c|c|c|}
\hline \multirow{6}{*}{20} & \multirow{6}{*}{$12 / 03 / 2010$} & 1 & $\begin{array}{l}\text { Consideración de la suscripción de Letras del Tesoro de la Prov de Buenos Aires del 2do } \\
\text { tramo por } 80 \text { millones. }\end{array}$ \\
\hline & & 2 & Consideración de la suscripción de VRD de Barragán por $\$ 900$ millones \\
\hline & & 3 & $\begin{array}{l}\text { Avances del proceso de venta títulos valores extranjeros. Consideración de la modificación a } \\
\text { los lineamientos generales para la selección de Operadores de Mercado para la operatoria } \\
\text { en mercados secundarios. }\end{array}$ \\
\hline & & 4 & Consideración de las operaciones realizadas en el mes de febrero \\
\hline & & 5 & Consideración de las mandas e informes de las Asambleas \\
\hline & & 6 & Consideración de la cartera al 31/01/2010 \\
\hline \multirow{9}{*}{21} & \multirow{9}{*}{$12 / 04 / 2010$} & 1 & Suscripción de Discount \\
\hline & & 2 & Modificación de un párrafo de Contrato de Fideicomiso \\
\hline & & 3 & Letras de la Provincia de Buenos Aires por VN 80 Millones \\
\hline & & 4 & Lineamientos generales para plazo fijo \\
\hline & & 5 & Conversión de ADR en acciones ordinarias \\
\hline & & 6 & Conversión de acciones ordinarias en ADR para su venta y venta de activos del exterior \\
\hline & & 7 & Consideración de las operaciones realizadas en el mes de marzo \\
\hline & & 8 & Consideración de las mandas e informes de las Asambleas \\
\hline & & 9 & Consideración de la cartera al 28/02/2010 \\
\hline \multirow{2}{*}{22} & \multirow{2}{*}{$12 / 04 / 2010$} & 1 & Plan de inversiones 2010 \\
\hline & & 2 & Consideración de los gastos por operaciones del FGS \\
\hline 23 & $12 / 04 / 2010$ & - & $\begin{array}{l}\text { Consideración de la suscripción de i) VRD Serie IV Clase } 1 \text { por VN } 85 \text { mill y ii) VRD serie IV } \\
\text { Clase } 2 \text { por VN } 765 \text { millones emitidos por SISVIAL }\end{array}$ \\
\hline 24 & $29 / 04 / 2010$ & - & Consideración de la tercer addenda de Atucha II + suscripción de VRD "B" por 445 Mill. \\
\hline \multirow{9}{*}{25} & \multirow{9}{*}{$21 / 05 / 2010$} & 1 & Consideración de la suscripción de Bonar $X$ por hasta $\$ 1.000$ millones \\
\hline & & 2 & Consideración de la venta de Discount $\$ 1.200$ millones \\
\hline & & 3 & Consideración de la suscripción de Bonar X por hasta $\$ 1.200$ millones \\
\hline & & 4 & $\begin{array}{l}\text { Consideración de la suscripción de Letras del Tesoro de Prov. BsAs. Quinto tramo VN \$ } 20 \\
\text { millones }\end{array}$ \\
\hline & & 5 & $\begin{array}{l}\text { Consideración de la inversión en el financiamiento de proyectos productivos de PyMES y } \\
\text { MEGRAN en conjunto con el Ministerio de Industria y Turismo, por hasta la suma de } \$ 400 \\
\text { millones. }\end{array}$ \\
\hline & & 6 & Consideración de la asistencia a asambleas anuales de TS y TEF \\
\hline & & 7 & Consideración de las operaciones realizadas en el mes de abril \\
\hline & & 8 & Consideración de las mandas e informes de las Asambleas \\
\hline & & 9 & Consideración de la cartera al 31/03/2010 \\
\hline \multirow{7}{*}{26} & \multirow{7}{*}{$10 / 06 / 2010$} & 1 & $\begin{array}{l}\text { Consideración de la suscripción de Letras del Tesoro de Prov. Bs. As. Sexto tramo VN \$ } 10 \\
\text { millones }\end{array}$ \\
\hline & & 2 & Consideración de la suscripción de Discount $\$ 300$ millones \\
\hline & & 3 & Canje de títulos elegibles y letras del tesoro nacional \\
\hline & & 4 & Eximición del BNA de los Lineamientos Generales de PF \\
\hline & & 5 & Lineamientos de contraparte para operar en el MAE \\
\hline & & 6 & Consideración de las operaciones realizadas en el mes de mayo \\
\hline & & 7 & Consideración de la cartera al 30/04/2010 \\
\hline 27 & $22 / 06 / 2010$ & 1 & Tercera enmienda EPEC \\
\hline 28 & 06/07/2010 & 1 & Suscripción VRD VN \$ 280 Mill. A ser emitidos por VIVIENDA CHACO \\
\hline \multirow{4}{*}{29} & \multirow{4}{*}{$14 / 07 / 2010$} & $1 . i$ & Cuarta Addenda Atucha II \\
\hline & & 1.ii & Cancelación de VRD privados con suscripción de VRD públicos \\
\hline & & 1.iii & Suscripción de VRDB en efectivo \\
\hline & & 2 & Ampliación límite a las inversiones del inciso q) \\
\hline 30 & $20 / 07 / 2010$ & 1 & Consideración de la suscripción de CHA XII 2010-1 por hasta \$259.931.800 \\
\hline
\end{tabular}




\begin{tabular}{|c|c|c|c|}
\hline \multirow{7}{*}{31} & \multirow{7}{*}{$26 / 07 / 2010$} & 1 & $\begin{array}{l}\text { Consideración de la suscripción de Letras del Tesoro de la Prov de Buenos Aires del } \\
\text { Séptimo tramo por } \$ 10 \text { millones }\end{array}$ \\
\hline & & 2 & $\begin{array}{l}\text { Consideración de la suscripción de Letras del Tesoro Nacional por } \$ 730.000 .000 \text { y por U } \$ S \\
125.000 .000\end{array}$ \\
\hline & & 3 & Consideración de la situación patrimonial de Emgasud y Metrogas \\
\hline & & 4 & $\begin{array}{l}\text { Consideración de la propuesta de modificación a los lineamientos generales para la } \\
\text { selección de Operadores de Mercado }\end{array}$ \\
\hline & & 5 & Consideración de las operaciones realizadas en el mes de junio \\
\hline & & 6 & Consideración de las mandas e informes de las Asambleas \\
\hline & & 7 & Consideración de la cartera al 31/05/2010 \\
\hline 32 & $11 / 08 / 2010$ & 1 & Terceras addendas a Barragán y a Brigadier-López \\
\hline \multirow{5}{*}{33} & \multirow{5}{*}{$23 / 08 / 2010$} & 1 & $\begin{array}{l}\text { Consideración de la suscripción de Letras del Tesoro de la Prov de Buenos Aires del Noveno } \\
\text { tramo por } \$ 15 \text { millones }\end{array}$ \\
\hline & & 2 & Suscripción DICA por US\$312 millones \\
\hline & & 3 & Consideración de las operaciones realizadas en el mes de julio \\
\hline & & 4 & Consideración de las mandas e informes de las Asambleas \\
\hline & & 5 & Consideración de la cartera al 30/06/2010 \\
\hline \multirow{2}{*}{34} & \multirow{2}{*}{$28 / 09 / 2010$} & 1 & Análisis de la ejecución del plan de inversiones 2010 \\
\hline & & 2 & Consideración del plan de inversiones para el año 2011 \\
\hline \multirow{5}{*}{35} & \multirow{5}{*}{$28 / 09 / 2010$} & 1 & $\begin{array}{l}\text { Consideración de la suscripción de Letras del Tesoro de la Prov de Buenos Aires del Décimo } \\
\text { tramo por } \$ 10 \text { millones }\end{array}$ \\
\hline & & 2 & Consideración del límite para recursos líquidos \\
\hline & & 3 & Consideración de las operaciones realizadas en el mes de agosto \\
\hline & & 4 & Consideración de las mandas e informes de las Asambleas \\
\hline & & 5 & Consideración de la cartera al 31/07/2010 \\
\hline \multirow{7}{*}{36} & \multirow{7}{*}{$05 / 11 / 2010$} & 1 & $\begin{array}{l}\text { Consideración de la suscripción de Letras del Tesoro de la Prov. De Buenos Aires } 2010 . \\
\text { Undécimo Tramo, por hasta VN 15.000.000 }\end{array}$ \\
\hline & & 2 & $\begin{array}{l}\text { Consideración de la suscripción de Bonos de la Rep. Arg. Con Descuento en Dólares } \\
\text { Estadounidenses } 8,28 \% 2033 \text { ("Discount") por hasta } \mathrm{M} \$ 750\end{array}$ \\
\hline & & 3 & $\begin{array}{l}\text { Consideración de la suscripción de Bonos de la Rep. Arg. Con Descuento en Dólares } \\
\text { Estadounidenses } 8,28 \% 2033 \text { ("Discount") por hasta } \mathrm{M} \$ 1.280\end{array}$ \\
\hline & & 4 & Consideración de la suscripción de VRD Serie II por hasta VN 400 millones FF Hídrico \\
\hline & & 5 & Consideración de las operaciones realizadas en el mes de septiembre \\
\hline & & 6 & Consideración de las mandas e informes de las Asambleas \\
\hline & & 7 & Consideración de la cartera al 31/08/2010 \\
\hline \multirow{3}{*}{37} & \multirow{3}{*}{$16 / 11 / 2010$} & 1 & Consideración de la suscripción por hasta la suma de M\$ 100 de VRD Serie I de SIFER \\
\hline & & 2 & $\begin{array}{l}\text { Consideración de la suscripción de VRD Serie V Clases } 1 \text { y } 2 \text { por hasta V/N M\$ } 1.050 \\
\text { Decreto } 976 / 01 \text { - Ley } 26.028\end{array}$ \\
\hline & & 3 & $\begin{array}{l}\text { Consideración de la suscripción de Valores de Deuda Fiduciaria del CHA Serie XIII 2010-2 } \\
\text { por hasta } \$ 110.299 .100\end{array}$ \\
\hline \multirow{5}{*}{38} & \multirow{5}{*}{$01 / 12 / 2010$} & 1 & $\begin{array}{l}\text { Consideración de la suscripción de Bonos de la Rep. Arg. Con Descuento en Dólares } \\
\text { Estadounidenses } 8,28 \% 2033 \text { ("Discount") por hasta } \mathrm{M} \$ 977\end{array}$ \\
\hline & & 2 & Consideración de la oferta de recompra de ON Edenor Clase 7 y/o Canje por ON Clase 9 \\
\hline & & 3 & Consideración de las operaciones realizadas en el mes de octubre \\
\hline & & 4 & Consideración de las mandas e informes de las Asambleas \\
\hline & & 5 & Consideración de la cartera al 30/09/2010 \\
\hline 39 & $13 / 12 / 2010$ & 1 & $\begin{array}{l}\text { Consideración de la suscripción de VRD Serie } 1 \text { por hasta } \$ 60 \text { millones "Programa Federal } \\
\text { Plurianual de Construcción de Viviendas" - La Rioja }\end{array}$ \\
\hline \multirow{2}{*}{40} & \multirow{2}{*}{ 20/12/2010 } & 1 & $\begin{array}{l}\text { Consideración de la suscripción de Letras del Tesoro de la Prov. de Buenos Aires } 2010 . \\
\text { Décimo Cuarto Tramo, por hasta VN 15.000.000 }\end{array}$ \\
\hline & & 2 & $\begin{array}{l}\text { Consideración de la suscripción de Letras del Tesoro de la Prov. de Buenos Aires } 2010 . \\
\text { Décimo Quinto Tramo, por hasta VN 15.000.000 }\end{array}$ \\
\hline
\end{tabular}


Mercado de Capitales Argentino: Efectos de los fondos estatizados del sistema previsional sobre el mercado bursátil y las acciones cotizantes

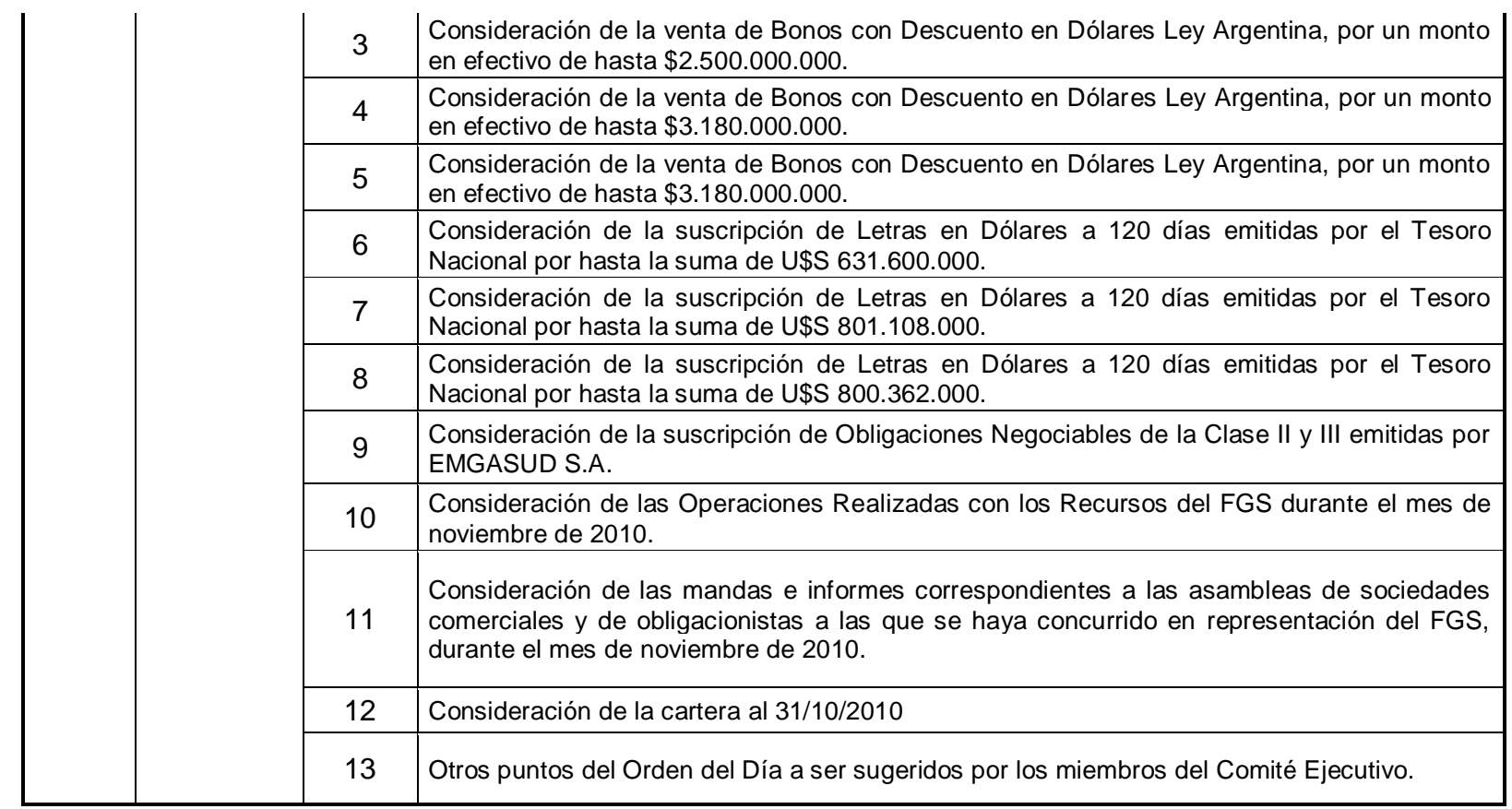

Fuente: Elaboración propia en base a ANSES. 
Tabla 8: Acciones de empresas argentinas que poseían las ex AFJP antes del traspaso hacia la ANSES. Información extraída del Comunicado Estadístico № 22 de la SAFJP de fecha $28 / 11 / 2008$

\begin{tabular}{|c|c|c|c|c|c|}
\hline \multicolumn{6}{|c|}{ CARTERA DE ACCIONES ARGENTINAS DEL FONDO DE JUBILACIONES Y PENSIONES AL 28/11/2008 } \\
\hline Código Instr. & INSTRUMENTO & $\begin{array}{l}\text { Precio de } \\
\text { valuación }\end{array}$ & \multirow[t]{2}{*}{ VN } & \multirow{2}{*}{\begin{tabular}{c|}
$\$$ \\
7.158 .590 .878
\end{tabular}} & \multirow{2}{*}{$\begin{array}{c}\begin{array}{c}\text { Participación } \\
\text { s/total FJP }\end{array} \\
8,95 \% \\
\end{array}$} \\
\hline Inc. h) ACC & \multicolumn{2}{|l|}{ ACCIONES DE SOCIEDADES ANÓNIMAS } & & & \\
\hline ALPA & Alpargatas S.A.I.C. & 1,950 & 7.682 & 14.980 & \\
\hline ALUA & Aluar Aluminio Argentino S.A.I.C. & 2,780 & 146.806 .954 & 408.123 .333 & \\
\hline APSA & Alto Palermo S.A. & 9,730 & 1.644 .433 & 16.000 .002 & \\
\hline BPAT & Banco Patagonia S.A. Ordinarias Clase B & 1,117 & 87.760 .113 & 97.984 .166 & \\
\hline BMA & Banco Macro & 3,708 & 163.774 .572 & 607.292 .490 & \\
\hline CAPX & Capex S.A. & 4,650 & 17.734 .186 & 82.463 .965 & \\
\hline CECO2 & Central Costanera S.A. & 1,845 & 18.629 .451 & 34.365 .748 & \\
\hline CEPU2 & Central Puerto S.A. & 3,298 & 3.255 .620 & 10.738 .337 & \\
\hline CRES & Cresud S.A. & 1,810 & 15.675 .459 & 28.374 .148 & \\
\hline CTIO & Consultatio S.A. 1 voto & 2,200 & 101.763 .528 & 223.879 .762 & \\
\hline DGCU2 & Distribuidora de Gas Cuyana & 2,667 & 48.482 .539 & 129.288 .387 & \\
\hline EDN & Edenor S.A. Acciones Ordinarias Clase B & 0,667 & 228.838 .206 & 152.589 .316 & \\
\hline EMDE & Emdersa S.A & 2,200 & 49.140 .652 & 108.109 .434 & \\
\hline ERAR & Siderar S.A. & 15,482 & 82.902 .121 & 1.283 .523 .798 & \\
\hline EURO & Euromayor S.A. & 1,500 & 3.083 .971 & 4.625 .957 & \\
\hline FRAN & BBVA Banco Francés S.A. & 2,560 & 31.409 .582 & 80.408 .530 & \\
\hline GBAN & Gas Natural BAN & 2,250 & 79.373 .594 & 178.590 .587 & \\
\hline GCLA & Grupo Clarín S.A. Ordinarias Clase B & 3,562 & 25.721 .441 & 91.609 .484 & \\
\hline GGAL & Grupo Financiero Galicia S.A. & 0,695 & 212.834 .004 & 147.919 .633 & \\
\hline INDU & Solvay Indupa S.A. & 2,550 & 63.725 .942 & 162.501 .152 & \\
\hline IRSA & IRSA Inversiones y Representaciones S.A. & 1,100 & 24.039 .391 & 26.443 .330 & \\
\hline JMIN & Juan Minetti S.A. & 1,600 & 36.489 .997 & 58.383 .995 & \\
\hline MOLI & Molinos Río de La Plata S.A. & 8,400 & 45.802 .413 & 384.740 .269 & \\
\hline MVIA & Metrovías S.A. & 3,120 & 1.171 .375 & 3.654 .690 & \\
\hline OEST & Grupo Consesionario del Oeste & 0,610 & 32.168 .486 & 19.622 .776 & \\
\hline PAMP & Pampa Holding S.A. & 0,920 & 272.046 .906 & 250.310 .358 & \\
\hline PATA & Imp. y Exp. de La Patagonia S.A. & 18,907 & 9.292 .406 & 175.691 .520 & \\
\hline PATY & Quickfood S.A. Ordinarias Clase B & 14,950 & 646.042 & 9.658 .328 & \\
\hline $\mathrm{PC}$ & Petrobrás Energía Participaciones S.A. & 2,180 & 279.515 .150 & 609.426 .882 & \\
\hline PERE & Pecom Energia S.A. & 8,900 & 8.866 .429 & 78.911 .218 & \\
\hline SAMI & S.A. San Miguel & 24,000 & 1.901 .404 & 45.633 .691 & \\
\hline STHE & Socotherm Americas S.A. & 4,550 & 15.258 .079 & 69.424 .259 & \\
\hline TECO2 & Telecom Arg.Stet-France Telecom S.A. & 5,827 & 226.150 .045 & 1.317 .685 .852 & \\
\hline TGNO4 & Transportadora de Gas del Norte S.A. & 0,420 & 2.972 .962 & 1.248 .644 & \\
\hline TGSU2 & Transportadora de Gas del Sur S.A. & 1,550 & 167.323 .777 & 259.351 .854 & \\
\hline Inc. i) ACP & ACCIONES DE EMPRESAS PRIVATIZAD & & & 228.020 .436 & $0,28 \%$ \\
\hline BHIP & Banco Hipotecario Nac. S.A. & 0,830 & 66.547 .815 & 55.234 .686 & \\
\hline CGPA2 & Camuzzi Gas Pampeana S.A. & 1,450 & 39.112 .241 & 56.712 .749 & \\
\hline METR & Metrogás S.A. & 1,150 & 43.011 .913 & 49.463 .700 & \\
\hline TRAN & Transener S.A. & 0,870 & 76.562 .414 & 66.609 .300 & \\
\hline TOTAL DE INV & ERSIONES & & & 76.635 .163 .278 & $95,78 \%$ \\
\hline TOTAL DEL F & $=O N D O$ COMPUTABLE DE JUBILACIONE & PENSIONES & & 80.013 .215 .100 & $100,00 \%$ \\
\hline
\end{tabular}


Tabla 9: Capital social, acciones del FGS y del grupo/s controlante/s (en valores nominales), participaciones relativas sobre el capital social, flotación y flotación extendida en empresas argentinas (\%) (Diciembre 2010).

\begin{tabular}{|c|c|c|c|c|c|c|c|}
\hline Descripción & $\begin{array}{l}\text { Capital Social } \\
\text { de la } \\
\text { Sociedad }\end{array}$ & $\begin{array}{l}\text { Total VN } \\
\text { FGS }\end{array}$ & $\begin{array}{c}\% \text { FGS } \\
\text { s/ } \\
\text { Capital } \\
\text { Social }\end{array}$ & $\begin{array}{l}\text { Cantidad de } \\
\text { Acciones } \\
\text { Controlante }\end{array}$ & $\begin{array}{c}\% \\
\text { Controlante } \\
\text { s/ Capital } \\
\text { Social }\end{array}$ & $\begin{array}{l}\text { Free } \\
\text { Float }\end{array}$ & $\begin{array}{c}\text { Float } \\
\text { extendido } \\
\text { (con } \\
\text { tenencia } \\
\text { FGS) }\end{array}$ \\
\hline Banco Macro & 594.485 .168 & 183.675 .387 & $30,90 \%$ & 237.306 .811 & $39,92 \%$ & $60,08 \%$ & $29,19 \%$ \\
\hline S.A. San Miguel & 15.250 .000 & 4.111 .992 & $26,96 \%$ & 8.955 .012 & $58,72 \%$ & $41,28 \%$ & $14,31 \%$ \\
\hline Gas Natural BAN & 325.539 .966 & 86.691 .181 & $26,63 \%$ & 227.877 .977 & $70,00 \%$ & $30,00 \%$ & $3,37 \%$ \\
\hline Consultatio S.A & 383.133 .150 & 102.004 .243 & $26,62 \%$ & 269.048 .067 & $70,22 \%$ & $29,78 \%$ & $3,15 \%$ \\
\hline Edenor S.A. & 906.455 .100 & 239.360 .725 & $26,41 \%$ & 462.292 .111 & $51,00 \%$ & $49,00 \%$ & $22,59 \%$ \\
\hline $\begin{array}{l}\text { Distribuidora de Gas } \\
\text { Cuyana }\end{array}$ & 202.351 .288 & 52.852 .416 & $26,12 \%$ & 92.272 .187 & $45,60 \%$ & $54,40 \%$ & $28,28 \%$ \\
\hline Siderar S.A. & 347.468 .771 & 90.225 .841 & $25,97 \%$ & 211.754 .474 & $60,94 \%$ & $39,06 \%$ & $13,09 \%$ \\
\hline Telecom Argentina S.A. & 984.380 .978 & 245.888 .716 & $24,98 \%$ & 538.866 .707 & $54,74 \%$ & $45,26 \%$ & $20,28 \%$ \\
\hline $\begin{array}{l}\text { Transportadora de Gas } \\
\text { del Sur S.A. }\end{array}$ & 794.495 .283 & 183.511 .187 & $23,10 \%$ & 439.325 .794 & $55,30 \%$ & $44,70 \%$ & $21,61 \%$ \\
\hline Pampa Energía S.A. & 1.314 .310 .895 & 295.465 .953 & $22,48 \%$ & 197.872 .164 & $15,06 \%$ & $84,94 \%$ & $62,46 \%$ \\
\hline $\begin{array}{l}\text { Grupo Concesionario } \\
\text { del Oeste }\end{array}$ & 160.000 .000 & 34.492 .226 & $21,56 \%$ & 109.919 .840 & $68,70 \%$ & $31,30 \%$ & $9,74 \%$ \\
\hline Mirgor S.A. & 4.000 .000 & 861.698 & $21,54 \%$ & 2.080 .000 & $52,00 \%$ & $48,00 \%$ & $26,46 \%$ \\
\hline Emdersa S.A. & 236.066 .302 & 49.476 .806 & $20,96 \%$ & 182.224 .095 & $77,19 \%$ & $22,81 \%$ & $1,85 \%$ \\
\hline $\begin{array}{ll}\text { Grupo } & \text { Financiero } \\
\text { Galicia S.A. } & \\
\end{array}$ & 1.241.407.017 & 253.745 .743 & $20,44 \%$ & 281.221 .650 & $22,65 \%$ & $77,35 \%$ & $56,91 \%$ \\
\hline \begin{tabular}{|l|} 
Imp. y Exp. de La \\
Patagonia S.A.
\end{tabular} & 50.000 .000 & 10.119 .774 & $20,24 \%$ & 38.435 .130 & $76,87 \%$ & $23,13 \%$ & $2,89 \%$ \\
\hline $\begin{array}{l}\text { Molinos Río de La Plata } \\
\text { S.A. }\end{array}$ & 250.448 .539 & 49.868 .079 & $19,91 \%$ & 187.901 .666 & $75,03 \%$ & $24,97 \%$ & $5,06 \%$ \\
\hline Transener S.A. & 444.673 .795 & 83.508 .937 & $18,78 \%$ & 234.129.232 & $52,65 \%$ & $47,35 \%$ & $28,57 \%$ \\
\hline \begin{tabular}{ll|} 
Socotherm Americas \\
S.A.
\end{tabular} & 87.700 .000 & 16.303 .945 & $18,59 \%$ & 66.500 .000 & $75,83 \%$ & $24,17 \%$ & $5,58 \%$ \\
\hline Solvay Indupa S.A. & 414.283 .186 & 69.211 .294 & $16,71 \%$ & 292.459 .492 & $70,59 \%$ & $29,41 \%$ & $12,70 \%$ \\
\hline Banco Patagonia S.A. & 748.155 .678 & 109.699 .338 & $14,66 \%$ & 442.942 .580 & $59,20 \%$ & $40,80 \%$ & $26,13 \%$ \\
\hline Endesa Costanera S.A. & 146.988 .378 & 19.697 .480 & $13,40 \%$ & 102.543 .055 & $69,76 \%$ & $30,24 \%$ & $16,84 \%$ \\
\hline \begin{tabular}{ll|} 
Camuzzi & Gas \\
Pampeana S.A. & \\
\end{tabular} & 333.281 .049 & 42.154 .002 & $12,65 \%$ & 286.928.194 & $86,09 \%$ & $13,91 \%$ & $1,26 \%$ \\
\hline Petrobrás Energía S.A. & 1.009 .618 .410 & 119.570 .920 & $11,84 \%$ & 678.395 .778 & $67,19 \%$ & $32,81 \%$ & $20,96 \%$ \\
\hline Juan Minetti S.A. & 352.056 .899 & 39.804 .176 & $11,31 \%$ & 280.274 .876 & $79,61 \%$ & $20,39 \%$ & $9,08 \%$ \\
\hline Capex S.A. & 179.802 .282 & 19.297 .220 & $10,73 \%$ & 134.500 .709 & $74,80 \%$ & $25,20 \%$ & $14,46 \%$ \\
\hline $\begin{array}{ll}\text { Aluar } & \text { Aluminio } \\
\text { Argentino S.A.I.C. }\end{array}$ & 1.943.000.000 & 180.751 .564 & $9,30 \%$ & 1.410 .242 .120 & $72,58 \%$ & $27,42 \%$ & $18,12 \%$ \\
\hline Grupo Clarin S.A. & 287.418 .584 & 25.866 .395 & $9,00 \%$ & 75.980 .304 & $26,44 \%$ & $73,56 \%$ & $64,57 \%$ \\
\hline Metrovías S.A. & 13.700 .000 & 1.171 .375 & $8,55 \%$ & 12.420 .128 & $90,66 \%$ & $9,34 \%$ & $0,79 \%$ \\
\hline
\end{tabular}


Mercado de Capitales Argentino: Efectos de los fondos estatizados del sistema previsional sobre el mercado bursátil y las acciones cotizantes

\begin{tabular}{|c|c|c|c|c|c|c|c|}
\hline Metrogas S.A. & 569.171 .000 & 46.249 .934 & $8,13 \%$ & 437.361 .565 & $76,84 \%$ & $23,16 \%$ & $15,03 \%$ \\
\hline $\begin{array}{l}\text { BBVA Banco Francés } \\
\text { S.A. }\end{array}$ & 536.361 .306 & 40.242 .518 & $7,50 \%$ & 407.473 .499 & $75,97 \%$ & $24,03 \%$ & $16,53 \%$ \\
\hline Euromayor S.A. & 52.500 .000 & 3.279 .882 & $6,25 \%$ & 21.839 .937 & $41,60 \%$ & $58,40 \%$ & $52,15 \%$ \\
\hline Quickfood S.A. & 36.469 .606 & 1.920 .294 & $5,27 \%$ & 32.841 .224 & $90,05 \%$ & $9,95 \%$ & $4,68 \%$ \\
\hline $\begin{array}{l}\text { Banco Hipotecario Nac. } \\
\text { S.A. }{ }^{22}\end{array}$ & 1.500 .000 .000 & 73.000 .783 & $4,87 \%$ & 446.578 .517 & $29,77 \%$ & $70,23 \%$ & $65,36 \%$ \\
\hline $\begin{array}{l}\text { IRSA Inversiones y } \\
\text { Representaciones S.A. }\end{array}$ & 578.676 .460 & 25.840 .221 & $4,47 \%$ & 332.666 .752 & $57,49 \%$ & $42,51 \%$ & $38,05 \%$ \\
\hline Central Puerto S.A. & 88.505 .982 & 3.499 .080 & $3,95 \%$ & 52.299 .229 & $59,09 \%$ & $40,91 \%$ & $36,96 \%$ \\
\hline Cresud S.A. & 501.560 .929 & 17.566 .482 & $3,50 \%$ & 185.660 .594 & $37,02 \%$ & $62,98 \%$ & $59,48 \%$ \\
\hline Alto Palermo S.A. & 125.960 .841 & 1.739 .334 & $1,38 \%$ & 119.525 .400 & $94,89 \%$ & $5,11 \%$ & $3,73 \%$ \\
\hline $\begin{array}{l}\text { Transportadora de Gas } \\
\text { del Norte S.A. }\end{array}$ & 439.373 .939 & 3.192 .459 & $0,73 \%$ & 247.604 .059 & $56,35 \%$ & $43,65 \%$ & $42,92 \%$ \\
\hline Ledesma S.A. & 440.000 .000 & 1.663 .636 & $0,38 \%$ & 397.649 .526 & $90,37 \%$ & $9,63 \%$ & $9,25 \%$ \\
\hline Y.P.F. S.A. ${ }^{23}$ & 3.933 .127 .930 & 56.222 & $0,014 \%$ & 3.139 .013 .980 & $79,81 \%$ & $20,19 \%$ & $20,18 \%$ \\
\hline Alpargatas S.A.I.C. & 70.122 .108 & 8.536 & $0,012 \%$ & 49.569 .771 & $70,69 \%$ & $29,31 \%$ & $29,30 \%$ \\
\hline
\end{tabular}

Fuente: Elaboración propia en base a datos de BCBA, ANSES y CNV.

22 A diciembre de 2010 los principales accionistas de la clase "D" del Banco Hipotecario eran tenedores en conjunto de 446.653 .517 acciones representativas de 29,78 \% del Capital Social. Solamente se consideró a este grupo de accionistas como controlantes dado que poseían el $46,48 \%$ del derecho a votos, ya que esta clase le confiere derecho a tres votos por acción, y son los que informa la compañía en el inciso q) del Art. 62 como accionistas controlantes. Como se verá en otro punto, el free float para este banco de acuerdo con el IAMC era de $7,7 \%$ a esa fecha. Dicha diferencia se debe a que consideran la tenencia del Gobierno Argentino que posee acciones clase "A", con casi un $44 \%$ de las acciones, el Programa de Propiedad Participada con un $5 \%$ del total de acciones, Fideicomiso de Asistencia al Fondo Federal de Infraestructura Regional con 5\% de las acciones, el Banco Hipotecario S.A. con el 2,5\% de las acciones, entre otros, todas ellas con derecho a 1 voto por acción.

${ }^{23}$ El inciso o) del Art. 62 del Reglamento de cotización de la BCBA, acerca de las Acciones que pertenecen al grupo controlante Repsol al 31 de diciembre de 2010, establece que la cantidad de acciones que le pertenecían a dichos accionistas de la sociedad asciende a 313.901 .398 acciones clase D y representan el $79,81 \%$ del capital social. El valor nominal por cada acción es de 10. 
Tabla 10: Clasificación de empresas argentinas en las que el FGS de la ANSES tiene participación según sector de la economía donde se desarrolla.

\begin{tabular}{|c|c|}
\hline Sector & Empresa \\
\hline \multirow{7}{*}{ Electricidad } & Edenor S.A. \\
\hline & Emdersa S.A \\
\hline & Pampa Holding S.A. \\
\hline & Transener S.A. \\
\hline & Endesa Costanera S.A. \\
\hline & Central Puerto S.A. \\
\hline & Capex S.A. \\
\hline \multirow{10}{*}{$\begin{array}{c}\text { Petróleo, Gas y } \\
\text { Petroquímica }\end{array}$} & Distribuidora de Gas Cuyana \\
\hline & Transportadora de Gas del Sur \\
\hline & Gas Natural BAN \\
\hline & Socotherm Americas S.A. \\
\hline & Solvay Indupa S.A. \\
\hline & Petrobras Energia S.A. \\
\hline & Camuzzi Gas Pampeana S.A. \\
\hline & Metrogas S.A. \\
\hline & Transportadora de Gas del Norte \\
\hline & Y.P.F. S.A. \\
\hline \multirow{3}{*}{$\begin{array}{c}\text { Transporte e } \\
\text { Infraestructura }\end{array}$} & Metrovías S.A. \\
\hline & Grupo Consesionario del Oeste \\
\hline & Mirgor S.A. \\
\hline
\end{tabular}

\begin{tabular}{|c|c|}
\hline Sector & Empresa \\
\hline \multirow{2}{*}{ Siderurgia } & Siderar S.A. \\
\hline & Aluar Aluminio Argentino S.A.I.C. \\
\hline \multirow{5}{*}{ Real Estate } & Consultatio S.A. \\
\hline & Euromayor S.A. \\
\hline & IRSA Inversiones y Representac. \\
\hline & Alto Palermo S.A. \\
\hline & Juan Minetti S.A. \\
\hline \multirow{2}{*}{$\begin{array}{c}\text { Telecomunicaciones y } \\
\text { Medios }\end{array}$} & Telecom Arg.Stet-France Telecom \\
\hline & Grupo Clarín S.A. \\
\hline \multirow{5}{*}{ Servicios Financieros } & Banco Macro \\
\hline & Grupo Financiero Galicia S.A. \\
\hline & Banco Patagonia S.A. \\
\hline & BBVA Banco Francés S.A. \\
\hline & Banco Hipotecario Nac. S.A. \\
\hline \multirow{2}{*}{ Consumo Masivo } & Quickfood S.A. \\
\hline & Alpargatas S.A.I.C. \\
\hline \multirow{5}{*}{ Agronegocios } & S.A. San Miguel \\
\hline & Molinos Río de La Plata S.A. \\
\hline & Imp. y Exp. de La Patagonia S.A. \\
\hline & Cresud S.A. \\
\hline & Ledesma S.A. \\
\hline
\end{tabular}


Tabla 11: Controlante/s de empresas argentinas en las que el FGS de la ANSES tiene participación (a Diciembre 2010).

\begin{tabular}{|c|c|}
\hline Descripción & Controlante \\
\hline Banco Macro & $\begin{array}{l}\text { Jorge Horacio Brito, Delfín Jorge Ezequiel Carballo y Juan Pablo } \\
\text { Brito Devoto }\end{array}$ \\
\hline S.A. San Miguel & $\begin{array}{l}\text { Luis Mensegur,Frutales S.R.L, Carlos Miguens, Diego Miguens, } \\
\text { Cristina Miguens, Maria Luisa Miguens, Gonzalo Tanoira }\end{array}$ \\
\hline Gas Natural BAN & Invergas s.a y Gas Natural SDG Argentina \\
\hline Consultatio S.A & Eduardo Constantini $(66,44 \%)$, Carlos Terrabusi $(3,78 \%)$ \\
\hline Edenor S.A. & Electricidad Argentina S.A (Dolphin Energía S.A.) \\
\hline Distribuidora de Gas Cuyana & Inversora de Gas Cuyana SA \\
\hline Siderar S.A. & Ternium Internacional España S.L \\
\hline Telecom Argentina S.A. & Nortel Inversora S.A. \\
\hline Transportadora de Gas del Sur S.A. & Compañía de Inversiones de Energía S.A. \\
\hline Grupo Concesionario del Oeste & Autopista Concesionaria Española S.A/IJM Corporation Berhad \\
\hline Mirgor S.A. & II Tevere S.A \\
\hline Emdersa S.A. & A.E.I. Utilities S.L \\
\hline Grupo Financiero Galicia S.A. & EBA Holding S.A. \\
\hline Imp. y Exp. de La Patagonia S.A. & $\begin{array}{l}\text { Federico Braun, Pablo Braun y Ledesma, Inés Braun y Ledesma, } \\
\text { Santiago Braun, María Braun, Nicolás Braun y Miguel Braun. }\end{array}$ \\
\hline Molinos Río de La Plata S.A. & PCF S.A \\
\hline Pampa Energía S.A. & $\begin{array}{l}\text { Dolphin Créditos S.A. ,Dolphin Finance S.A., Grupo Dolphin S.A., } \\
\text { Pampa Holdings L.L.C., Dolphin Fund Management S.A., Mindlin, } \\
\text { Marcos; Mariani, Gustavo, Torres, Ricardo }\end{array}$ \\
\hline Transener S.A. & Citelec S.A \\
\hline Socotherm Americas S.A. & Socotherm SpA \\
\hline Solvay Indupa S.A. & Solvay Argentina S.A \\
\hline Banco Patagonia S.A. & Banco do Brasil S.A \\
\hline Endesa Costanera S.A. & $\begin{array}{l}\text { Endesa Argentina S.A, Empresa Nacional de Electricidad, Souththern } \\
\text { Cone Power Arg. S.A. }\end{array}$ \\
\hline Camuzzi Gas Pampeana S.A. & Sodigas Pampeana S.A. \\
\hline Petrobrás Energía S.A. & Petrobras Participaciones S.L. \\
\hline Juan Minetti S.A. & Holcim Investments Spain/Holcim LTD \\
\hline Capex S.A. & Compañias Asociadas Petroleras S.A. \\
\hline Euromayor S.A. & AVG Plan Fideicomiso Financiero \\
\hline Aluar Aluminio Argentino S.A.I.C. & Dolores Quintanilla de Madanes y Javier Santiago Madanes \\
\hline Grupo Clarin S.A. & GC Dominio S.A. \\
\hline Quickfood S.A. & Edubir S.A. y Mafrig Alimentos S.A. \\
\hline Metrovías S.A. & Benito Roggio Transporte S.A. \\
\hline Metrogás S.A. & Gas Argentino S.A. (70\%),British Gas International B.V. $(6,84 \%)$ \\
\hline BBVA Banco Francés S.A. & Banco Bilbao Vizcaya Argentina S.A. \\
\hline Banco Hipotecario Nac. S.A. & $\begin{array}{l}\text { Tyrus, Ritelco, E-Commerce Latina, Palermo Invest, IRSA } \\
\text { Inversiones y Representaciones e Inversora Bolívar }\end{array}$ \\
\hline IRSA Inversiones y Representaciones S.A. & Cresud S.A.C.I.F. y A. \\
\hline Central Puerto S.A. & Sociedad Argentina de Energía S.A. \\
\hline Cresud S.A. & Inversiones Financieras del Sur S.A \\
\hline Alto Palermo S.A. & IRSA \\
\hline Transportadora de Gas del Norte S.A. & Gasinvest S.A. \\
\hline Ledesma S.A. & María Elena Arrieta de Blaquier y Carlos Pedro Tadeo Blaquier \\
\hline Y.P.F.S.A. & Repsol YPF S.A. \\
\hline Alpargatas S.A.I.C. & São Paulo Alpargatas S.A. \\
\hline
\end{tabular}

Fuente: Elaboración propia en base a CNV, BOLSAR e información institucional de las empresas. 
Tabla 12: Cantidad de votos totales de la sociedad, del FGS y de la/s controlante/s de empresas argentinas (a Diciembre 2010).

\begin{tabular}{|c|c|c|c|c|c|c|}
\hline Descripción & $\begin{array}{c}\text { VN } \\
\text { c/accion }\end{array}$ & $\begin{array}{c}\text { Cantidad de } \\
\text { Votos Totales de } \\
\text { la Sociedad }\end{array}$ & $\begin{array}{c}\% \text { participacion } \\
\text { FGS sobre el } \\
\text { Total de Votos }\end{array}$ & $\begin{array}{l}\text { Cantidad de } \\
\text { Votos } \\
\text { Controlante }\end{array}$ & $\begin{array}{c}\% \text { sobre Votos } \\
\text { controlante }\end{array}$ & $\begin{array}{l}\text { Resto de } \\
\text { Votos }\end{array}$ \\
\hline Banco Macro & 1,00 & 639.427 .848 & $28,72 \%$ & 279.466 .391 & $43,71 \%$ & $27,57 \%$ \\
\hline S.A. San Miguel & 0,10 & 440.700 .000 & $9,33 \%$ & 377.633 .294 & $85,69 \%$ & $4,98 \%$ \\
\hline Gas Natural BAN & 1,00 & 325.539 .966 & $26,63 \%$ & 227.877 .977 & $70,00 \%$ & $3,37 \%$ \\
\hline Consultatio S.A & 1,00 & 383.133 .150 & $26,62 \%$ & 269.048 .067 & $70,22 \%$ & $3,15 \%$ \\
\hline Edenor S.A. & 1,00 & 906.455 .100 & $26,41 \%$ & 462.292 .111 & $51,00 \%$ & $22,59 \%$ \\
\hline Distribuidora de Gas Cuyana & 1,00 & 202.351 .288 & $26,12 \%$ & 92.272 .187 & $45,60 \%$ & $28,28 \%$ \\
\hline Siderar S.A. & 1,00 & 347.468 .771 & $25,97 \%$ & 211.754 .474 & $60,94 \%$ & $13,09 \%$ \\
\hline Telecom Argentina S.A. & 1,00 & 984.380 .978 & $24,98 \%$ & 538.866 .707 & $54,74 \%$ & $20,28 \%$ \\
\hline Transportadora de Gas del Sur. & 1,00 & 794.495 .283 & $23,10 \%$ & 439.325 .794 & $55,30 \%$ & $21,61 \%$ \\
\hline Grupo Concesionario del Oeste & 1,00 & 160.000 .000 & $21,56 \%$ & 109.919 .840 & $68,70 \%$ & $9,74 \%$ \\
\hline Mirgor S.A. & 0,10 & 81.600 .000 & $10,56 \%$ & 62.400 .000 & $76,47 \%$ & $12,97 \%$ \\
\hline Emdersa S.A. & 1,00 & 236.066 .302 & $20,96 \%$ & 182.224 .095 & $77,19 \%$ & $1,85 \%$ \\
\hline Grupo Financiero Galicia S.A. & 1,00 & 2.366 .293 .617 & $10,72 \%$ & 1.406 .108 .250 & $59,42 \%$ & $29,85 \%$ \\
\hline Imp. y Exp. de La Patagonia S.A. & 1,00 & 54.714 .148 & $18,50 \%$ & 43.146 .990 & $78,86 \%$ & $2,65 \%$ \\
\hline Molinos Río de La Plata S.A. & 1,00 & 254.611 .855 & $19,59 \%$ & 191.936 .236 & $75,38 \%$ & $5,03 \%$ \\
\hline Pampa Energía S.A. & 1,00 & 1.314.310.895 & $22,48 \%$ & 197.872 .164 & $15,06 \%$ & $62,46 \%$ \\
\hline Transener S.A. & 1,00 & 444.673 .795 & $18,78 \%$ & 234.129 .232 & $52,65 \%$ & $28,57 \%$ \\
\hline Socotherm Americas S.A. & 1,00 & 353.700 .000 & $4,61 \%$ & 332.500 .000 & $94,01 \%$ & $1,38 \%$ \\
\hline Solvay Indupa S.A. & 1,00 & 414.283 .186 & $16,71 \%$ & 292.459 .492 & $70,59 \%$ & $12,70 \%$ \\
\hline Banco Patagonia S.A. & 1,00 & 748.155 .678 & $14,66 \%$ & 442.942 .580 & $59,20 \%$ & $26,13 \%$ \\
\hline Endesa Costanera S.A. & 1,00 & 146.988 .378 & $13,40 \%$ & 102.543 .055 & $69,76 \%$ & $16,84 \%$ \\
\hline Camuzzi Gas Pampeana S.A. & 1,00 & 333.281 .049 & $12,65 \%$ & 286.928 .194 & $86,09 \%$ & $1,26 \%$ \\
\hline Petrobrás Energía S.A. & 1,00 & 1.009.618.410 & $11,84 \%$ & 678.395 .778 & $67,19 \%$ & $20,96 \%$ \\
\hline Juan Minetti S.A. & 1,00 & 352.056 .899 & $11,31 \%$ & 280.274 .876 & $79,61 \%$ & $9,08 \%$ \\
\hline Capex S.A. & 1,00 & 179.802 .282 & $10,73 \%$ & 134.500 .709 & $74,80 \%$ & $14,46 \%$ \\
\hline Euromayor S.A. & 0,01 & 5.250 .048 .420 & $6,25 \%$ & 2.183 .993 .705 & $41,60 \%$ & $52,15 \%$ \\
\hline Aluar Aluminio Argentino S.A.I.C. & 1,00 & 1.943.000.000 & $9,30 \%$ & 1.410 .242 .120 & $72,58 \%$ & $18,12 \%$ \\
\hline Grupo Clarin S.A. & 1,00 & 591.339 .800 & $4,37 \%$ & 379.901 .520 & $64,24 \%$ & $31,38 \%$ \\
\hline Quickfood S.A. & 1,00 & 36.469 .606 & $5,27 \%$ & 32.841 .224 & $90,05 \%$ & $4,68 \%$ \\
\hline Metrovías S.A. & 1,00 & 41.669 .920 & $2,81 \%$ & 40.390 .048 & $96,93 \%$ & $0,26 \%$ \\
\hline Metrogás S.A. & 1,00 & 569.171 .000 & $8,13 \%$ & 437.361 .565 & $76,84 \%$ & $15,03 \%$ \\
\hline BBVA Banco Francés S.A. & 1,00 & 536.361 .306 & $7,50 \%$ & 407.473 .499 & $75,97 \%$ & $16,53 \%$ \\
\hline Banco Hipotecario Nac. S.A. & 1,00 & 2.882 .938 .240 & $2,53 \%$ & 1.339 .735 .551 & $46,47 \%$ & $51,00 \%$ \\
\hline IRSA Inversiones y Rep. S.A. & 1,00 & 578.676 .460 & $4,47 \%$ & 332.666 .752 & $57,49 \%$ & $38,05 \%$ \\
\hline Central Puerto S.A. & 1,00 & 88.505 .982 & $3,95 \%$ & 52.299 .229 & $59,09 \%$ & $36,96 \%$ \\
\hline Cresud S.A. & 1,00 & 501.560 .929 & $3,50 \%$ & 185.660 .594 & $37,02 \%$ & $59,48 \%$ \\
\hline Alto Palermo S.A. & 0,10 & 1.259 .608 .410 & $1,38 \%$ & 1.195.253.997 & $94,89 \%$ & $3,73 \%$ \\
\hline Transportadora de Gas del Norte & 1,00 & 439.373 .939 & $0,73 \%$ & 247.604 .059 & $56,35 \%$ & $42,92 \%$ \\
\hline Ledesma S.A. & 1,00 & 440.000 .000 & $0,38 \%$ & 397.649 .526 & $90,37 \%$ & $9,25 \%$ \\
\hline Y.P.F. S.A. & 10,00 & 393.312 .793 & $0,014 \%$ & 313.901 .398 & $79,81 \%$ & $20,18 \%$ \\
\hline Alpargatas S.A.I.C. & 1,00 & \begin{tabular}{l|l}
70.122 .108 \\
\end{tabular} & $0,012 \%$ & 49.569 .771 & $70,69 \%$ & $29,30 \%$ \\
\hline
\end{tabular}

Fuente: Elaboración propia en base a CNV, BOLSAR, ANSES e información institucional de las empresas. 
Mercado de Capitales Argentino: Efectos de los fondos estatizados del sistema previsional sobre el mercado bursátil y las acciones cotizantes

Tabla 13: Resumen del marco normativo del FGS de la ANSES.

\begin{tabular}{|c|c|c|c|}
\hline Norma & Fecha & & Descripción \\
\hline Ley № 24.241 & Oct-93 & $\begin{array}{l}\text { Sistema Integrado de } \\
\text { Jubilaciones y } \\
\text { Pensiones (SIJP) }\end{array}$ & $\begin{array}{l}\text { Conforman este sistema: 1) Régimen } \\
\text { de Reparto y 2) Régimen de } \\
\text { Capitalización. }\end{array}$ \\
\hline Ley № 26.222 & Mar-07 & $\begin{array}{l}\text { Libre opción del } \\
\text { Régimen Jubilatorio }\end{array}$ & $\begin{array}{l}\text { Traspaso voluntario de los afiliados a } \\
\text { régimen de capitalización al Régimen } \\
\text { Previsional Público de Reparto. }\end{array}$ \\
\hline Decreto № $897 / 07$ & Jul-07 & $\begin{array}{l}\text { Fondo de Garantía de } \\
\text { Sustentabilidad del } \\
\text { Régimen Previsional } \\
\text { Público de Reparto } \\
\text { ("FGS1") }\end{array}$ & $\begin{array}{c}\text { Integrado por los bienes que reciba e } \\
\text { Régimen Previsional Público como } \\
\text { consecuencia de la transferencia de } \\
\text { los saldos de las cuentas de } \\
\text { capitalización. }\end{array}$ \\
\hline Ley № 26.425 & Dic-08 & $\begin{array}{l}\text { Fondo de Garantía de } \\
\text { Sustentabilidad del } \\
\text { Sistema Integrado } \\
\text { Previsional Argentino } \\
\text { (FGS) }\end{array}$ & $\begin{array}{l}\text { Unificación del SIJP en un único } \\
\text { régimen previsional público } \\
\text { denominado Sistema Integrado } \\
\text { Previsional Argentino (SIPA), } \\
\text { financiado a través de un sistema } \\
\text { solidario de reparto. }\end{array}$ \\
\hline
\end{tabular}

